\title{
De Novo Asymmetric Synthesis of Biologically Active Carbohydrate Natural Products and Related SAR studies
}

\author{
Bulan Wu \\ West Virginia University
}

Follow this and additional works at: https://researchrepository.wvu.edu/etd

\section{Recommended Citation}

Wu, Bulan, "De Novo Asymmetric Synthesis of Biologically Active Carbohydrate Natural Products and Related SAR studies" (2011). Graduate Theses, Dissertations, and Problem Reports. 4816.

https://researchrepository.wvu.edu/etd/4816

This Dissertation is protected by copyright and/or related rights. It has been brought to you by the The Research Repository @ WVU with permission from the rights-holder(s). You are free to use this Dissertation in any way that is permitted by the copyright and related rights legislation that applies to your use. For other uses you must obtain permission from the rights-holder(s) directly, unless additional rights are indicated by a Creative Commons license in the record and/ or on the work itself. This Dissertation has been accepted for inclusion in WVU Graduate Theses, Dissertations, and Problem Reports collection by an authorized administrator of The Research Repository @ WVU.

For more information, please contact researchrepository@mail.wvu.edu. 


\title{
Supporting Spectra
}

for

De Novo Asymmetric Synthesis of Biologically Active Carbohydrate Natural Products and Related SAR studies

\author{
Bulan Wu \\ Dissertation submitted to the \\ Eberly College of Arts and Sciences \\ at West Virginia University \\ in partial fulfillment of the requirements \\ for the degree of \\ Doctor of Philosophy \\ In \\ Organic Chemistry \\ John H. Penn, Ph.D., Chair \\ George A. O'Doherty, Ph.D. \\ Kung Wang, Ph.D. \\ Alan Stolzenberg, Ph.D. \\ Yon Rojanasakul, Ph.D. \\ C. Eugene Bennett Department of Chemistry \\ Morgantown, West Virginia \\ 2011
}

Keywords: SL0101, Methymycin, Cleistrisides and Cleistetrasides

Copyright 2011 Bulan Wu 


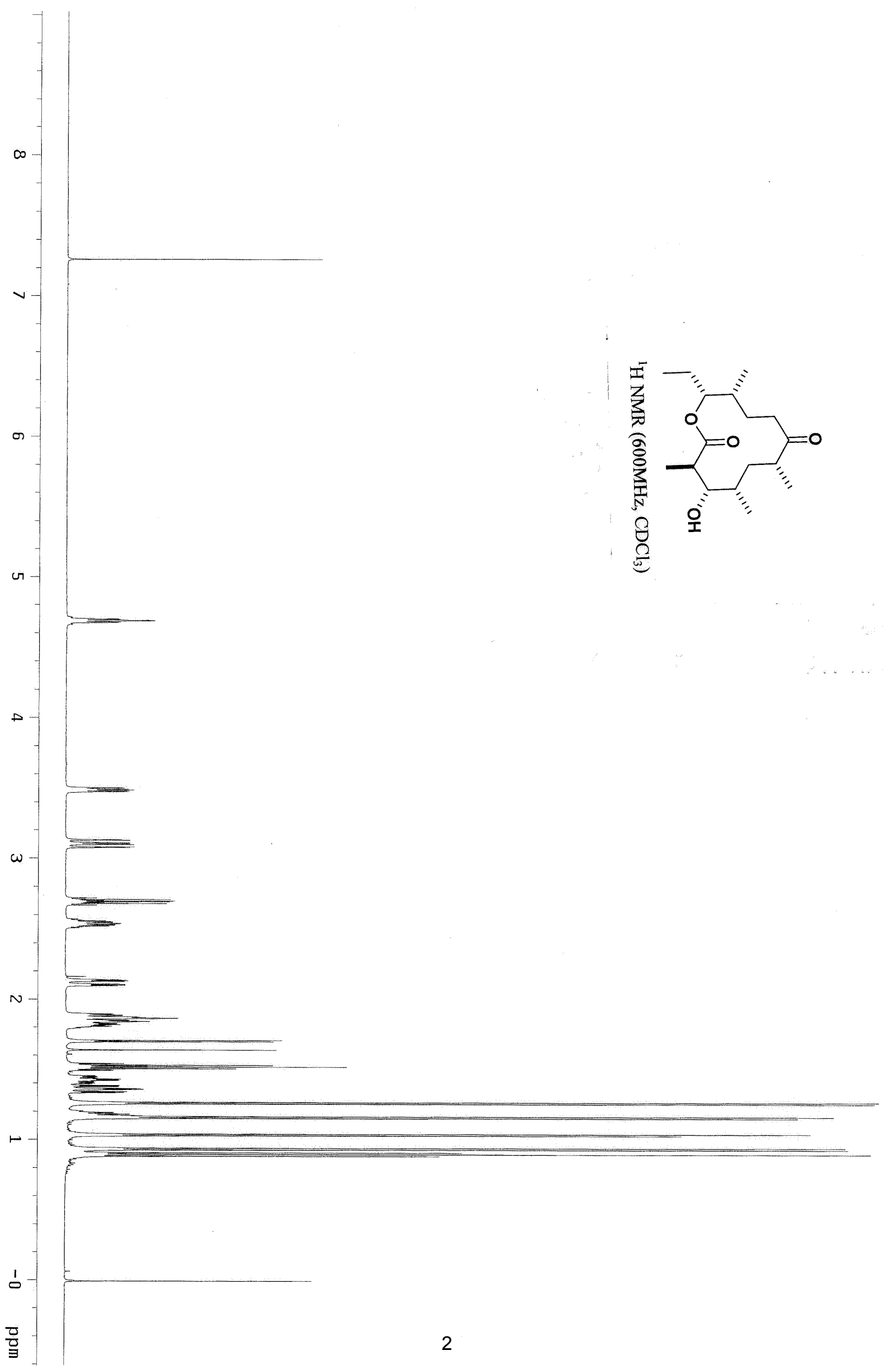




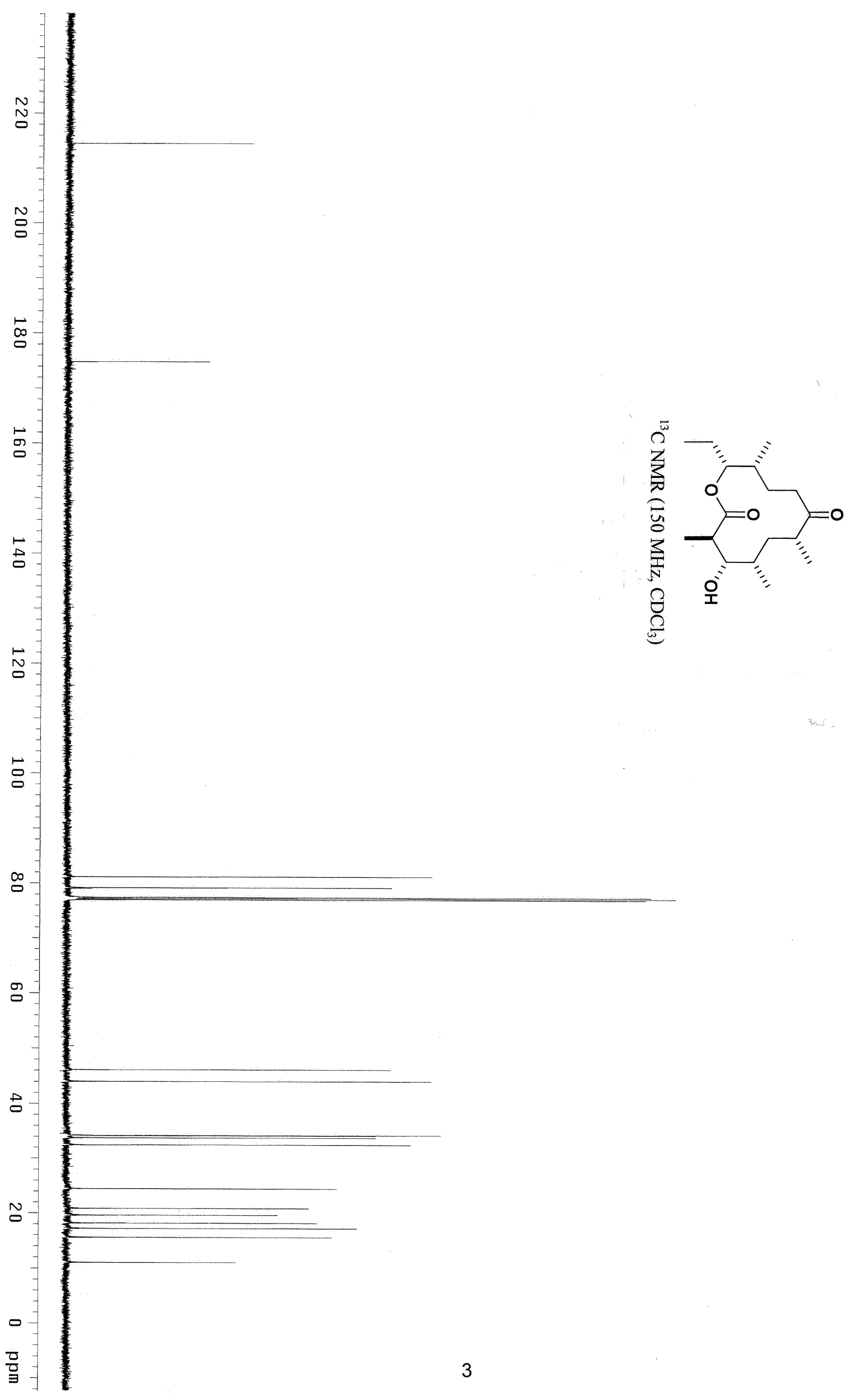




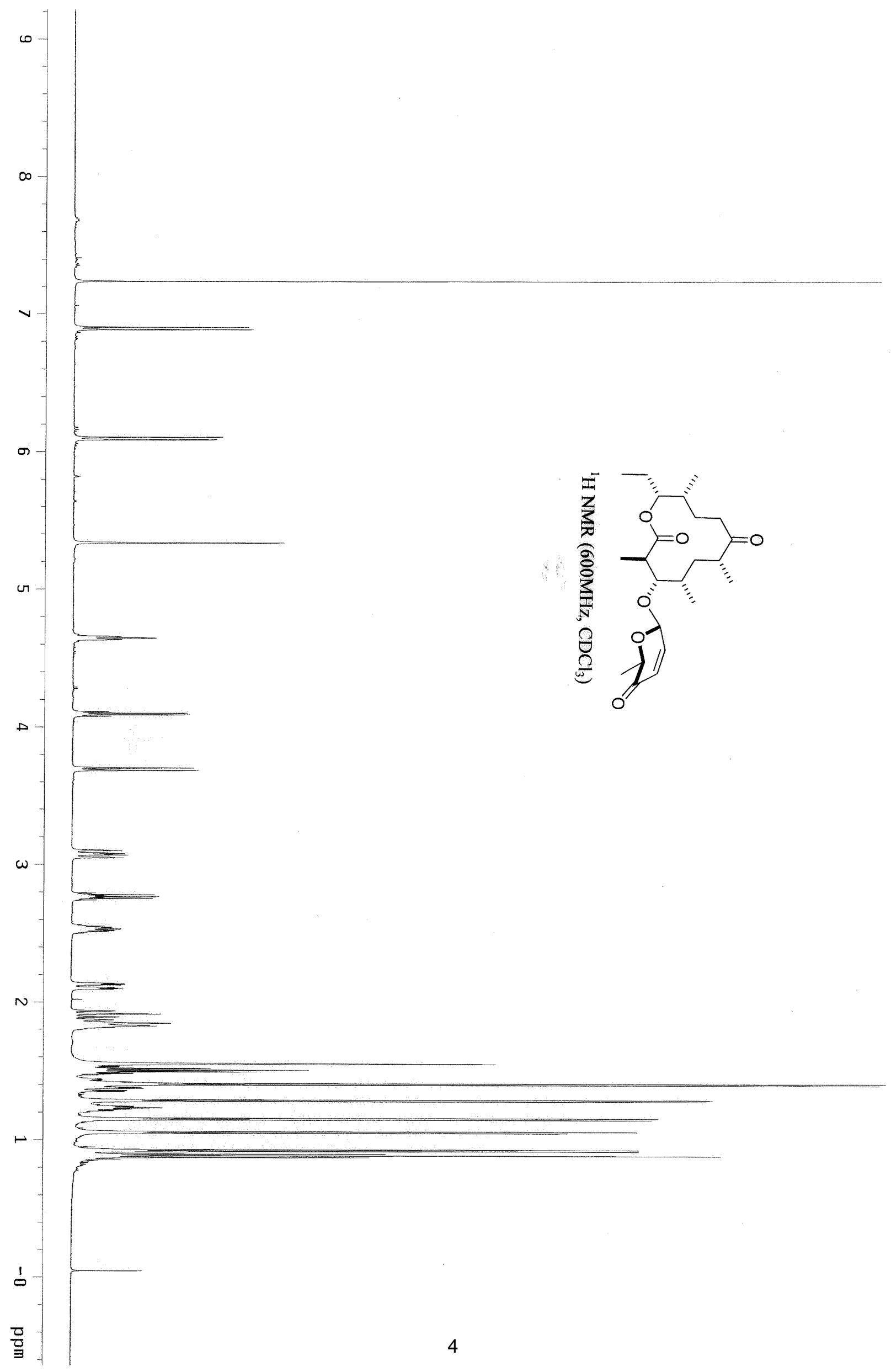




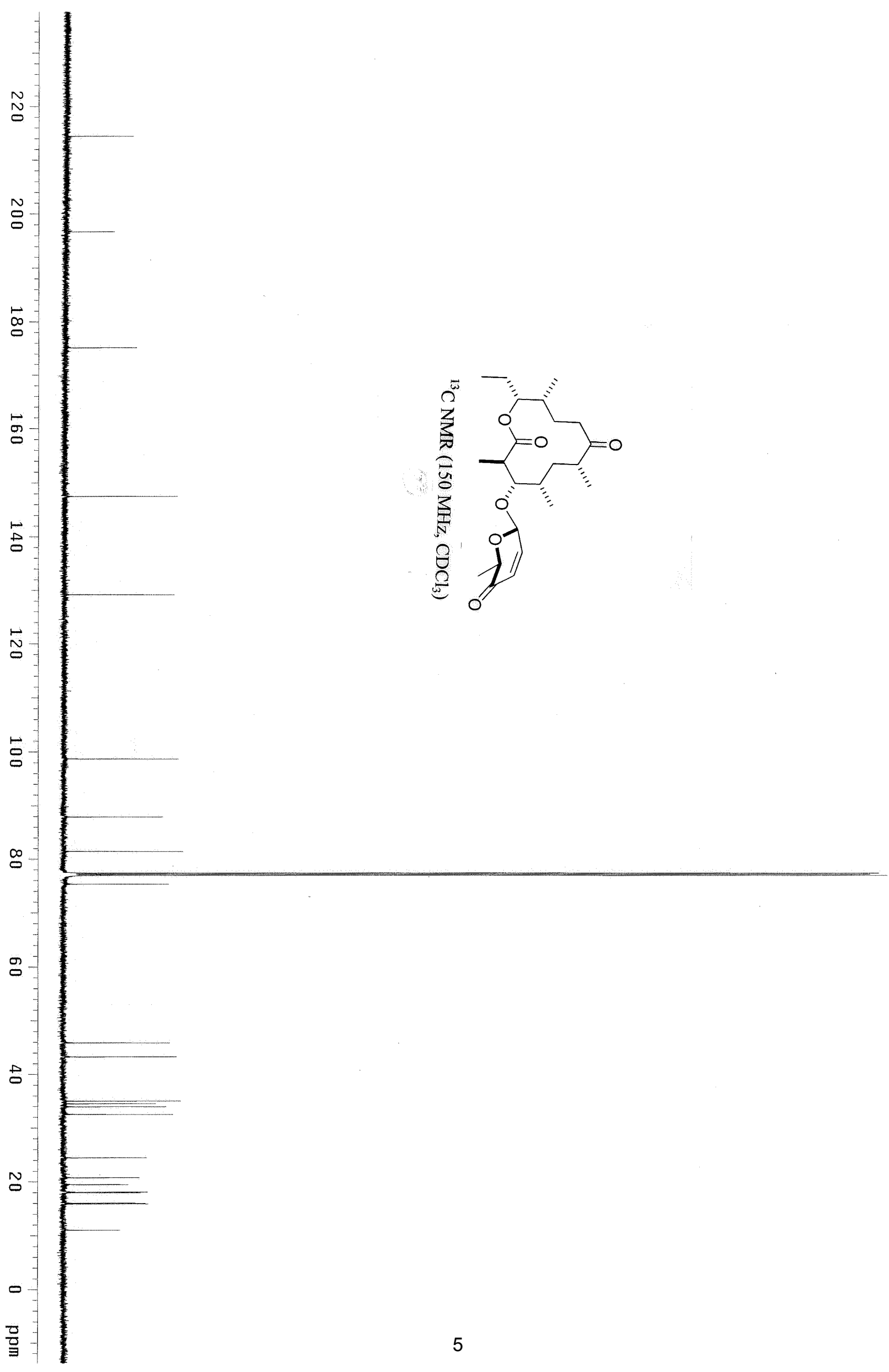




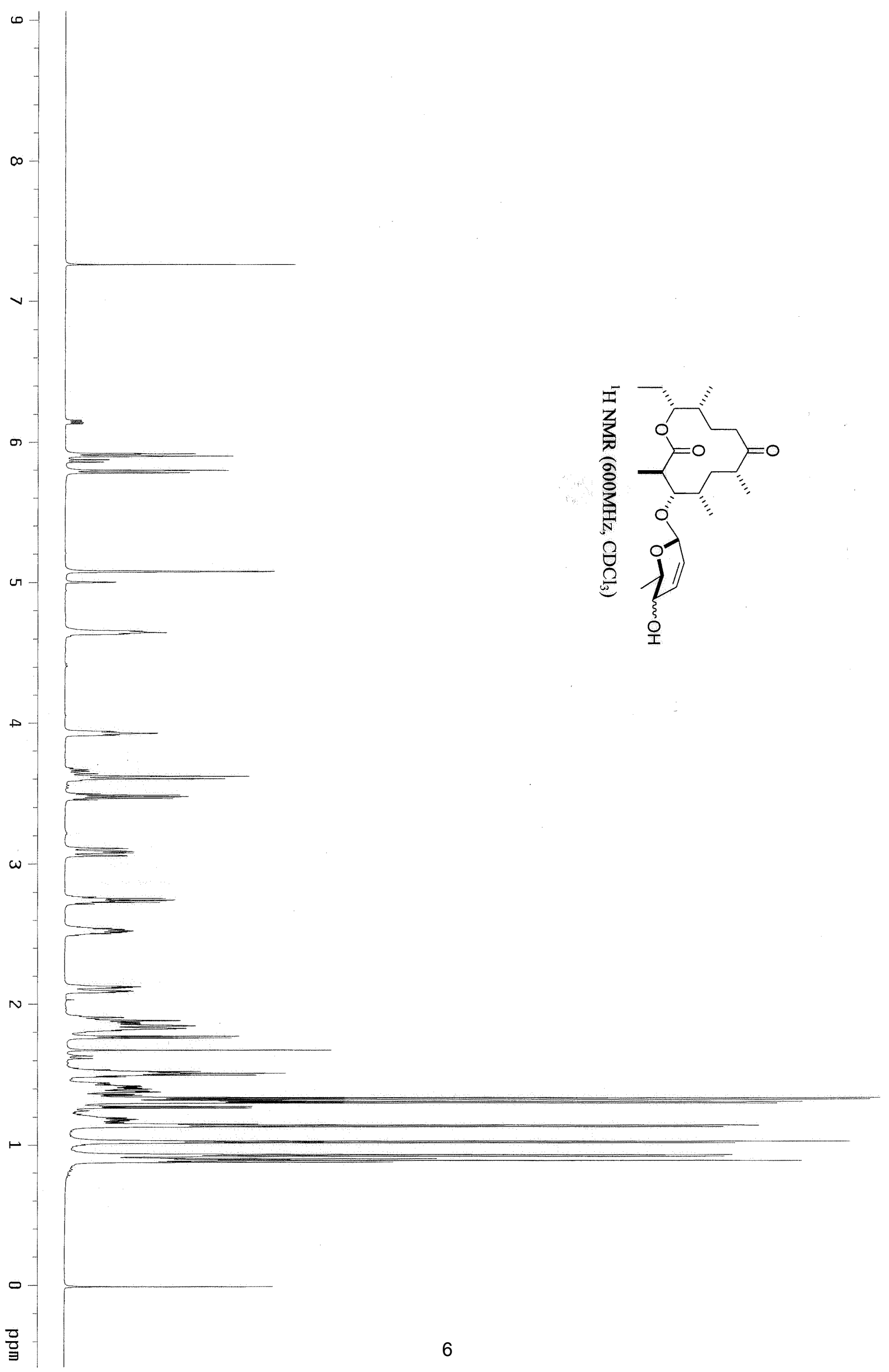




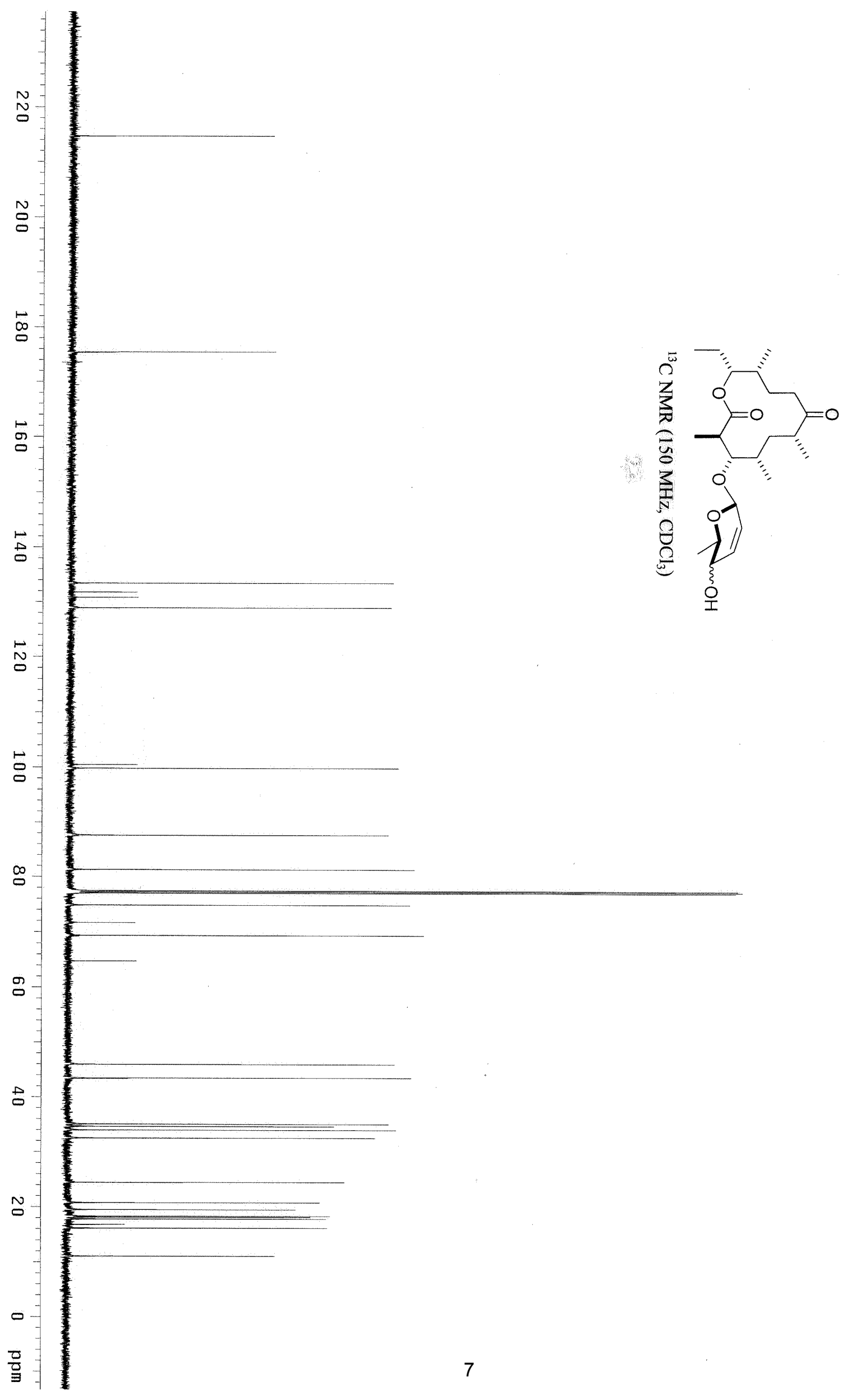




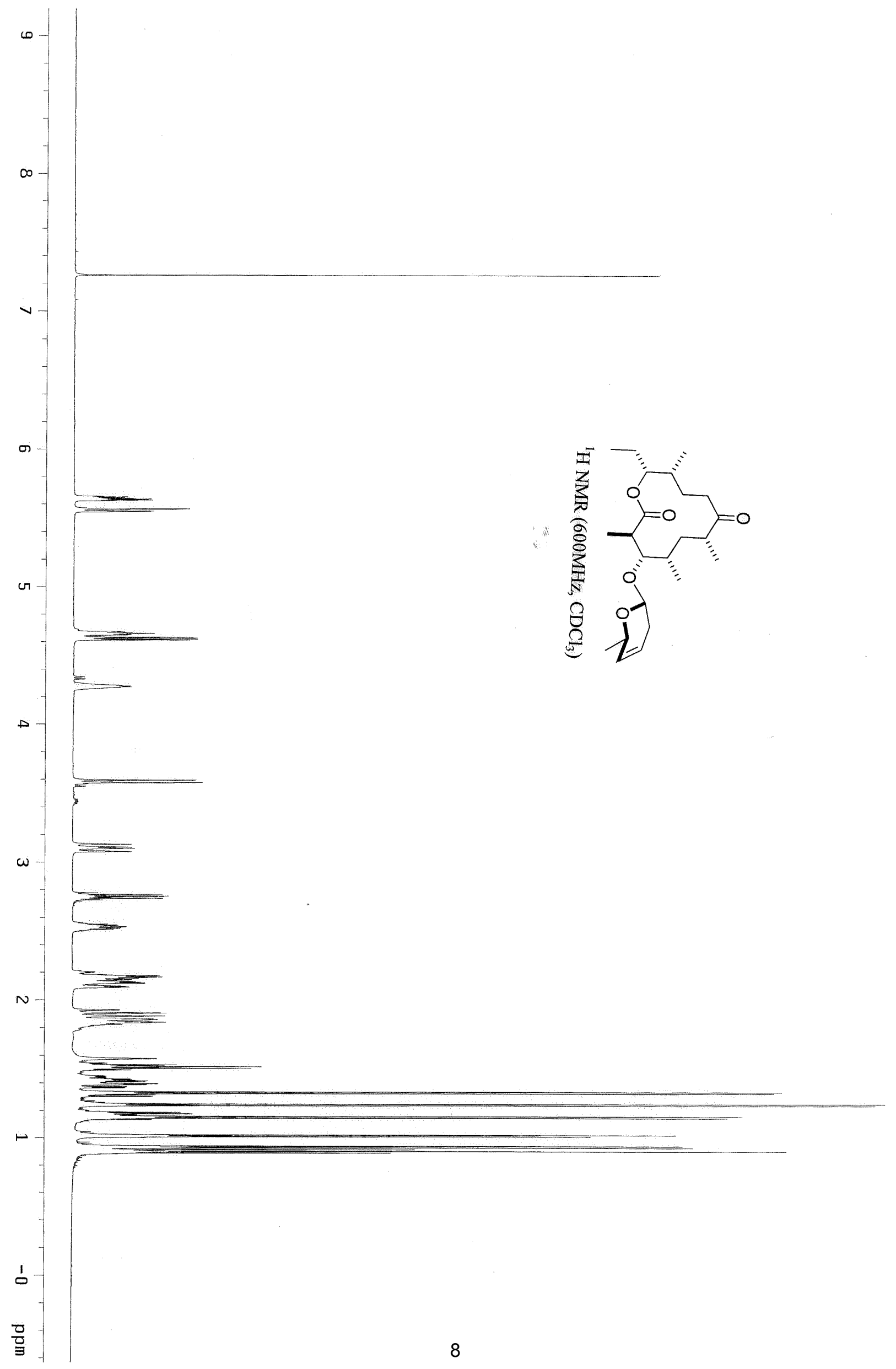




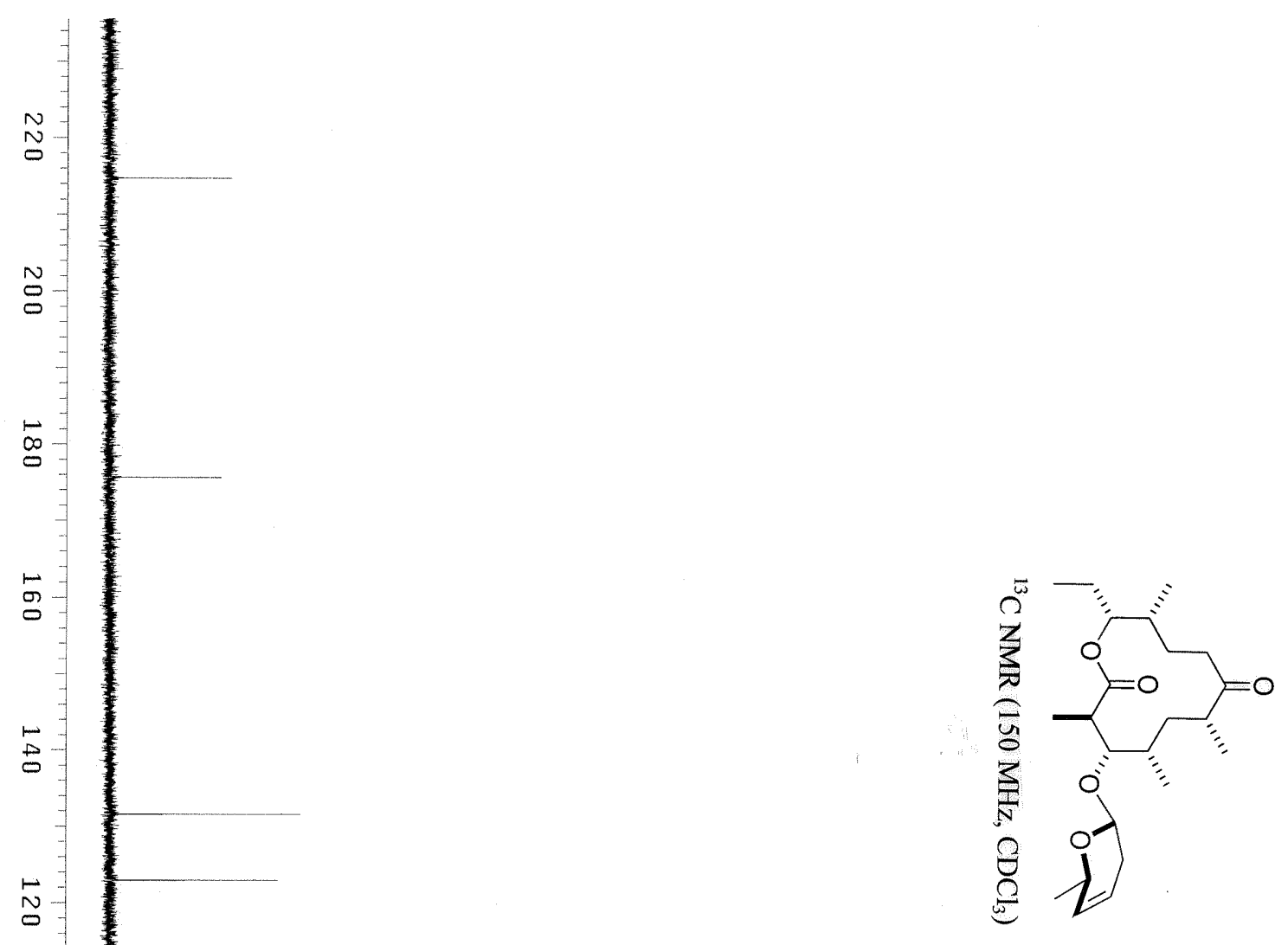




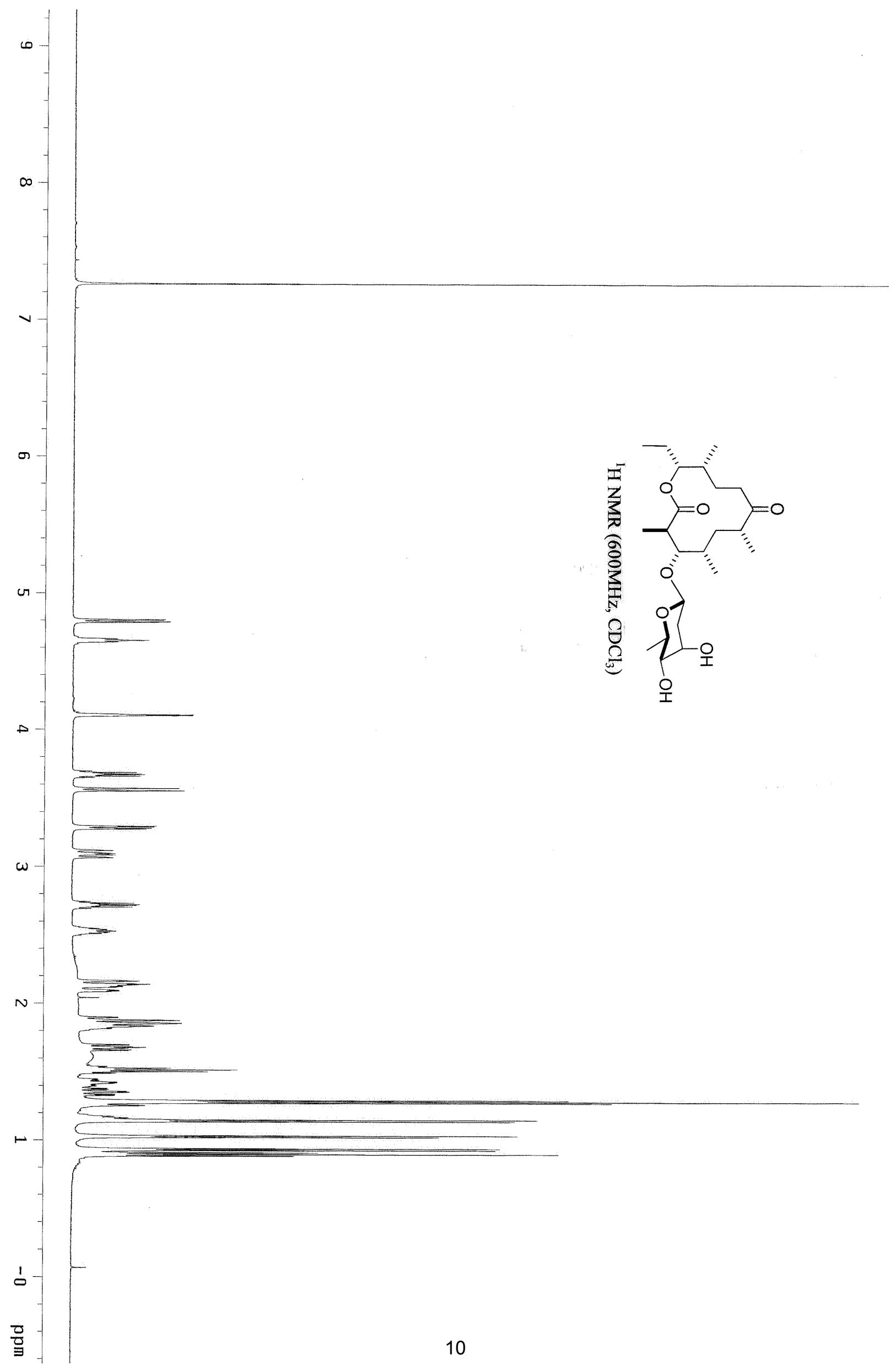




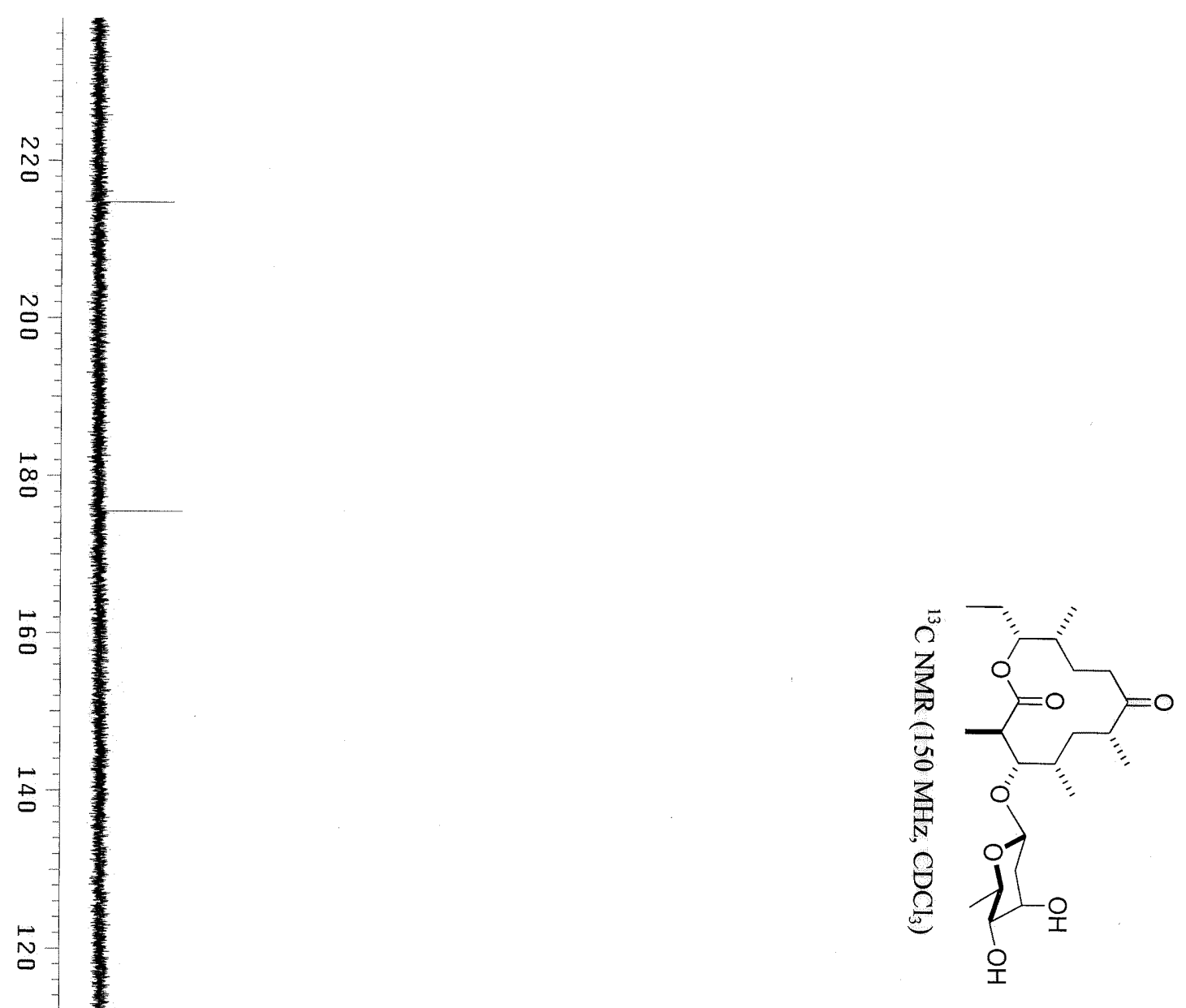

음

$\stackrel{\infty}{\circ}$

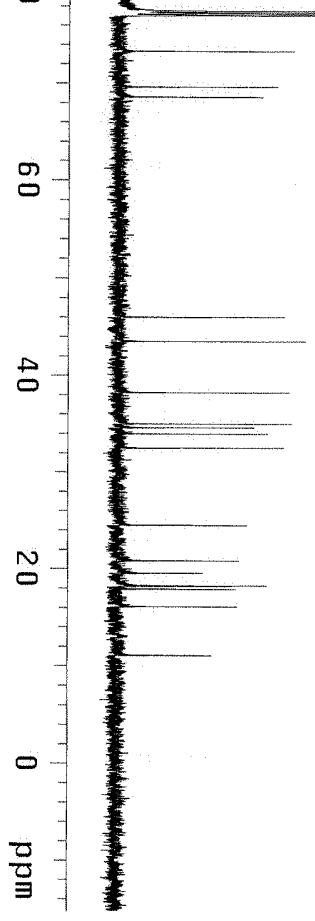




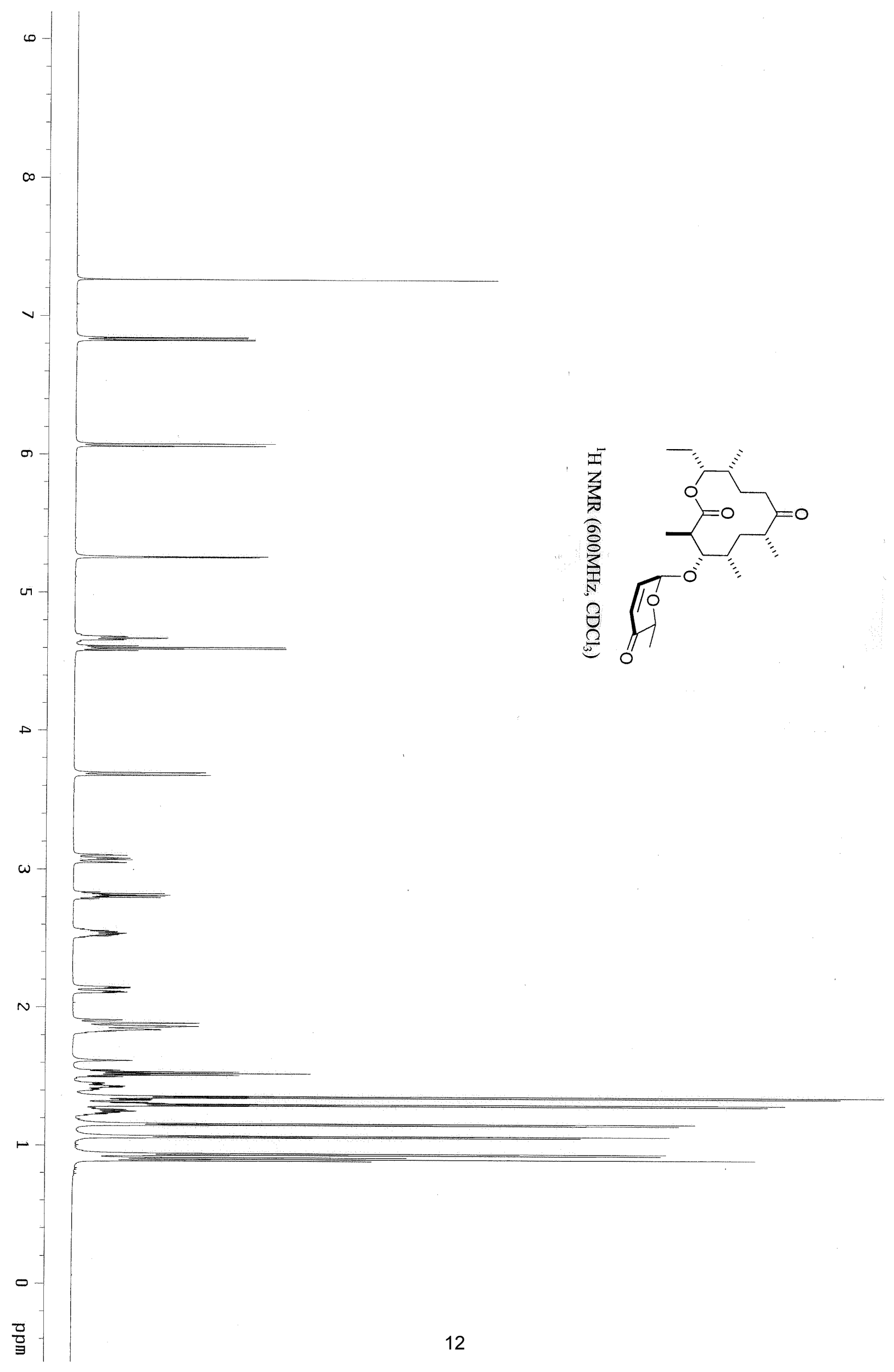




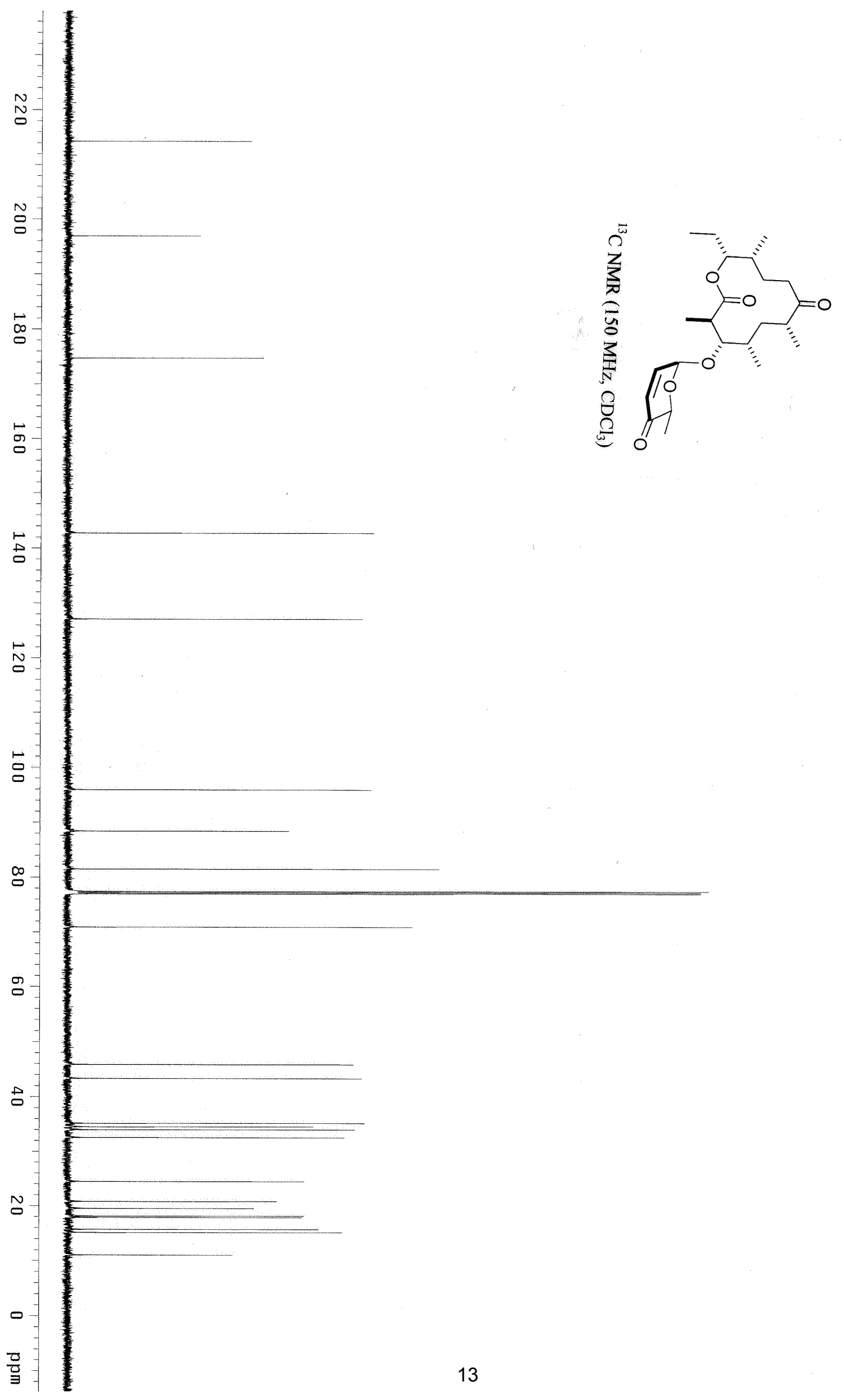




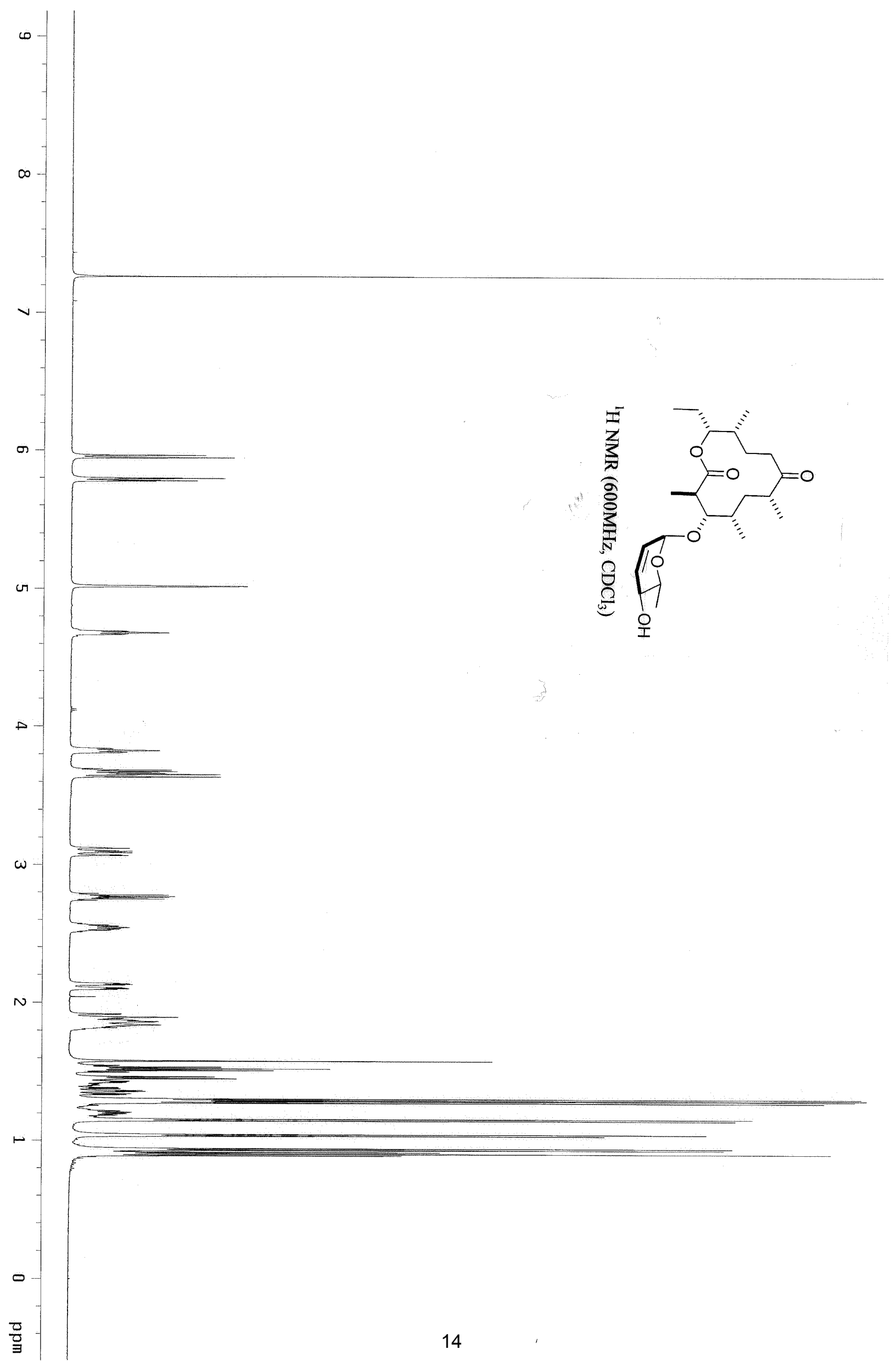




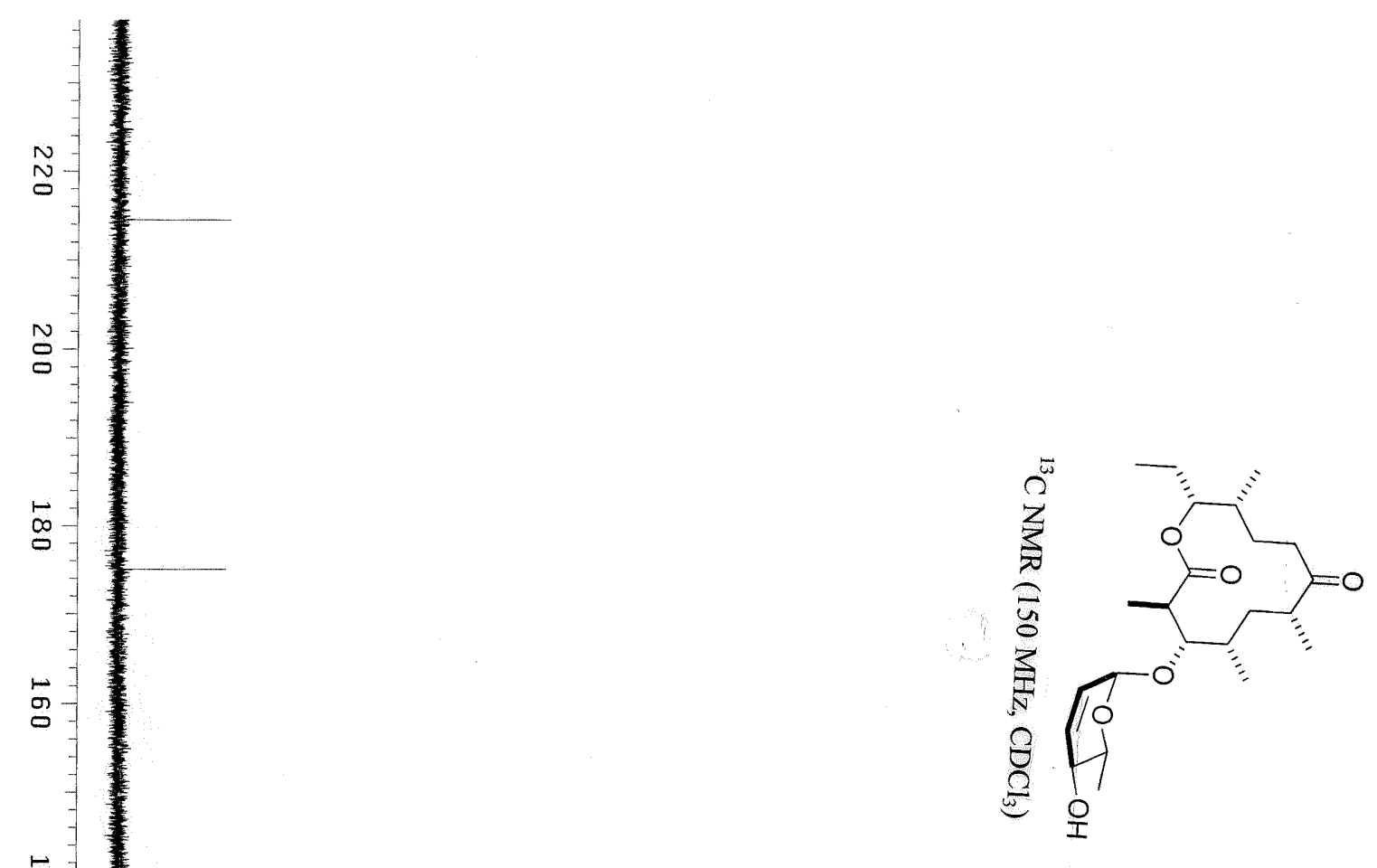

$\stackrel{\bullet}{\circ}$

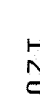

N

영

$\infty$

$\sqrt{1}$

믐

1

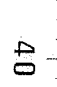

$8-$

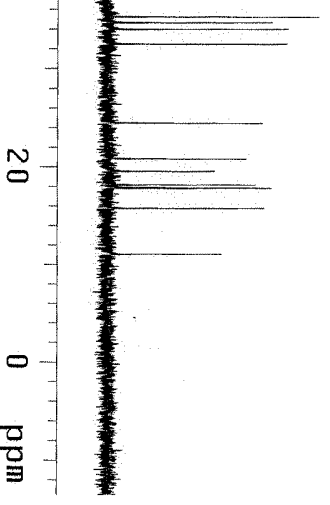




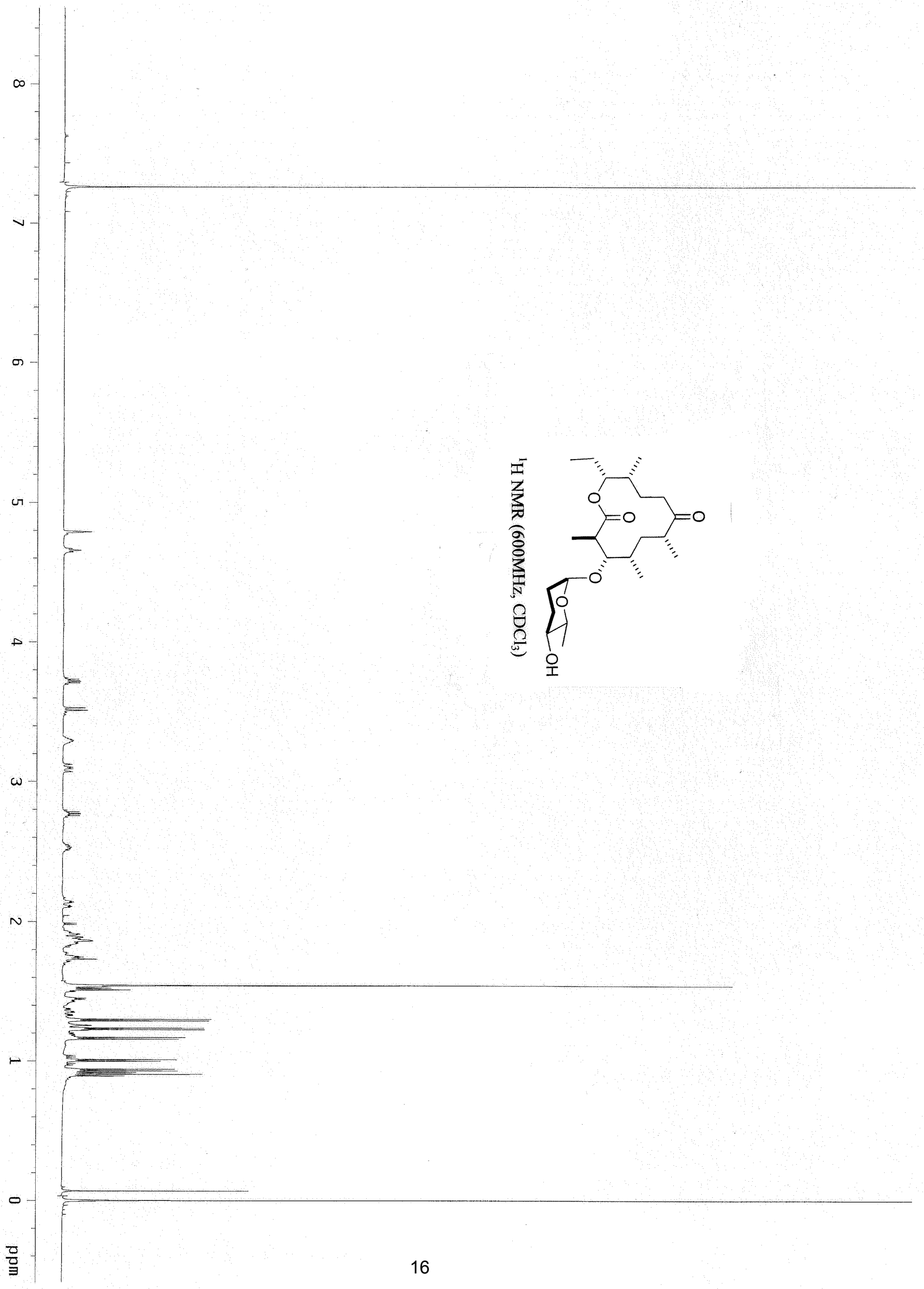




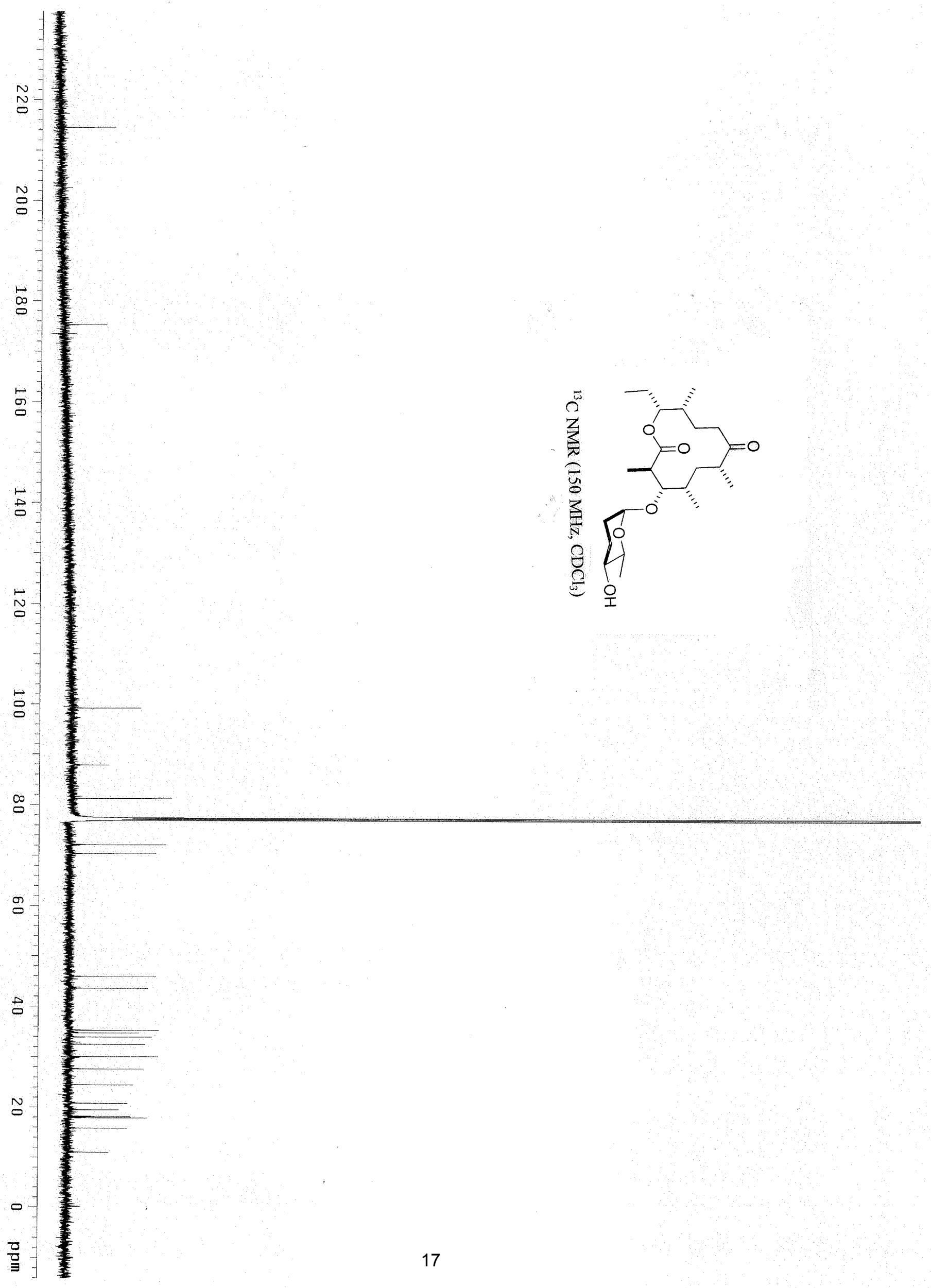




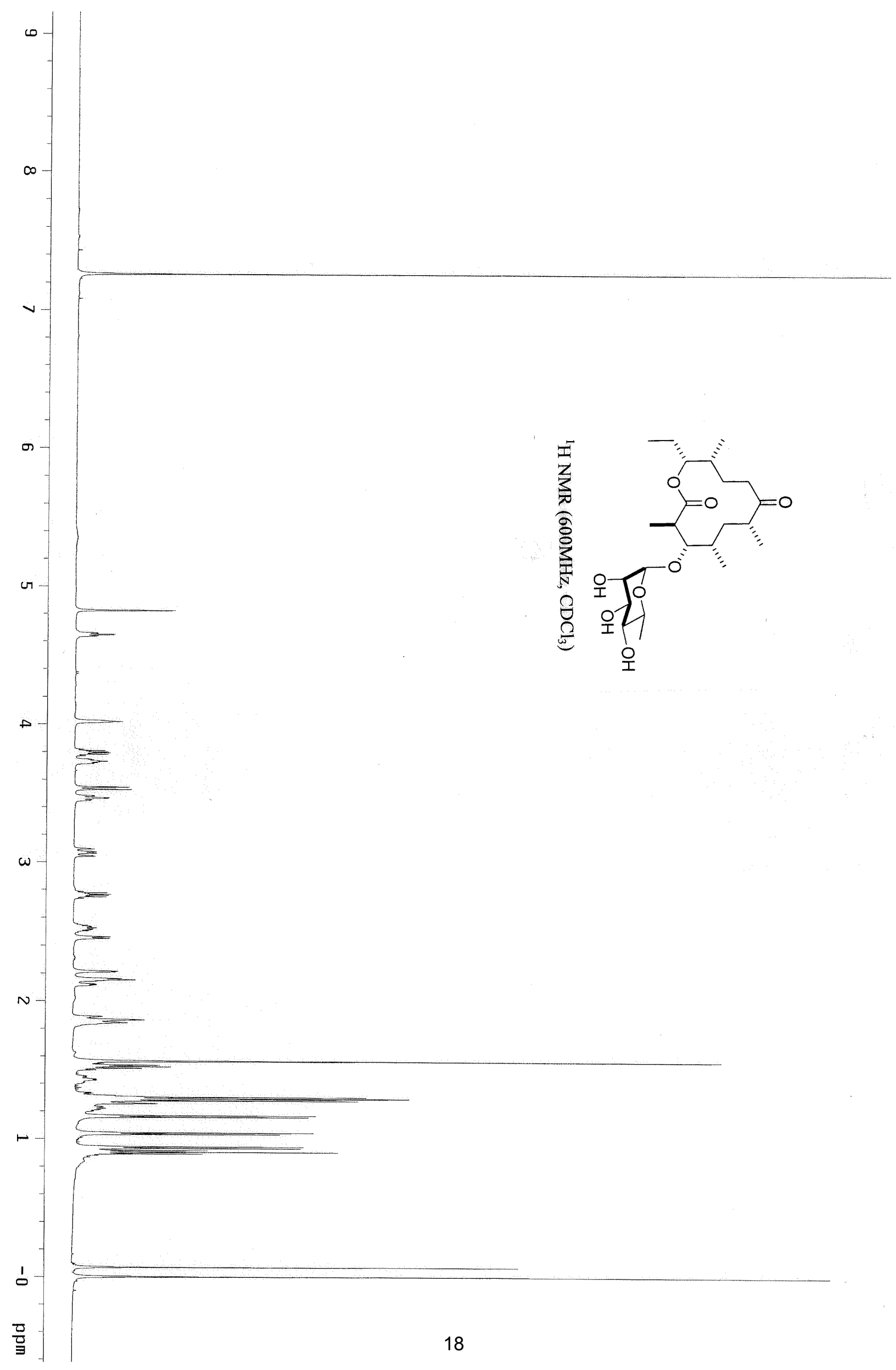




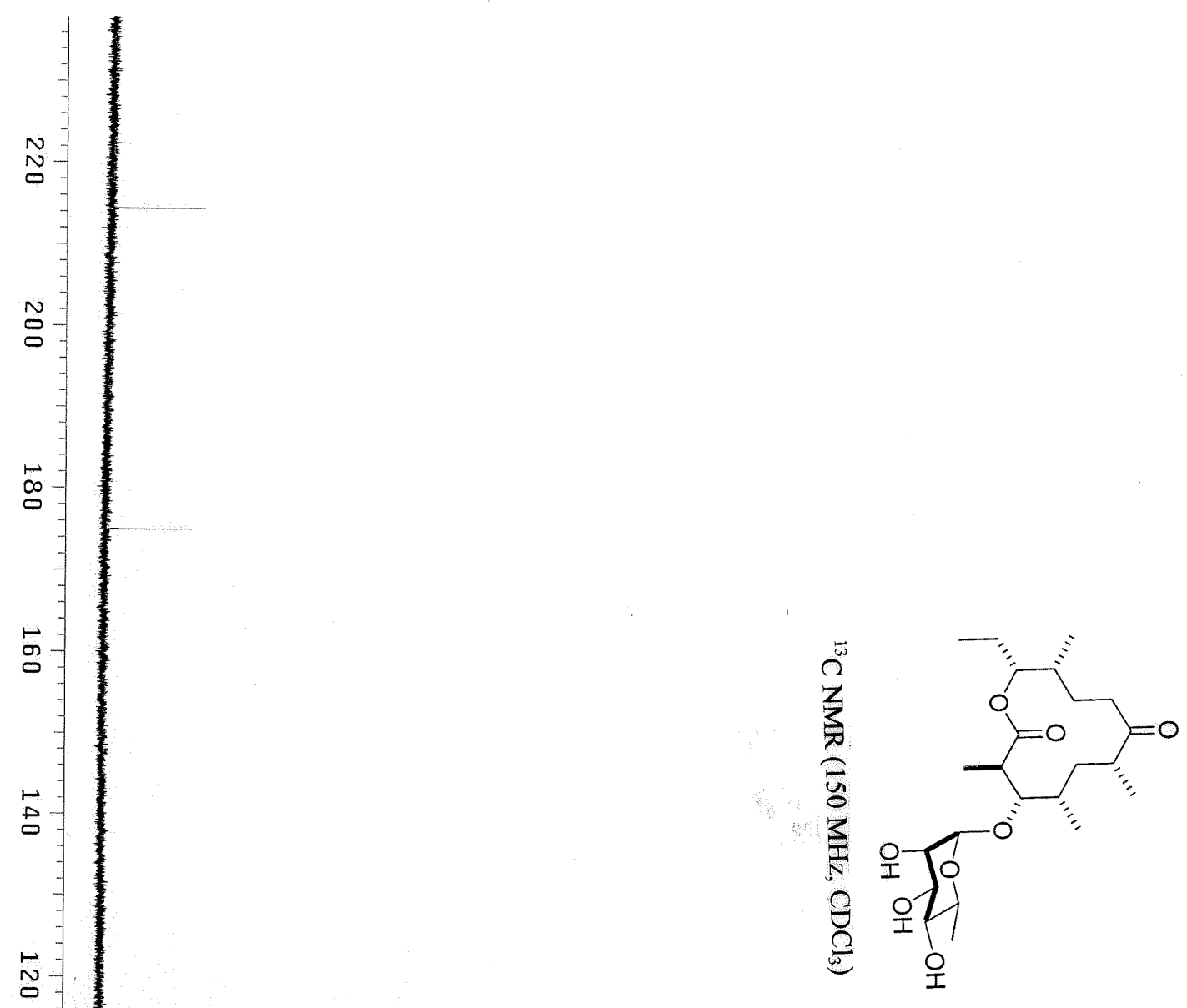

$$
\text { 量 }
$$




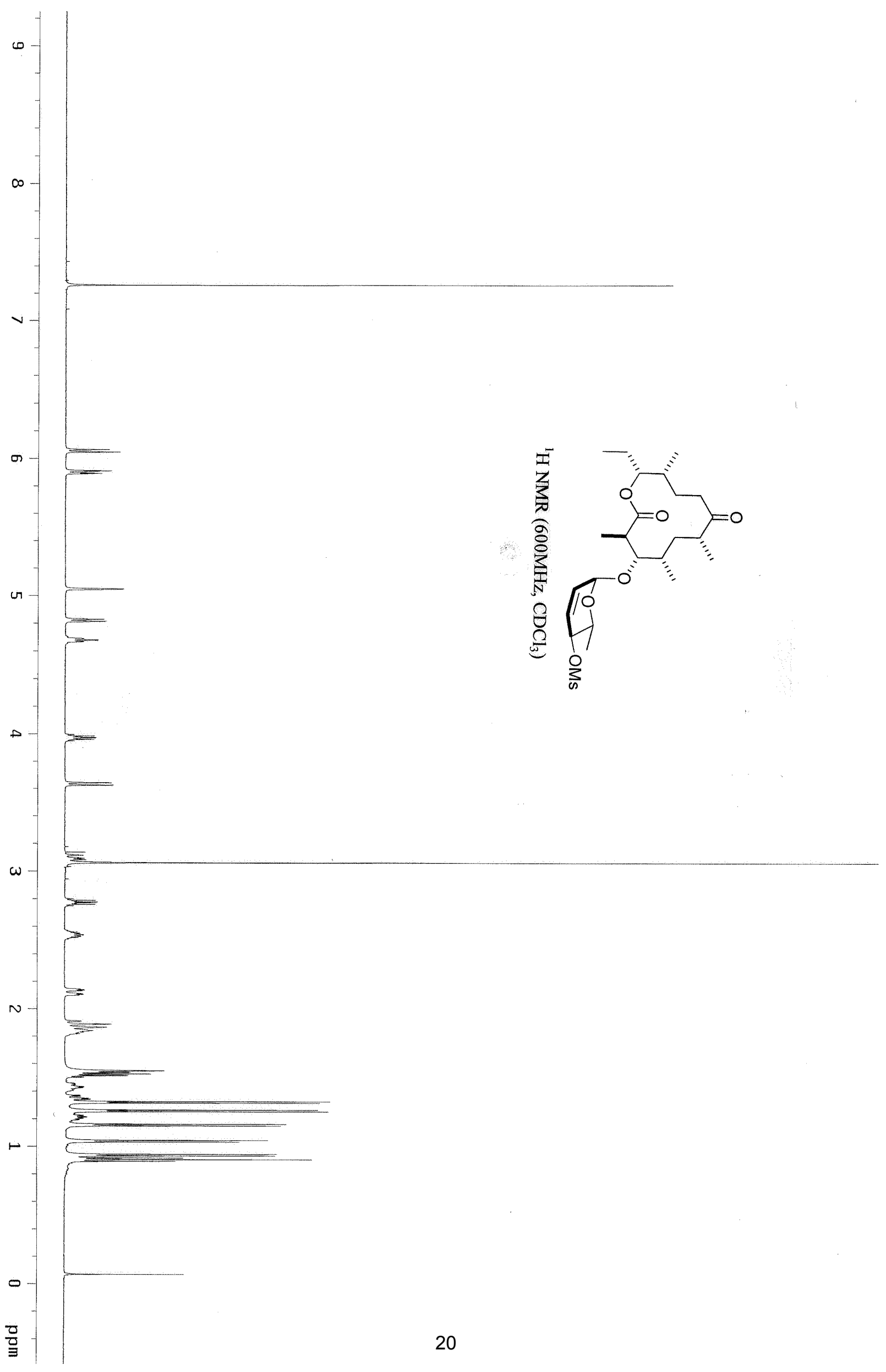




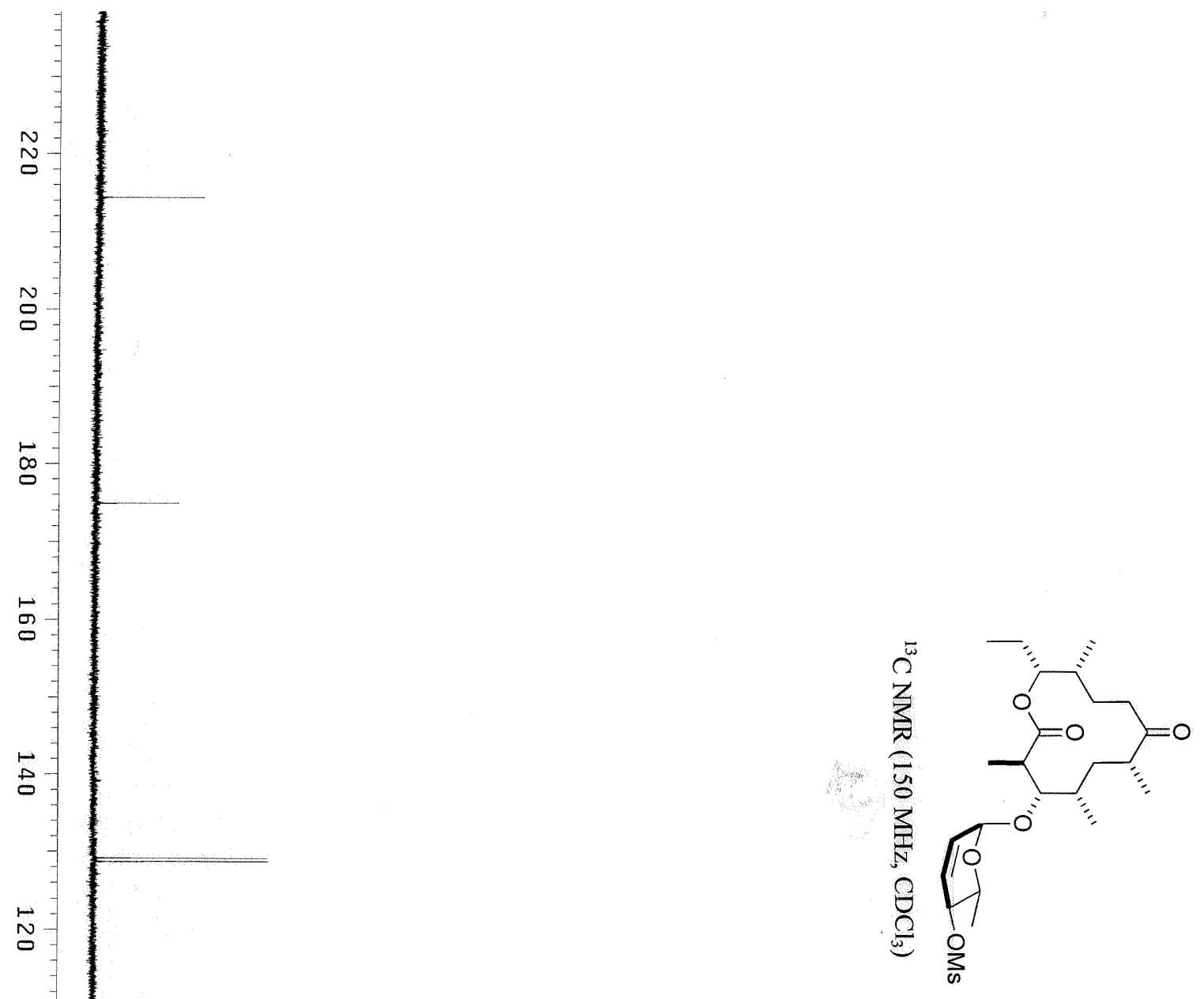

吕

$\infty$

$\infty$

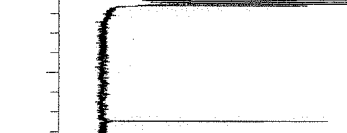

옴

임

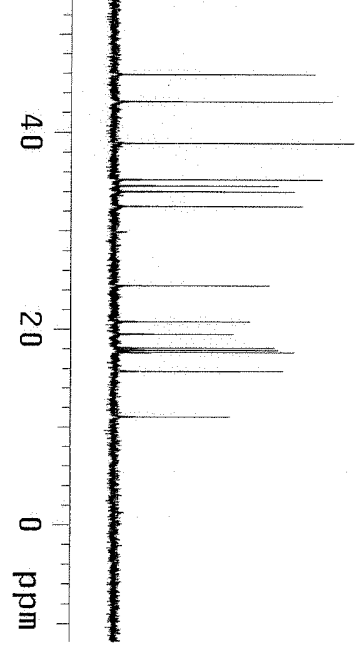




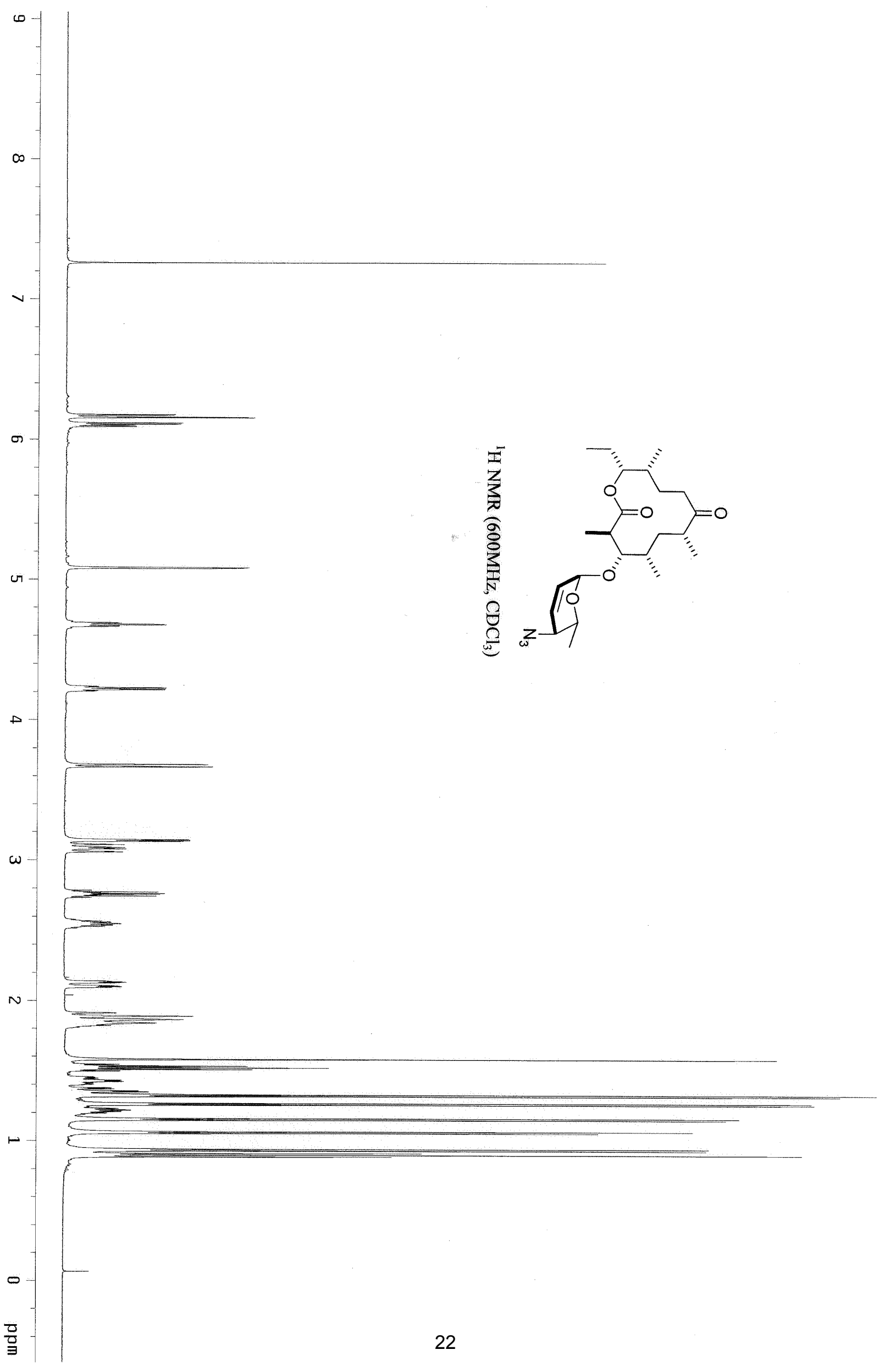




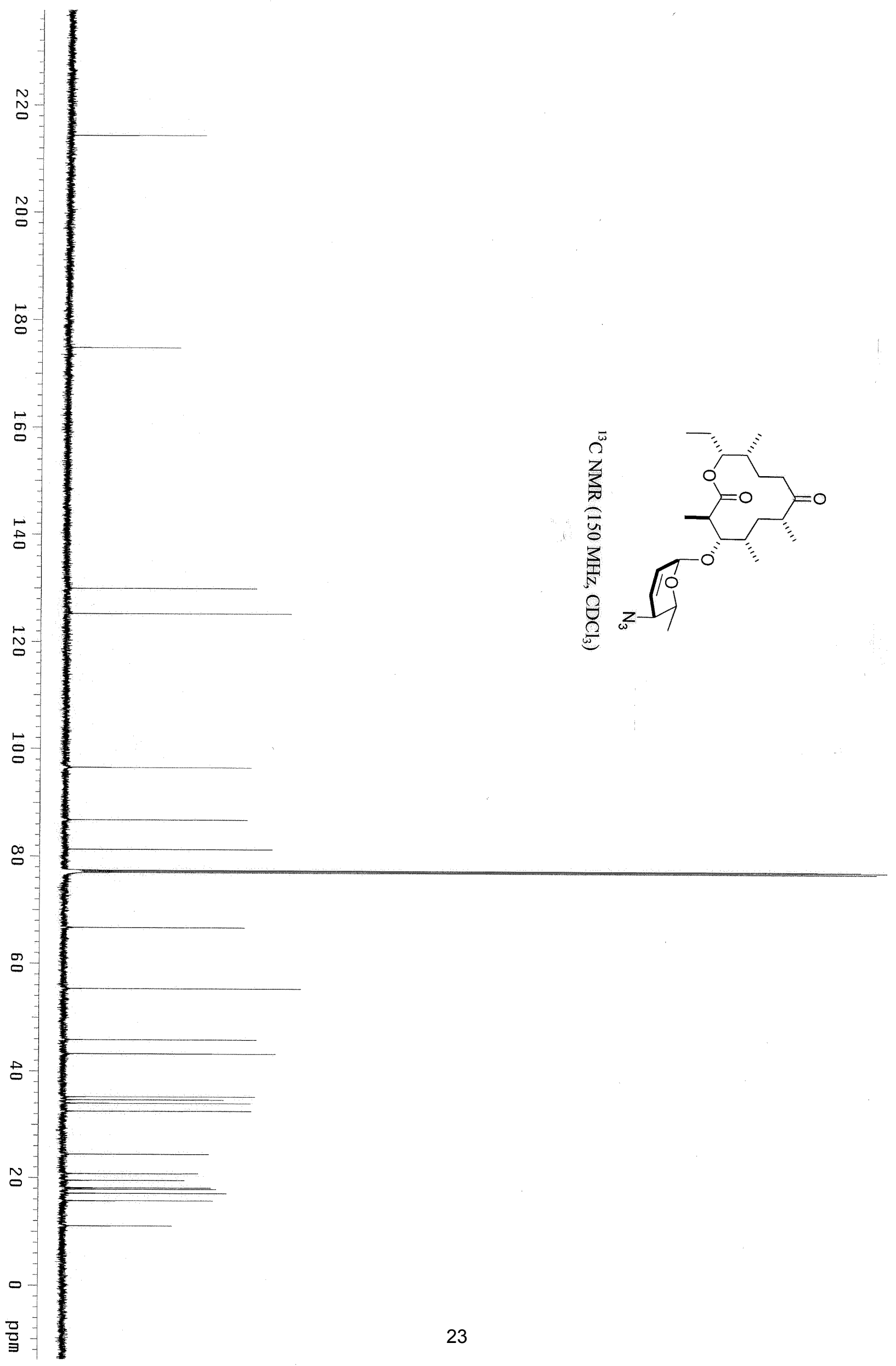




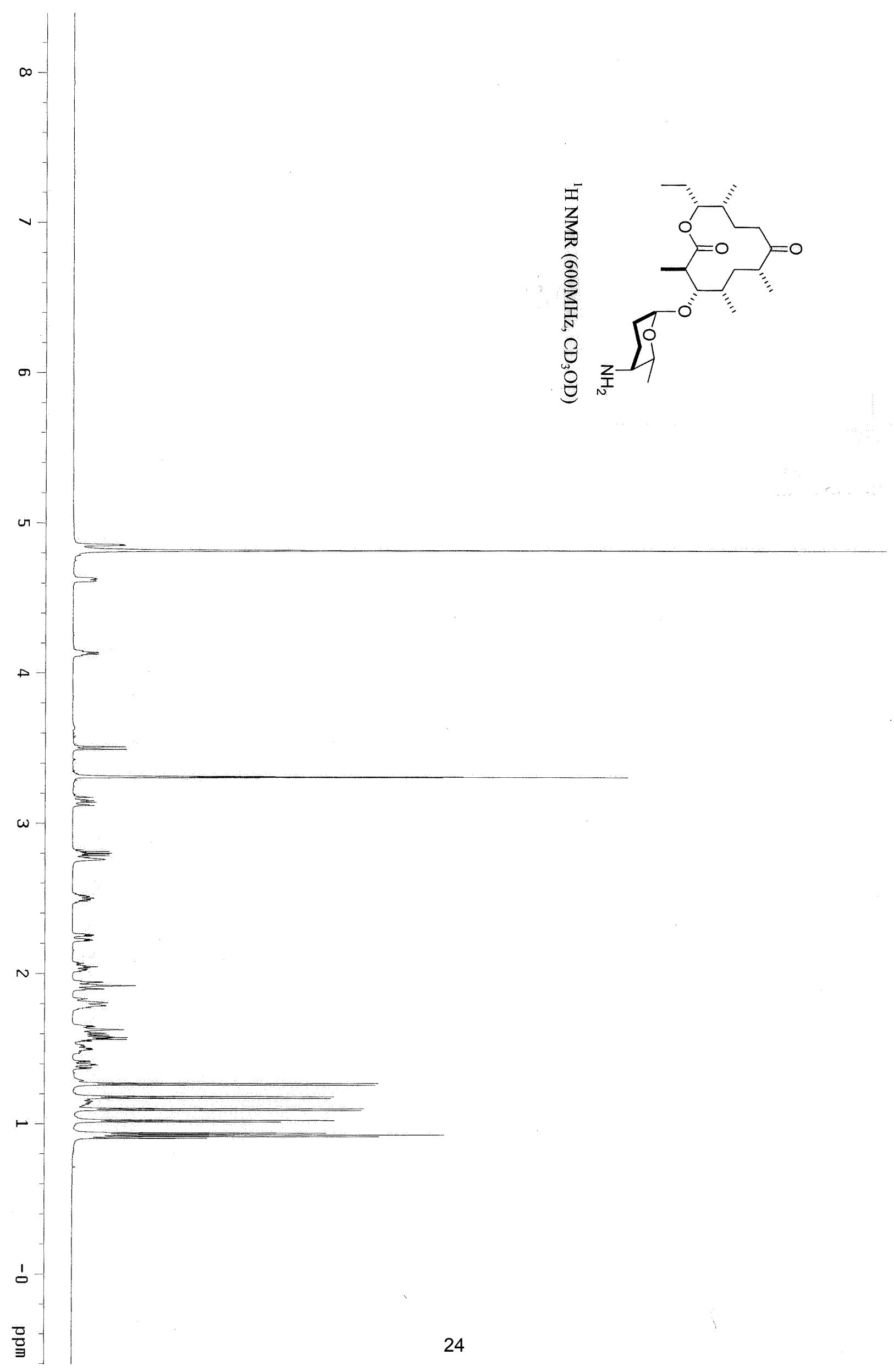




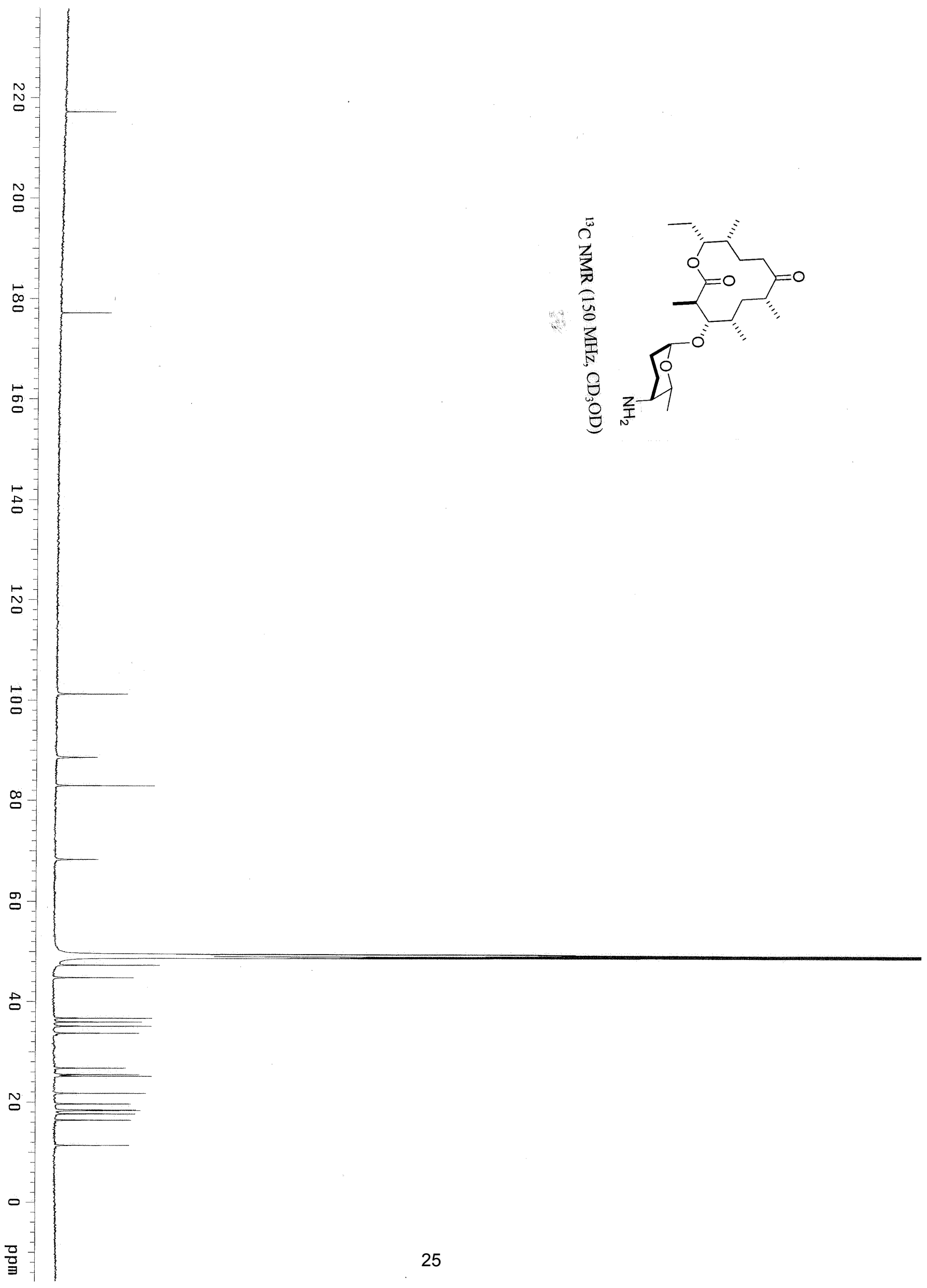




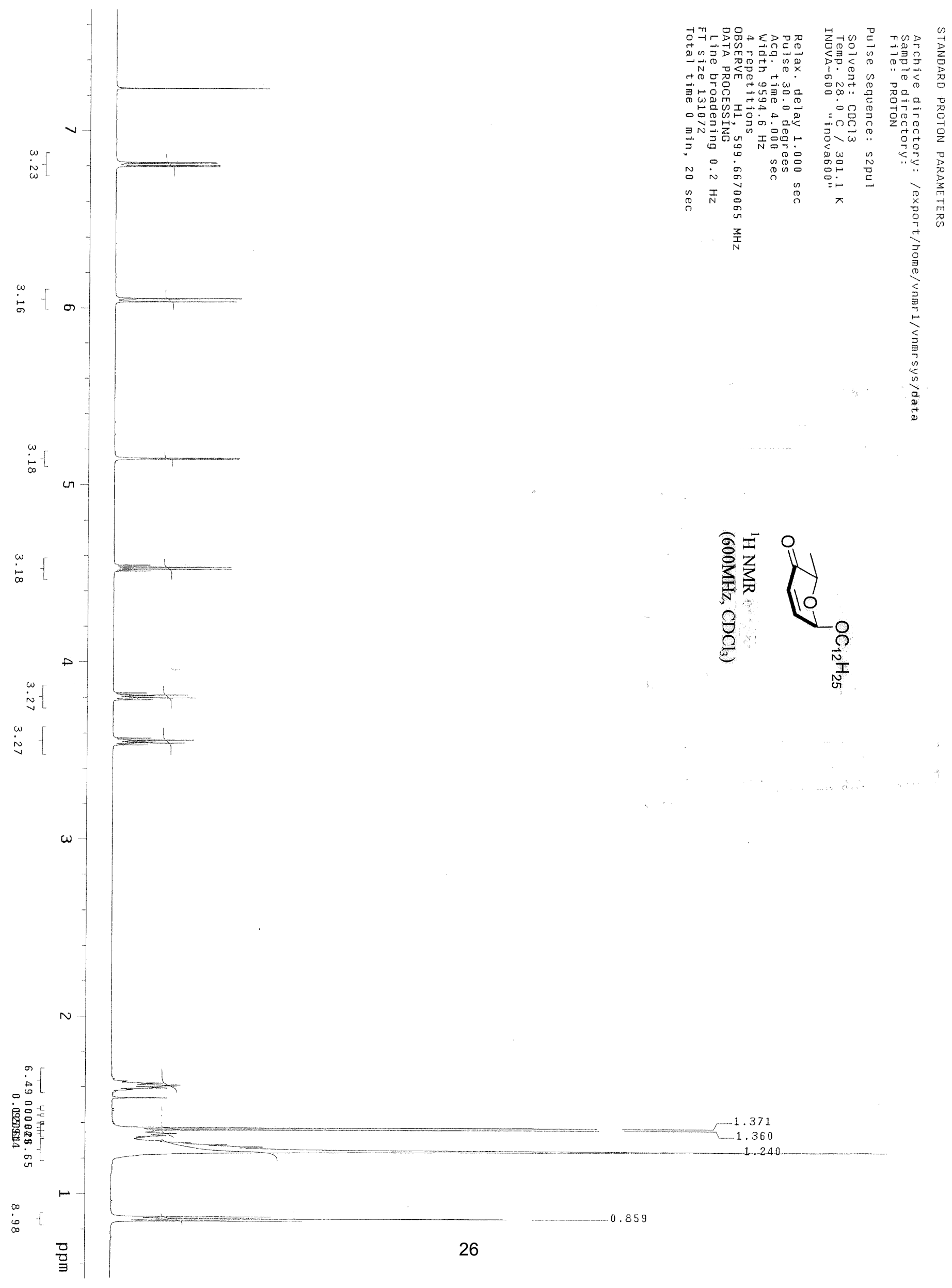




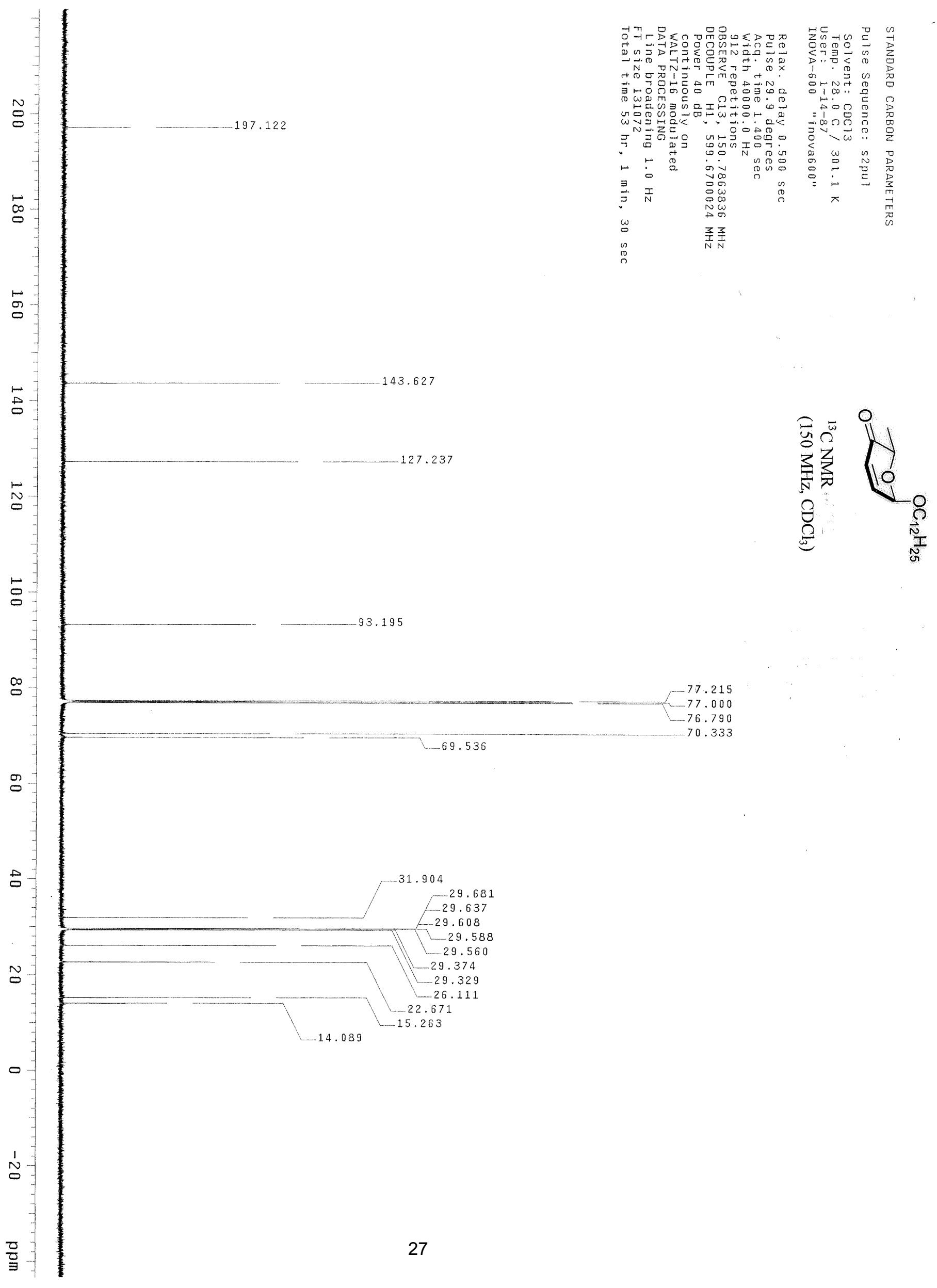




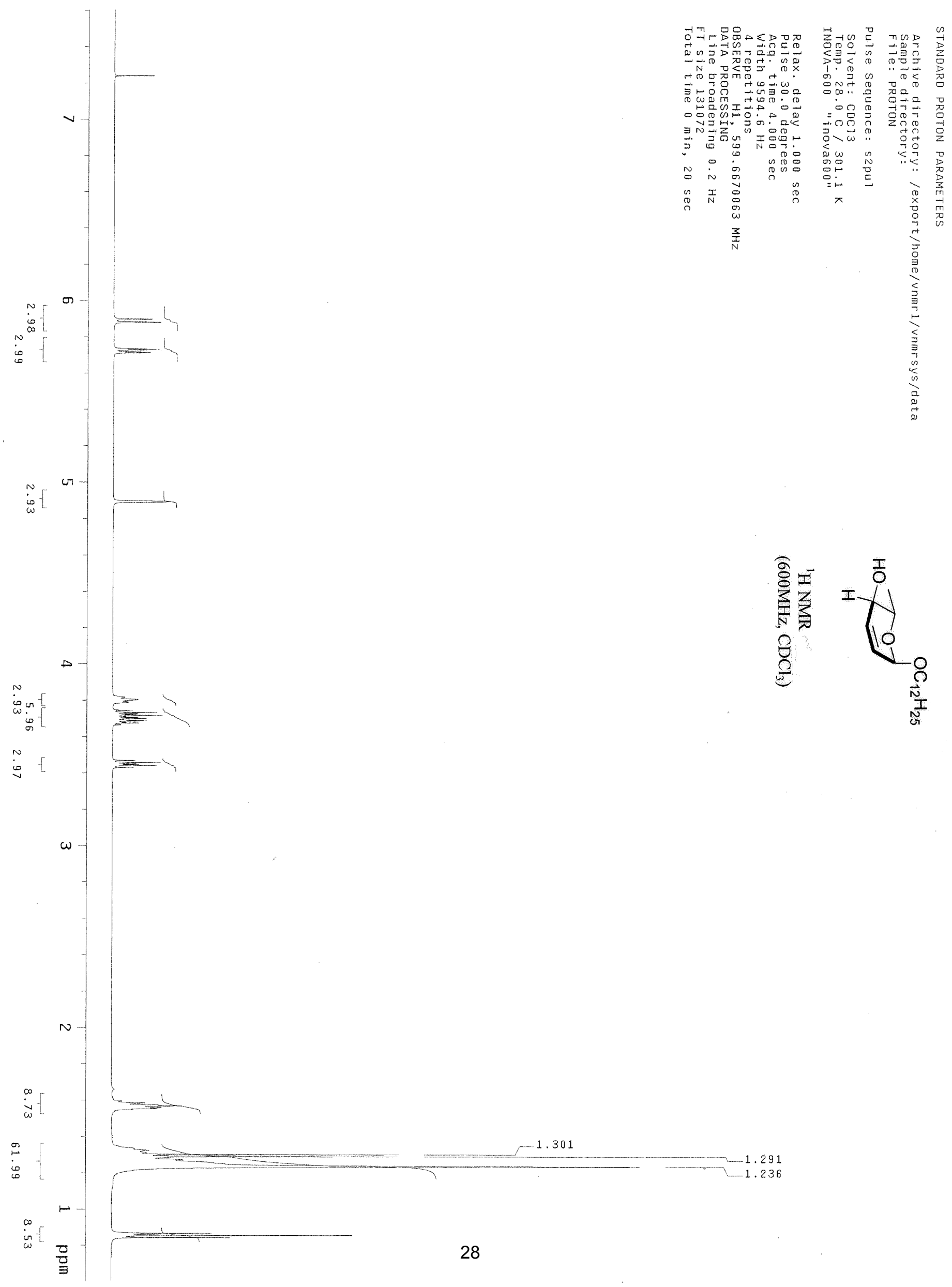



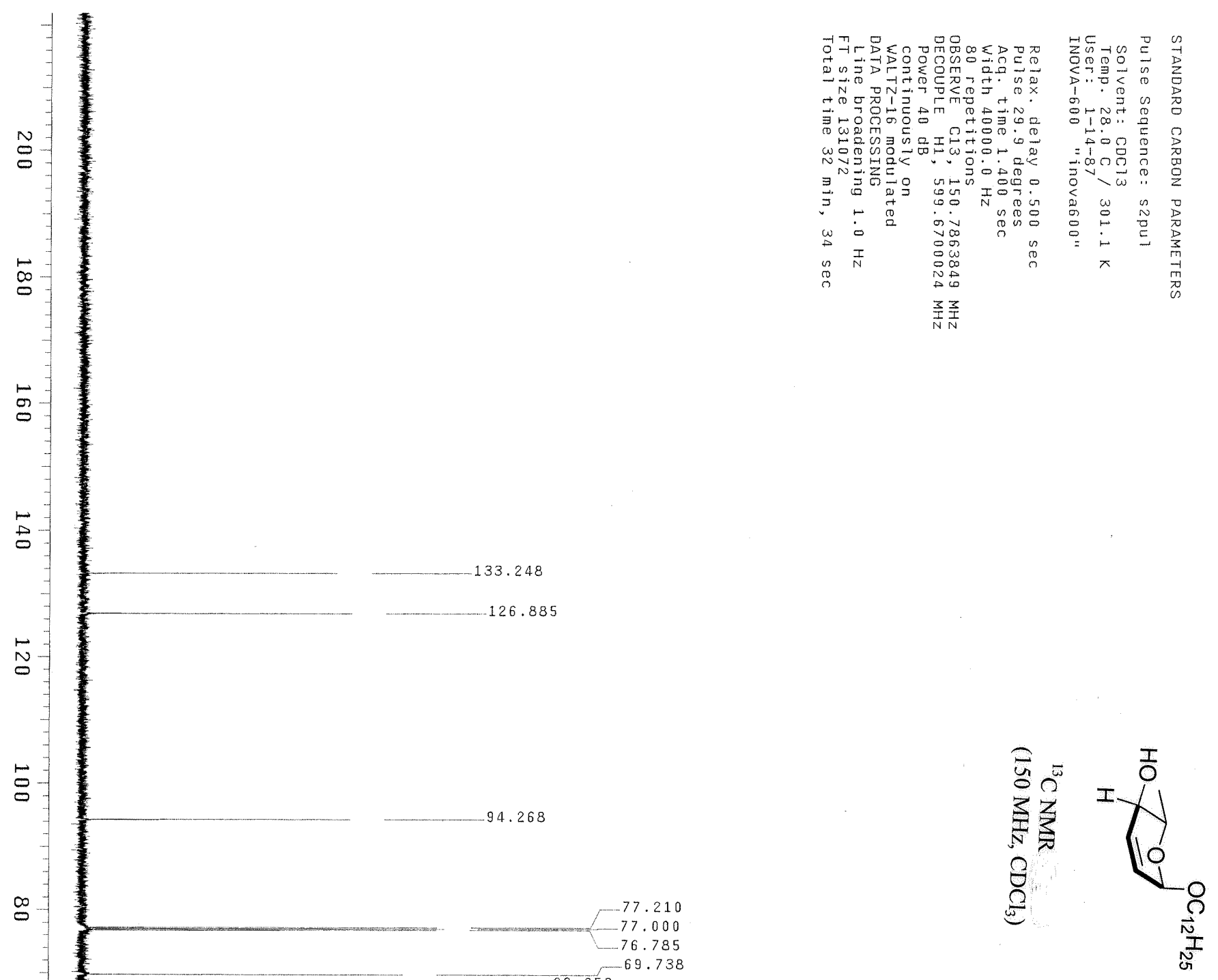


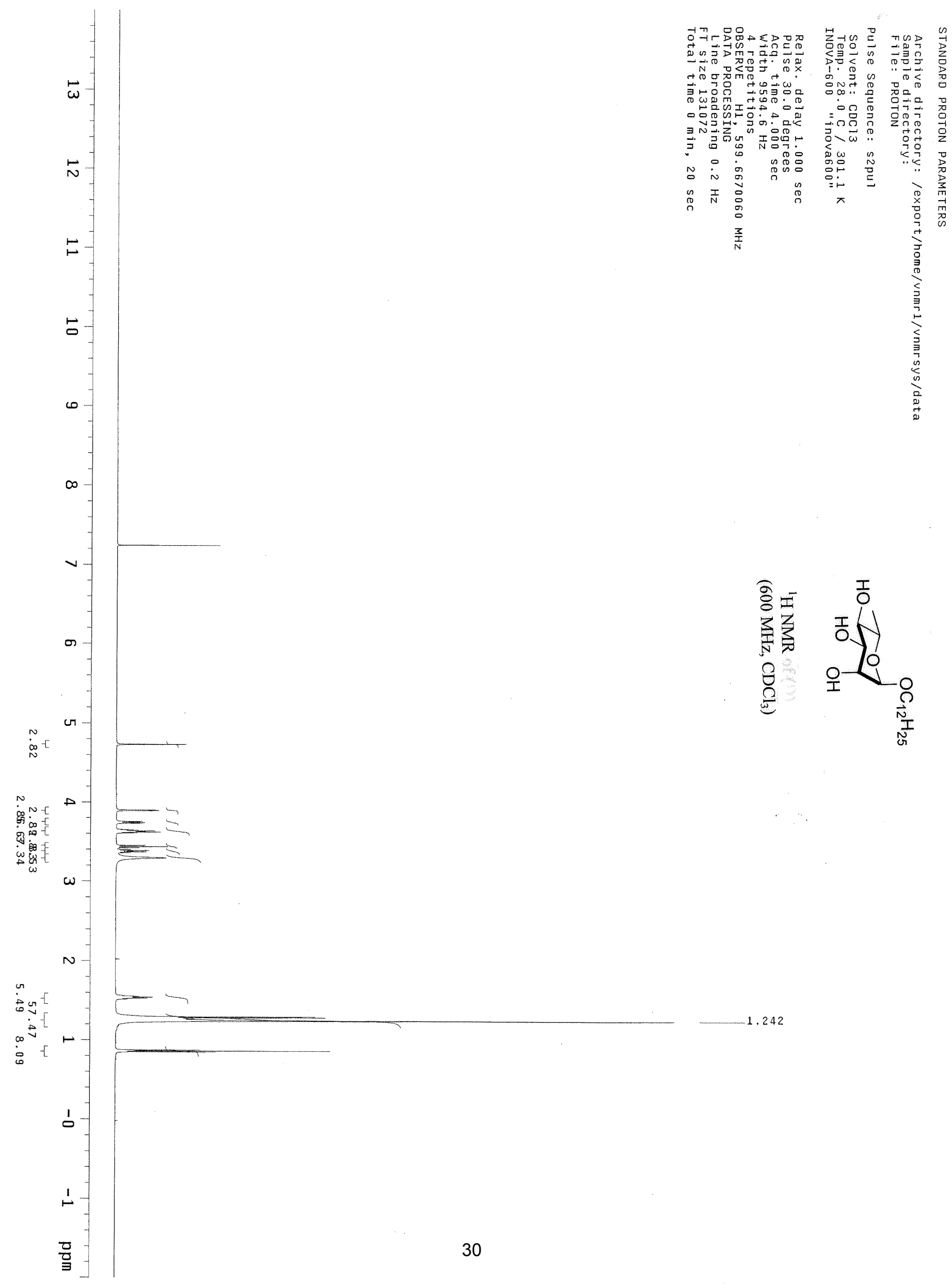



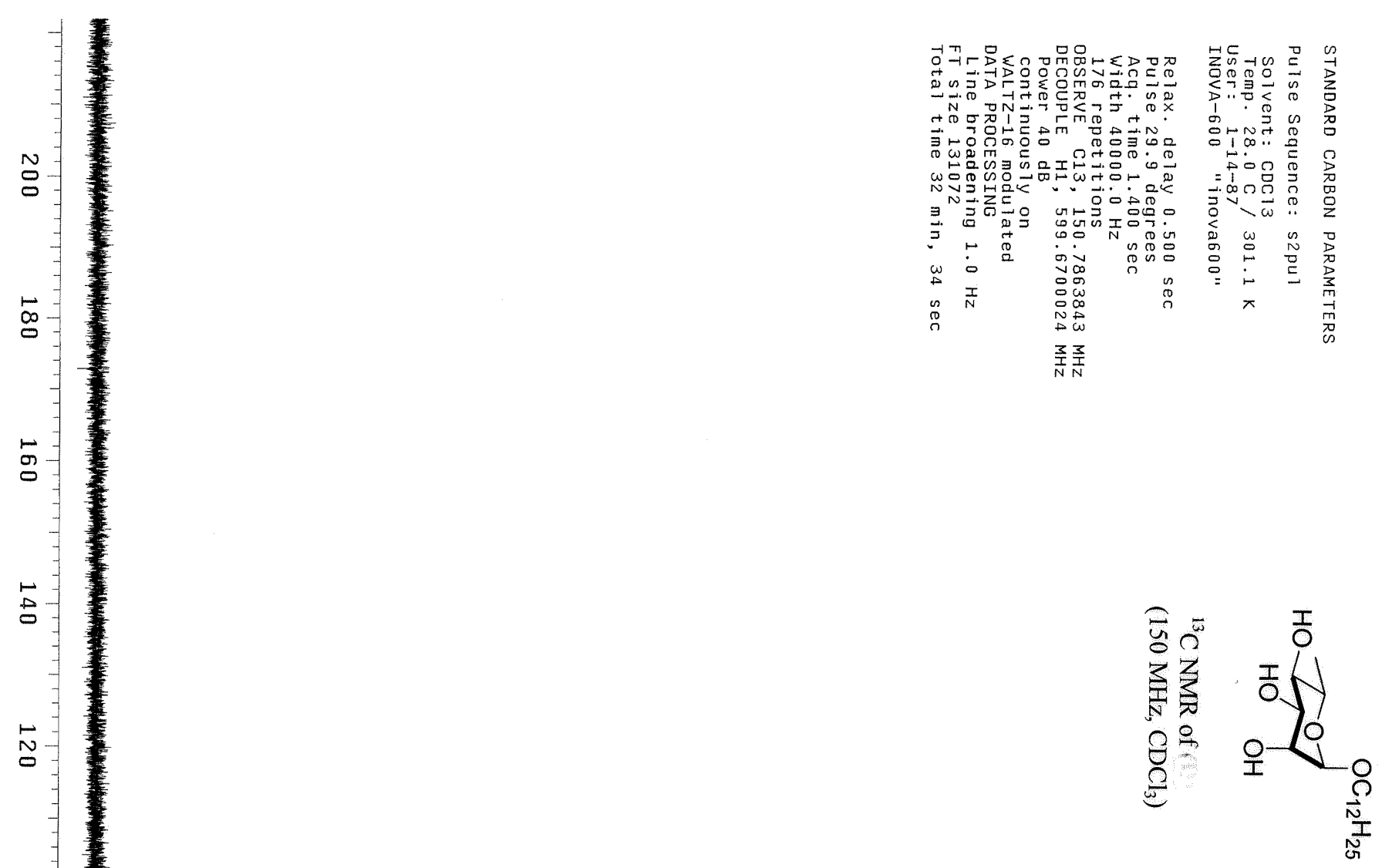


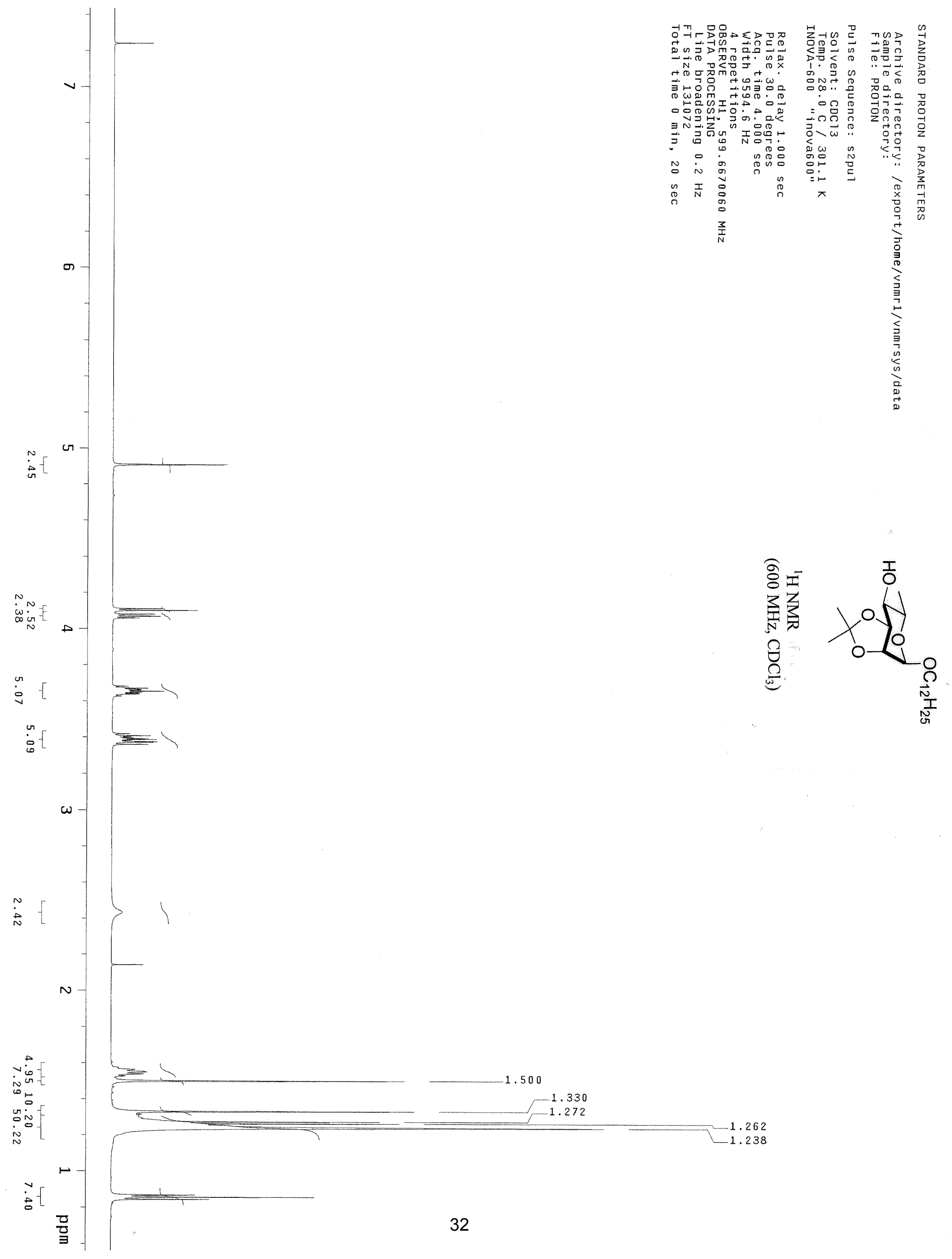



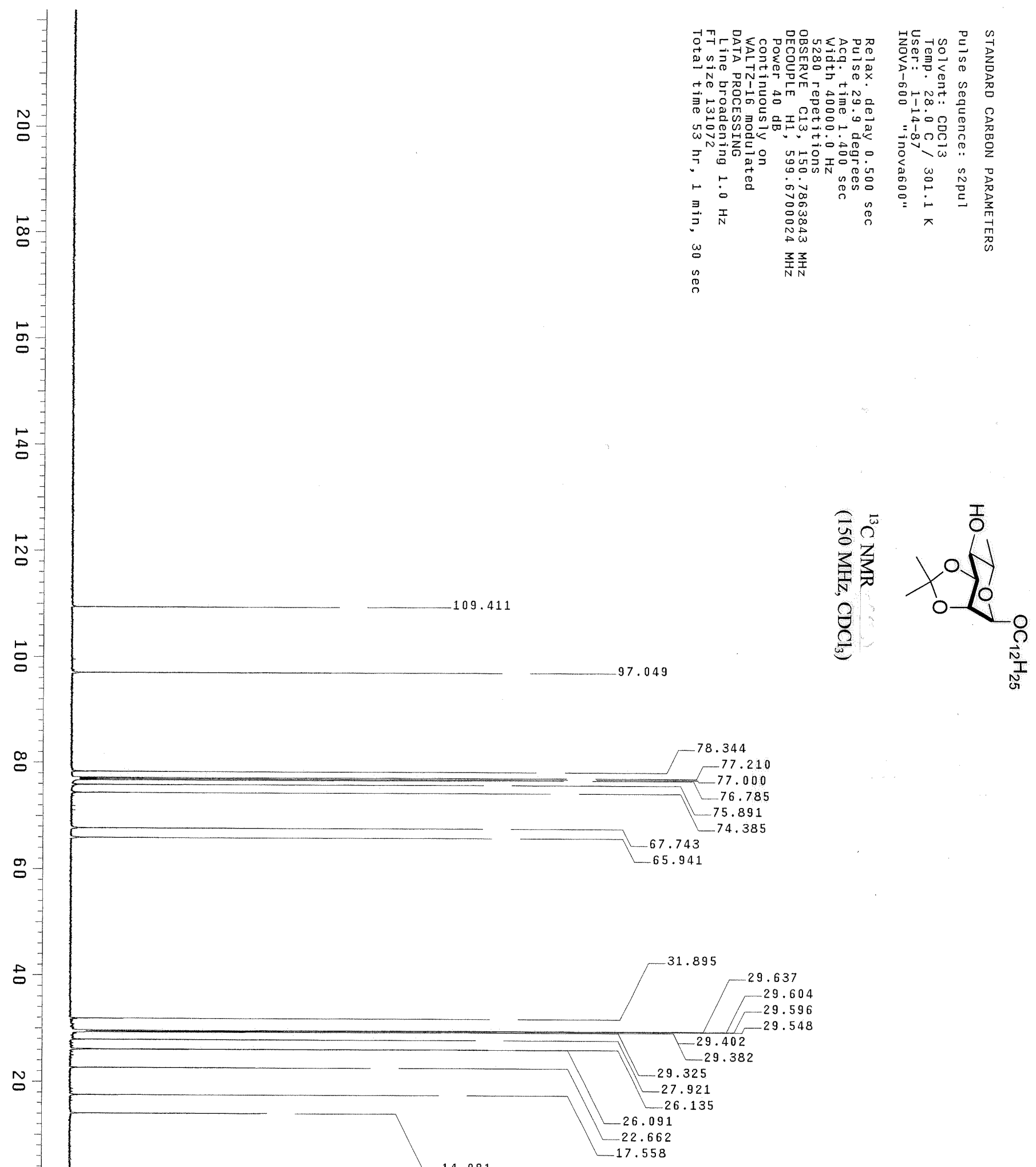

$\circ$

$-14.081$ 


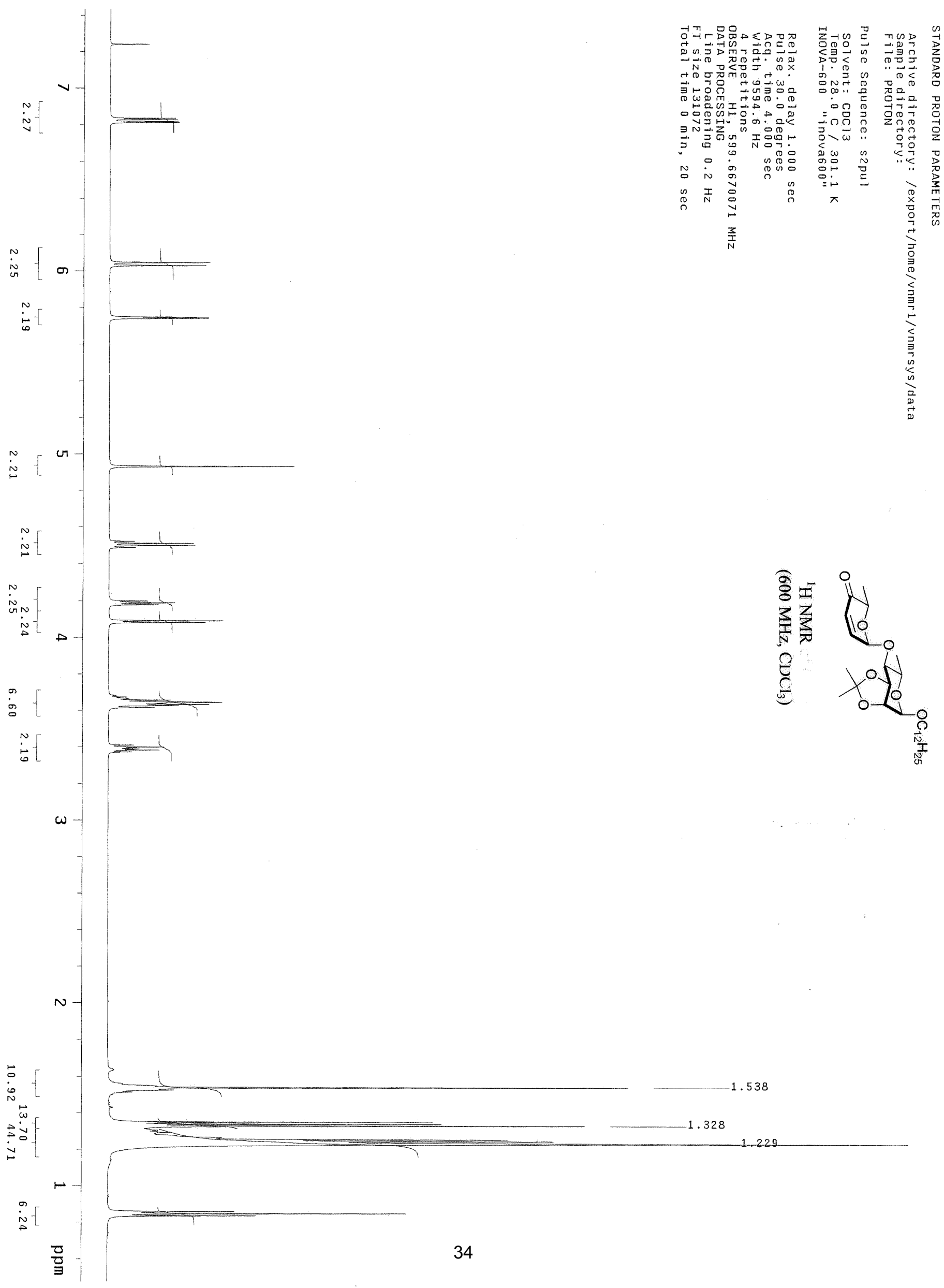




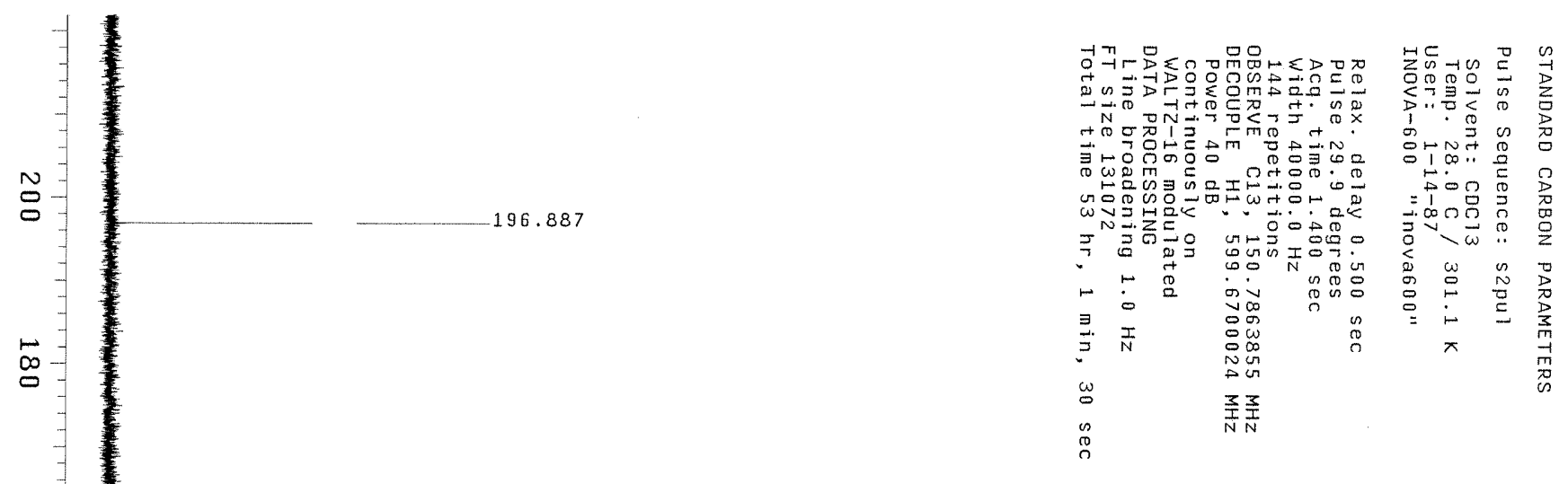

몸

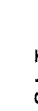

N

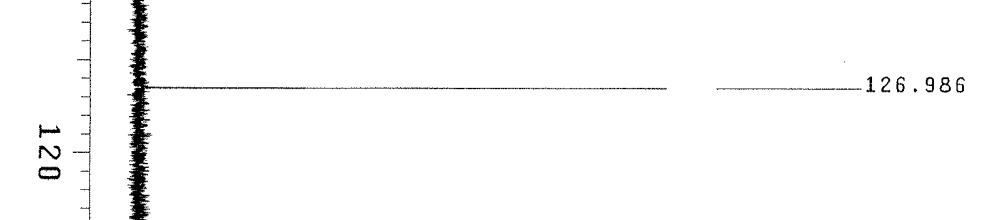

$-109.447$

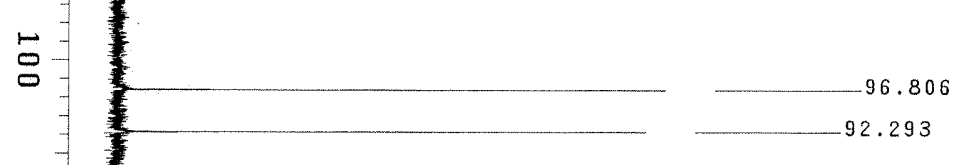

$\infty$

$\infty$

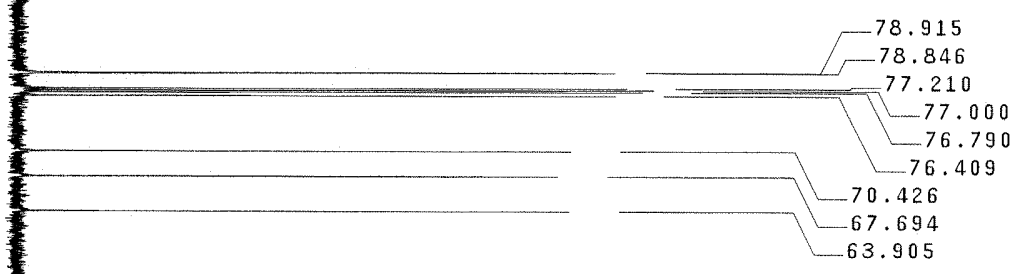

143.574

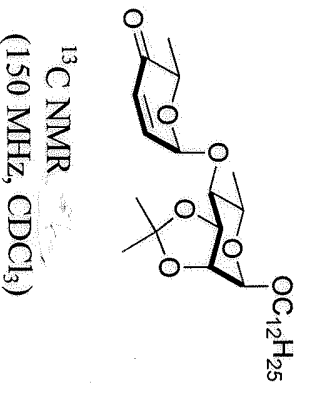




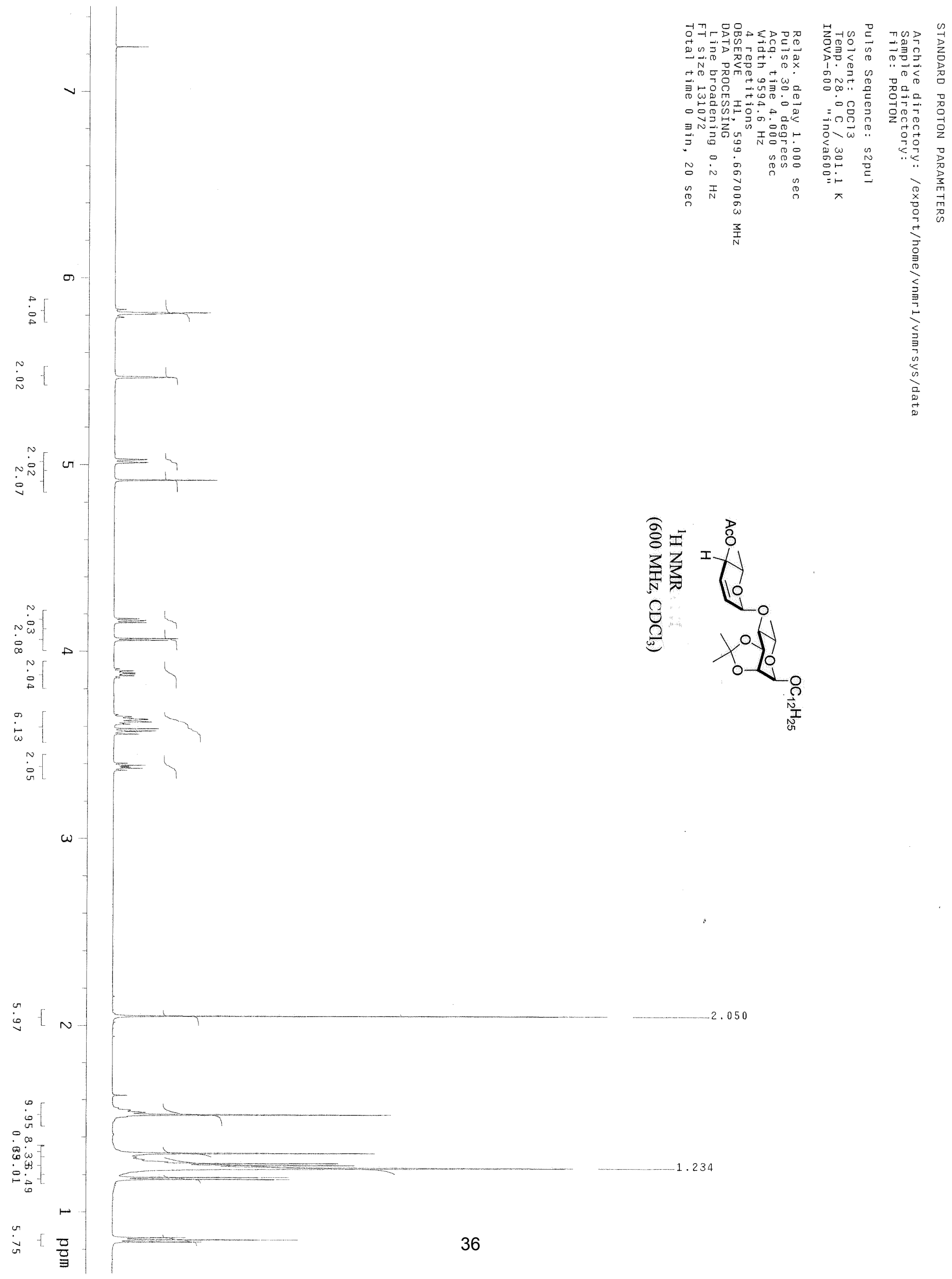



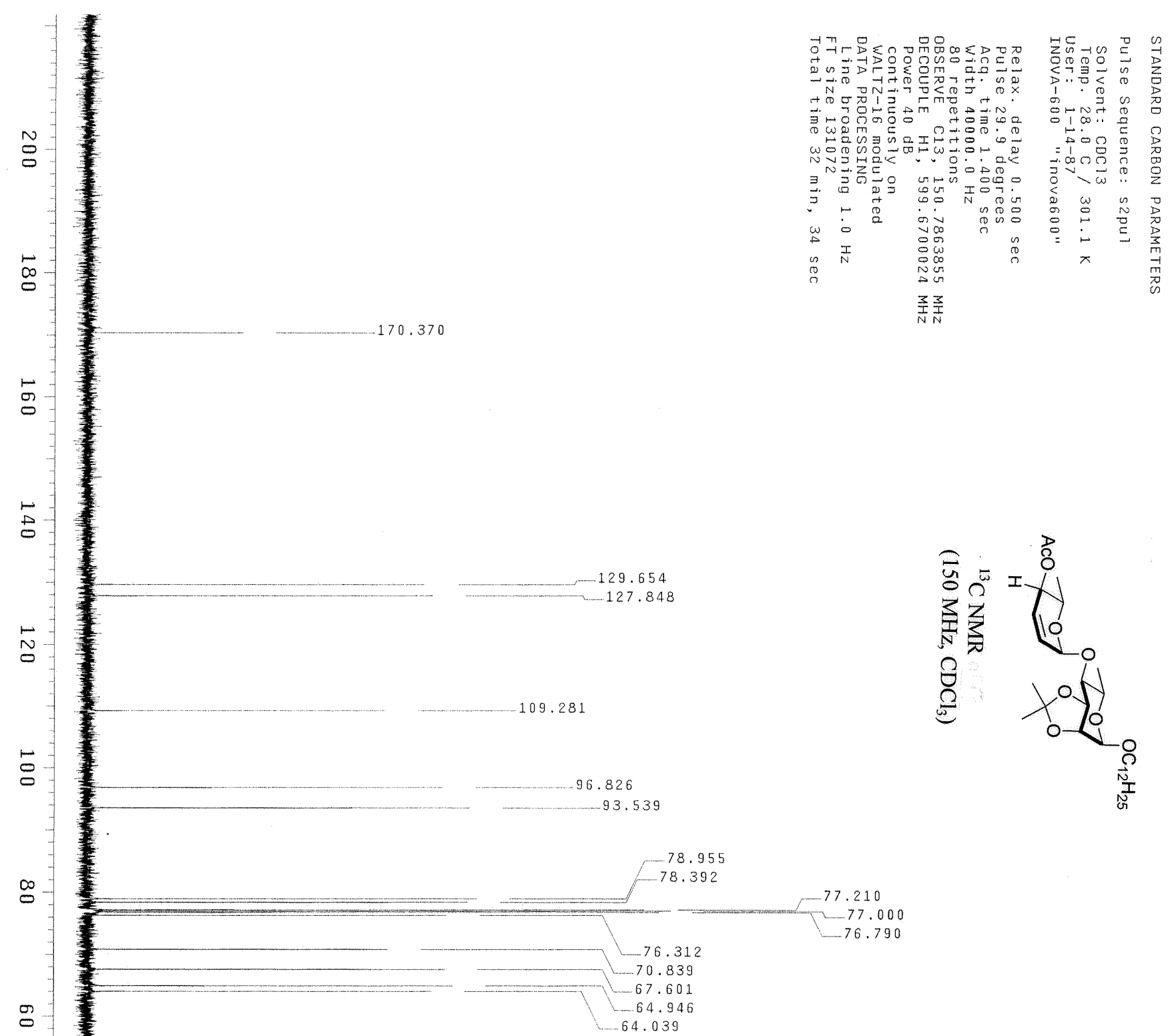


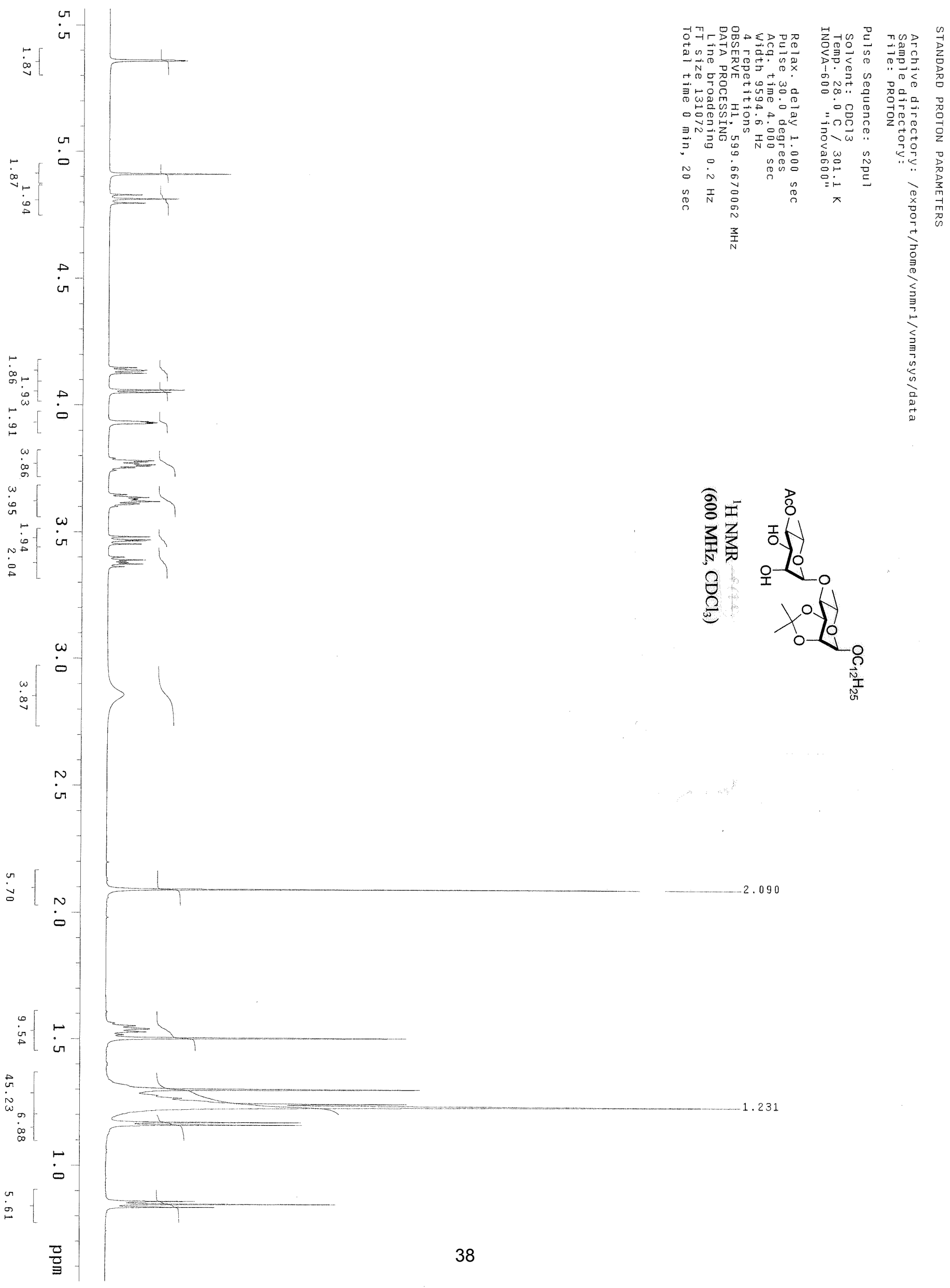




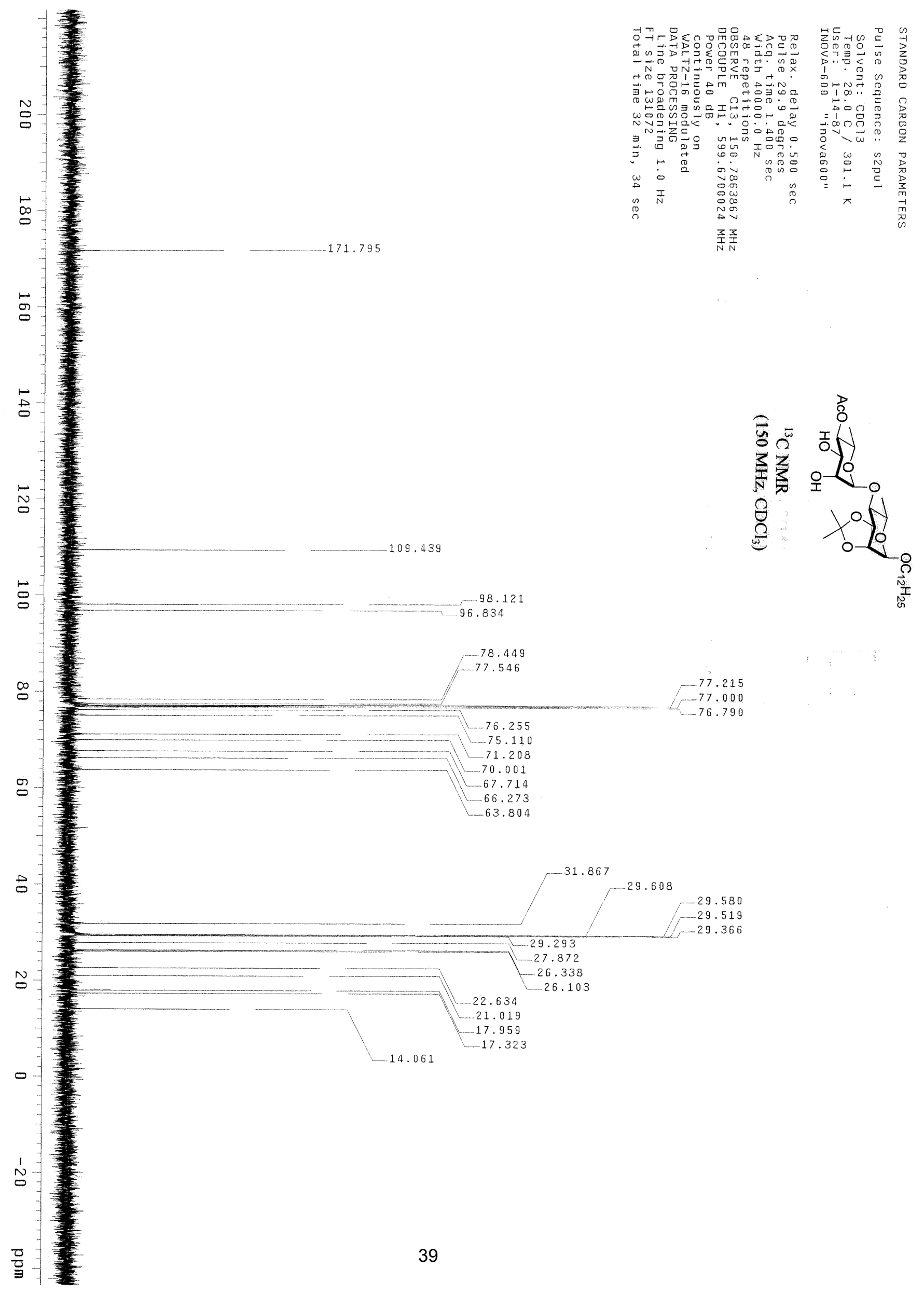




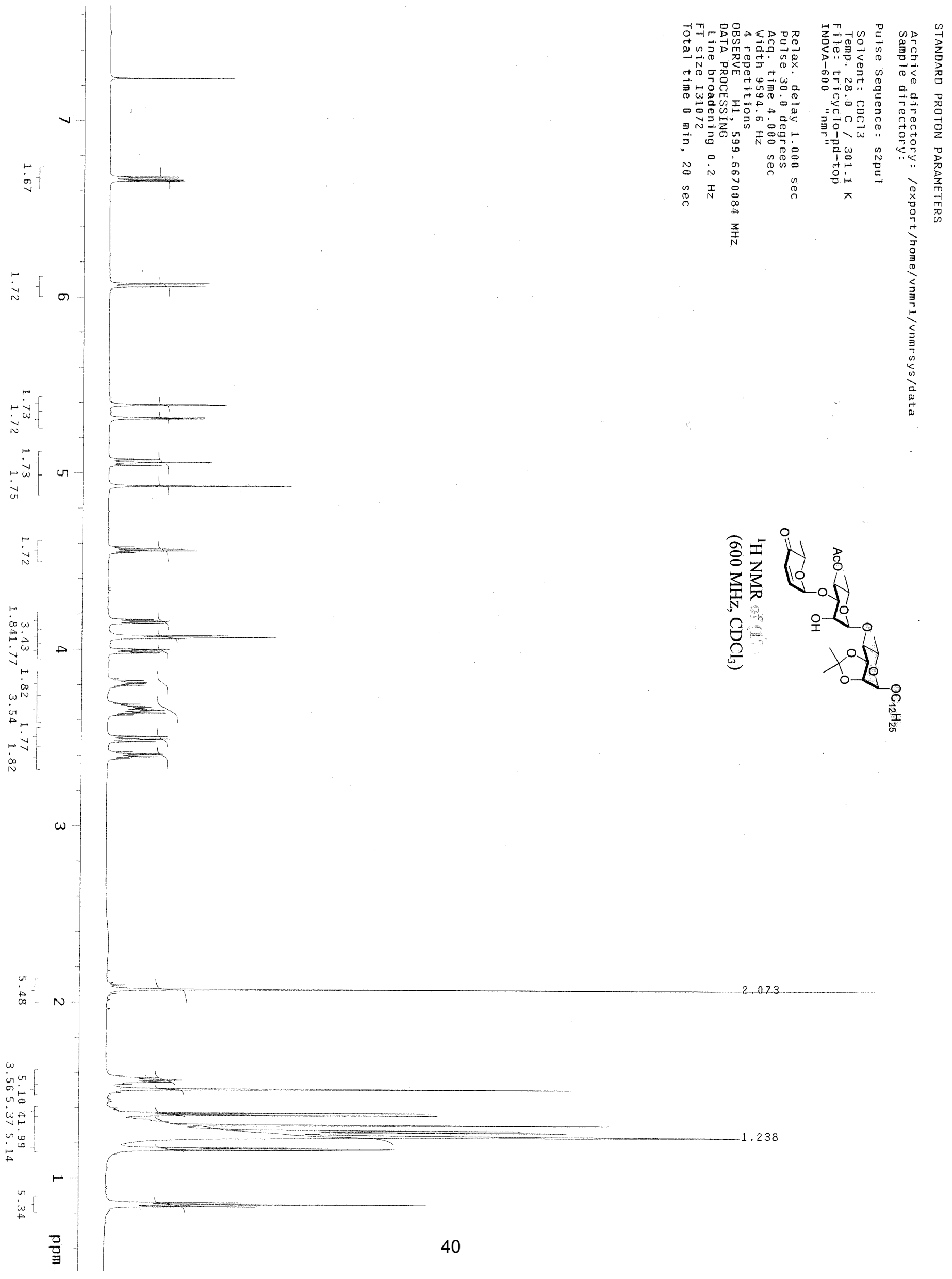




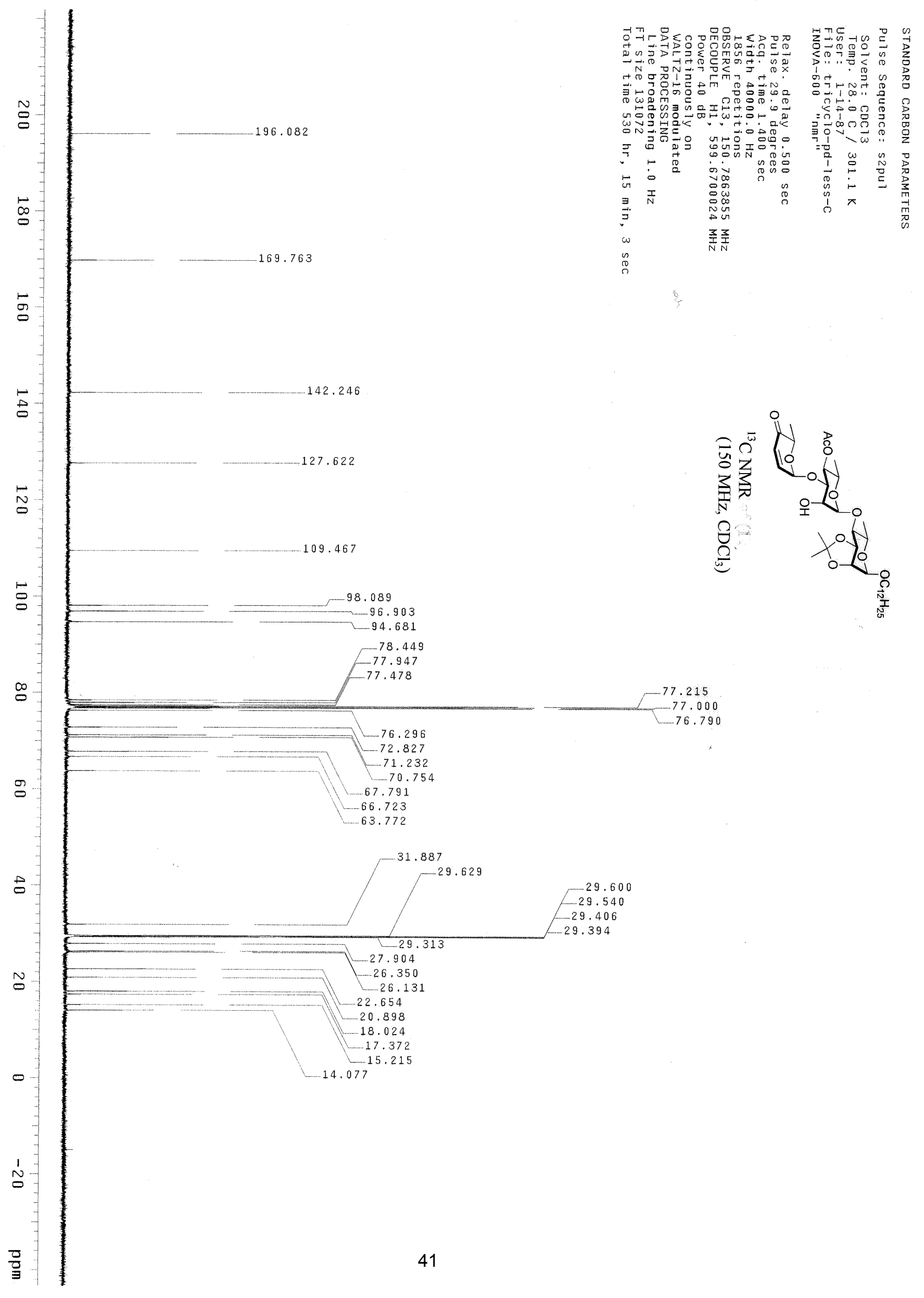




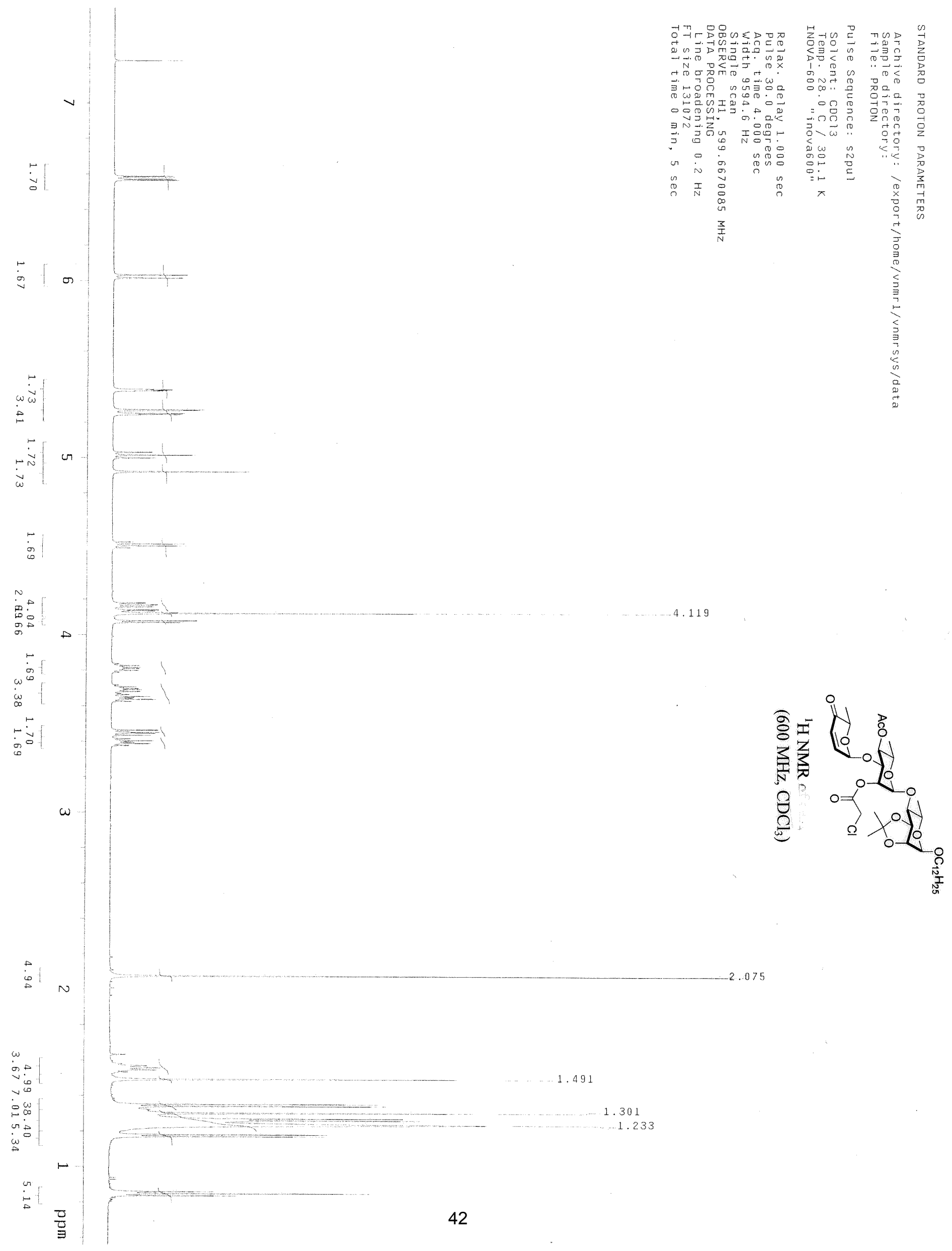



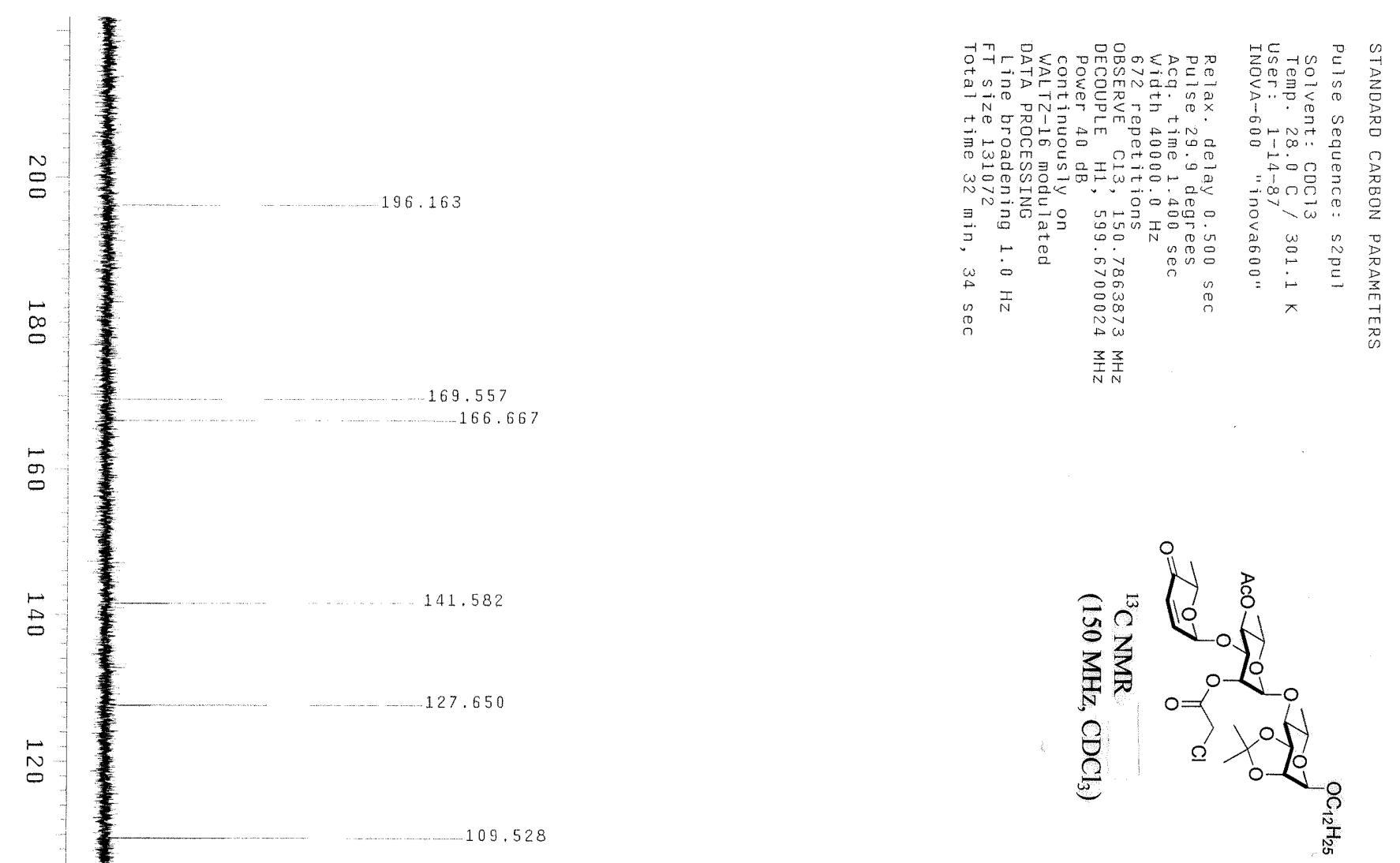


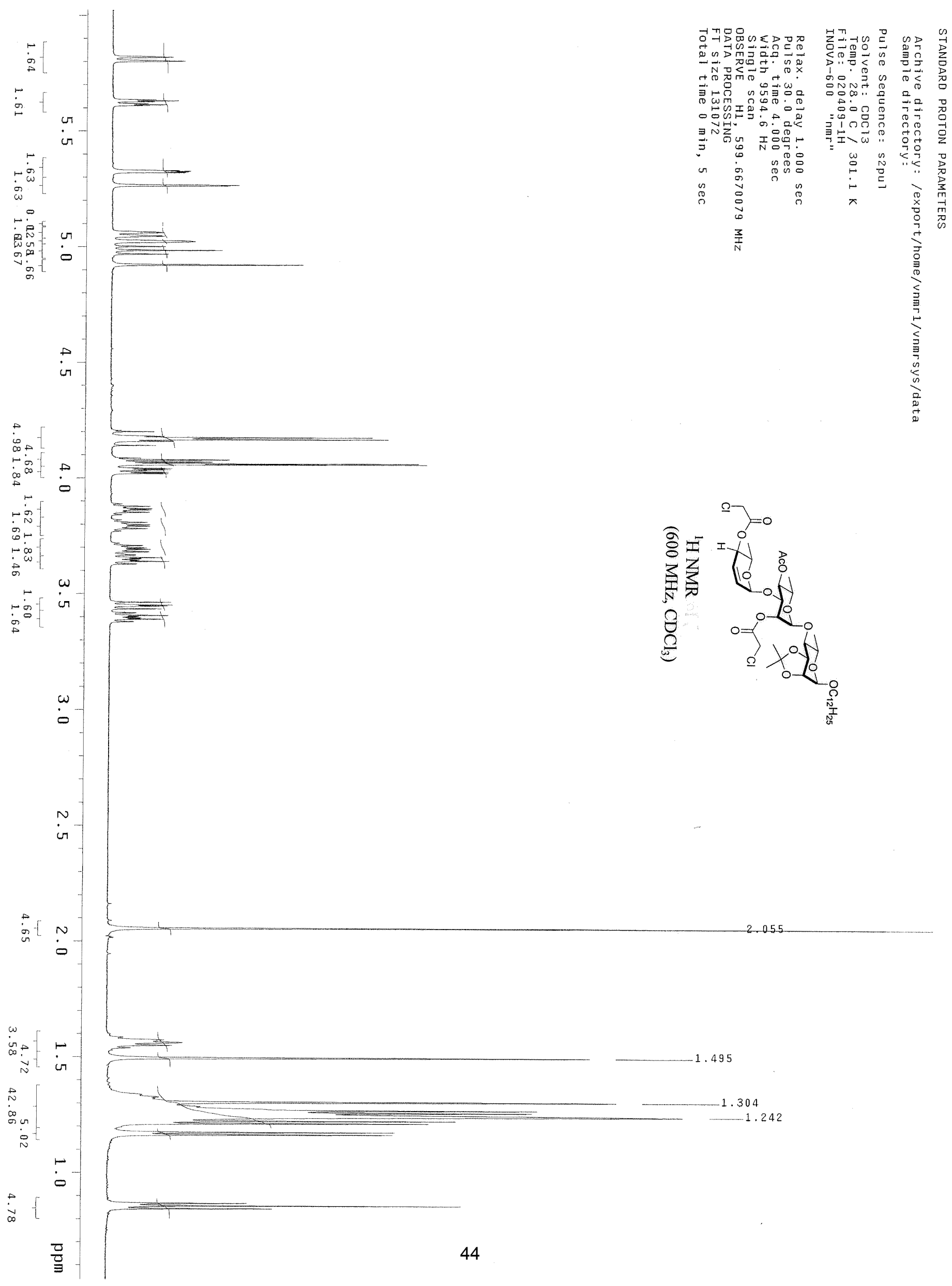



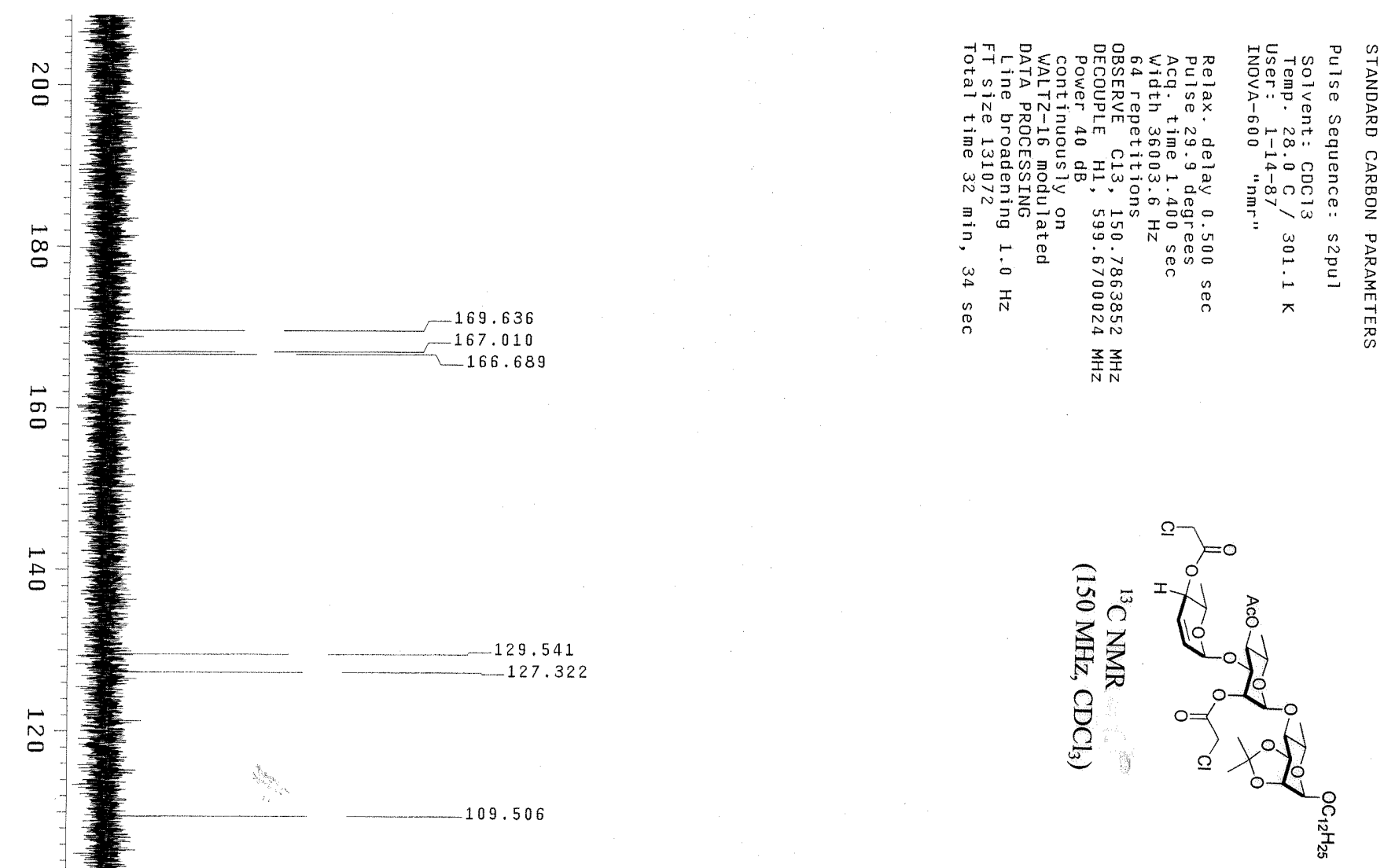

吕

$\stackrel{\sim}{\sigma}$

吕

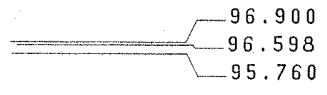

$\stackrel{\infty}{\circ}$

$\infty$

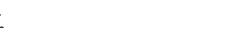

$-77.987$

25

$-77.000$

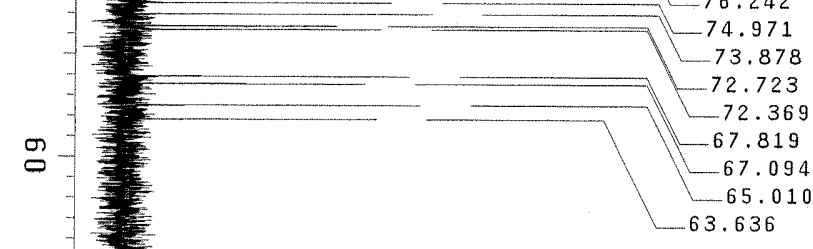

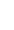




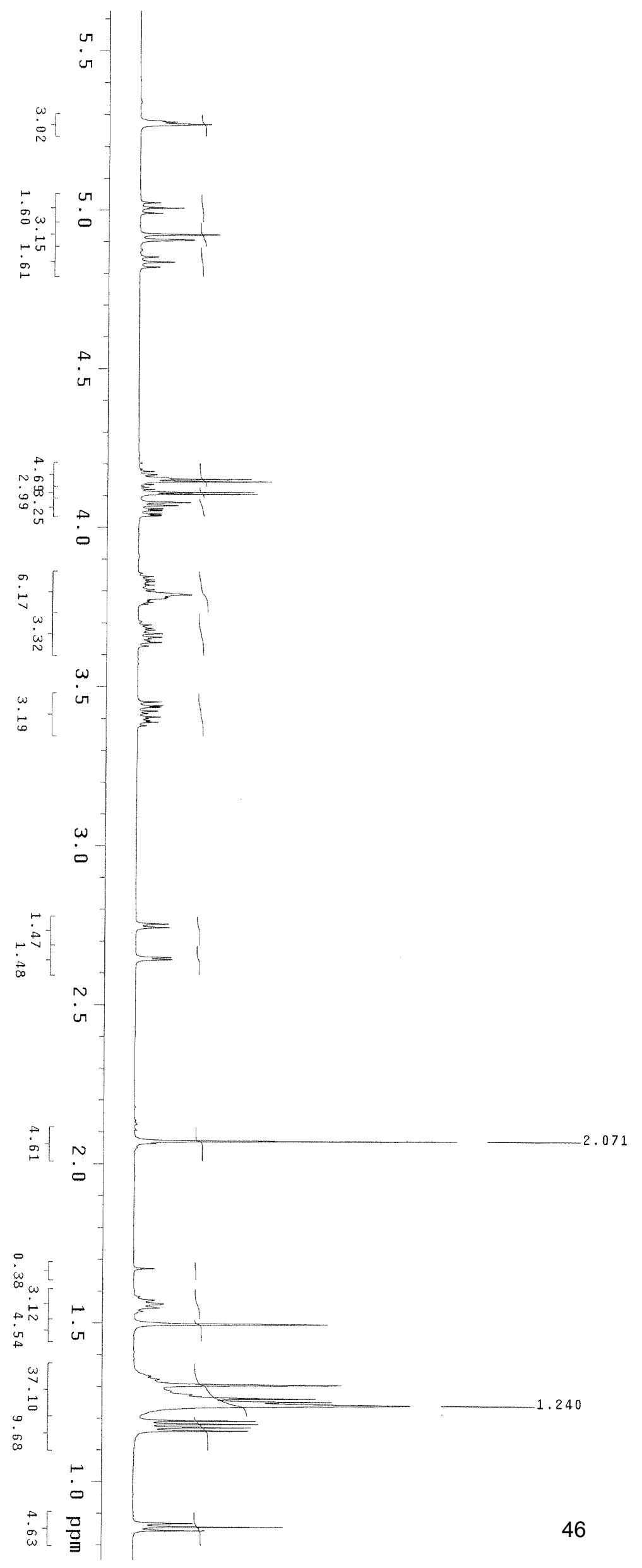

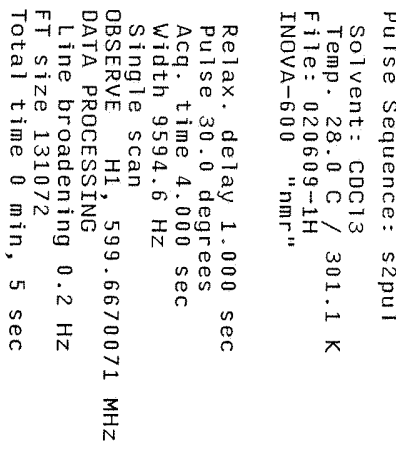
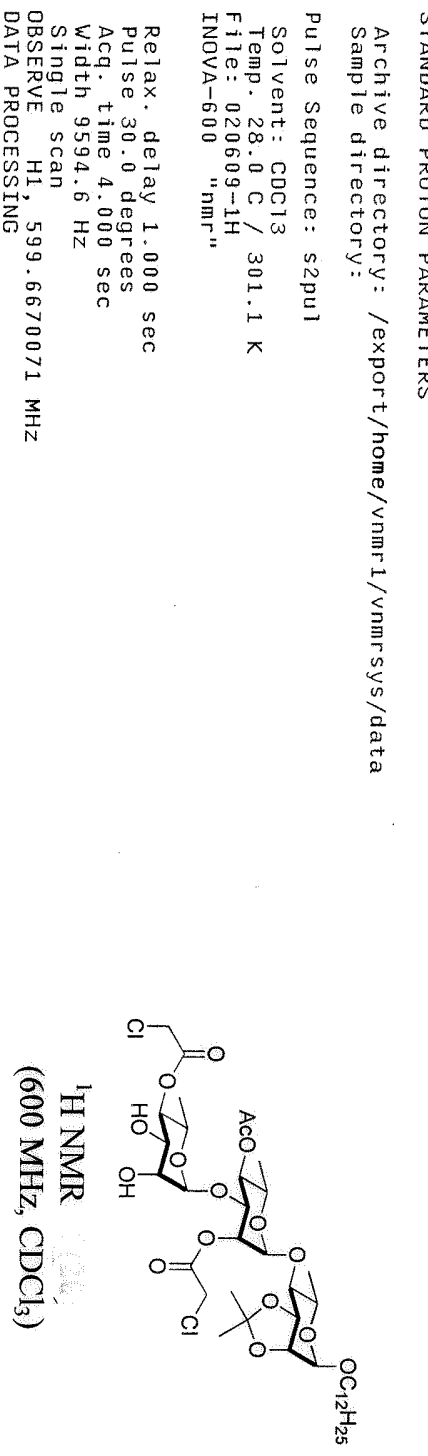

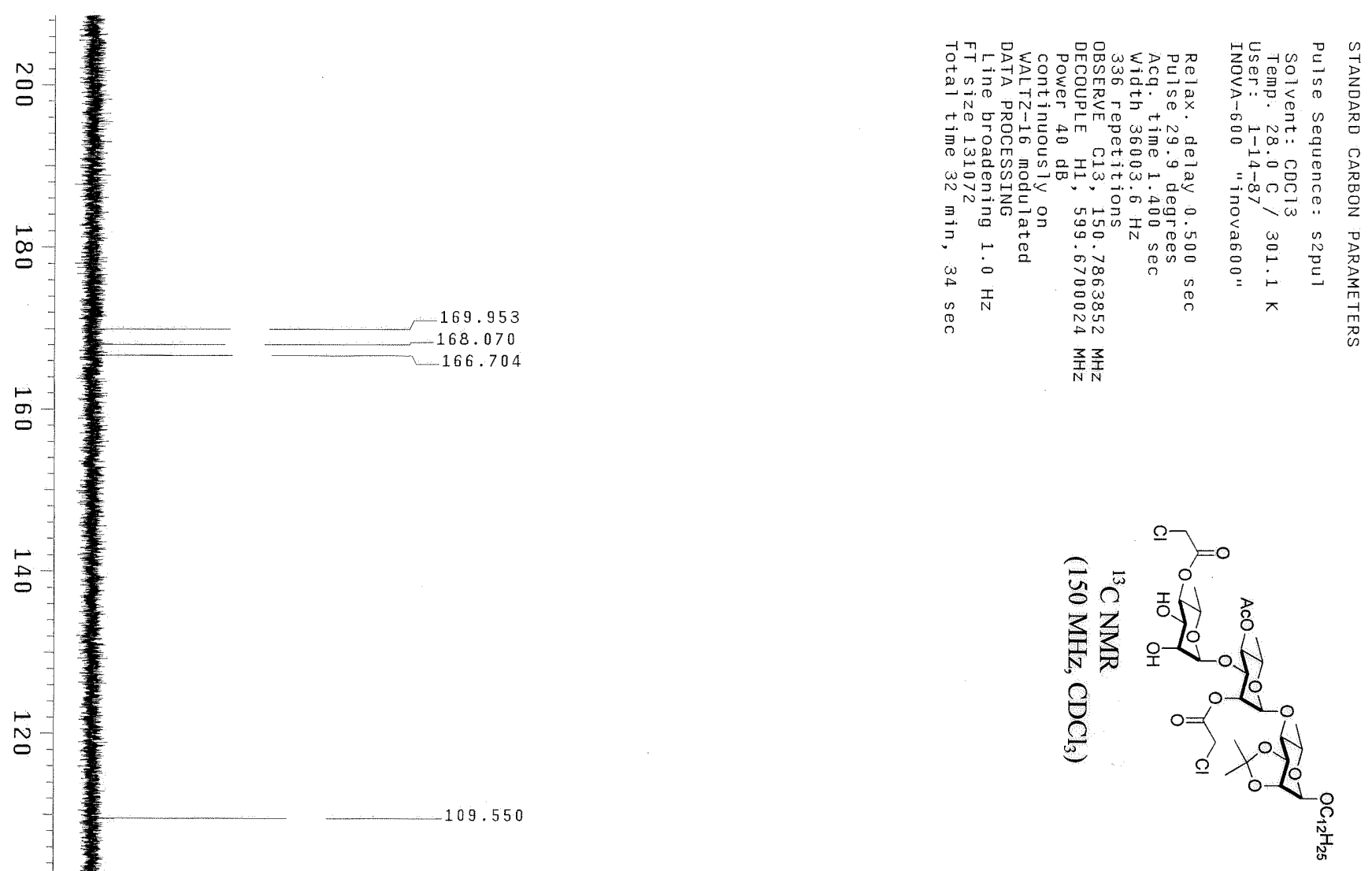


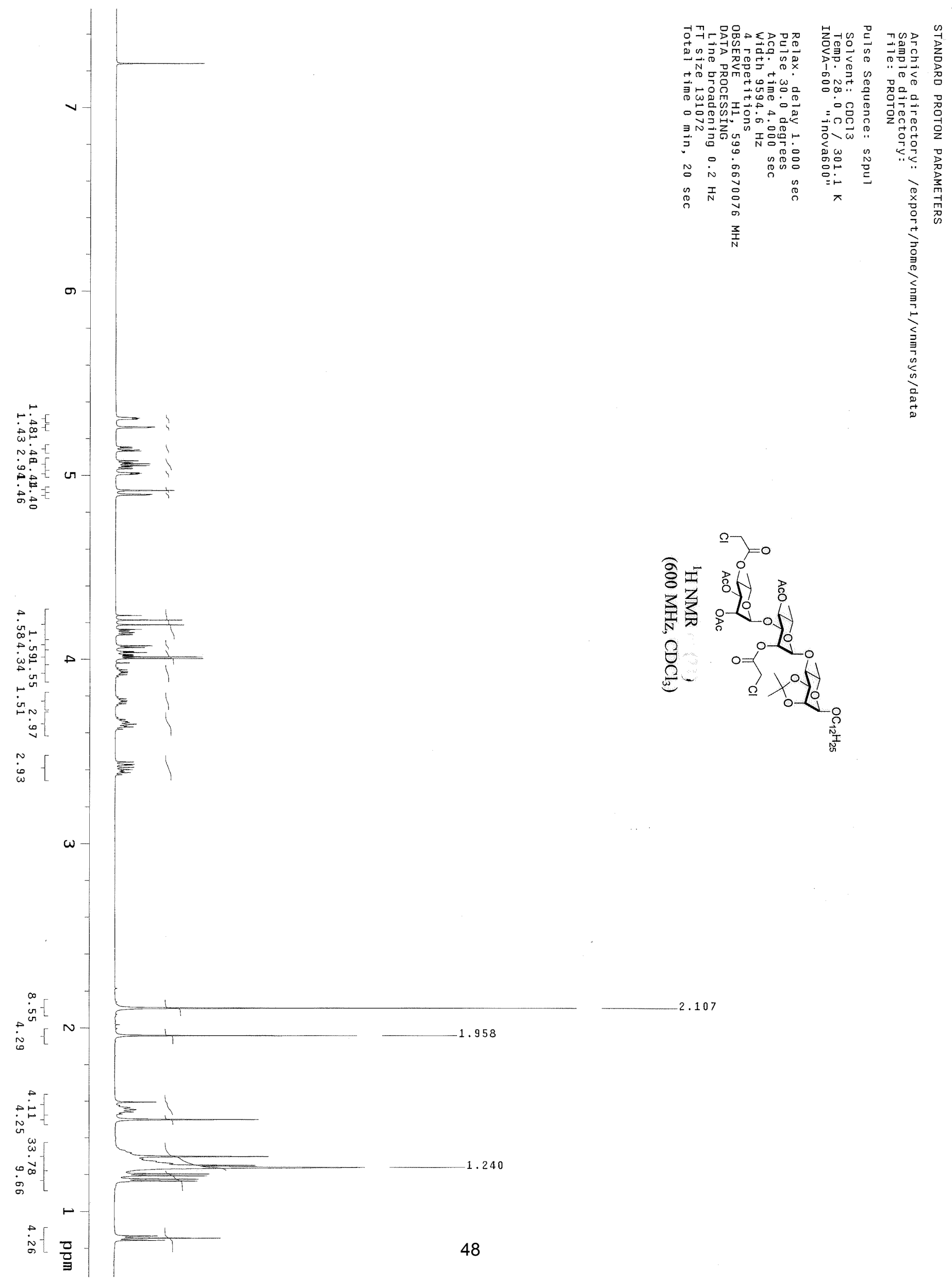



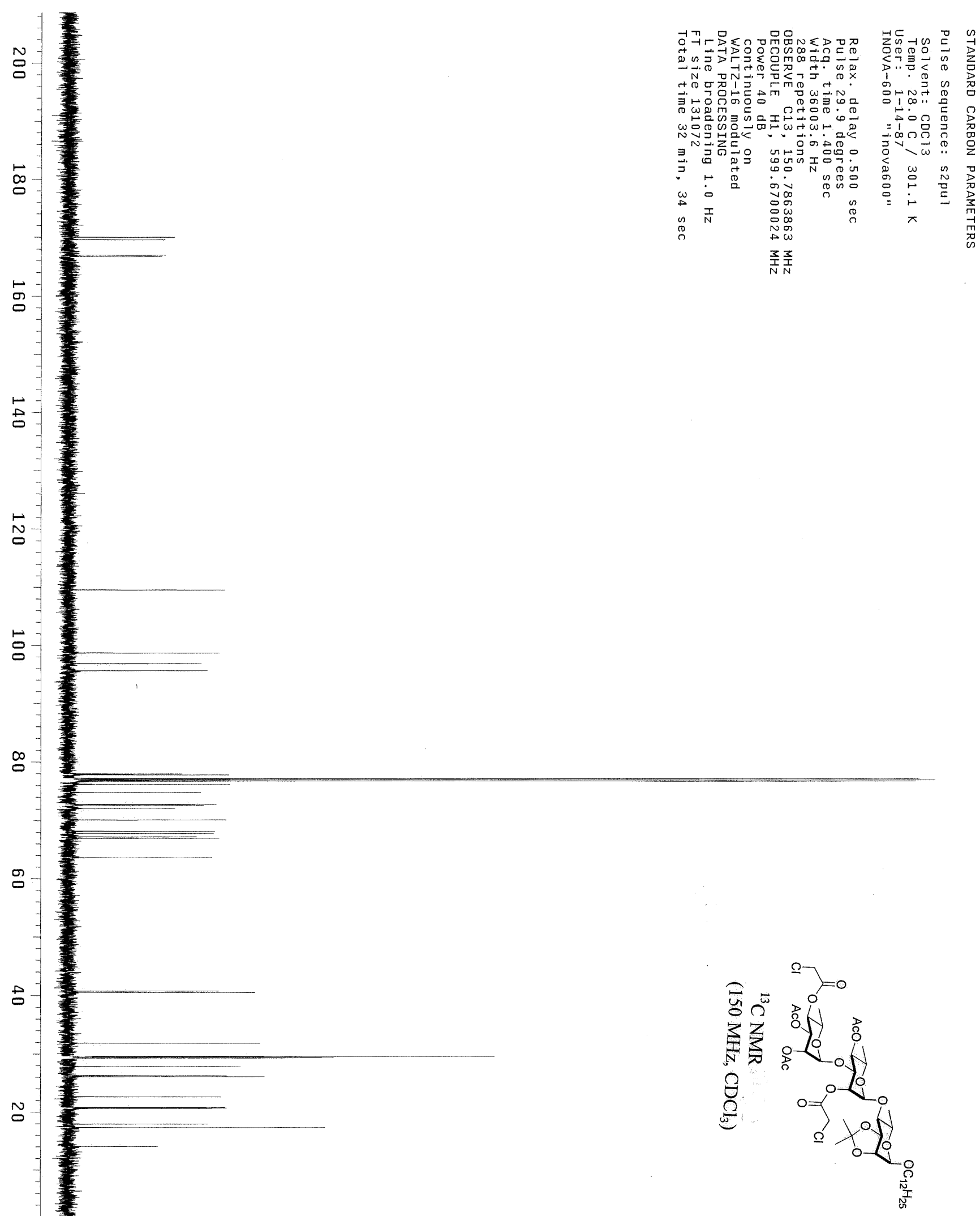


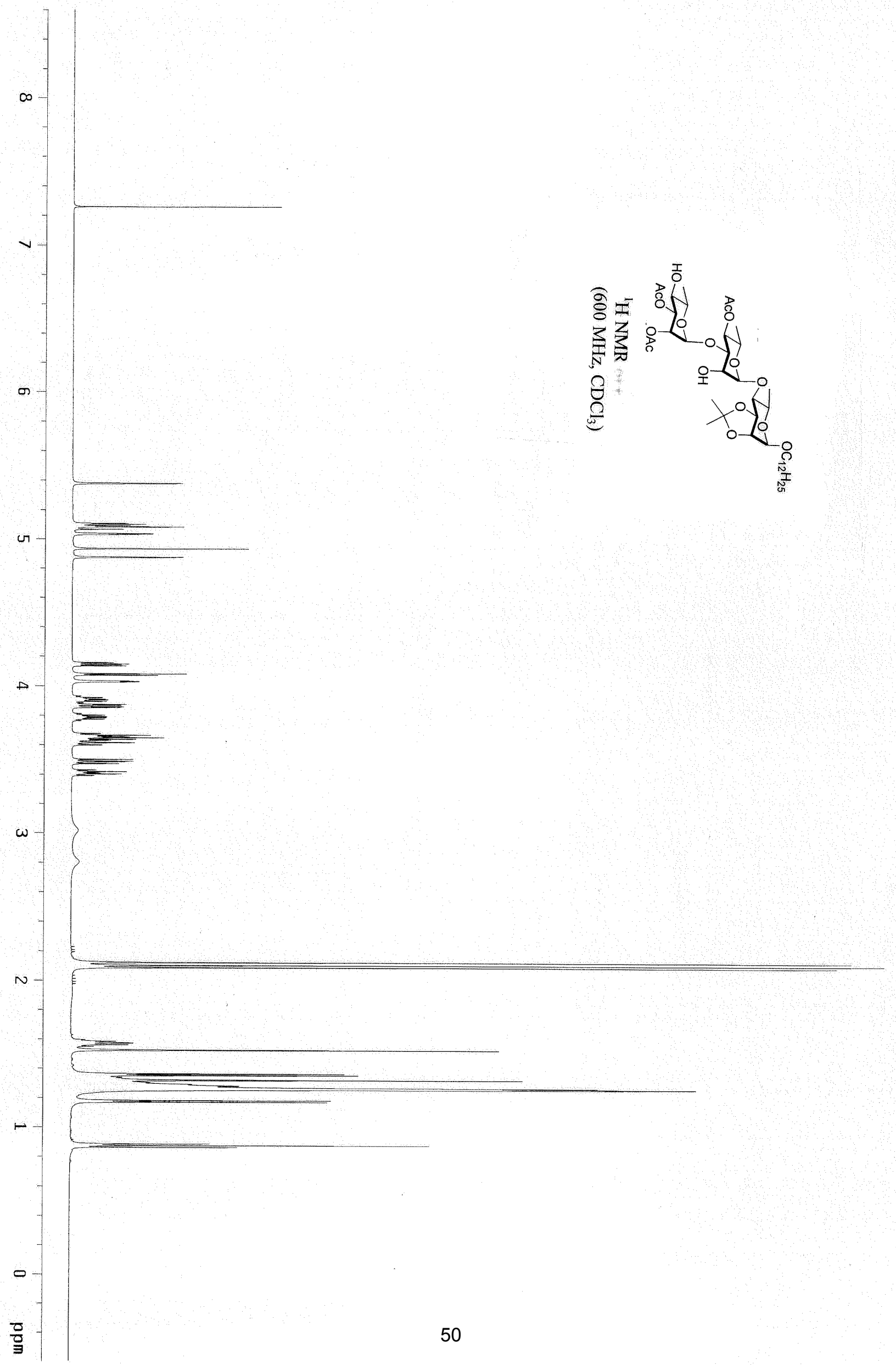




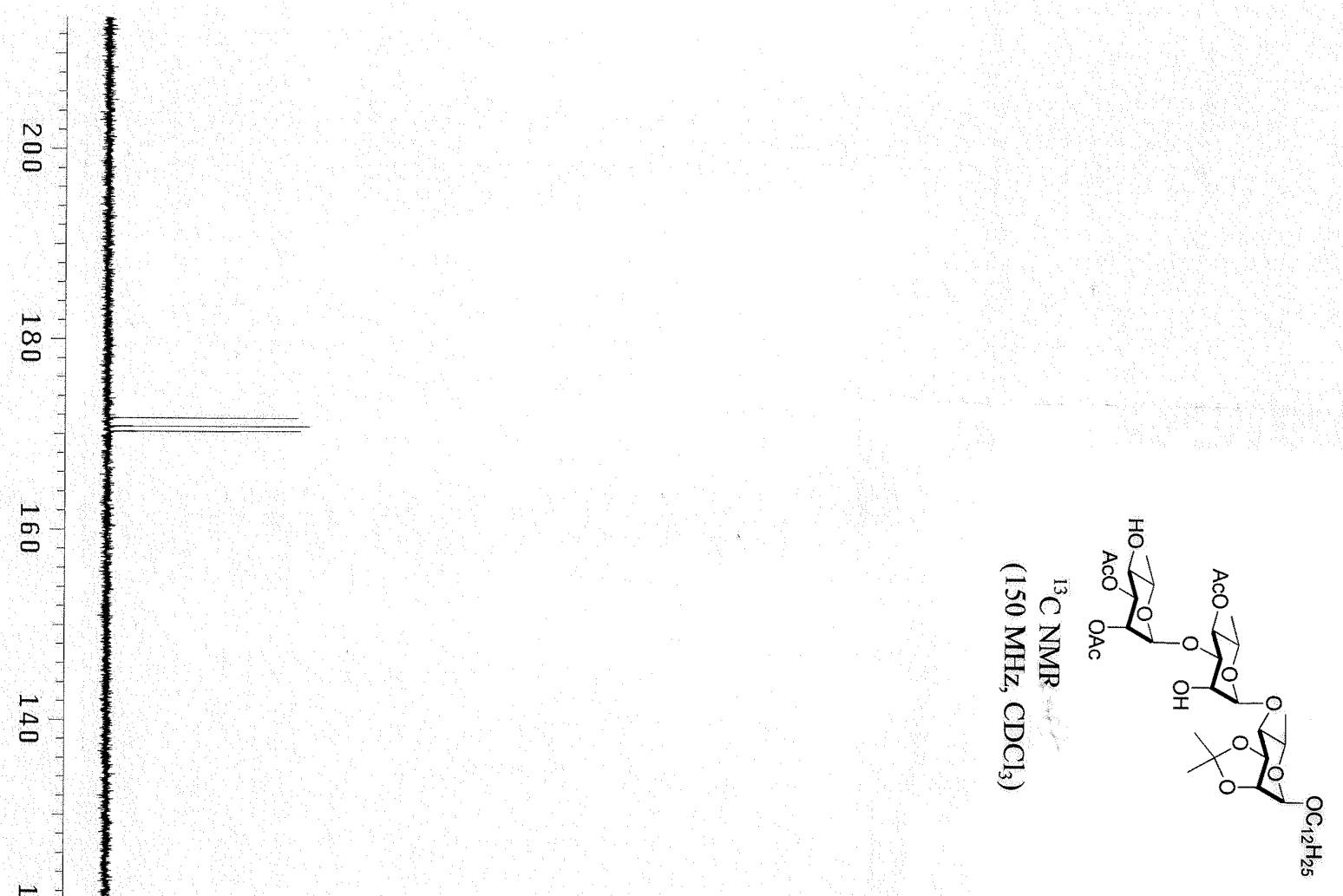

$\stackrel{\infty}{\circ}$
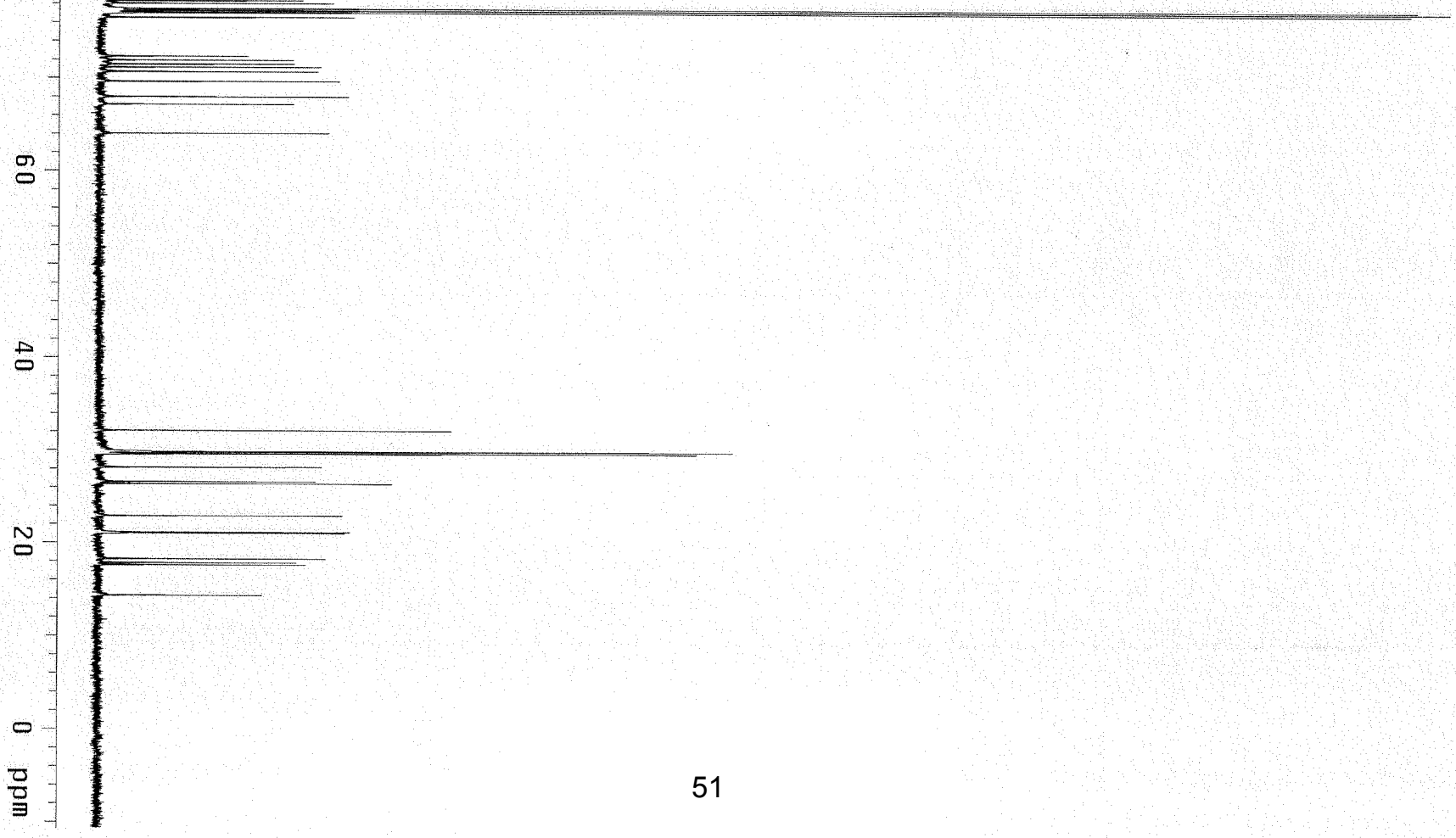

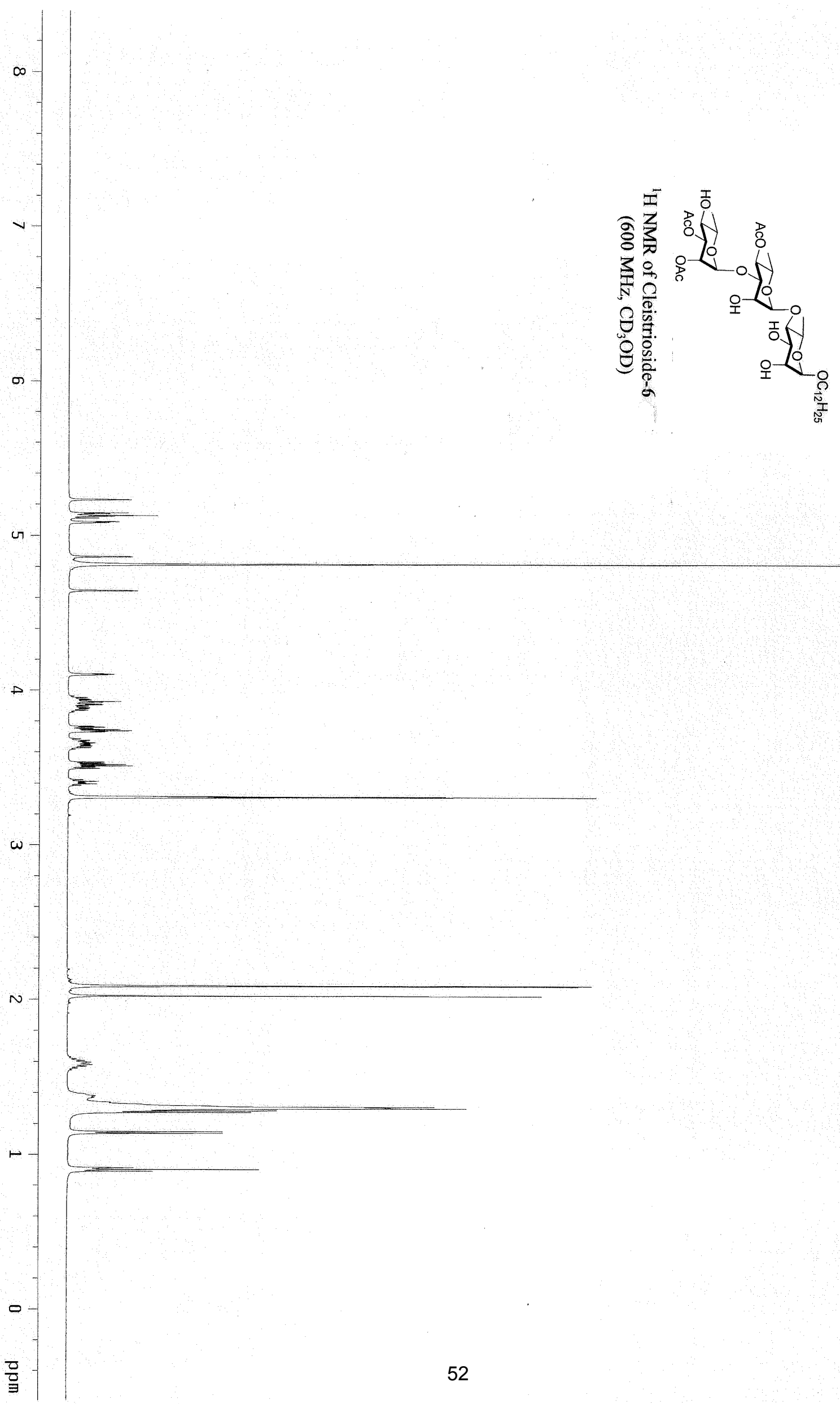


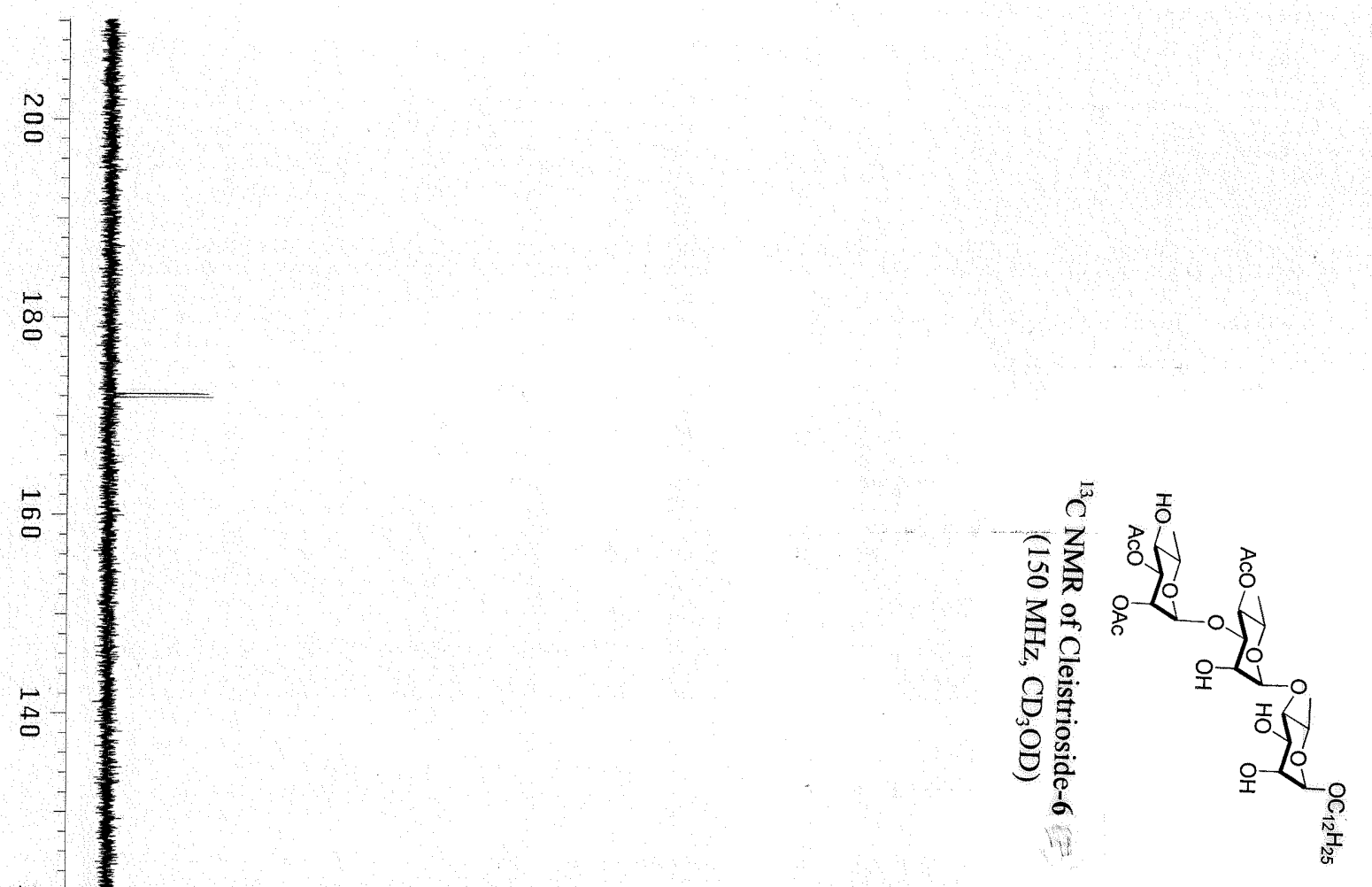

$\stackrel{\infty}{\circ}$

$\stackrel{\circ}{\circ}$

o-

8

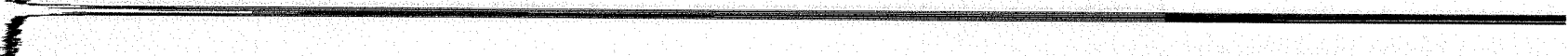

$\approx$

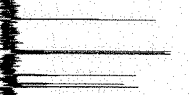

+

듭 


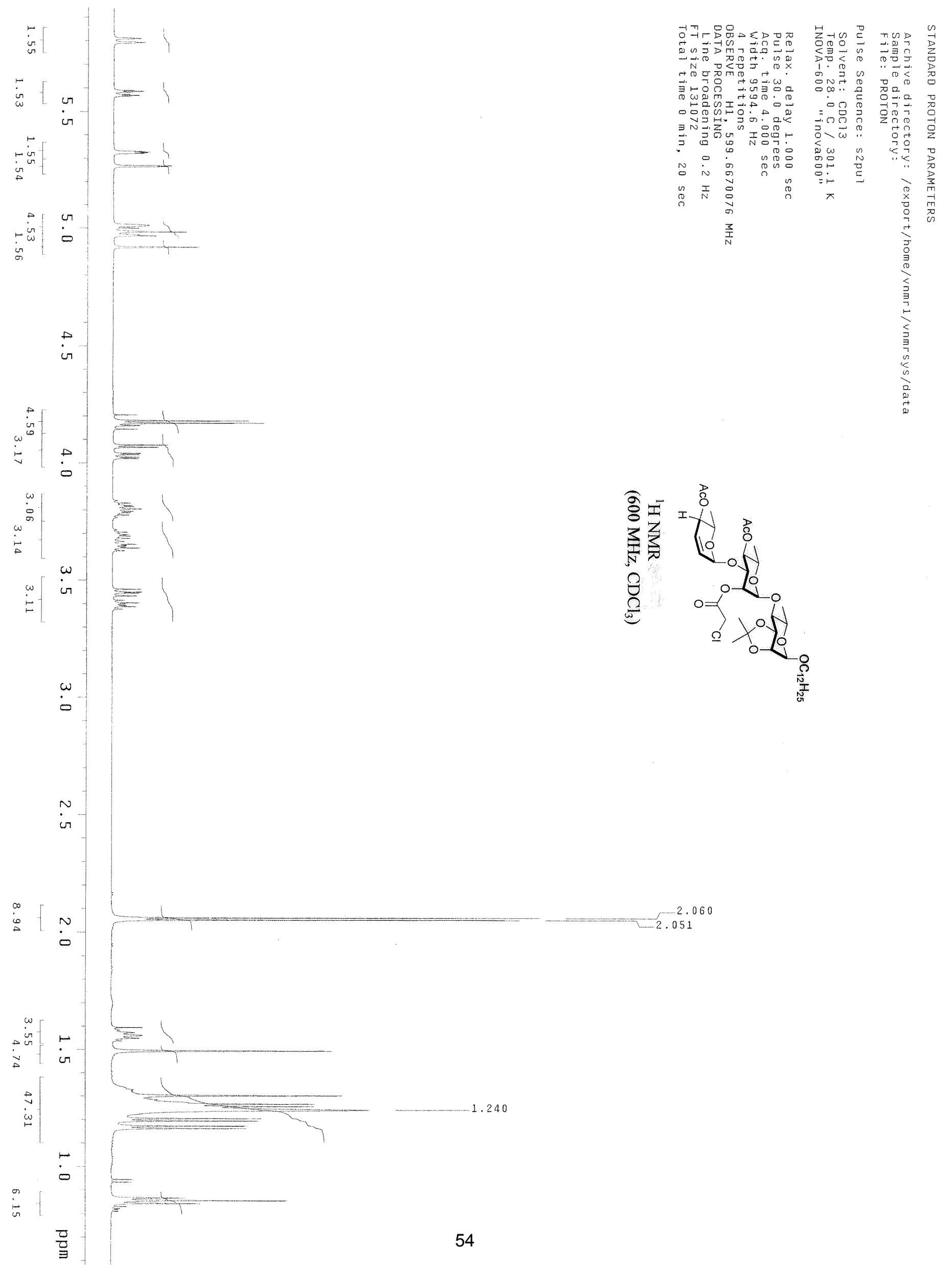



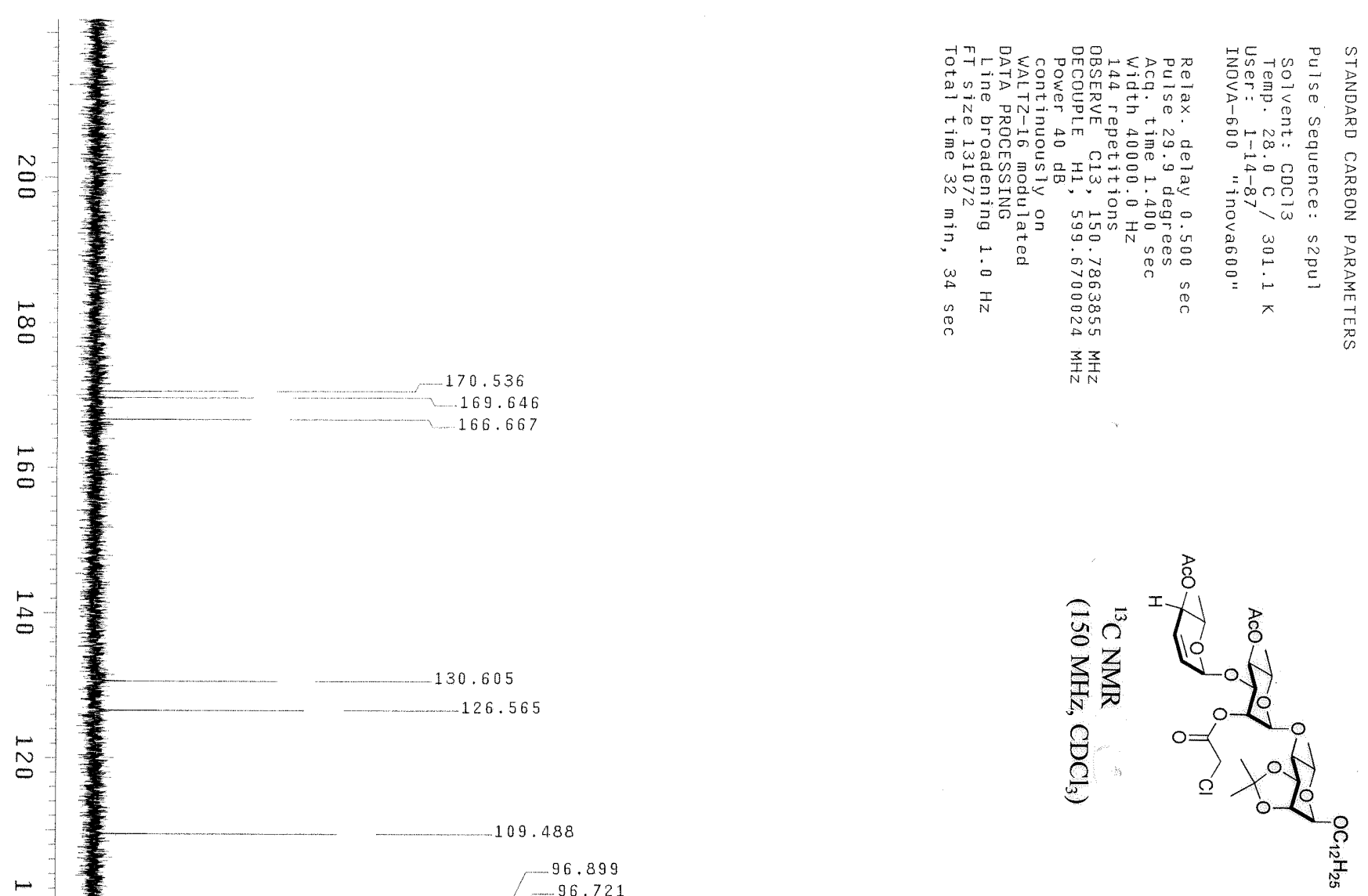

용

$\stackrel{\infty}{\circ}$

30.605

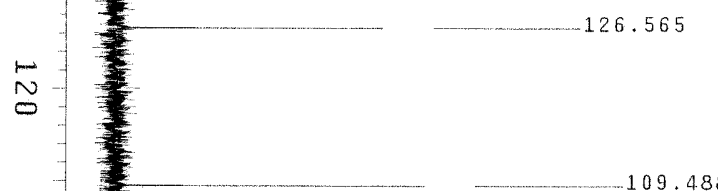

109.488

96.899

$-95.737$

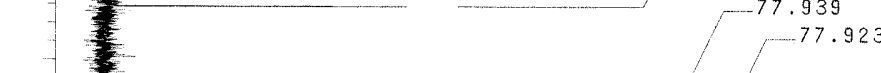

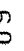

- 67.803

$\square .67 .095$

65.265

-

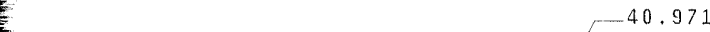

40.971

31.887

c.

t 26.135

$=\begin{array}{r}22.654 \\ 21.039\end{array}$

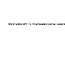

20.813
18.060

$-17.728$

$\circ$

$-14.077$ 


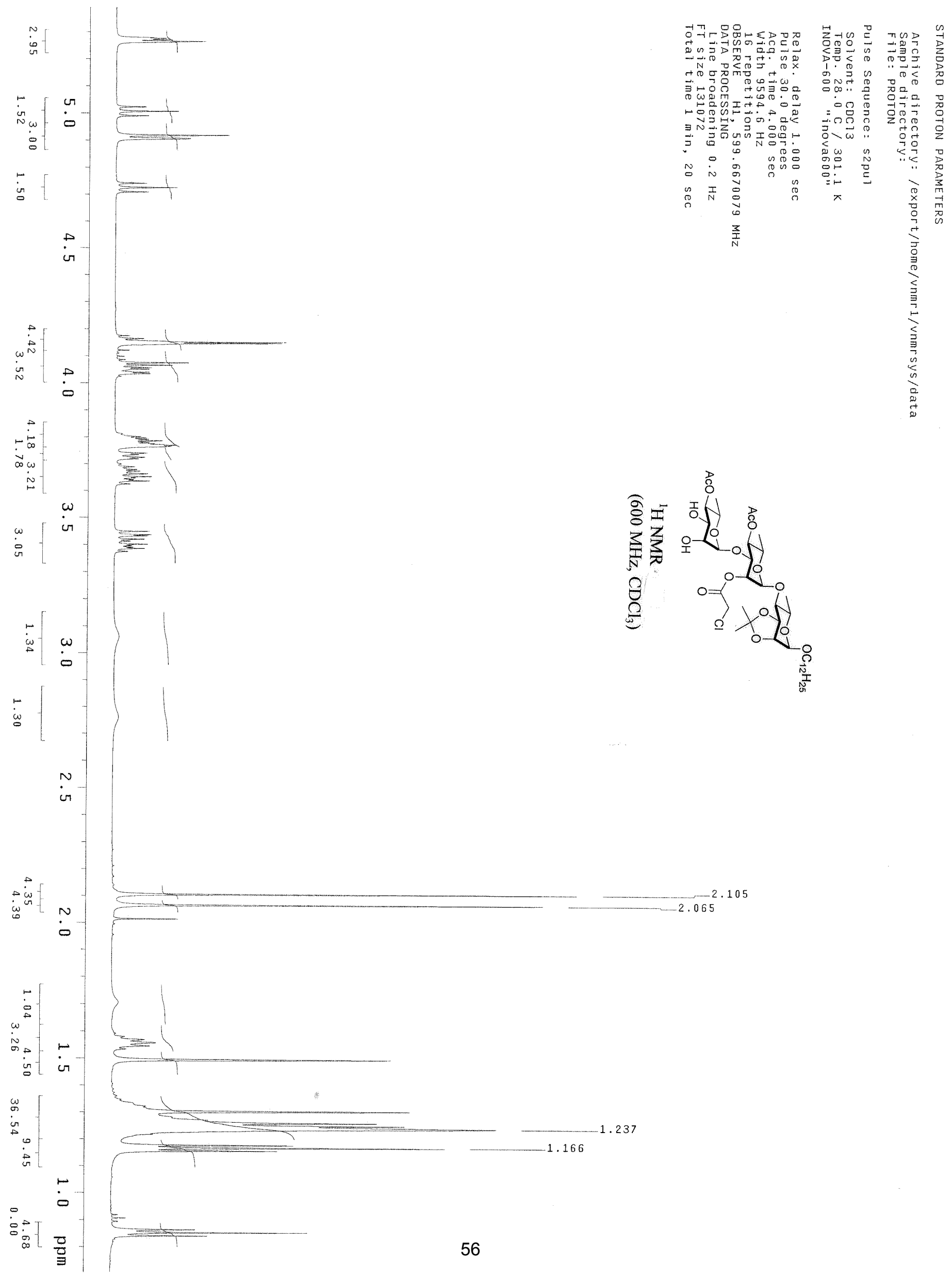




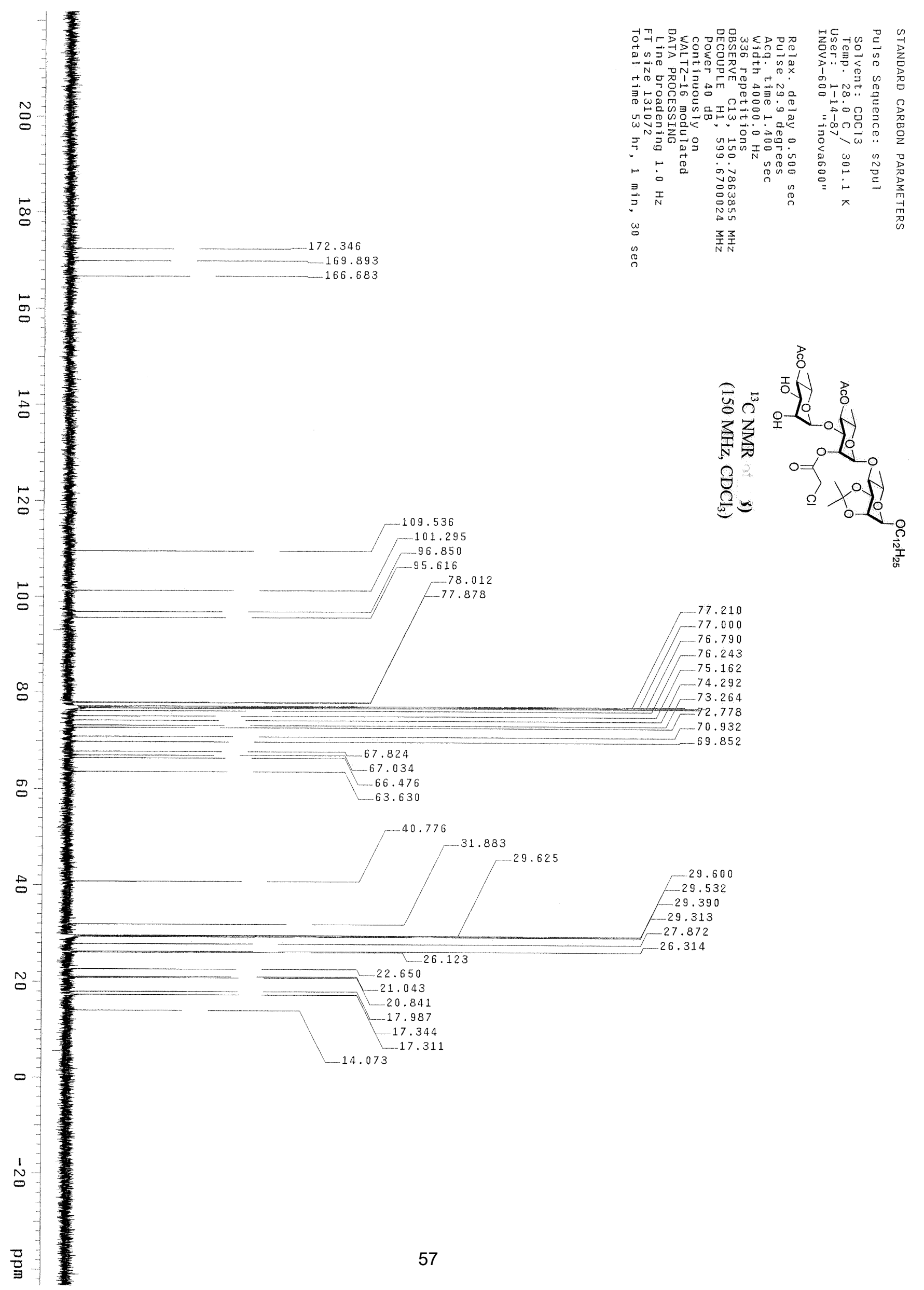




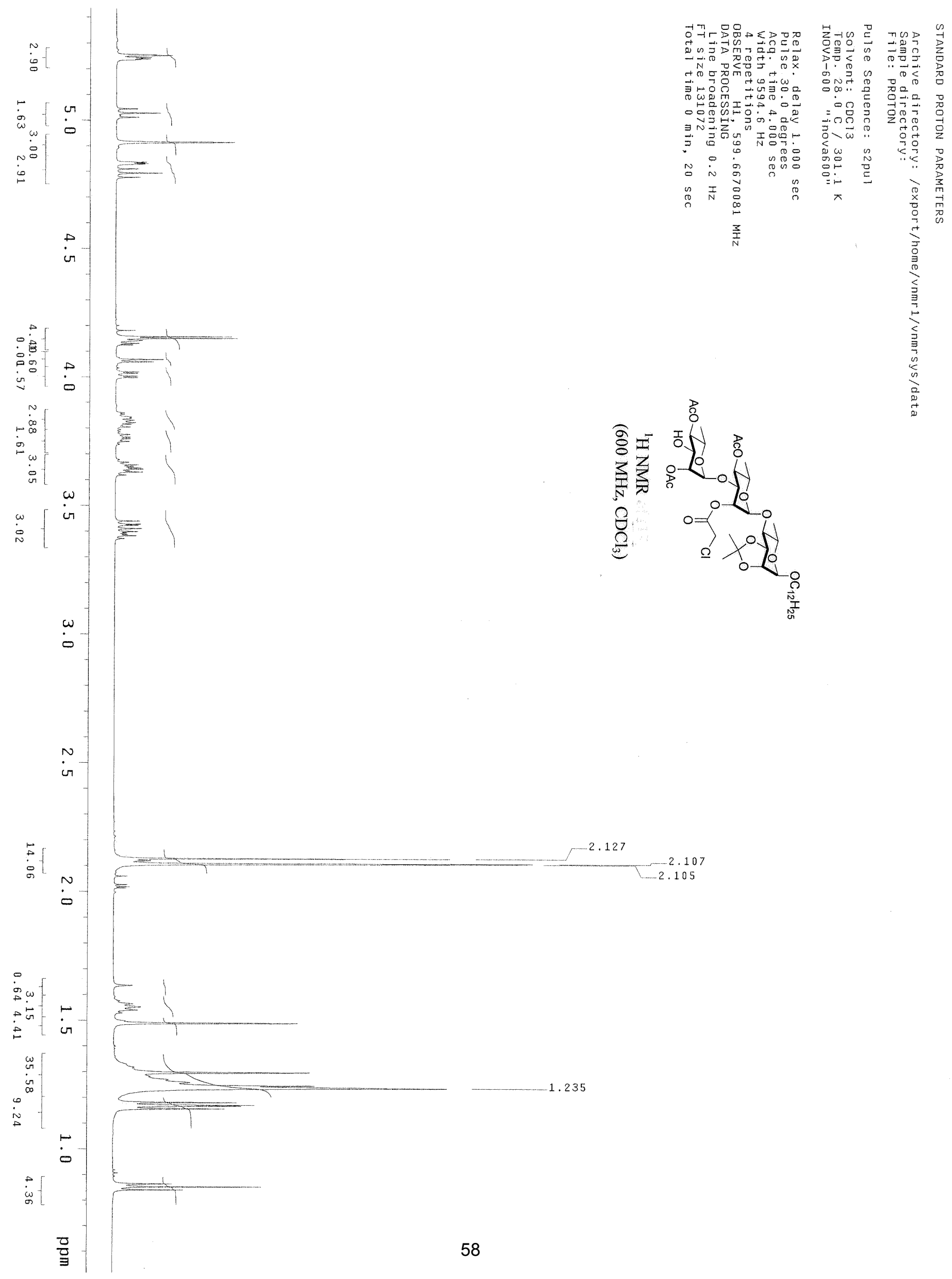



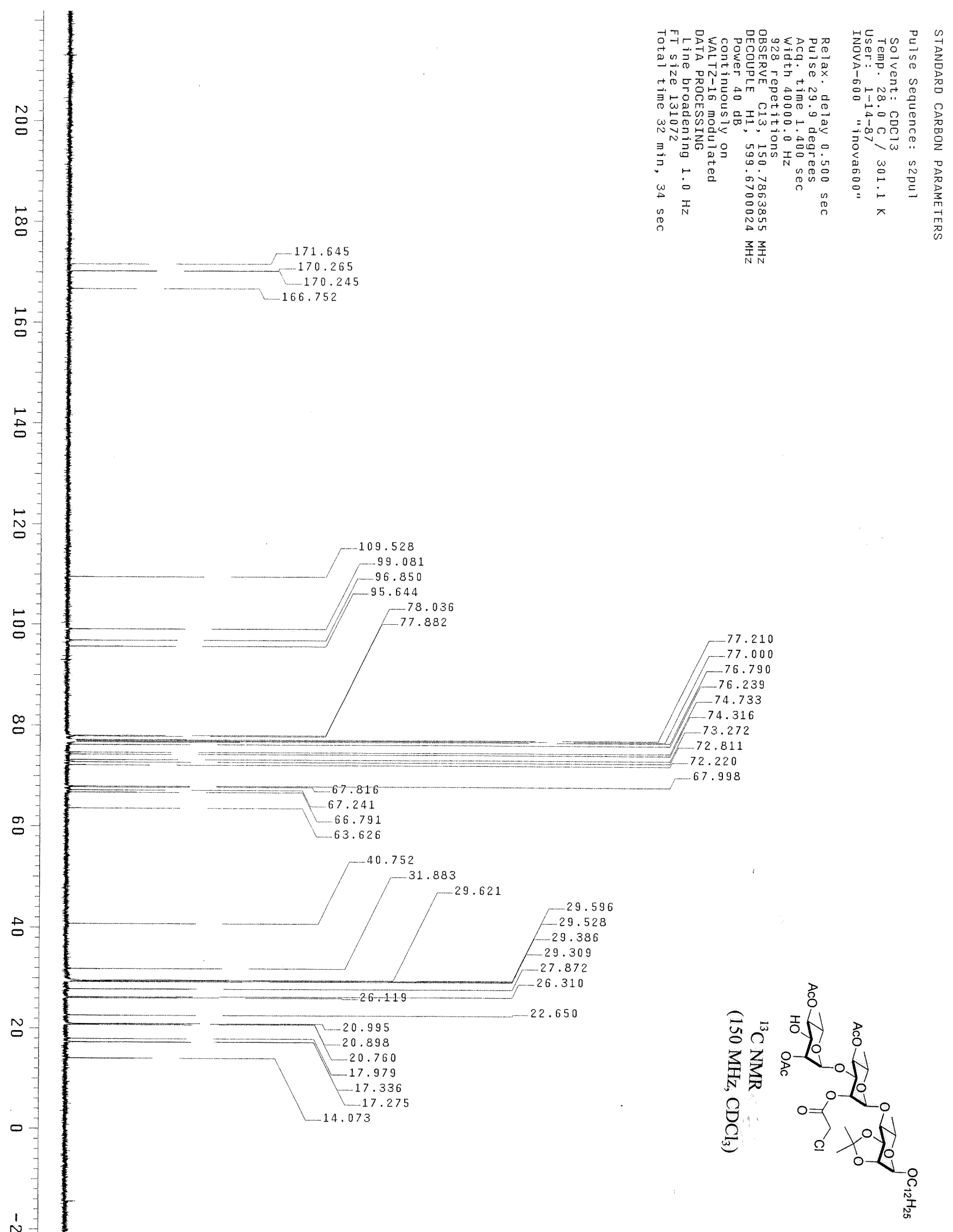


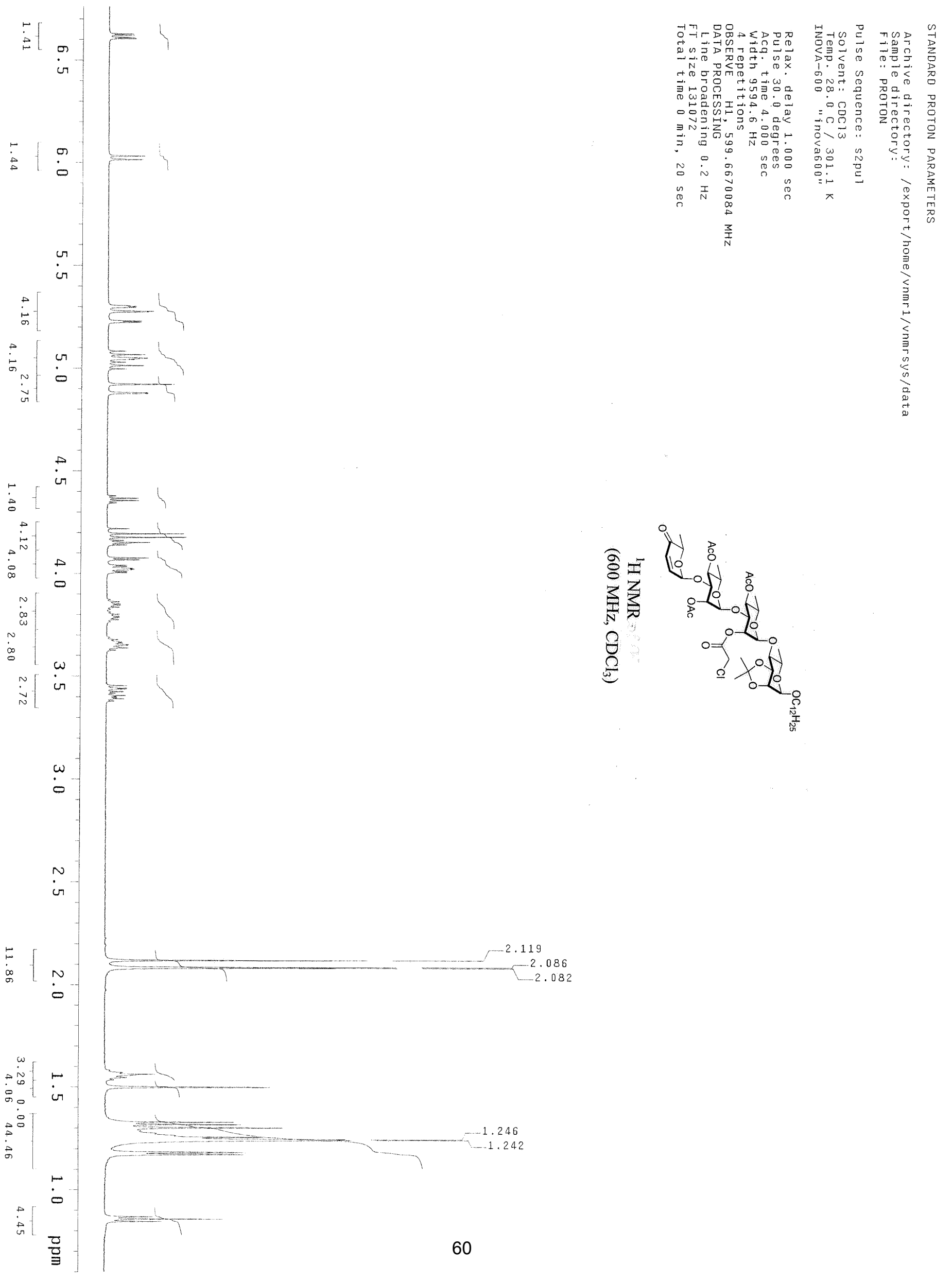



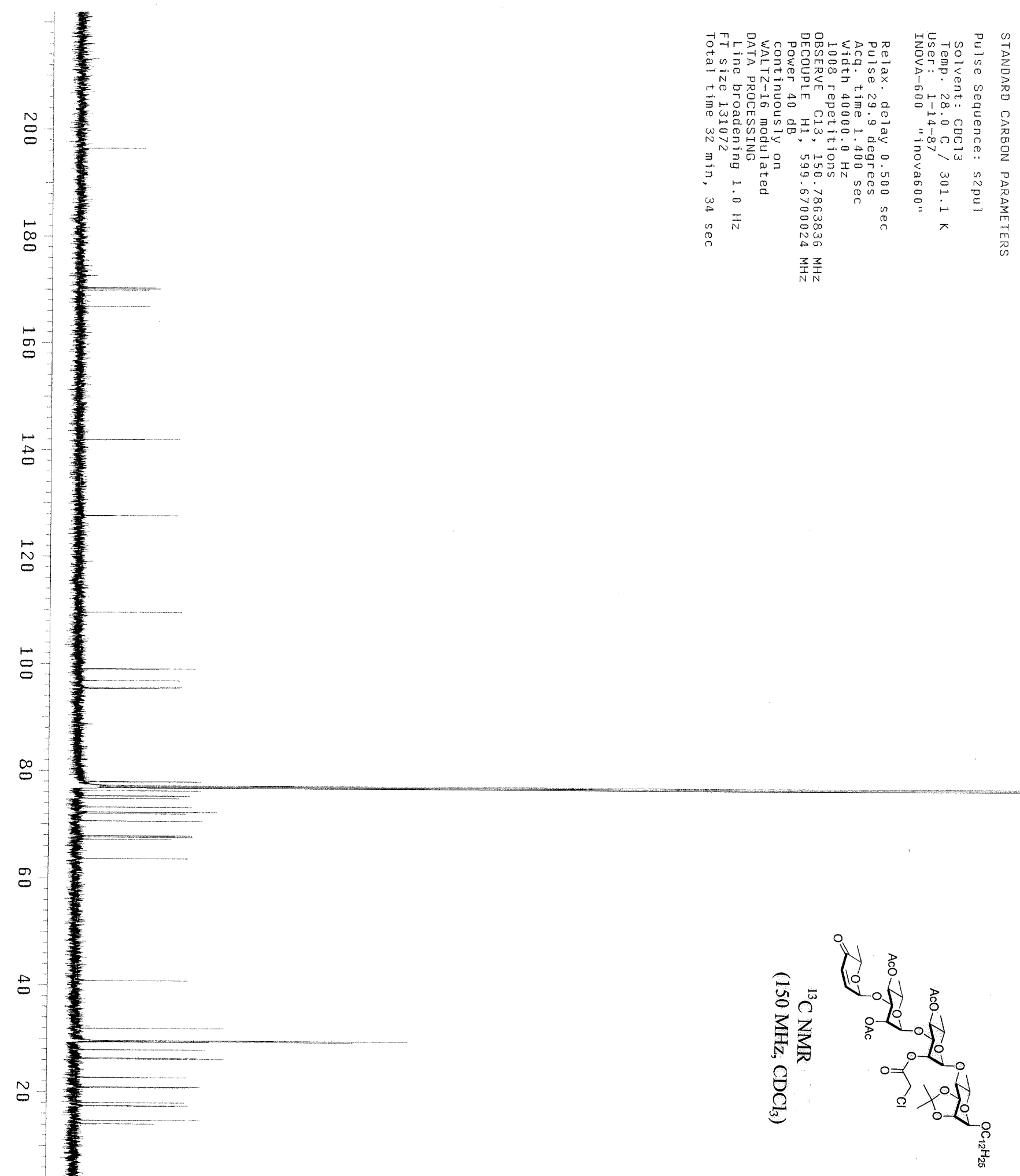


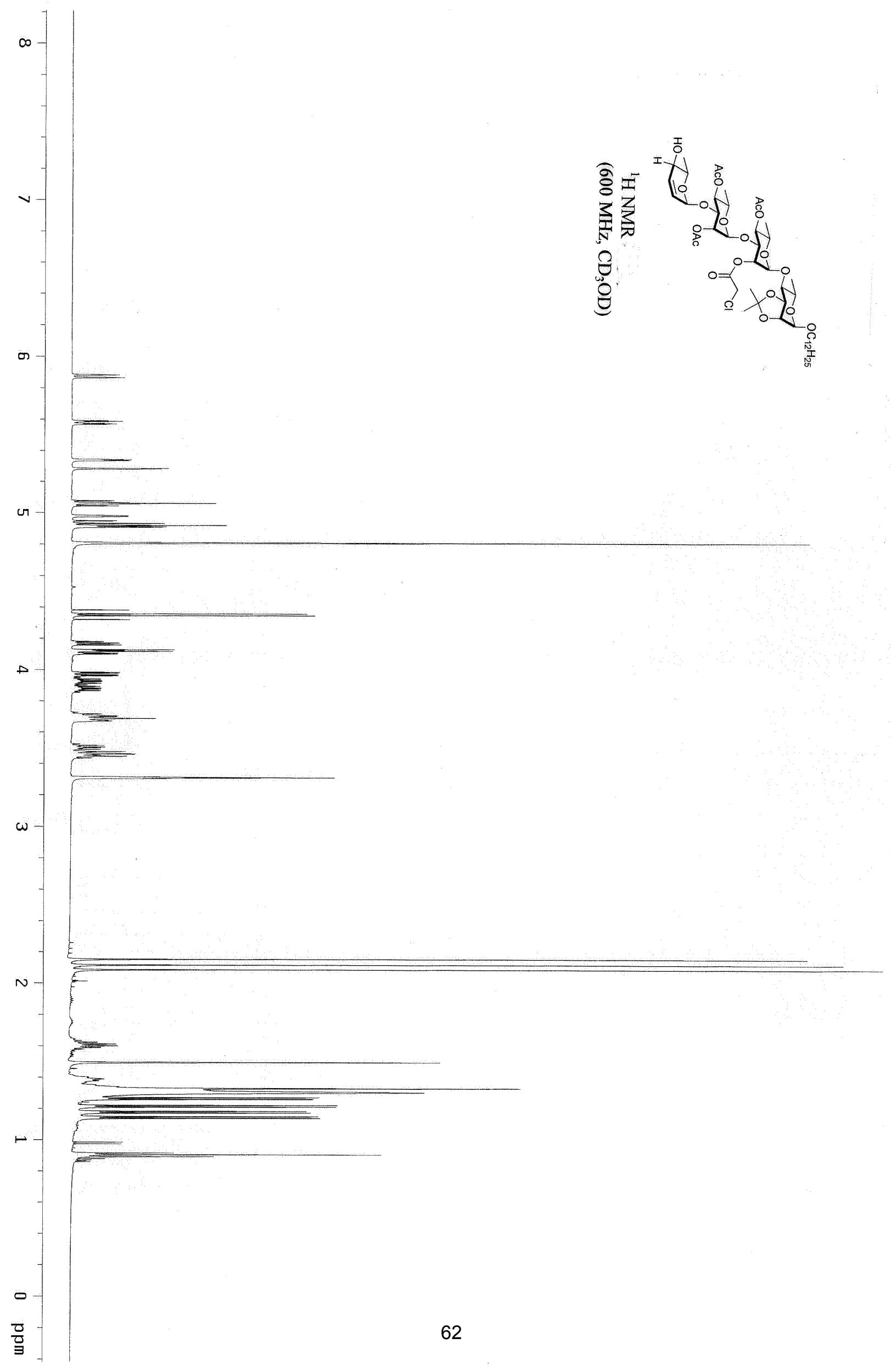




$$
\text { 1" }
$$




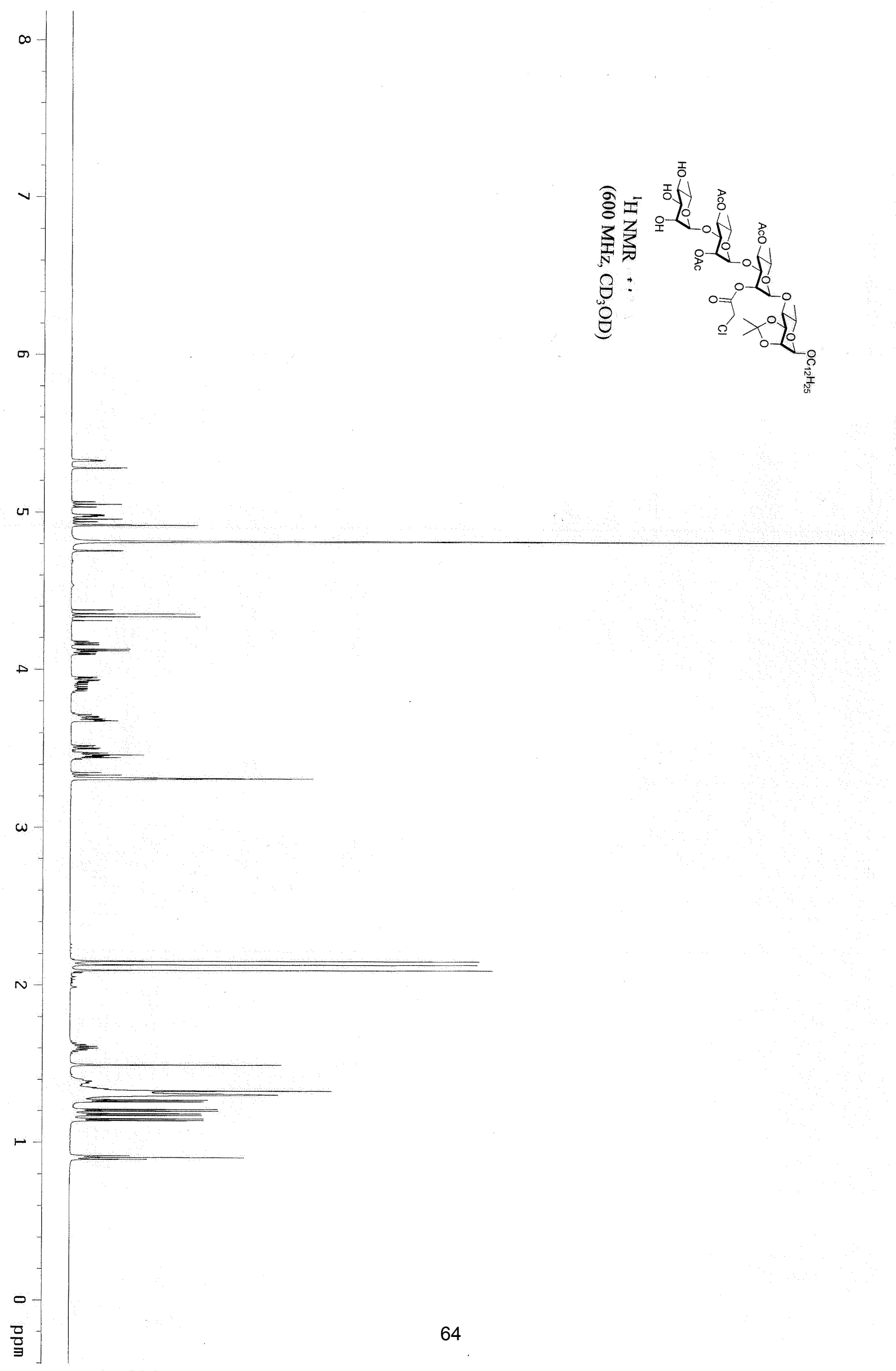




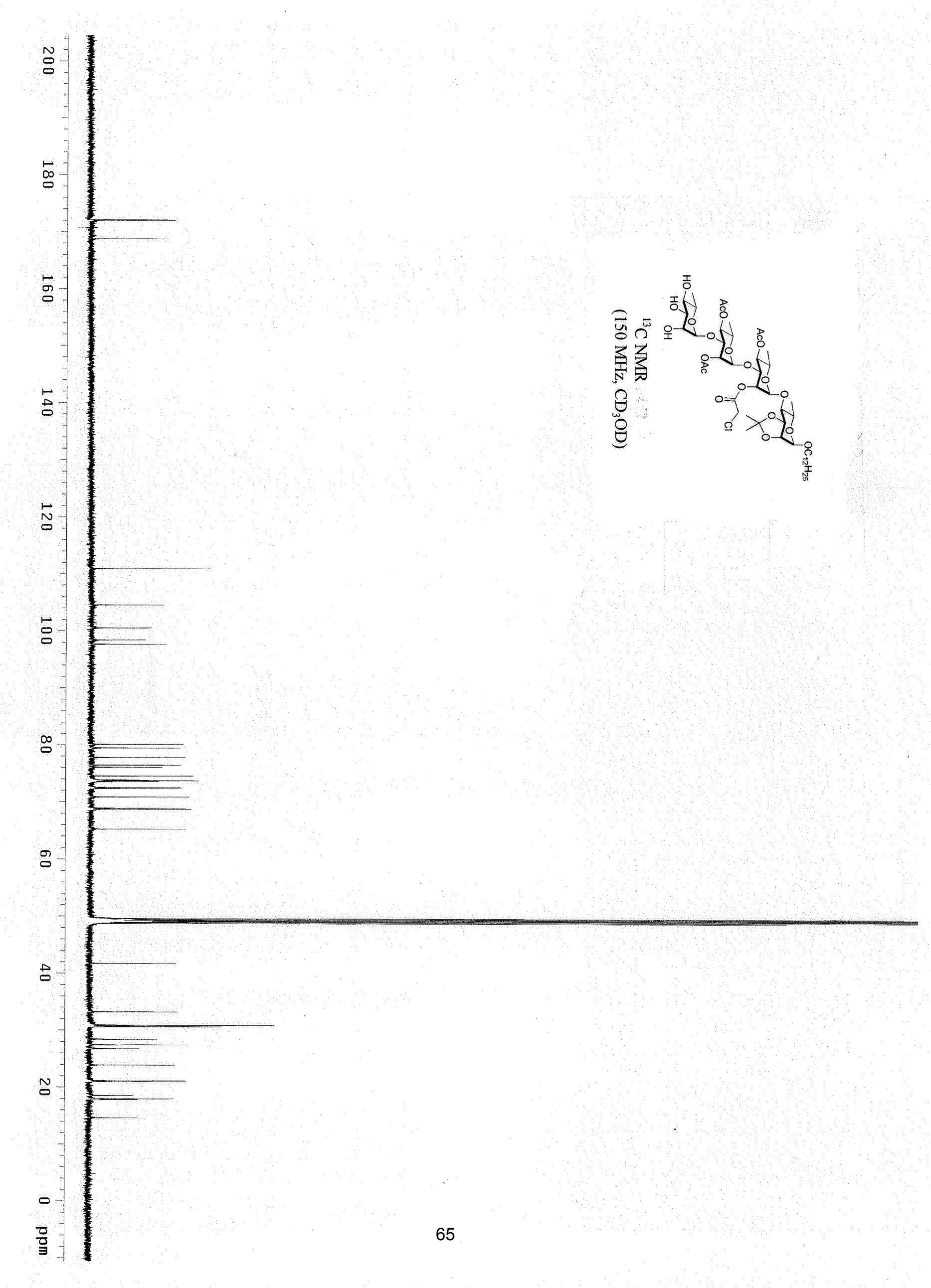




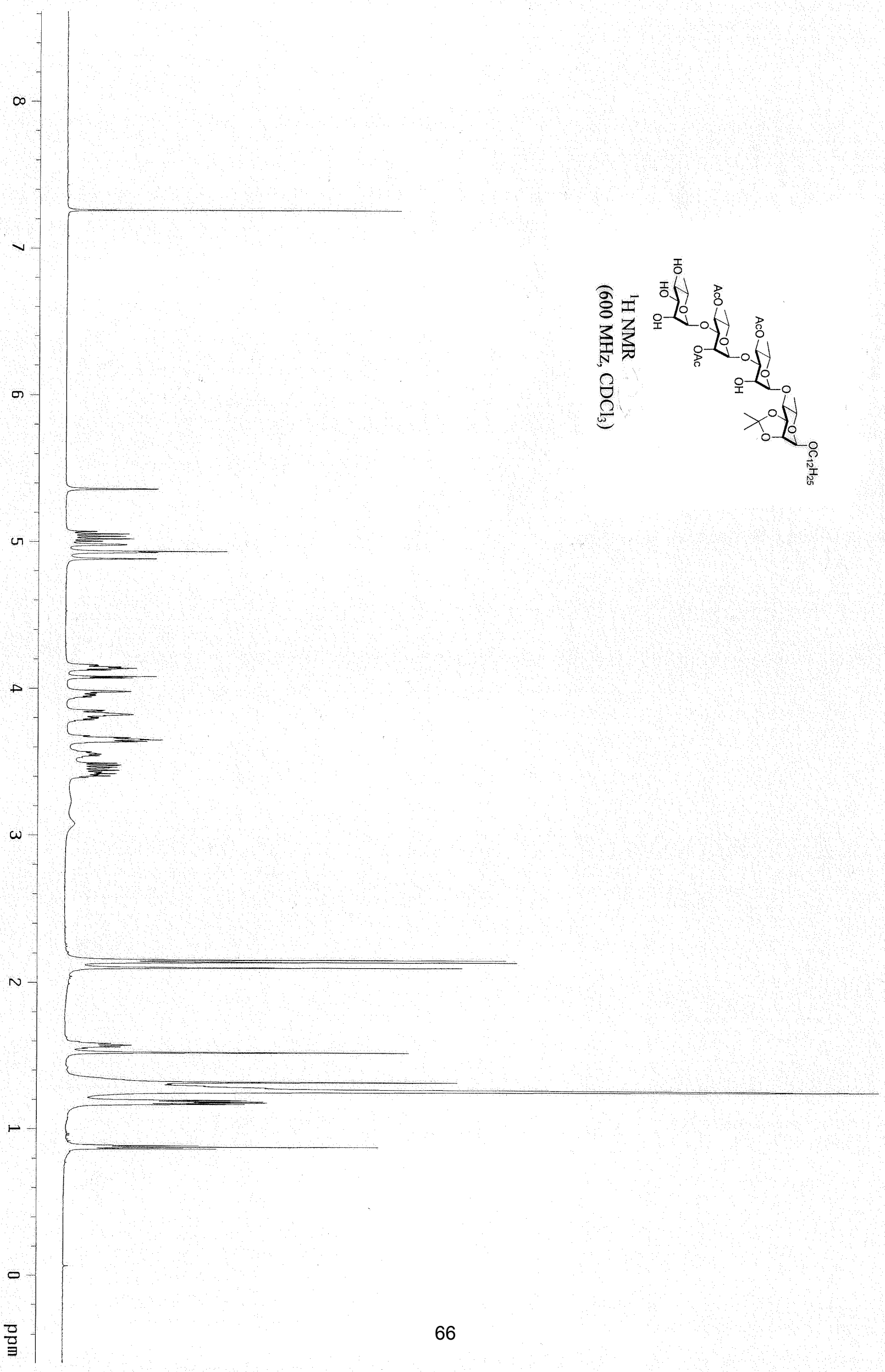




$$
f^{n}
$$




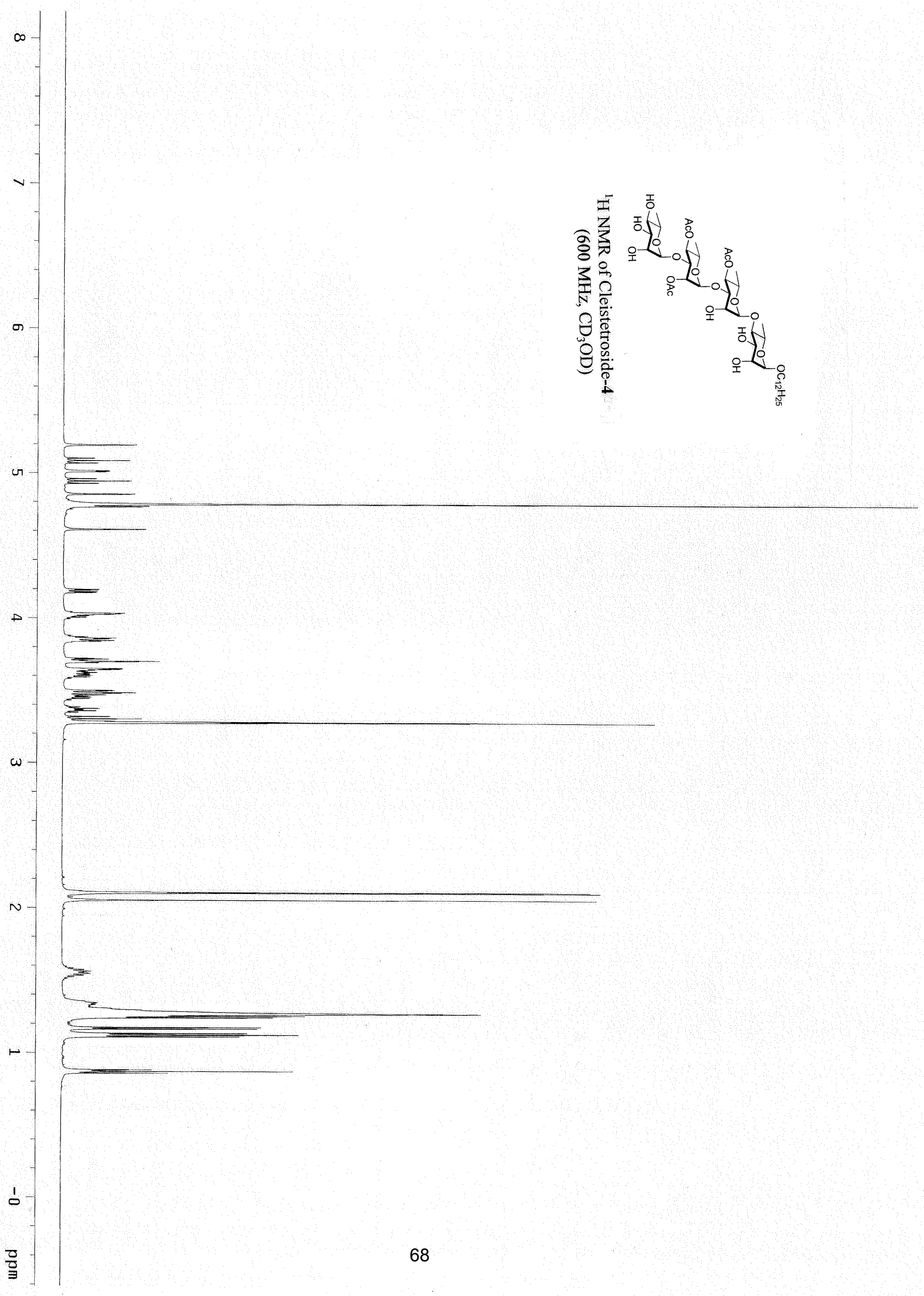




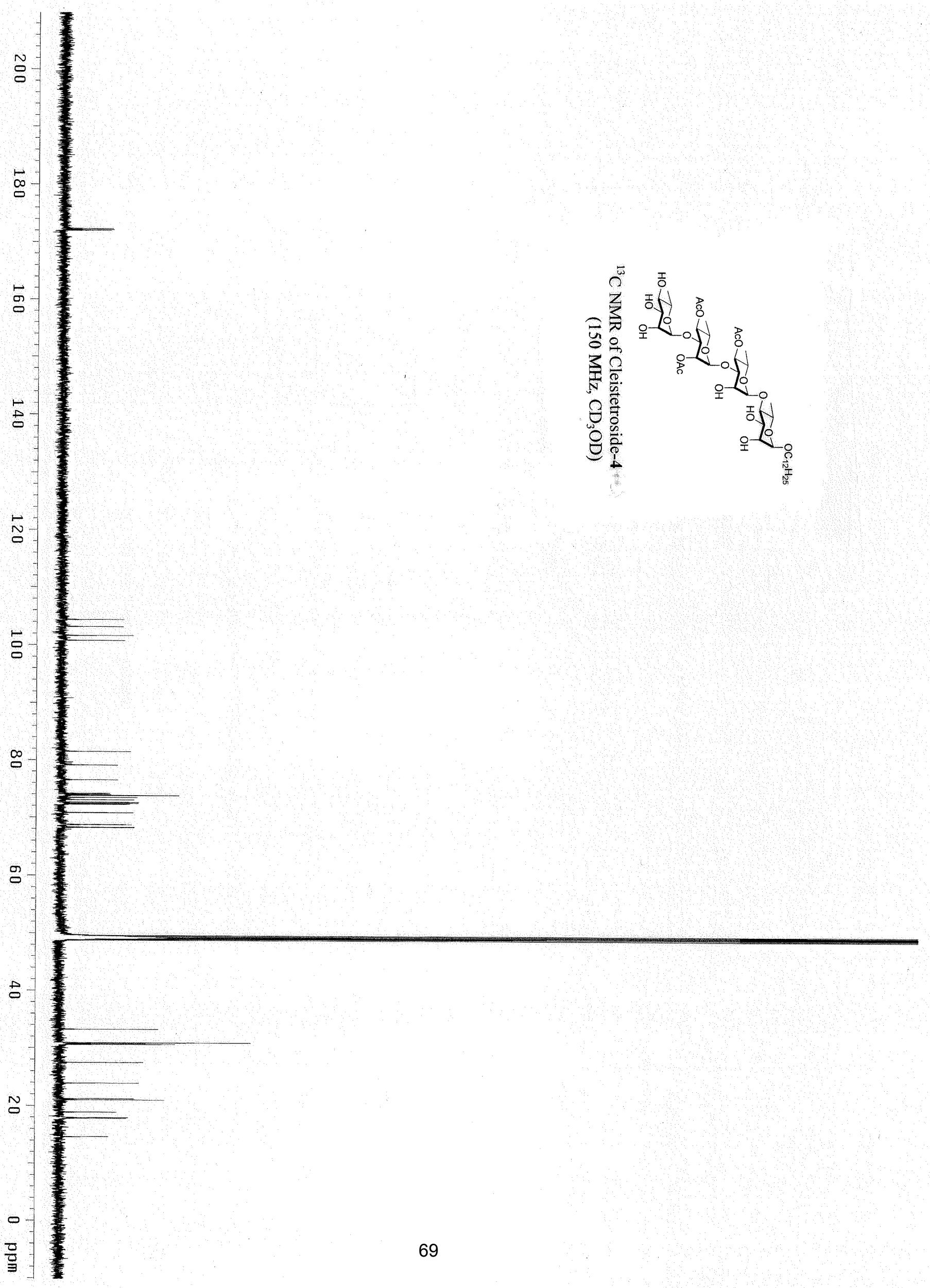



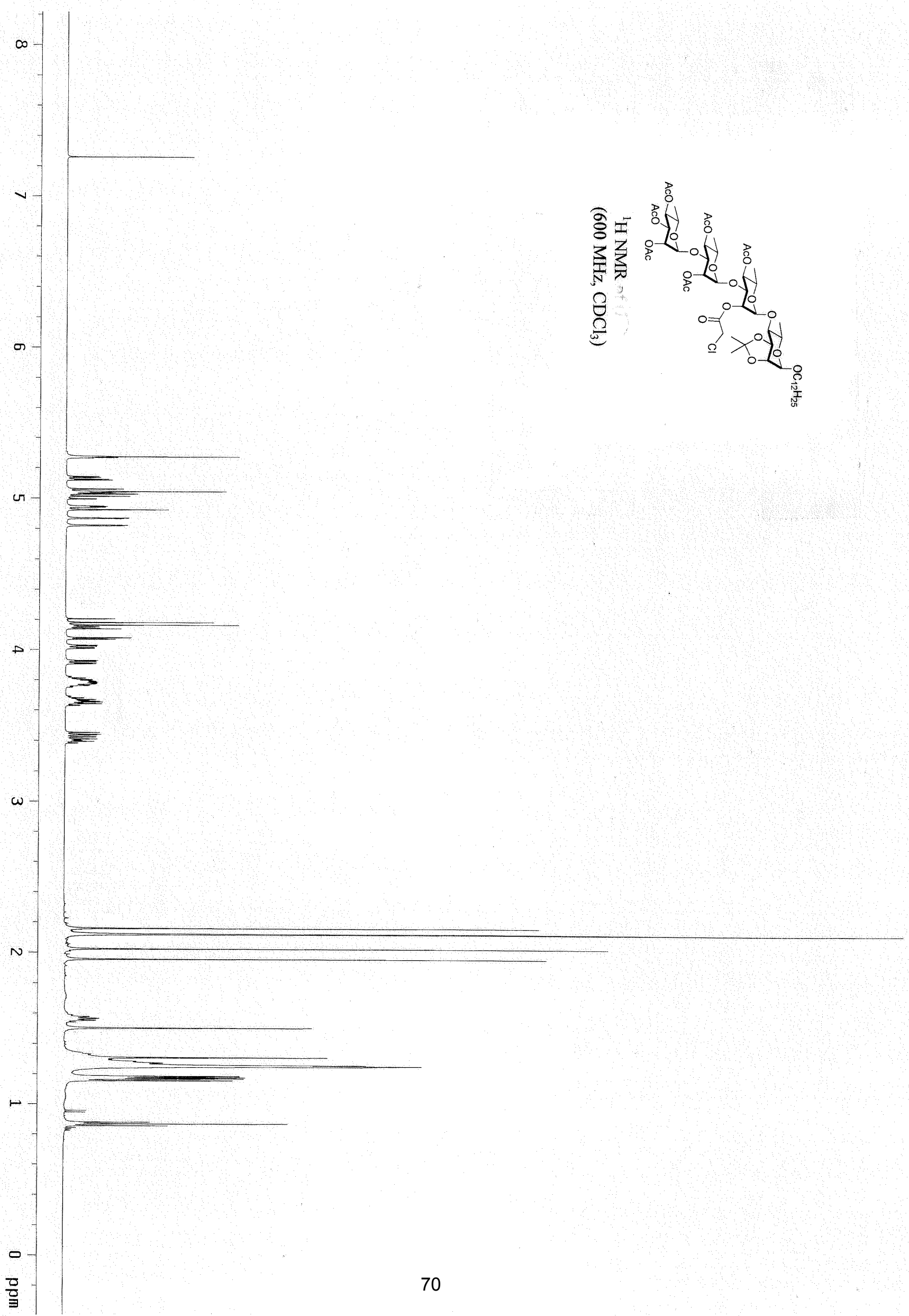


$$
=
$$




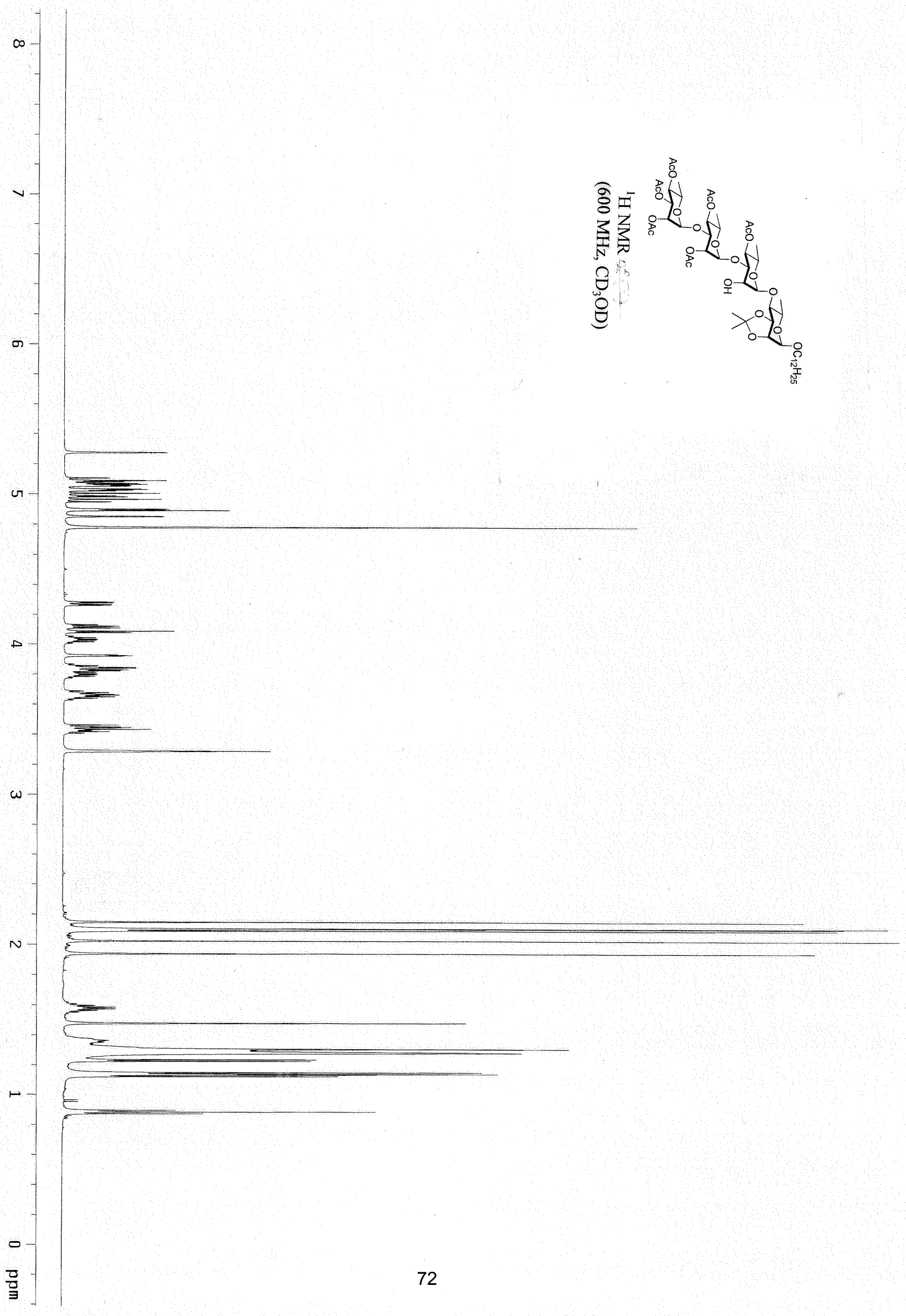




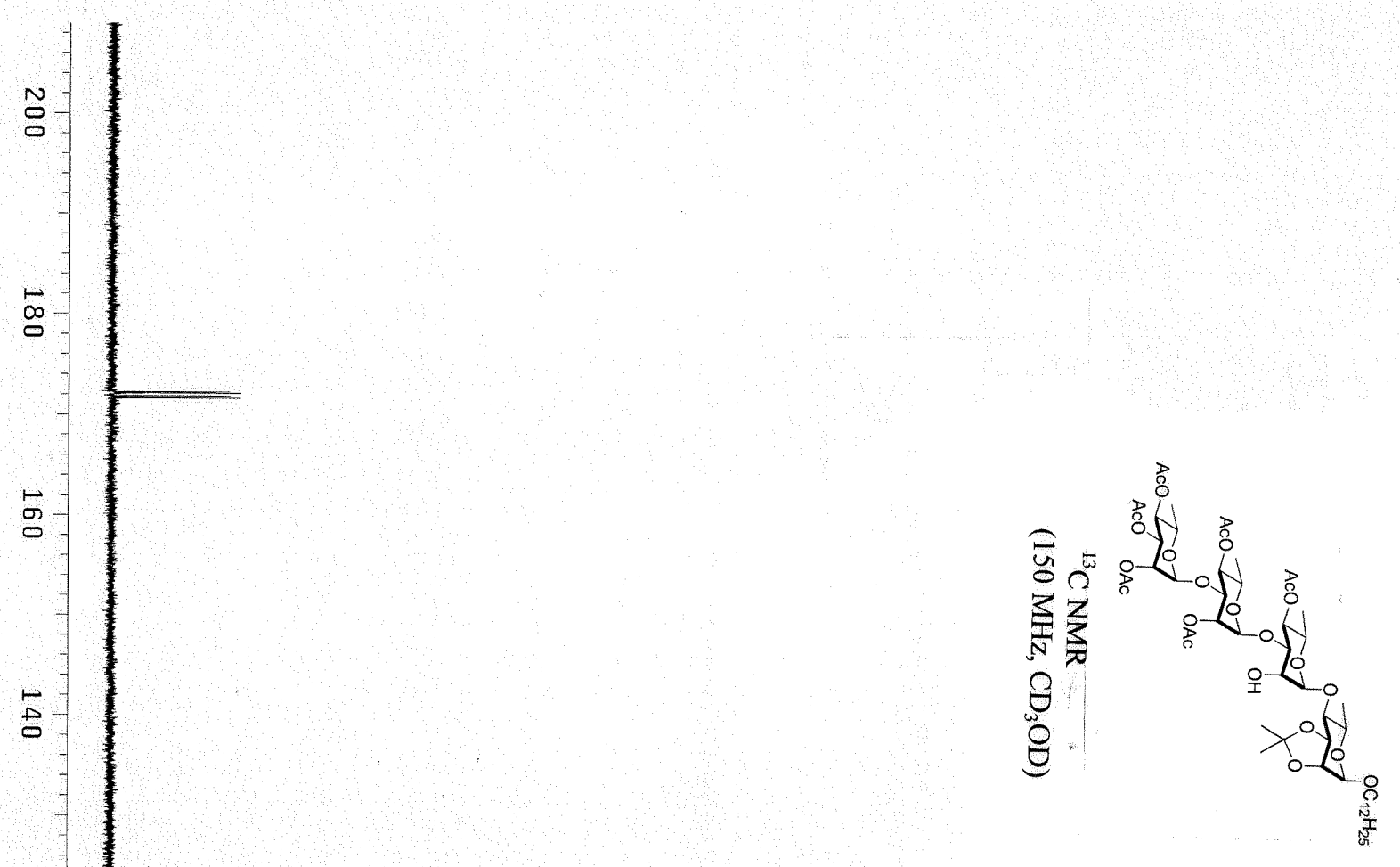

$\stackrel{N}{\circ}$

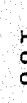

$\stackrel{\infty}{\circ}$

$\square$

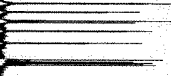

0

$8 \longdiv { 5 }$

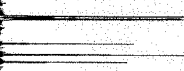

N

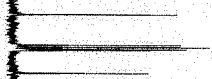

if 


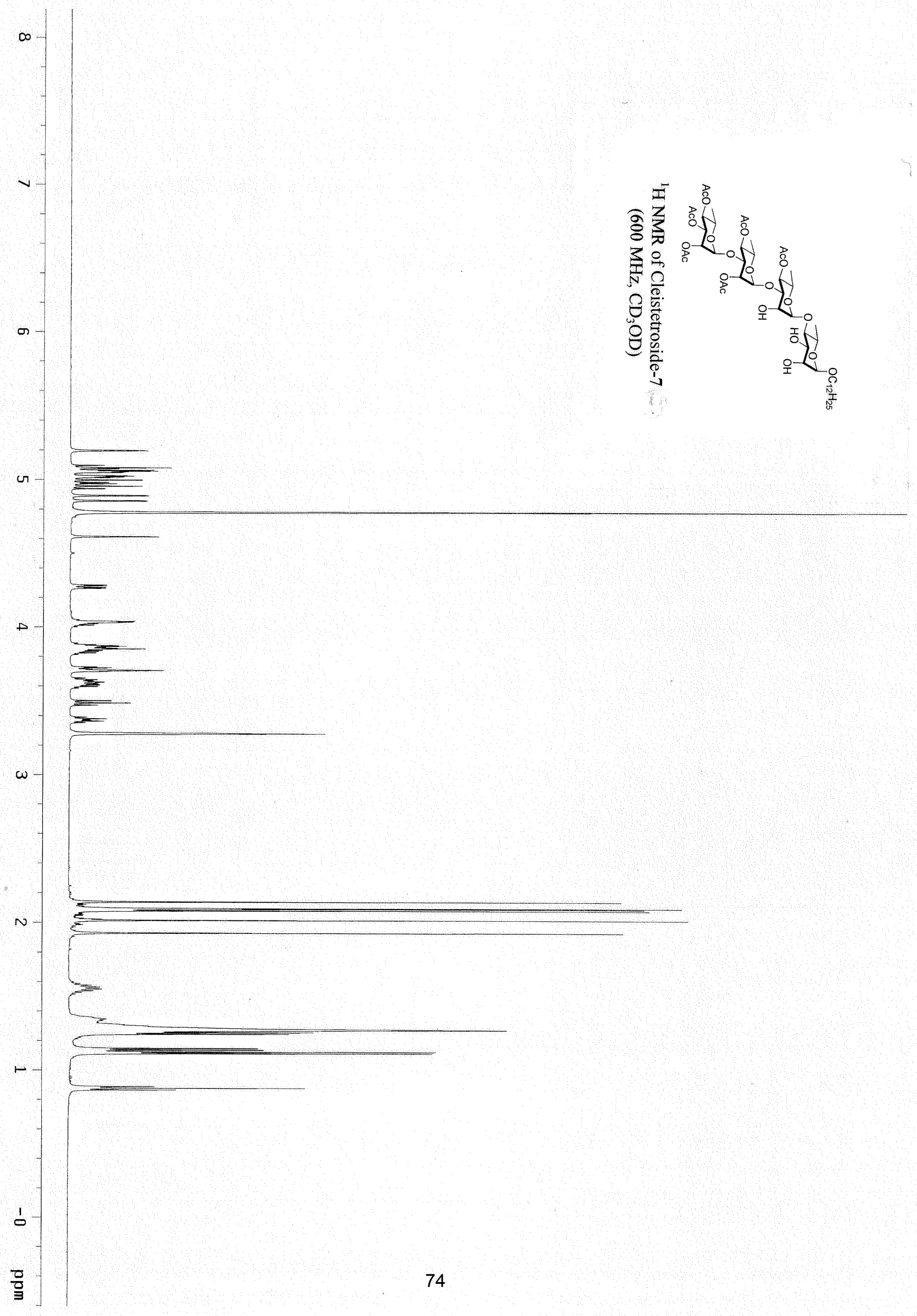




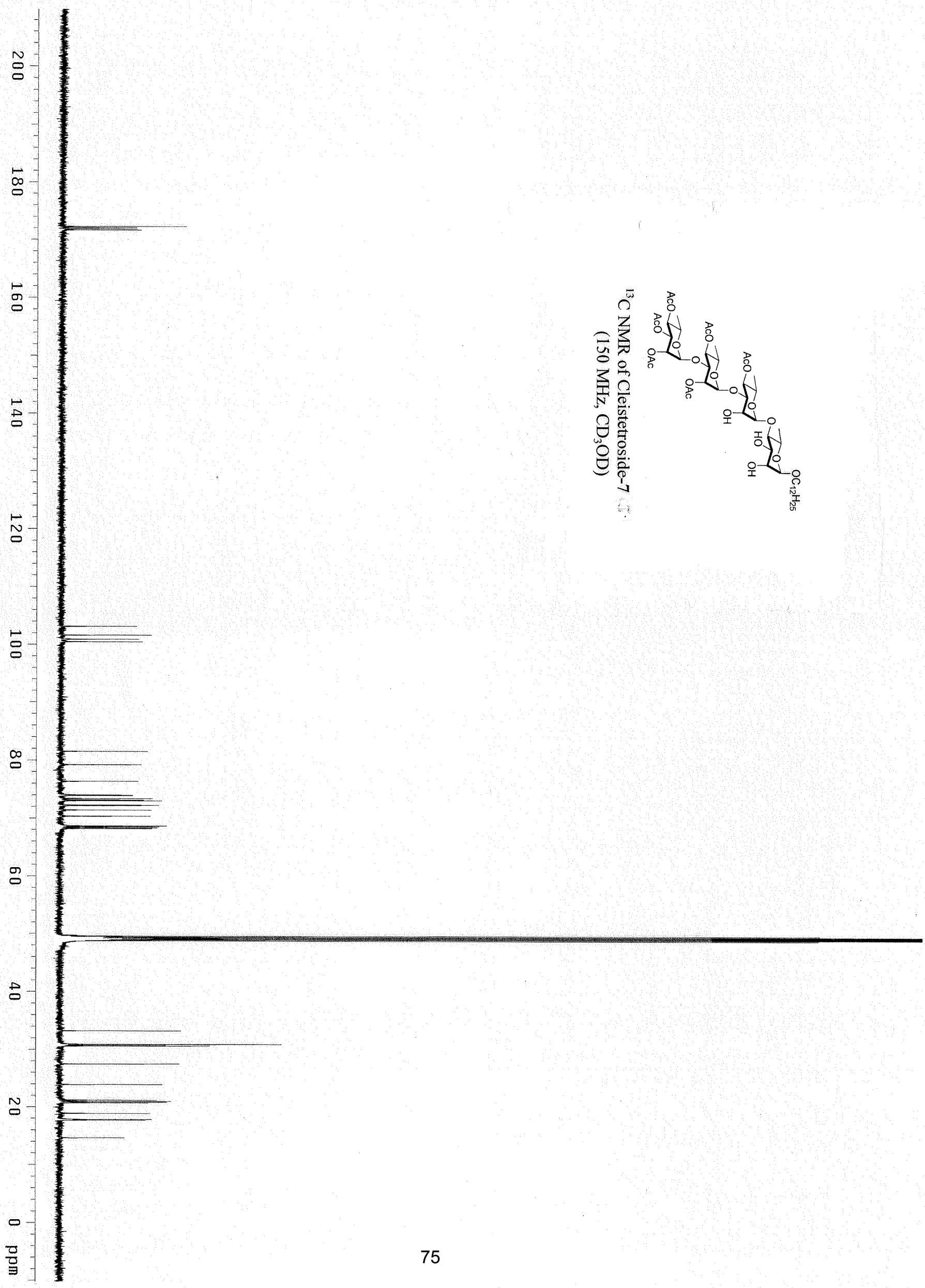




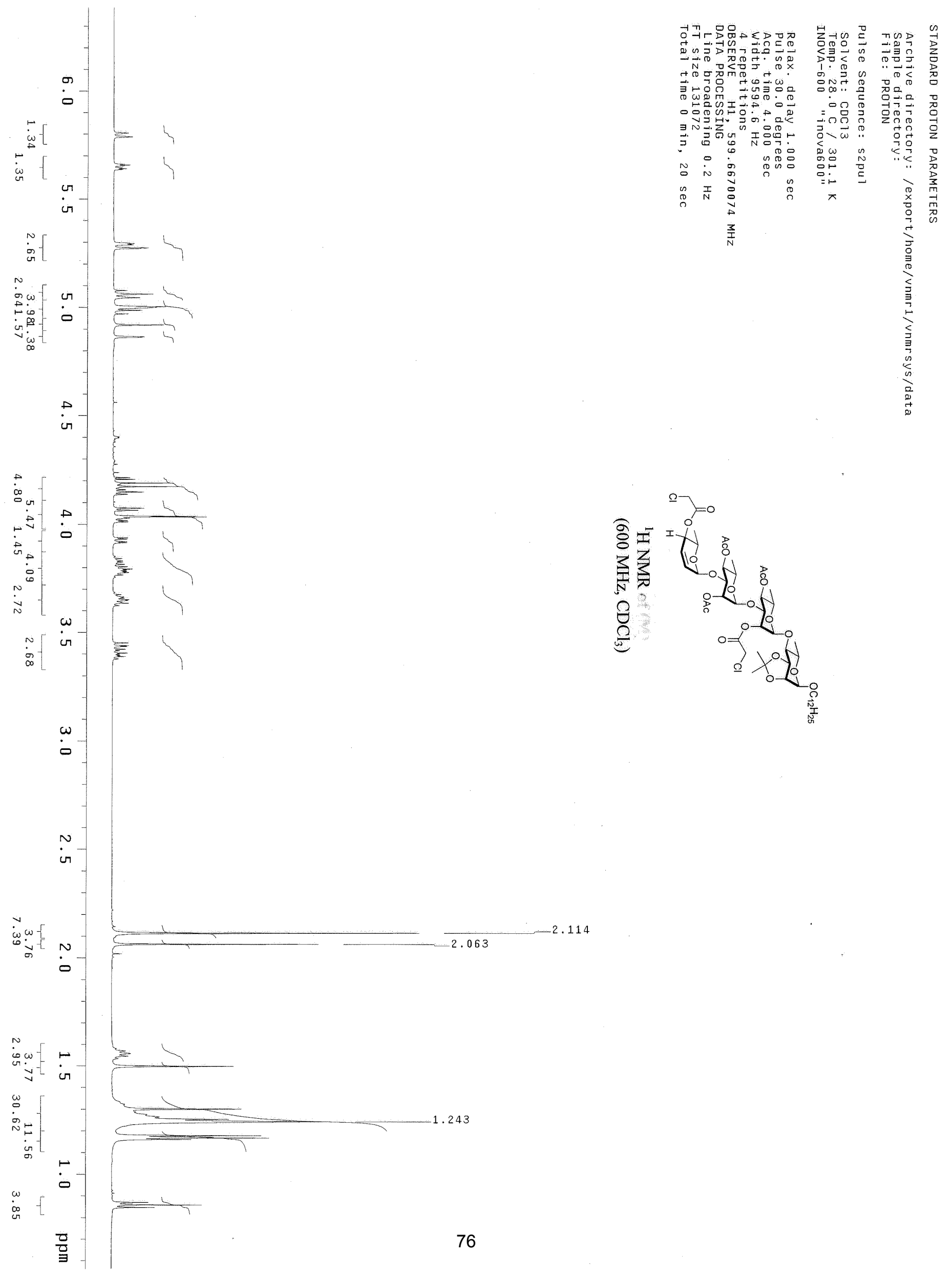




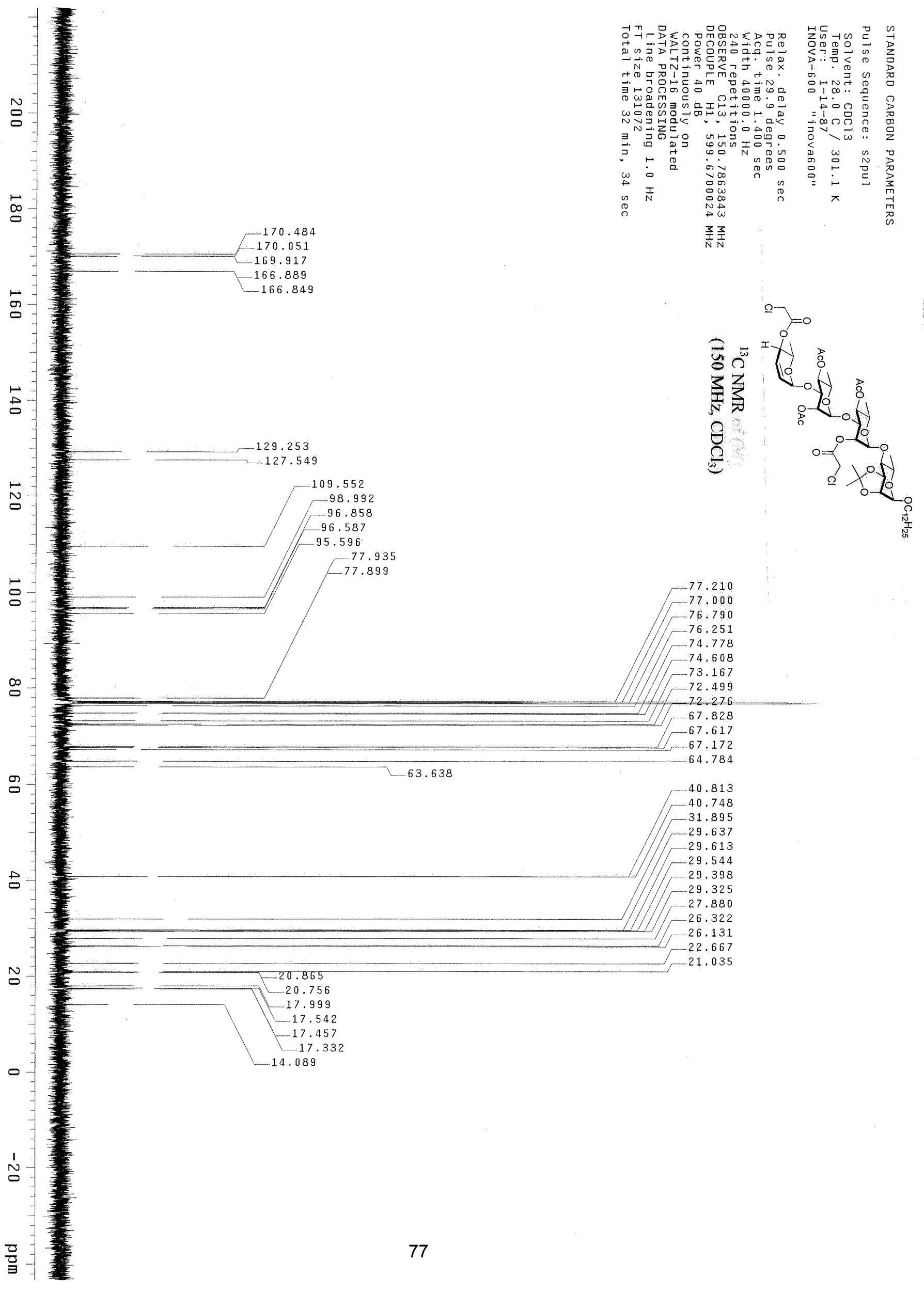




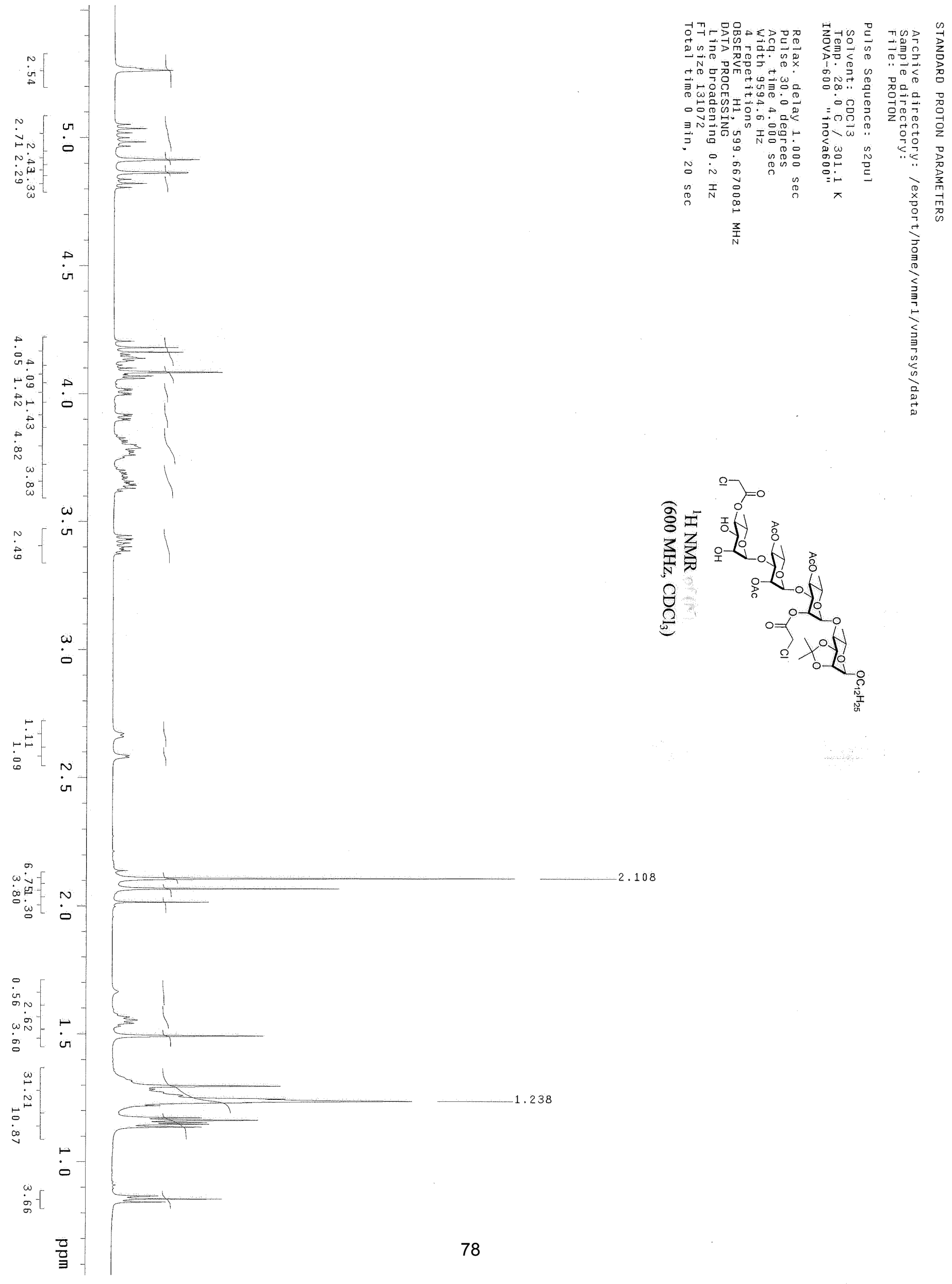



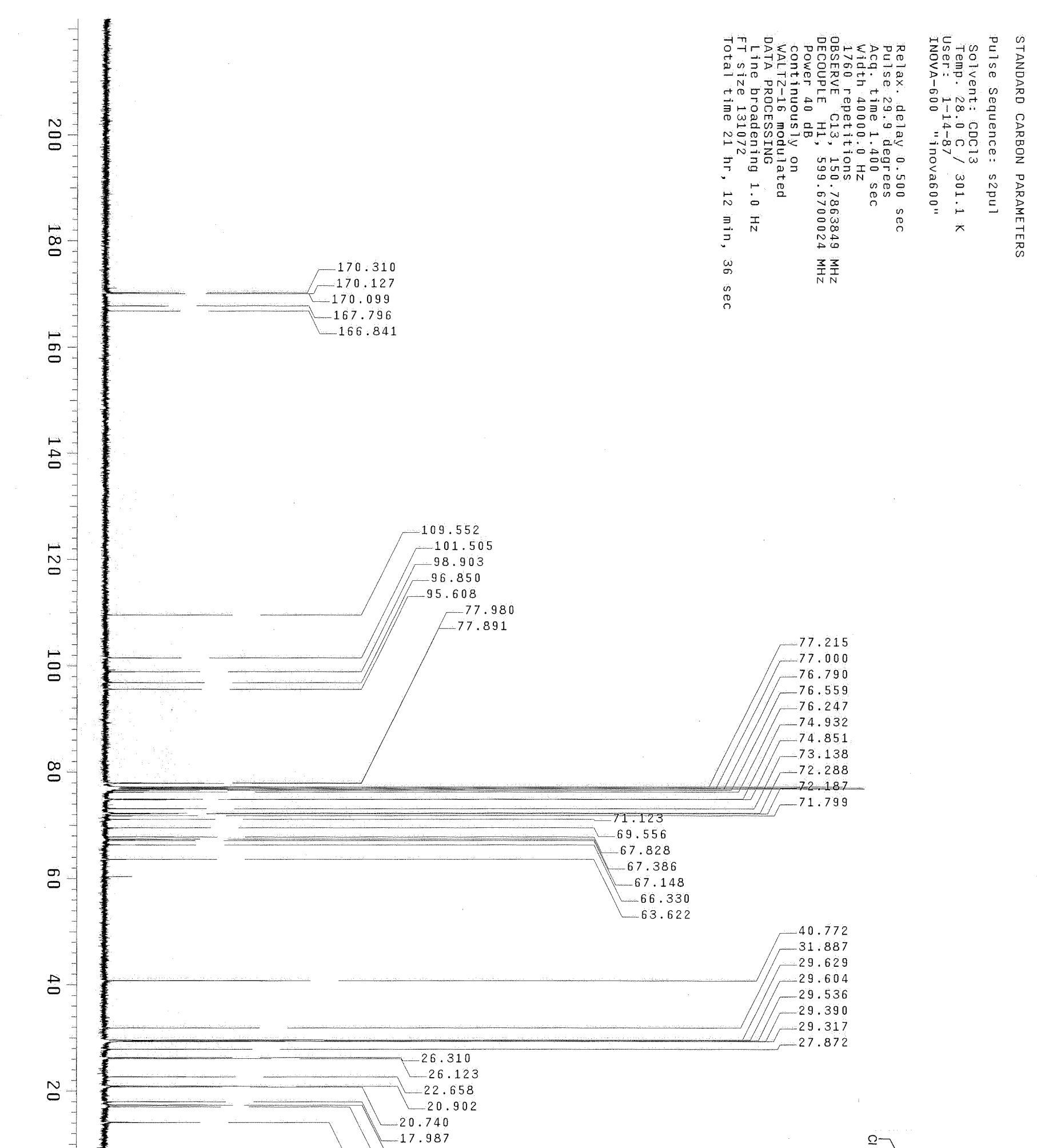

列
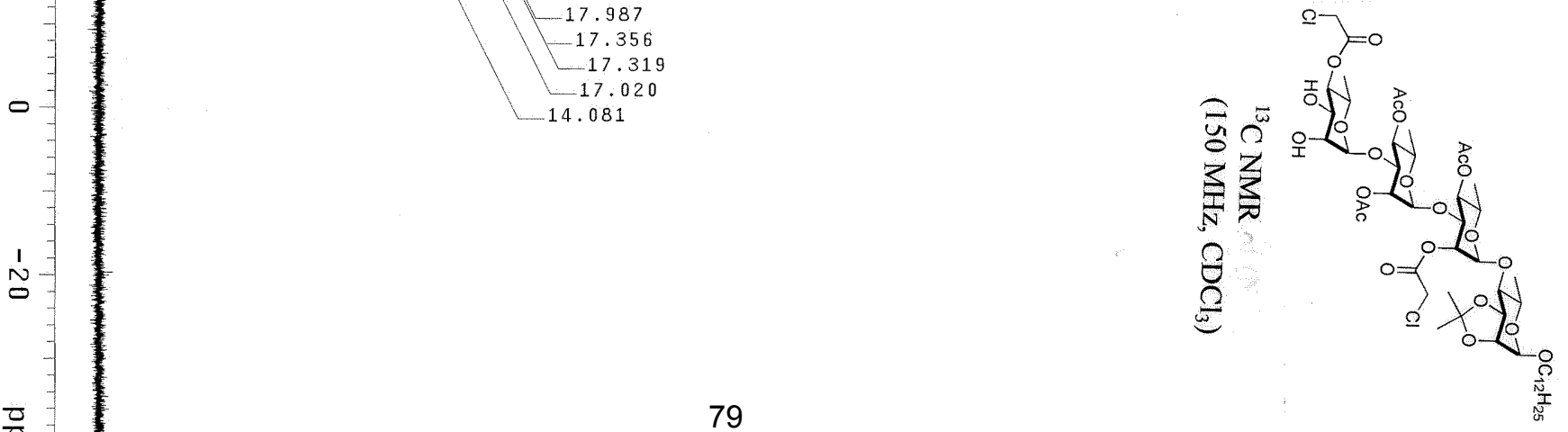


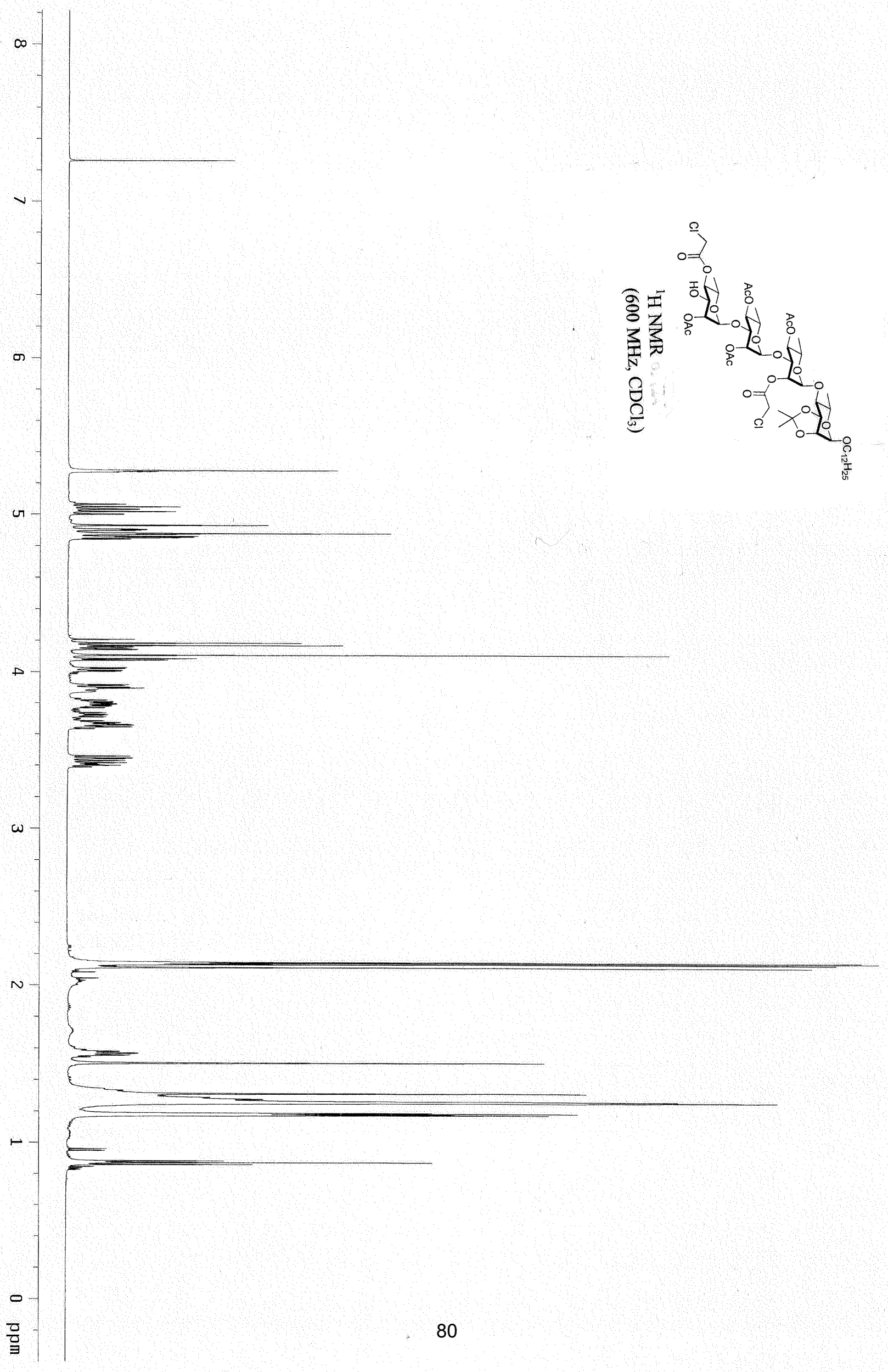




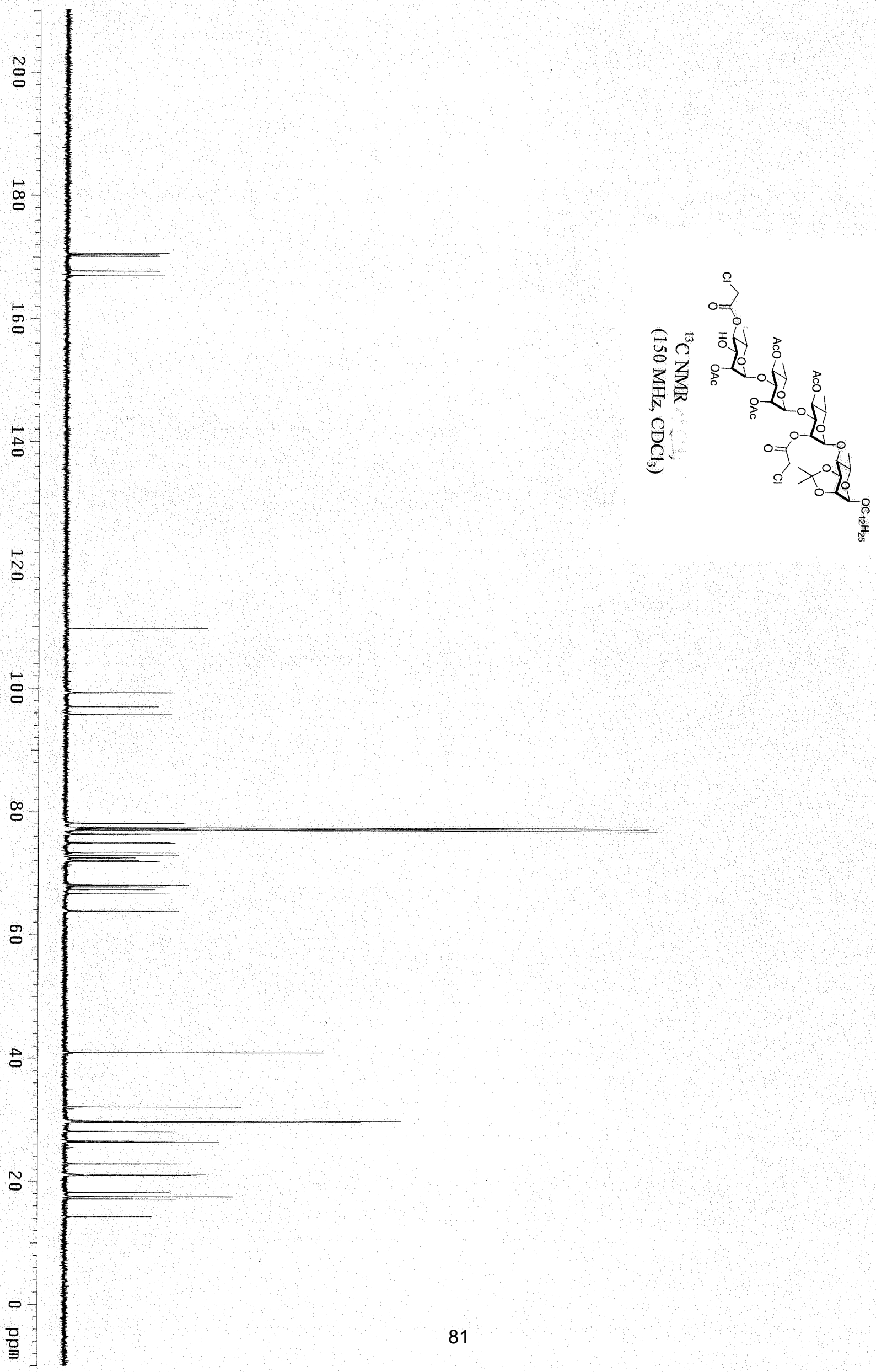




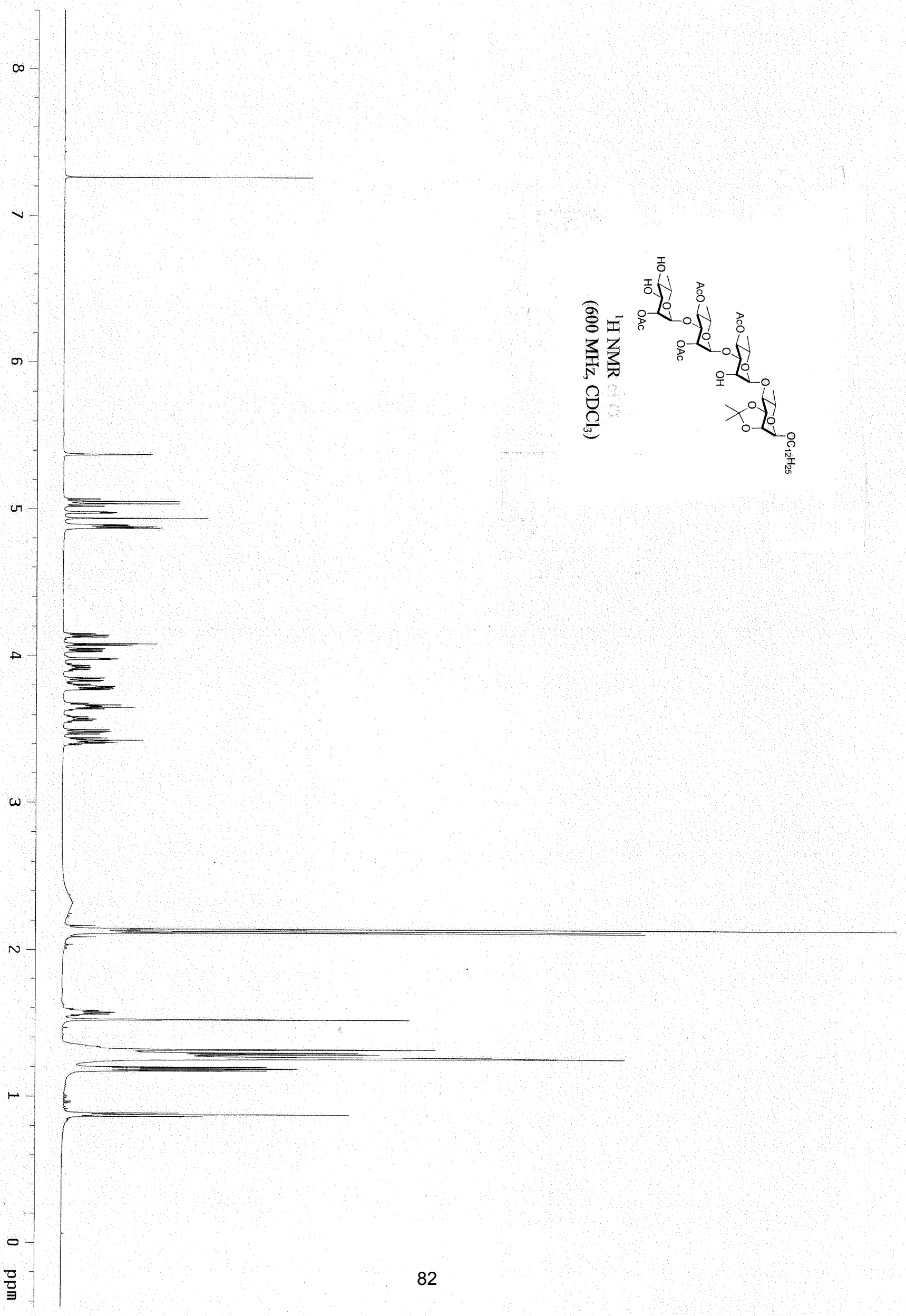




$$
\|=
$$




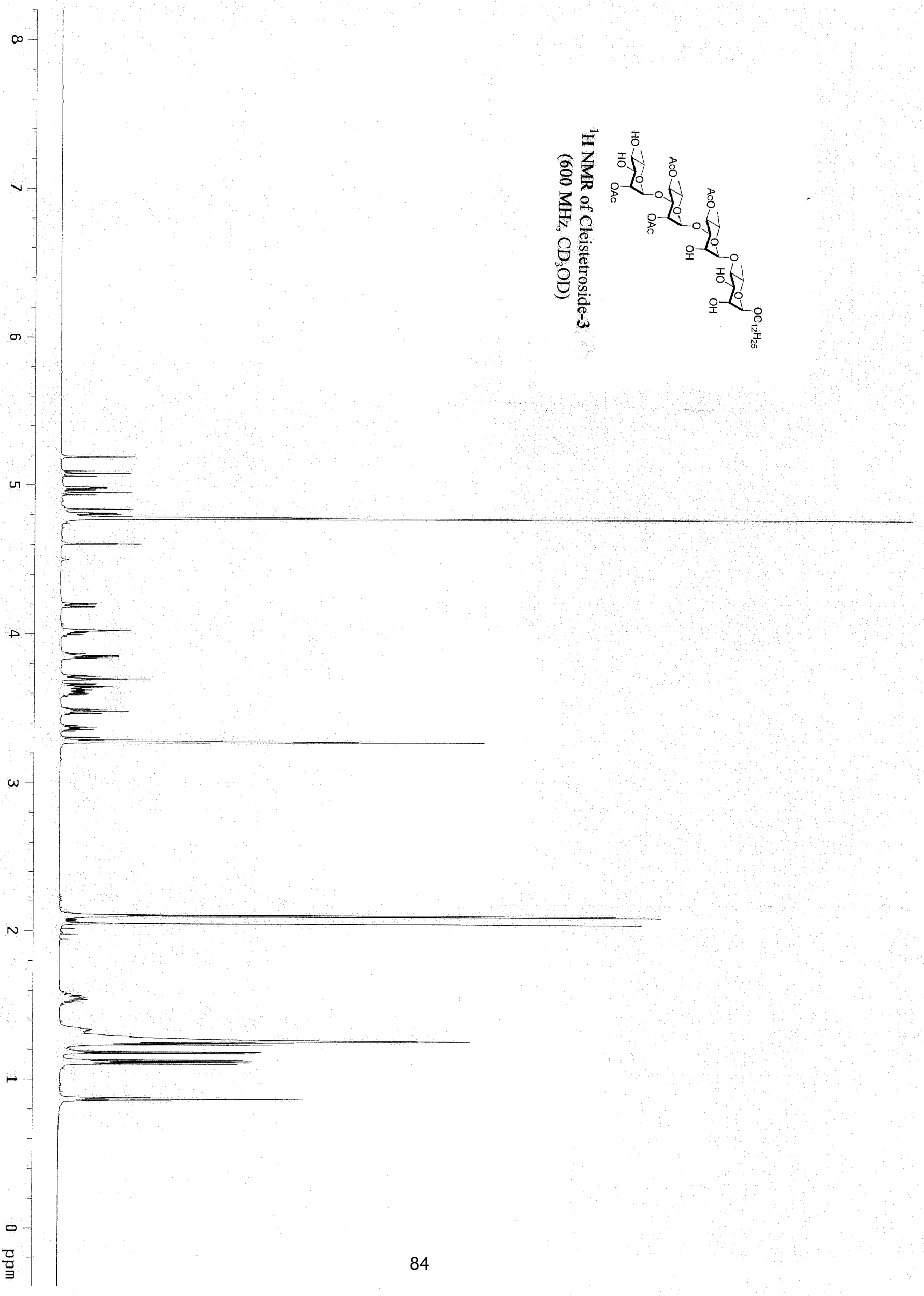



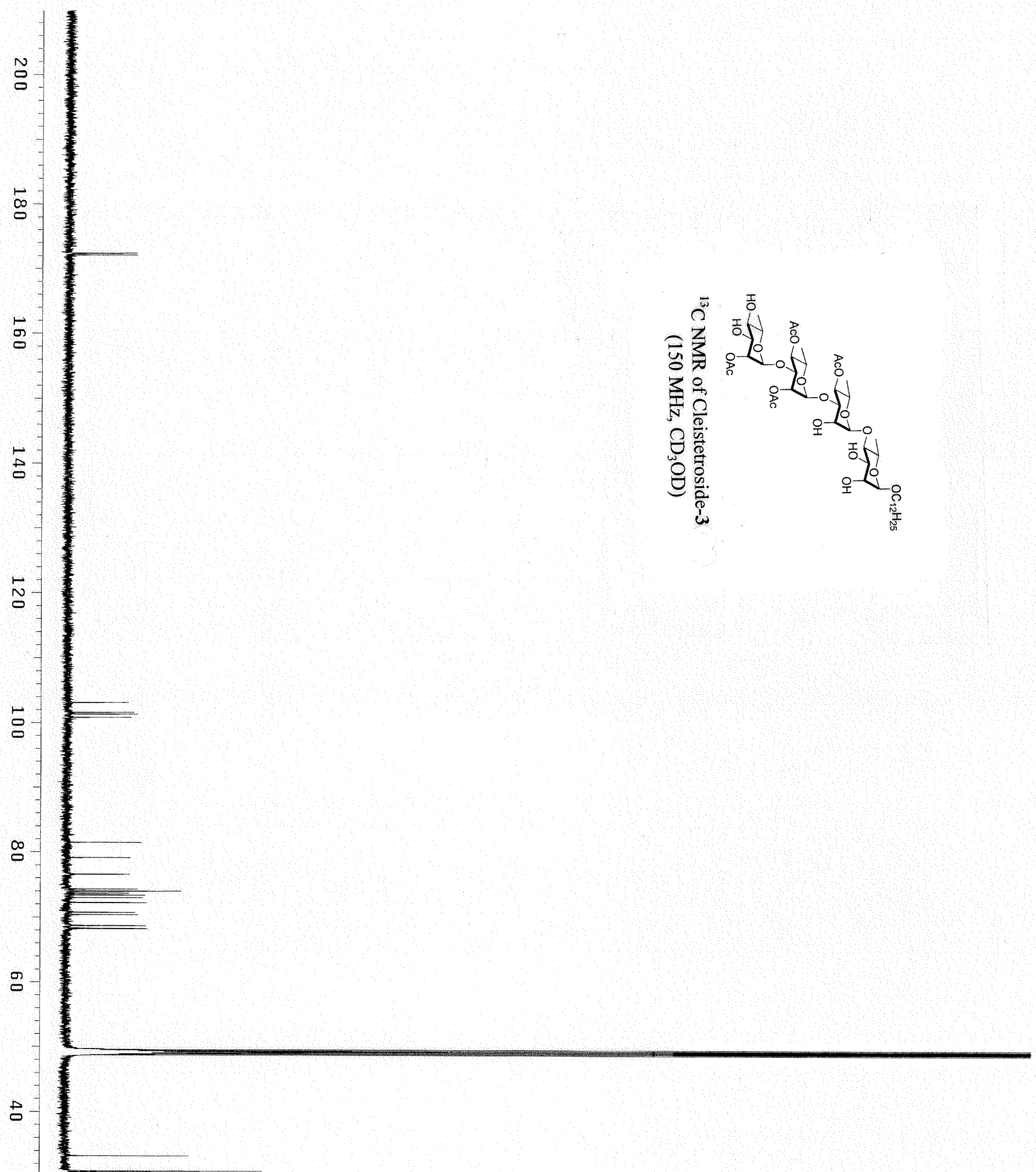

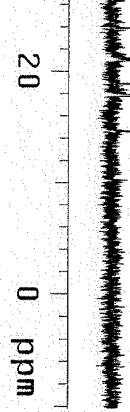




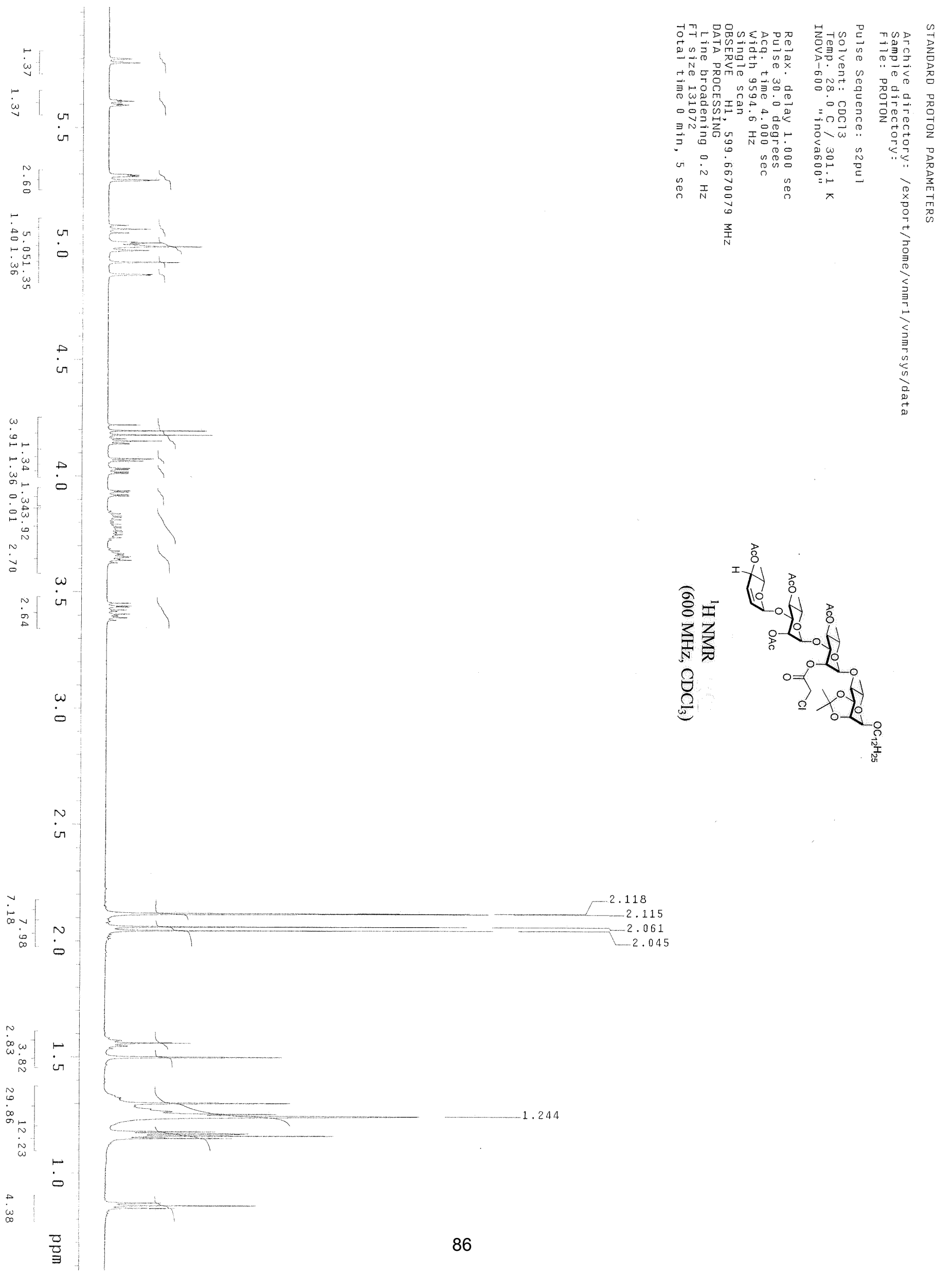




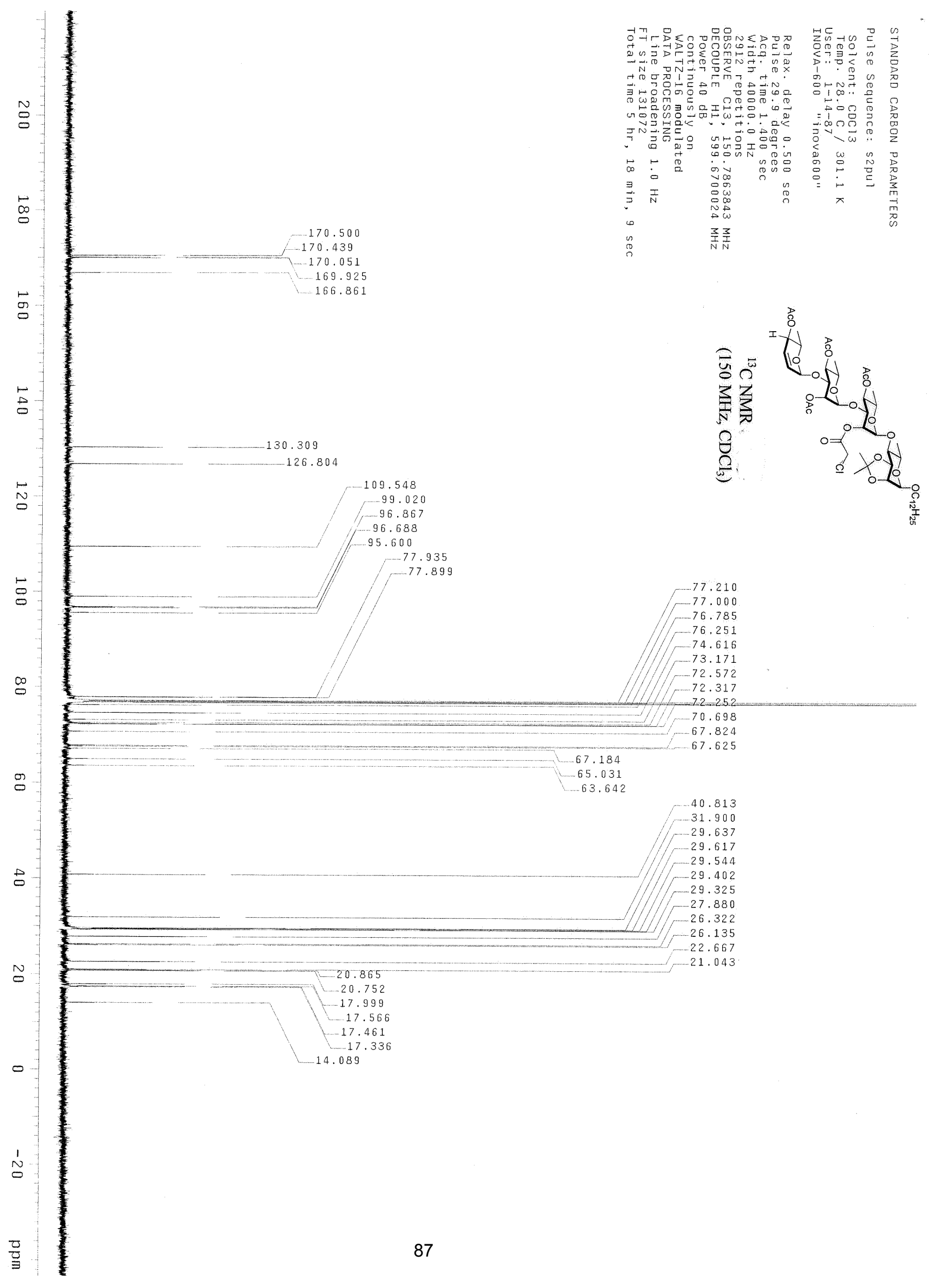




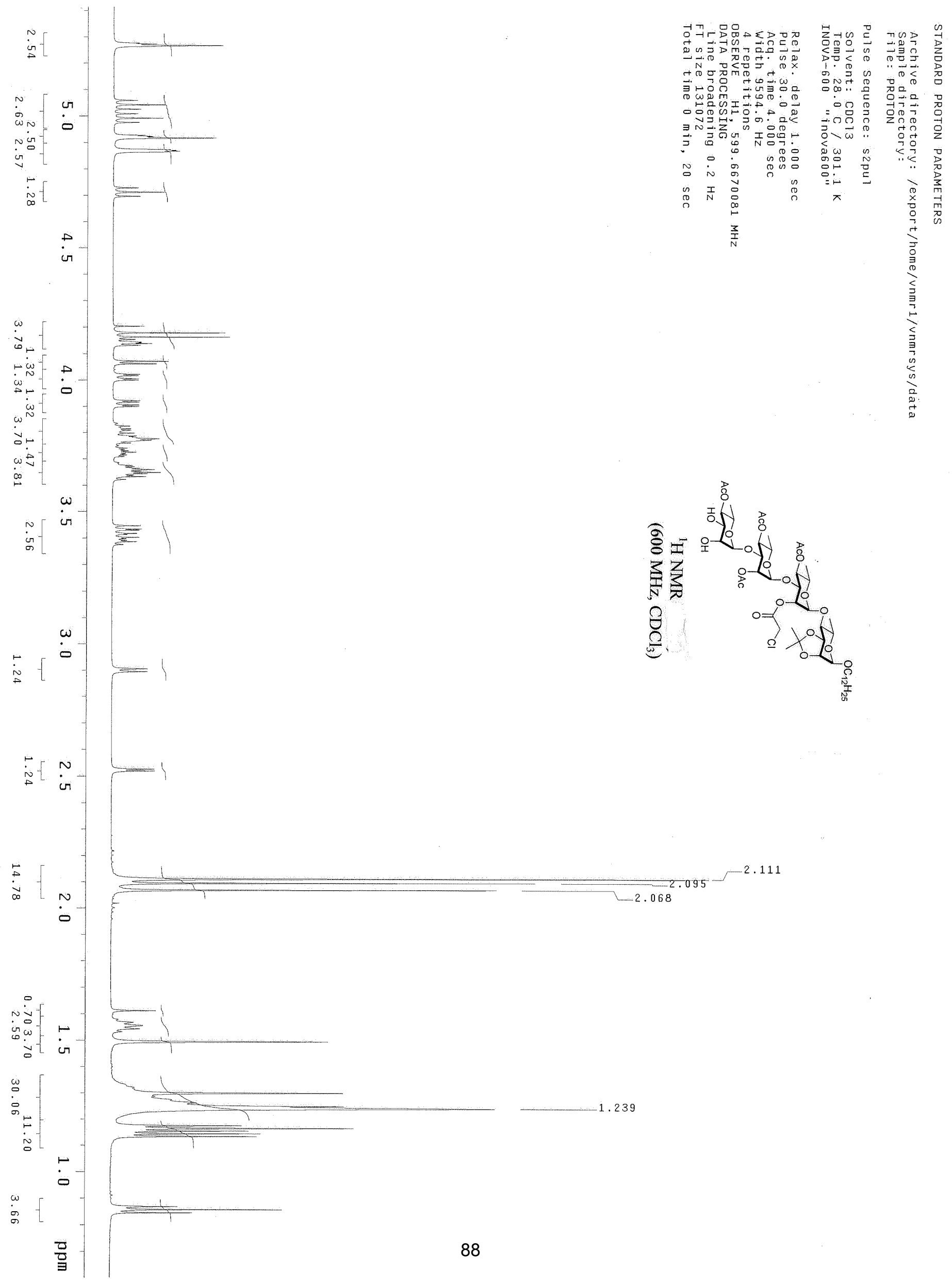




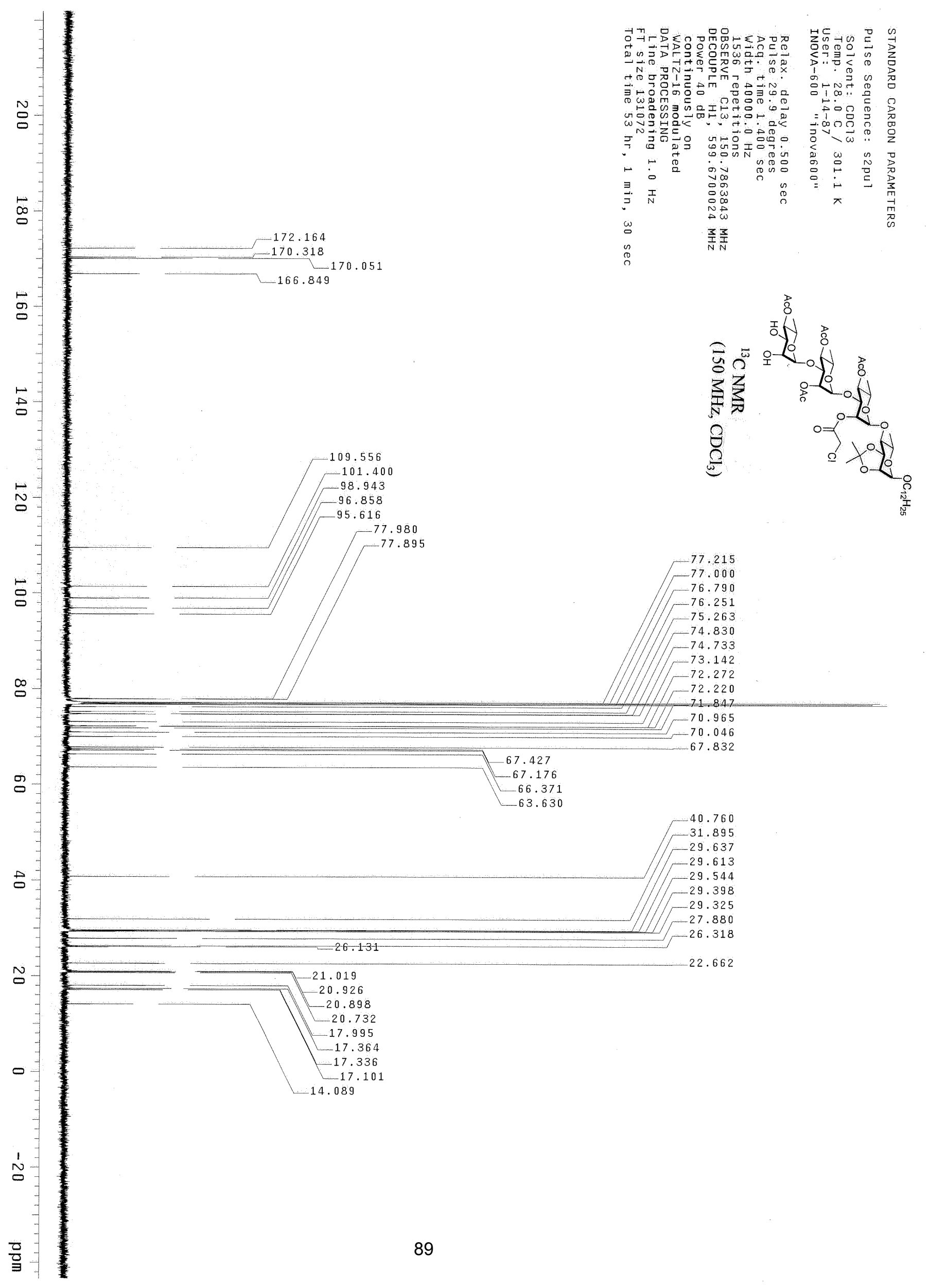




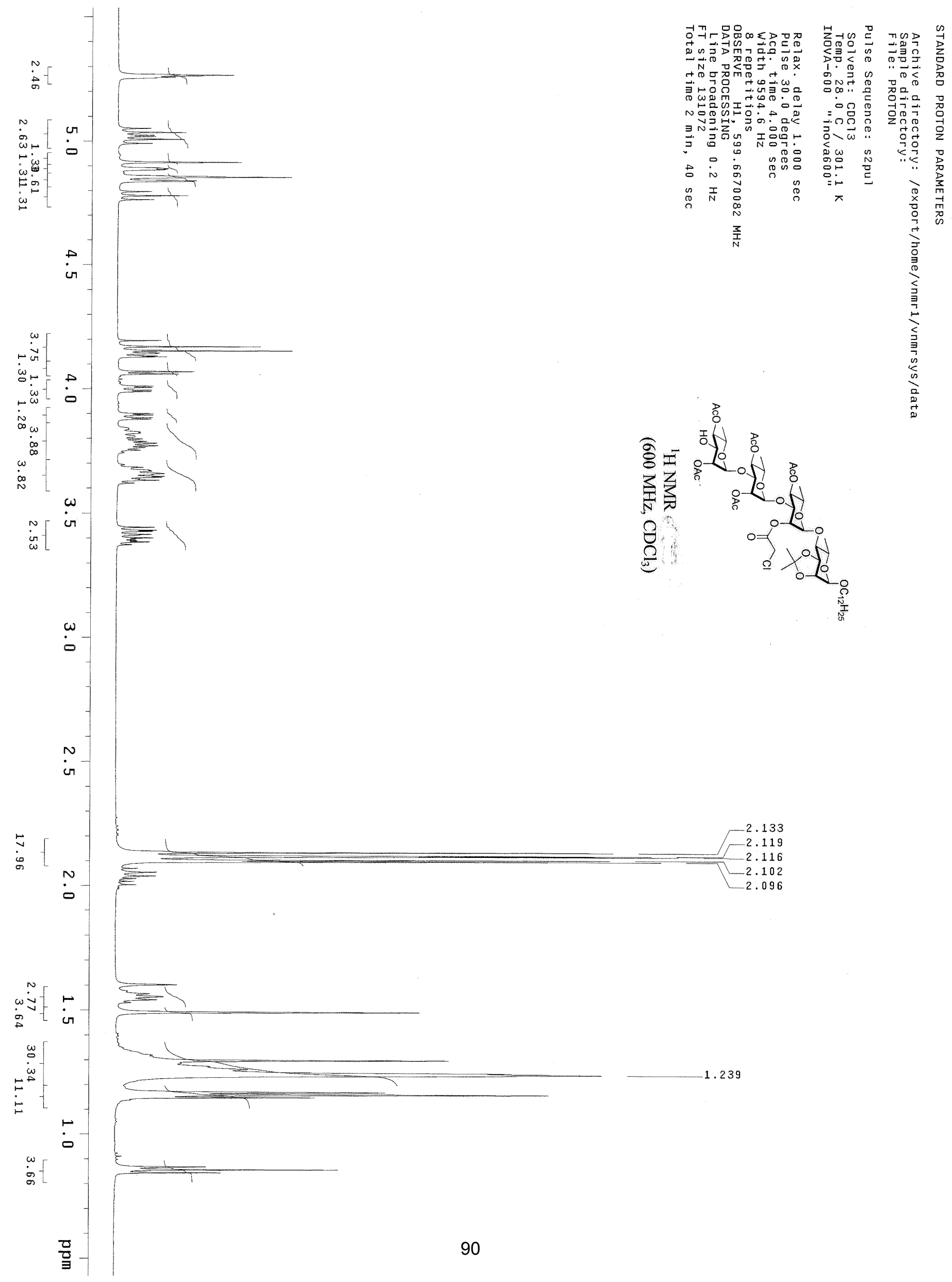



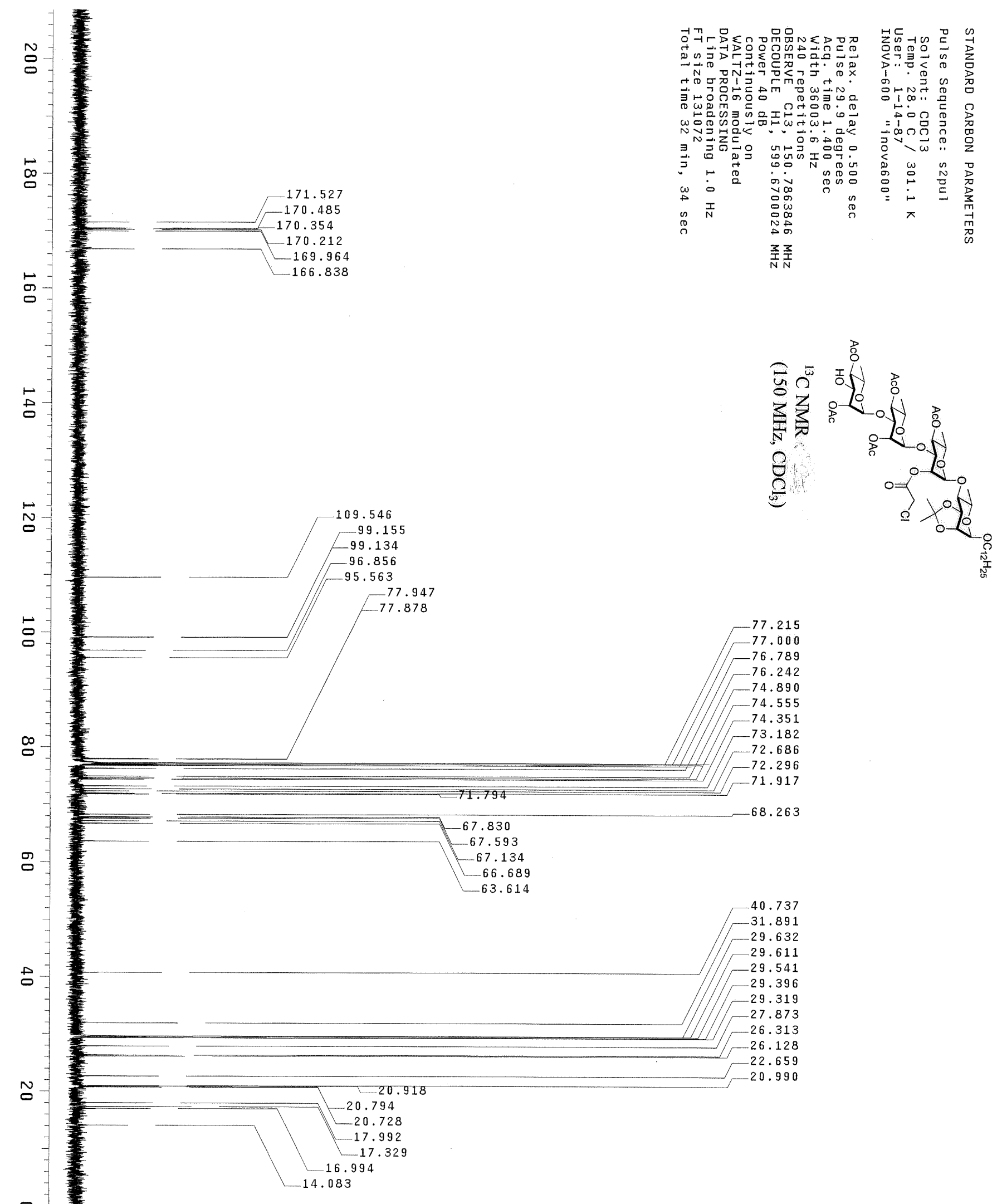

$\circ$ 


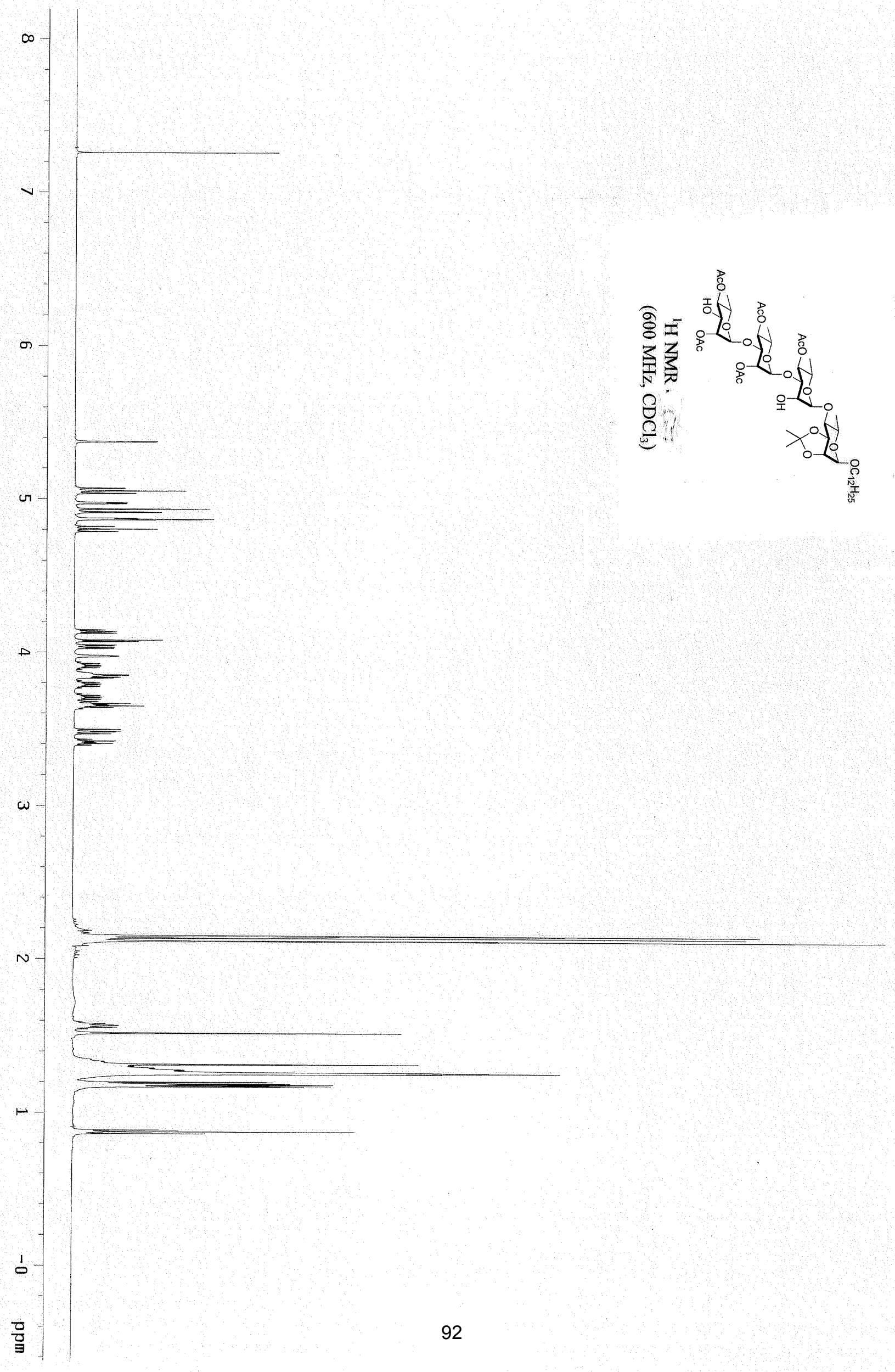




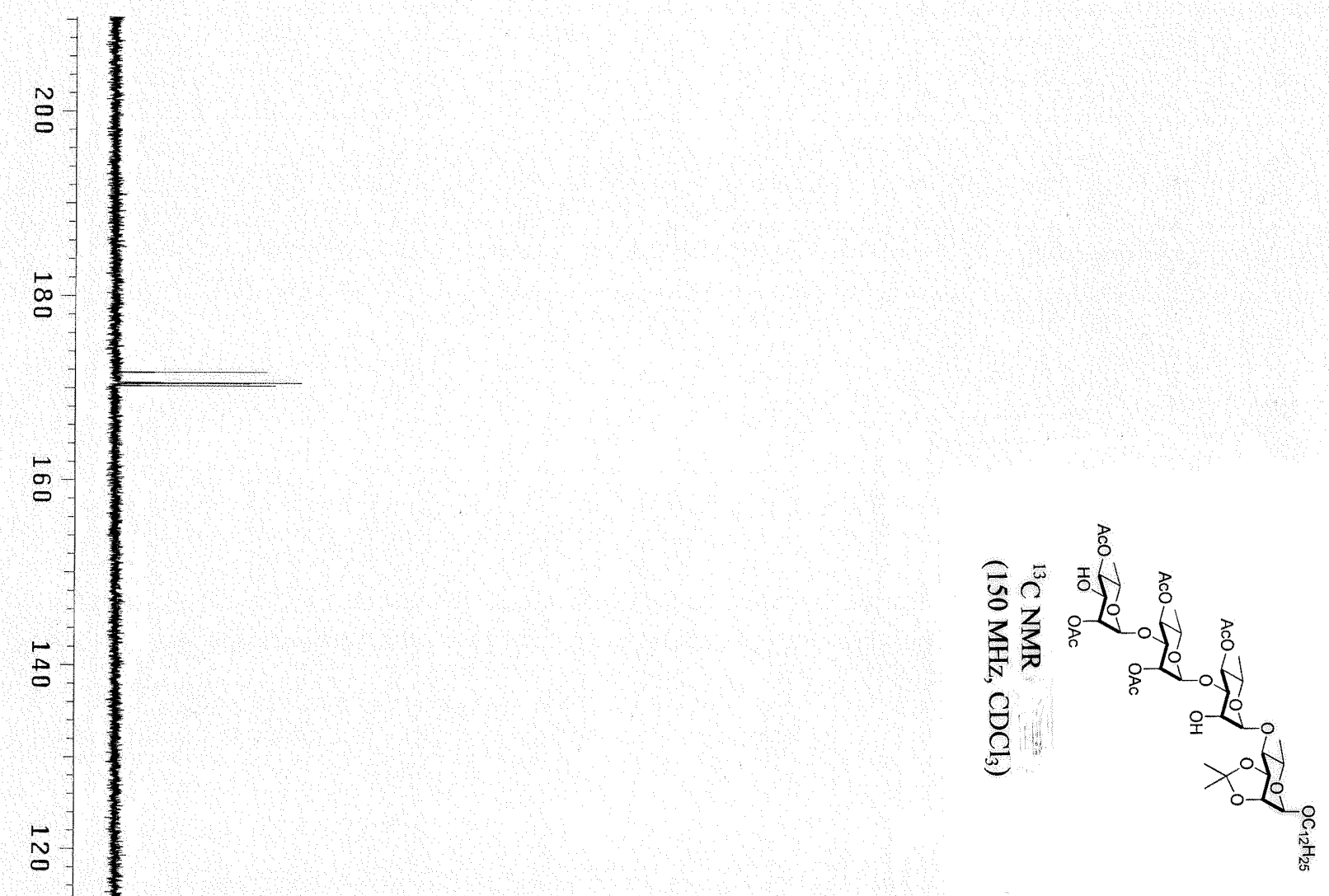

$\infty$
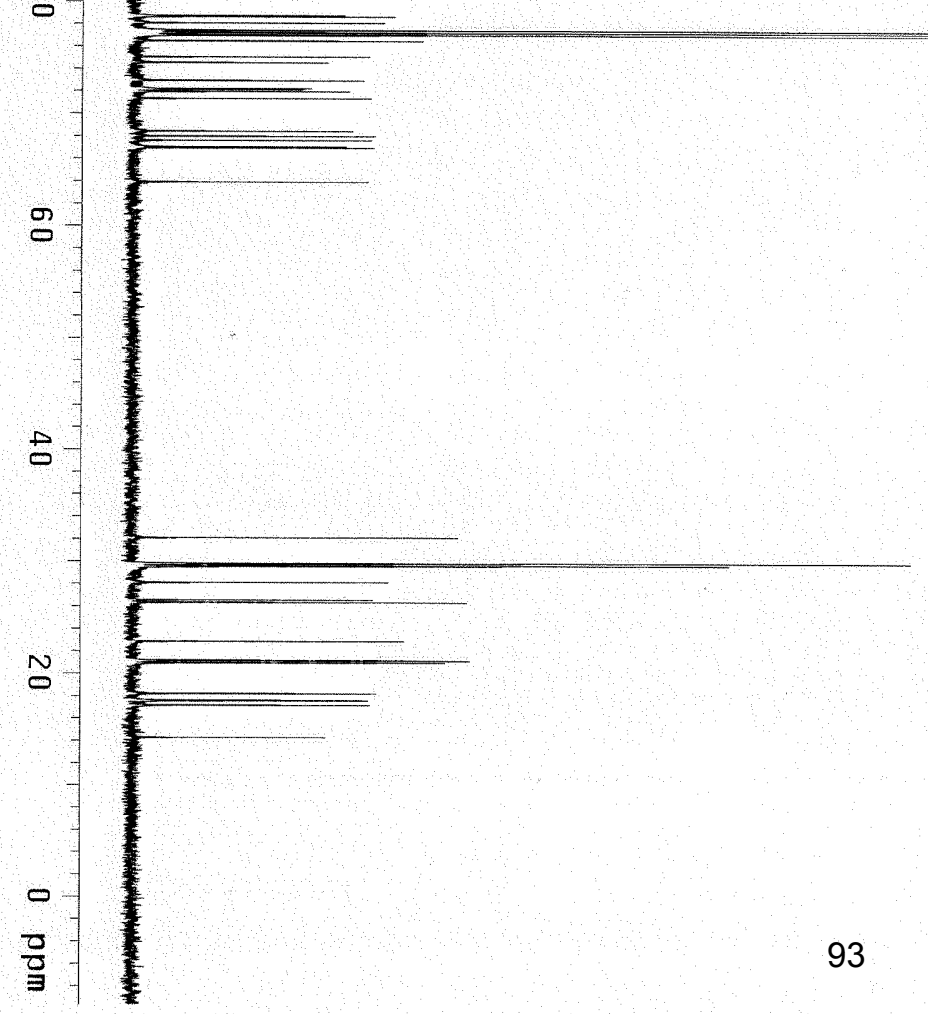


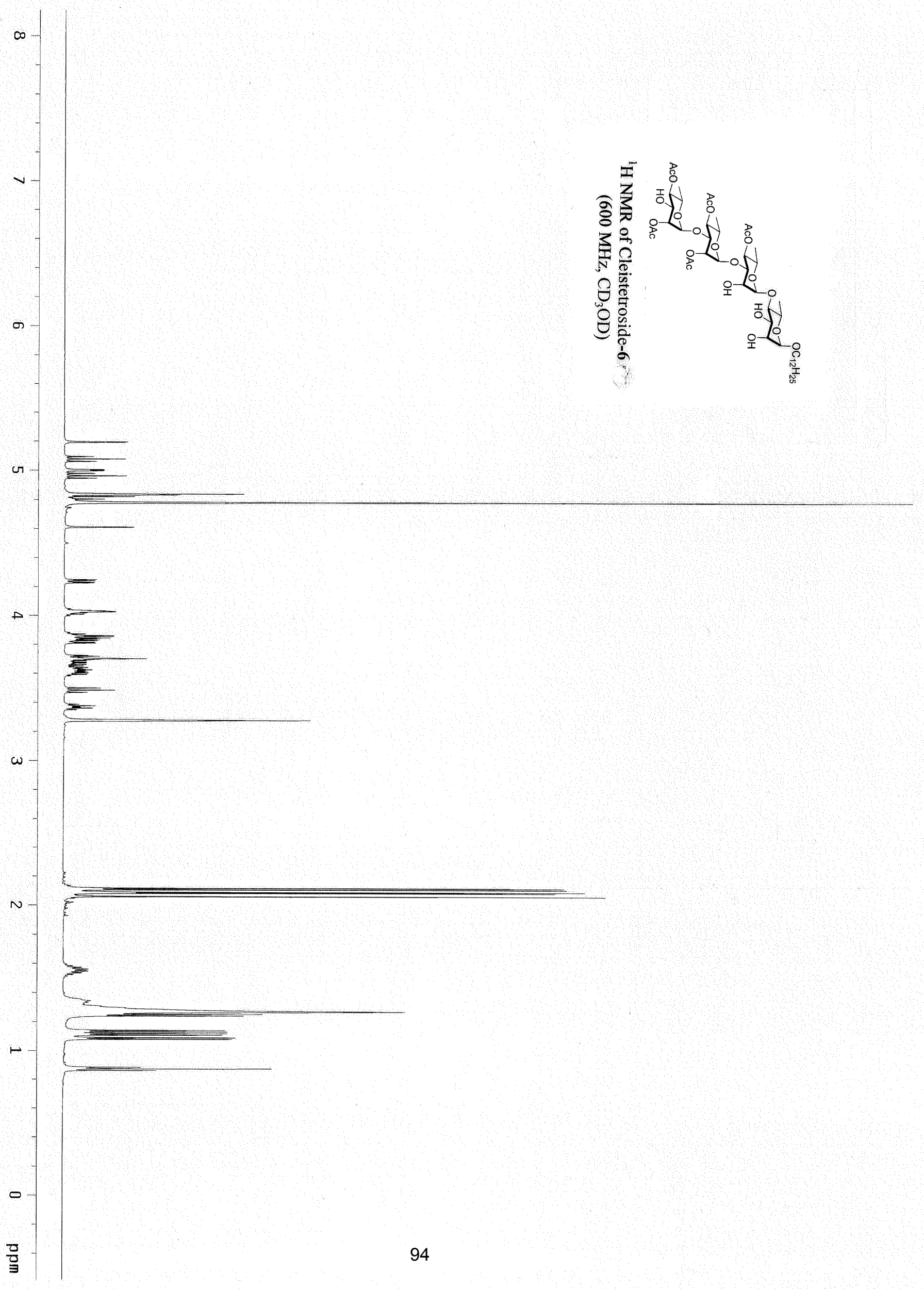



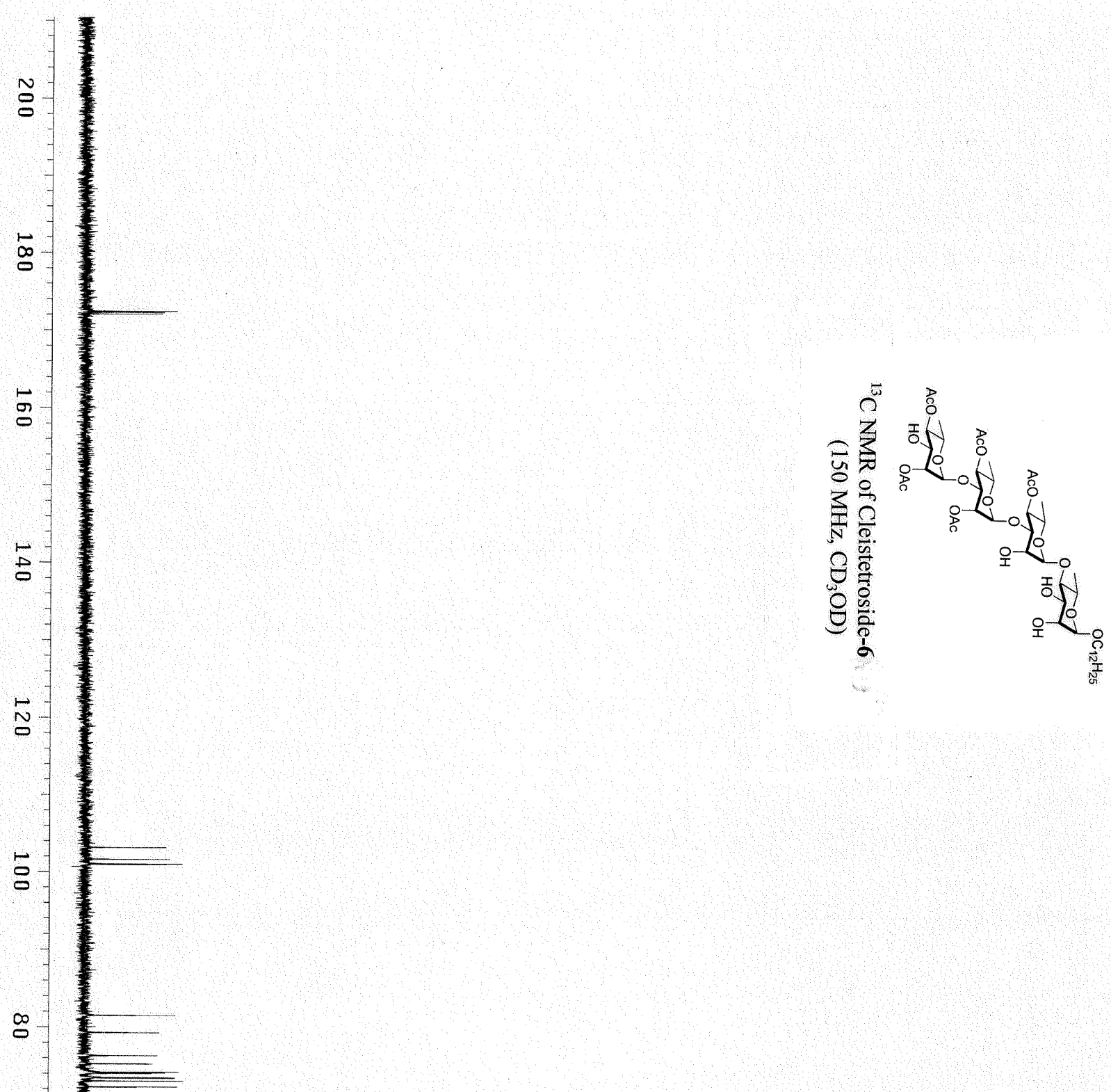

$\circ$

홍

5

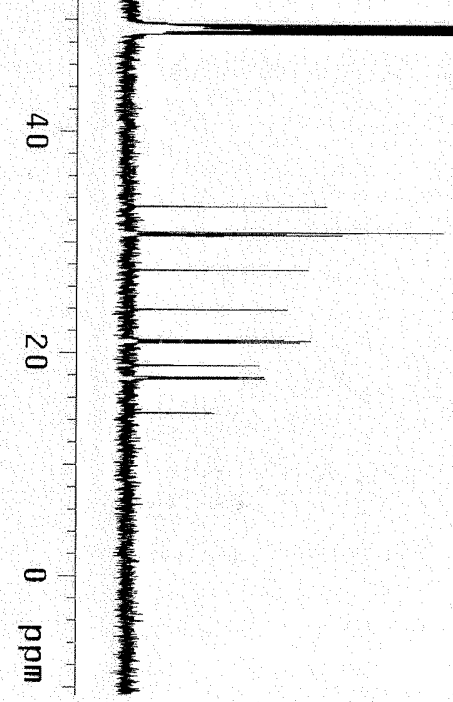



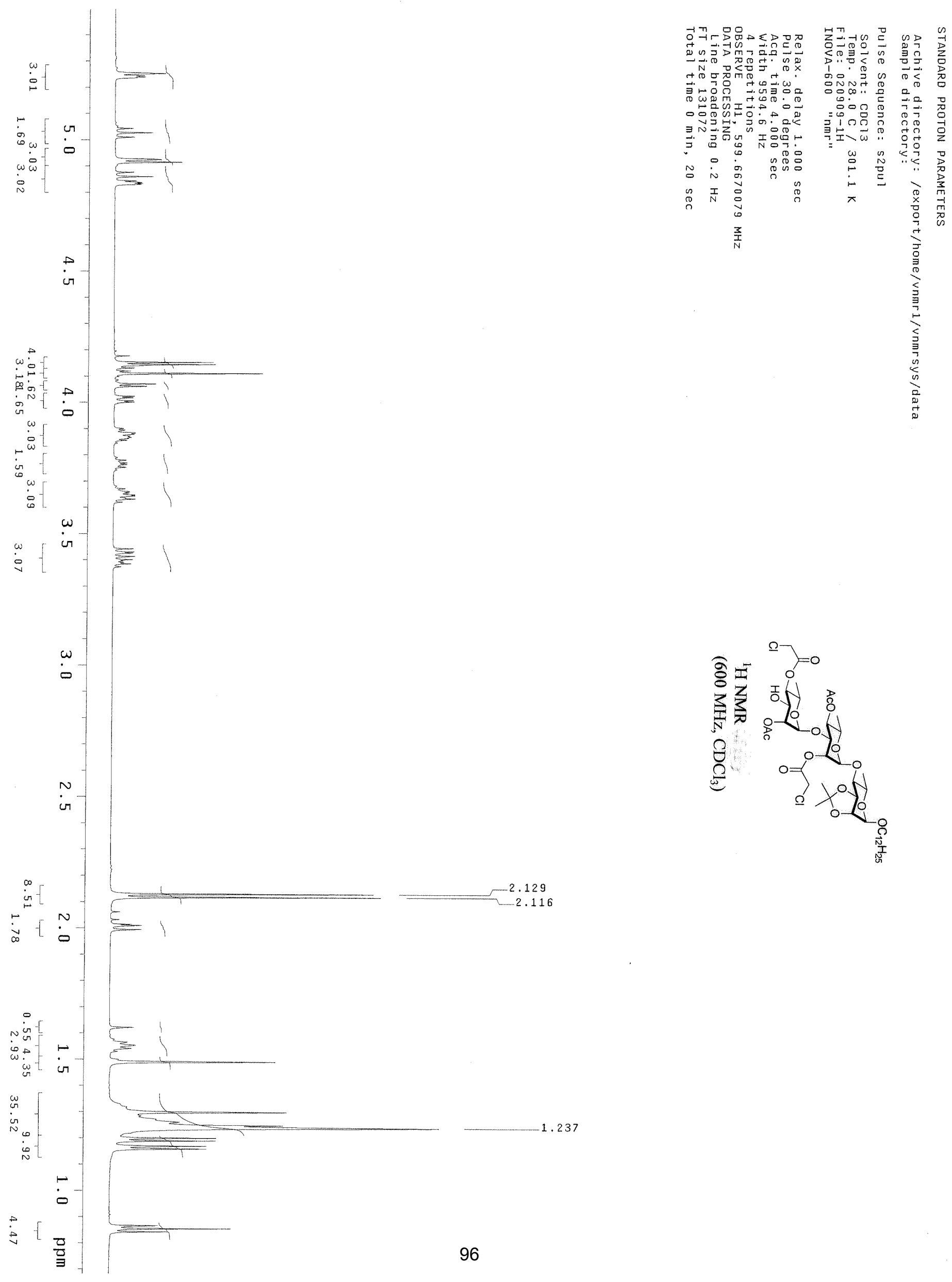

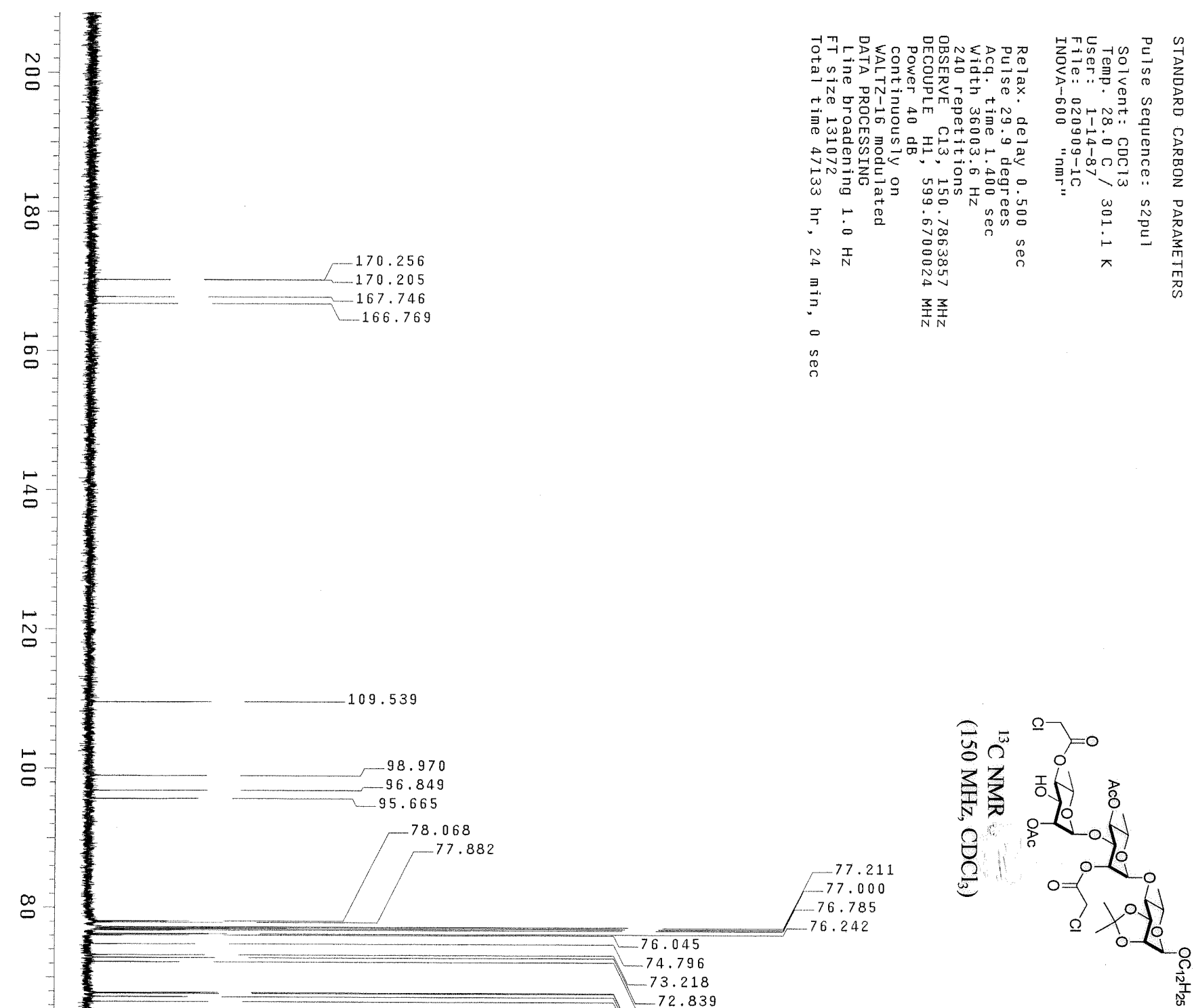


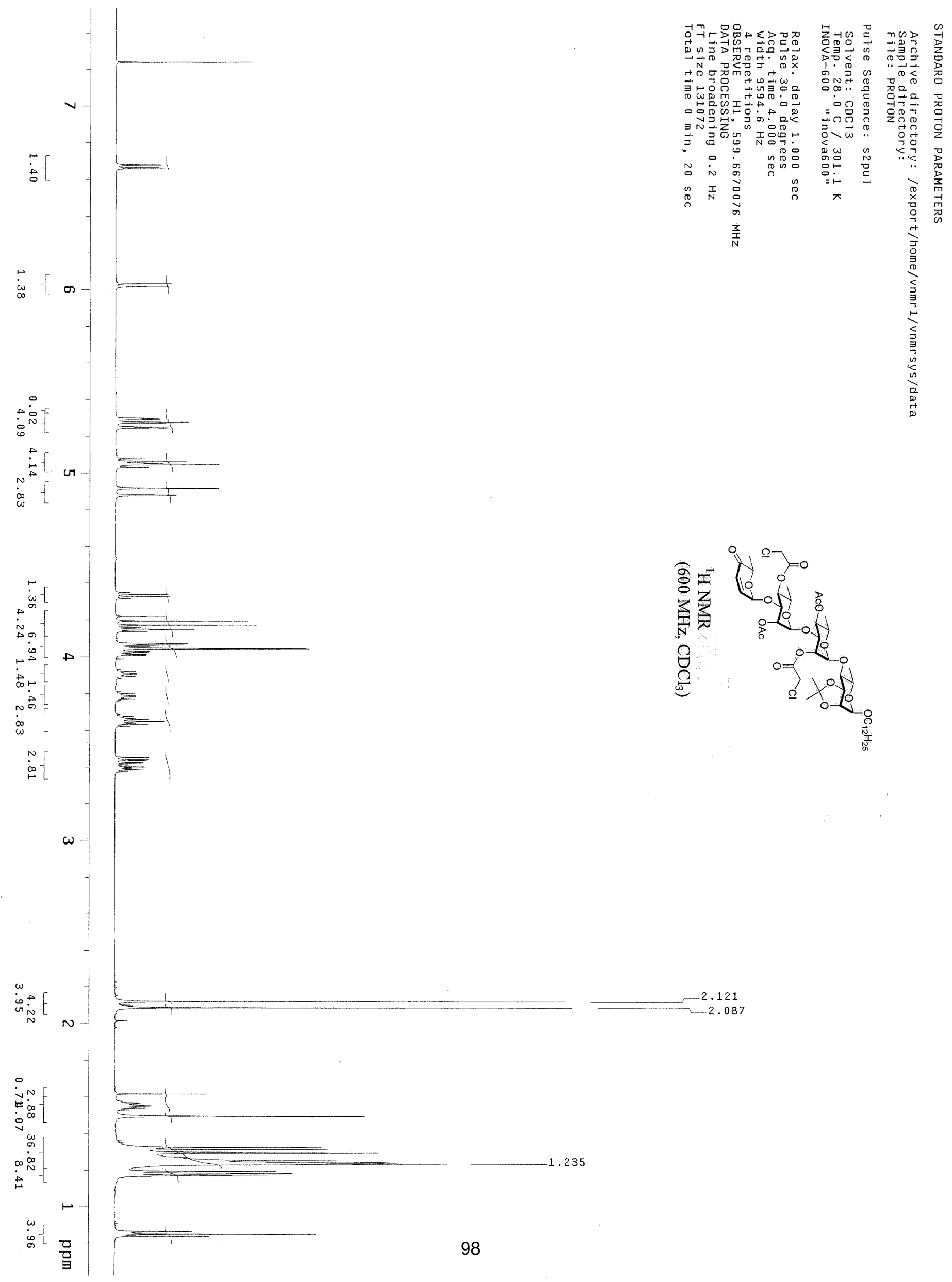




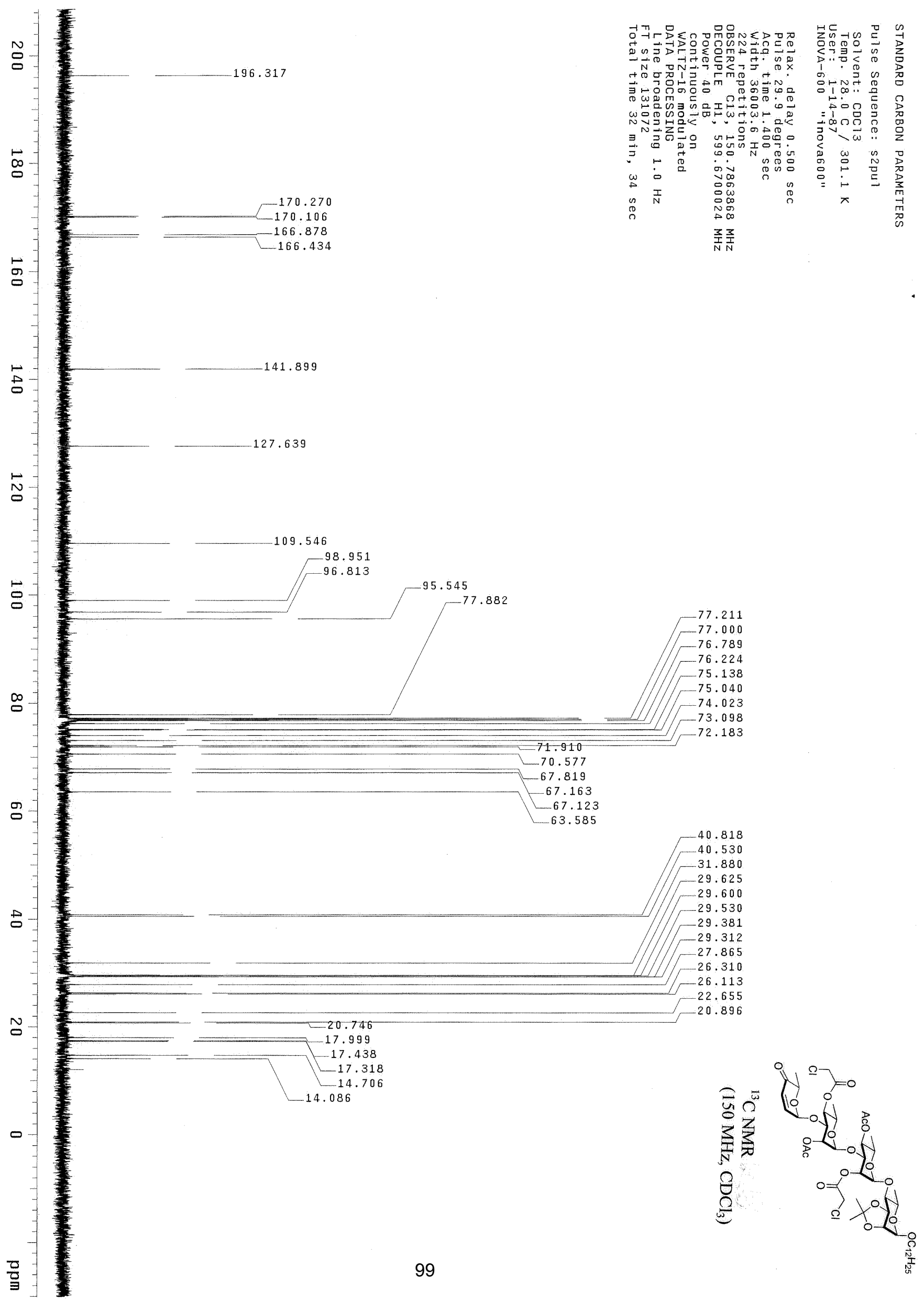




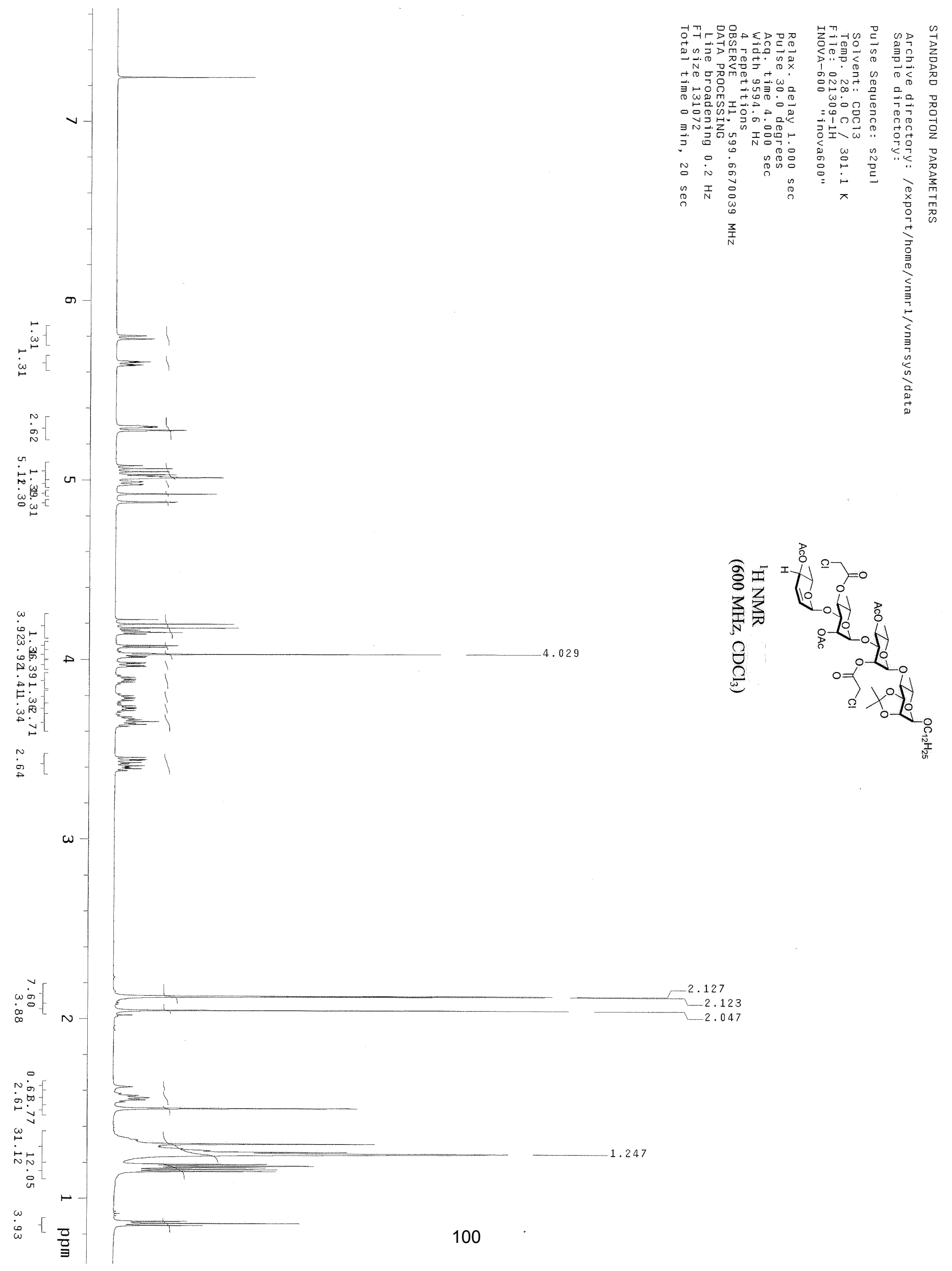



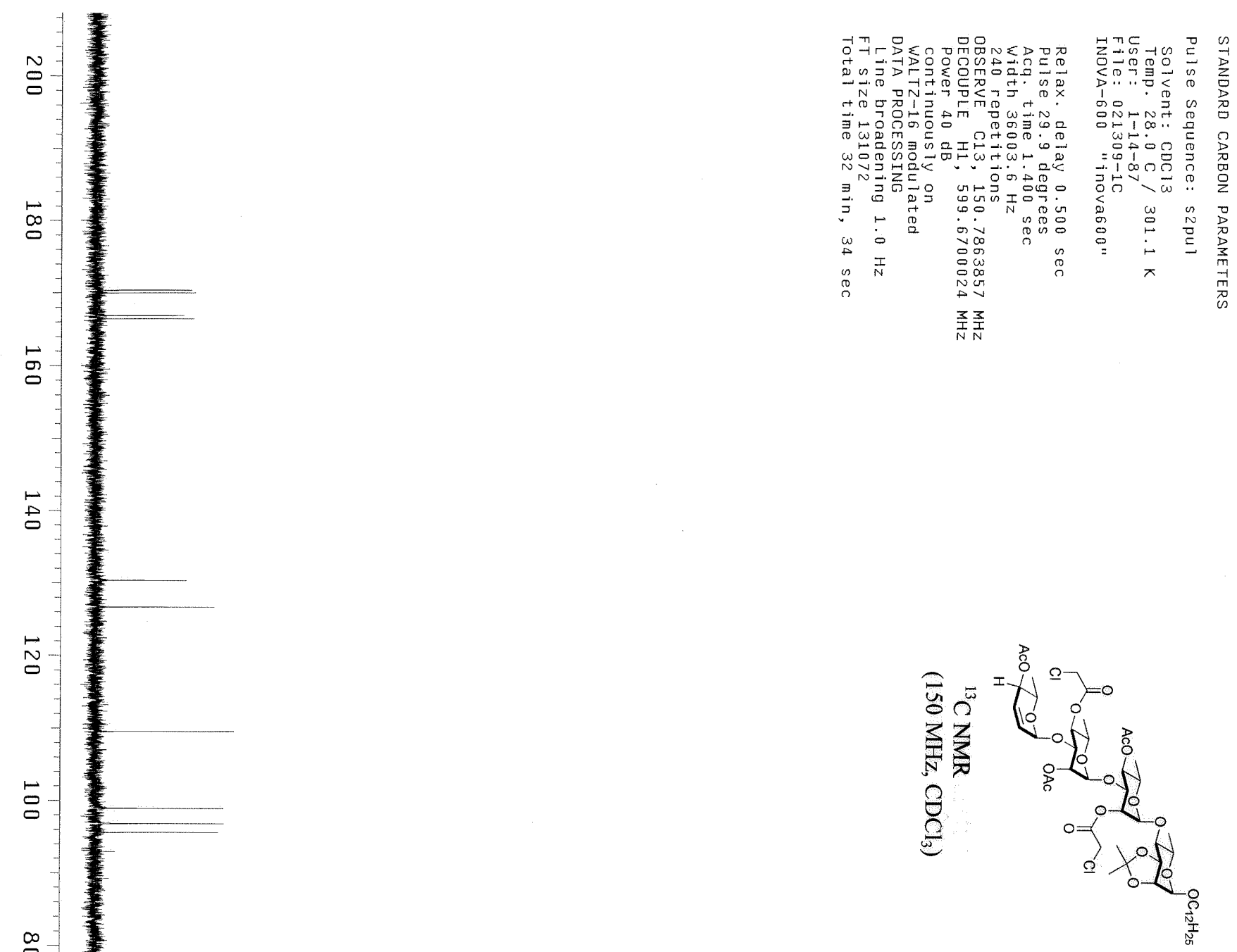

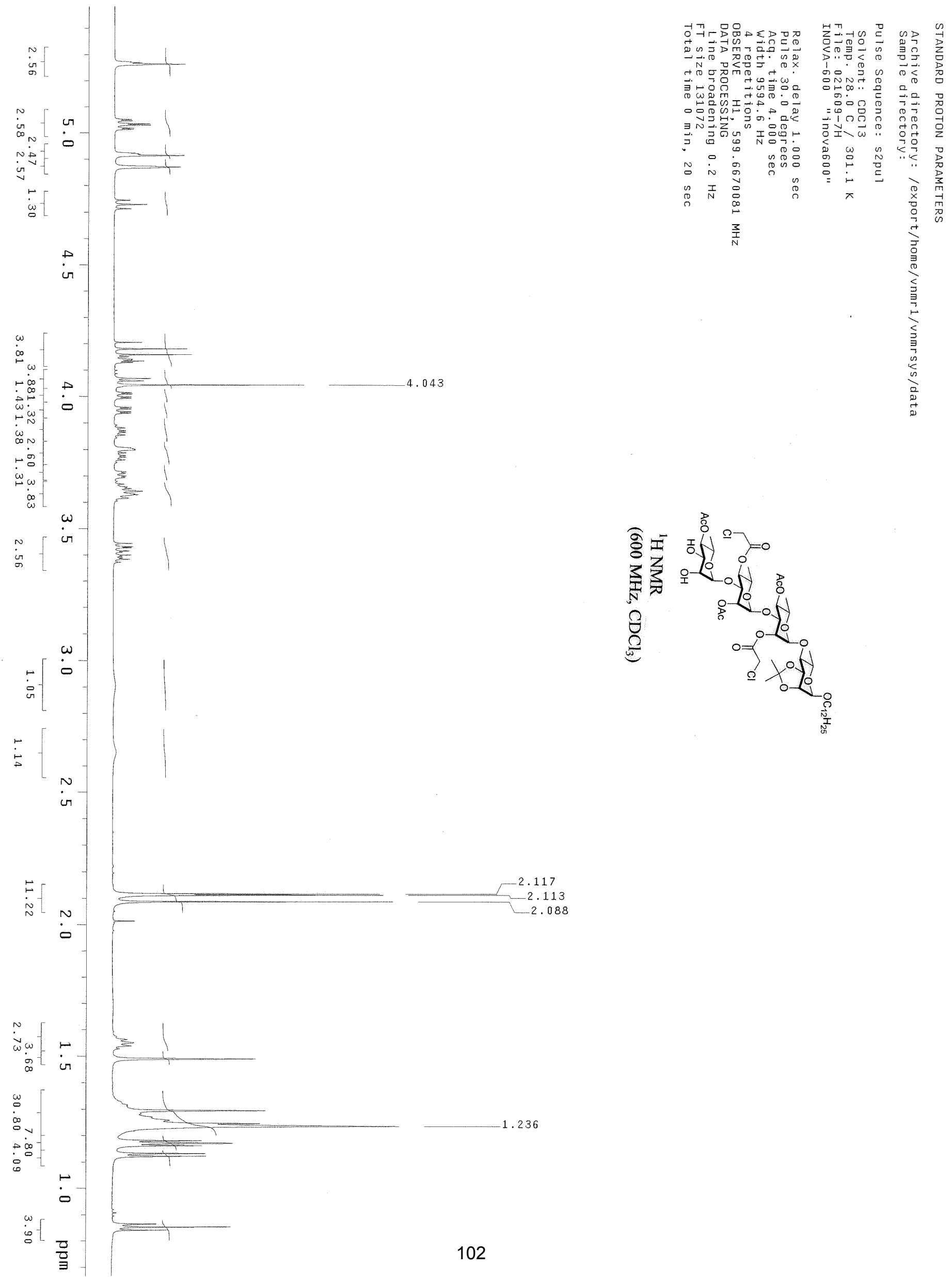

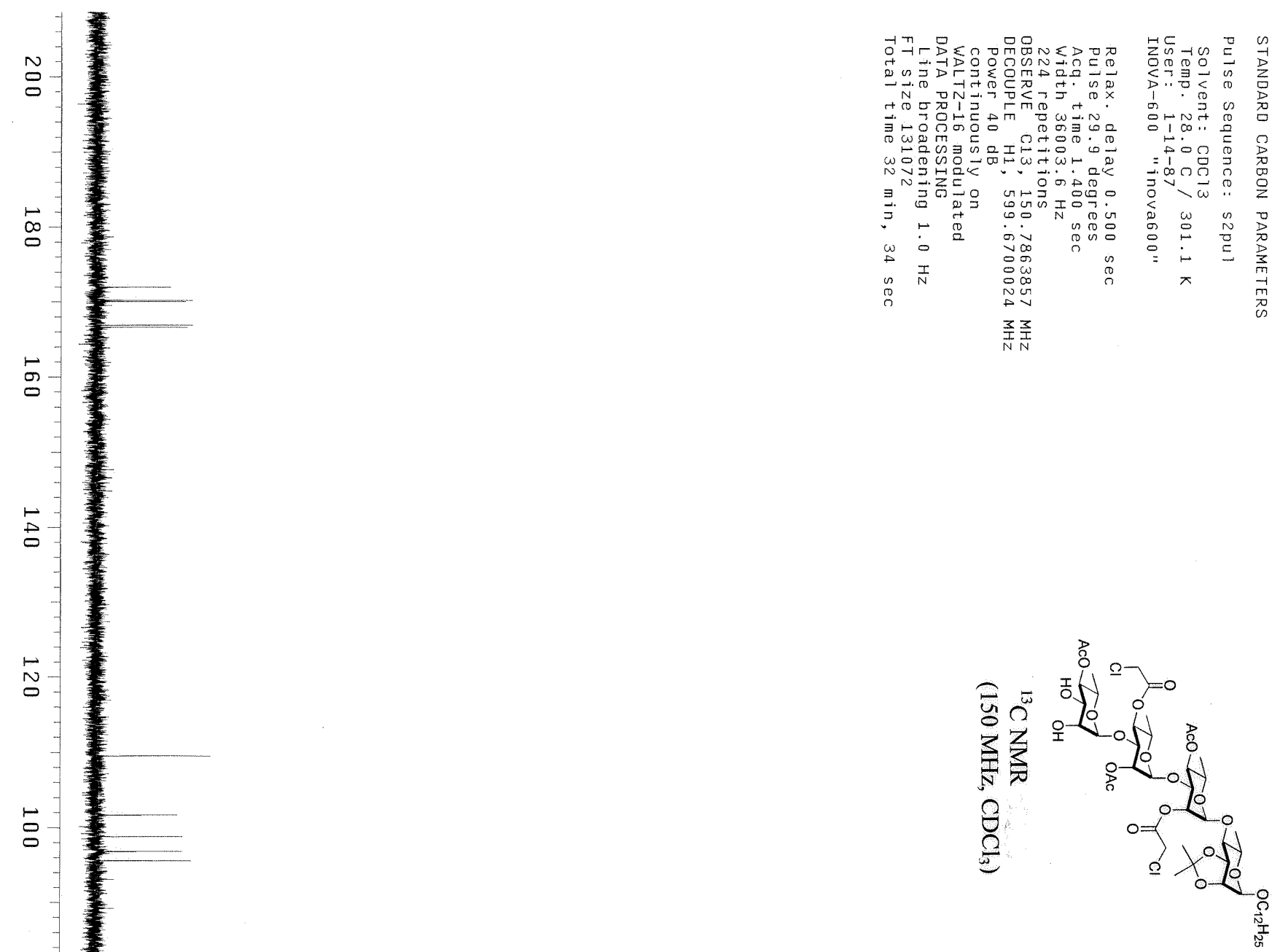


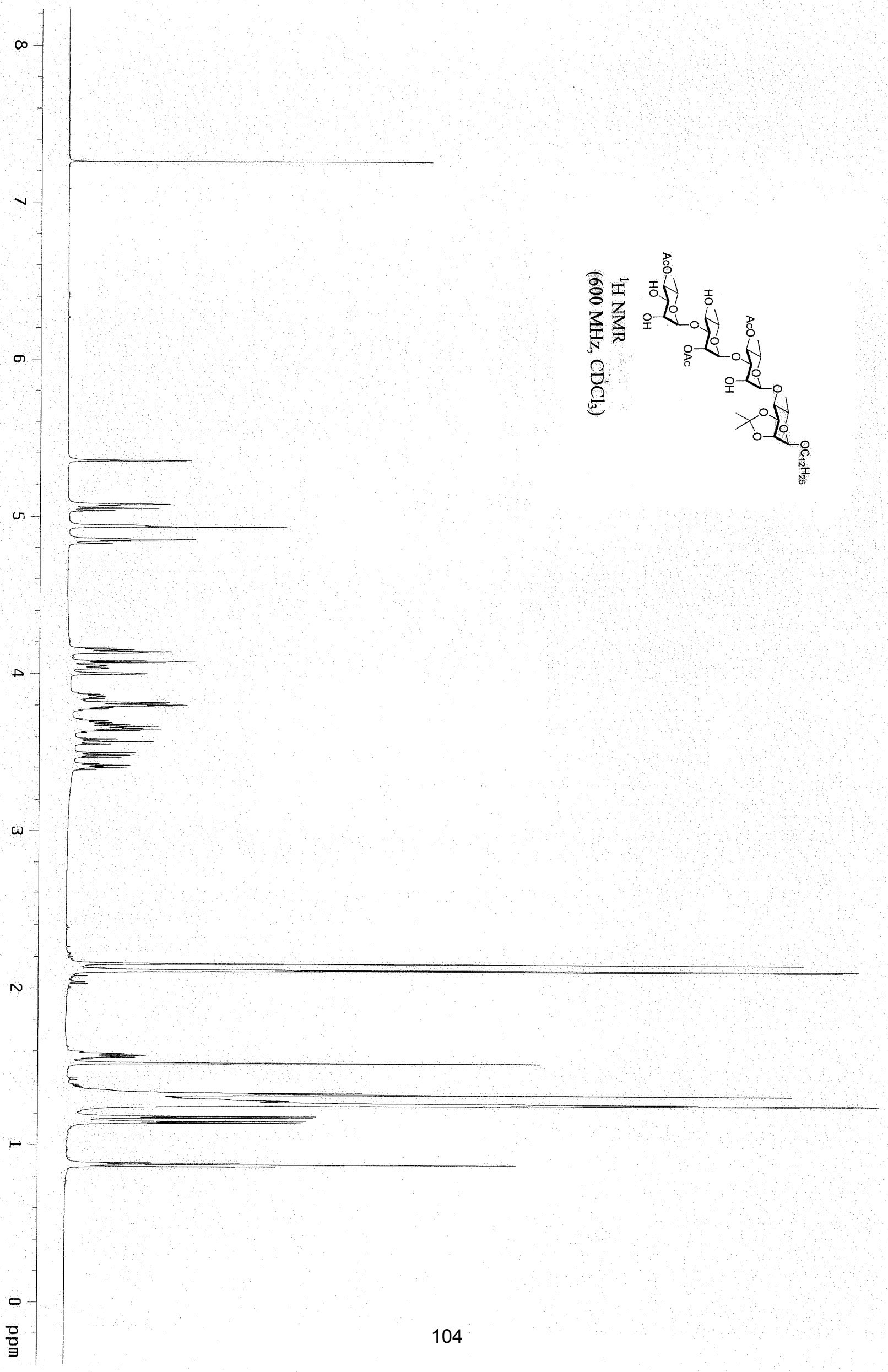




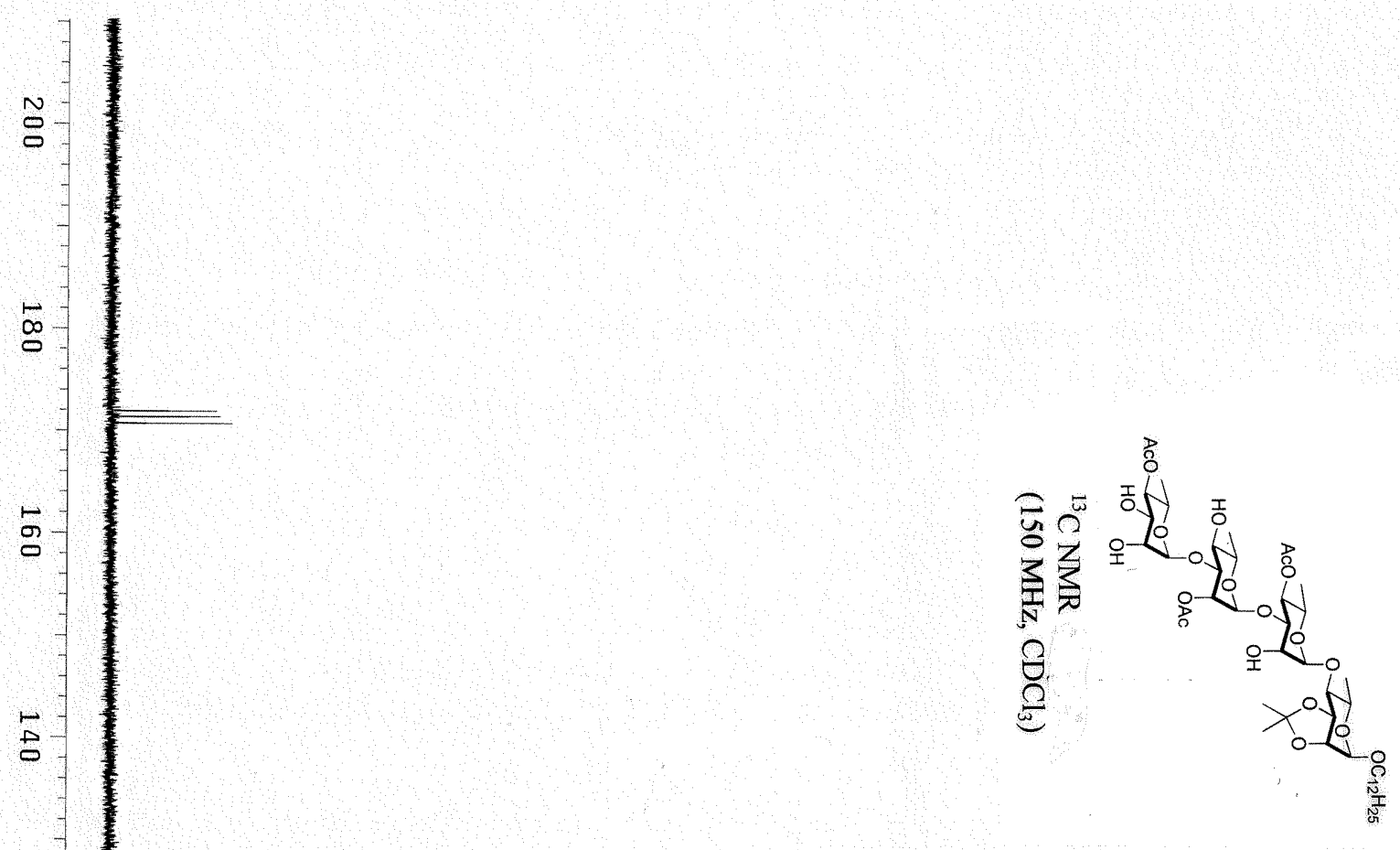

$\infty$

$\stackrel{5}{\circ}$

$\therefore$

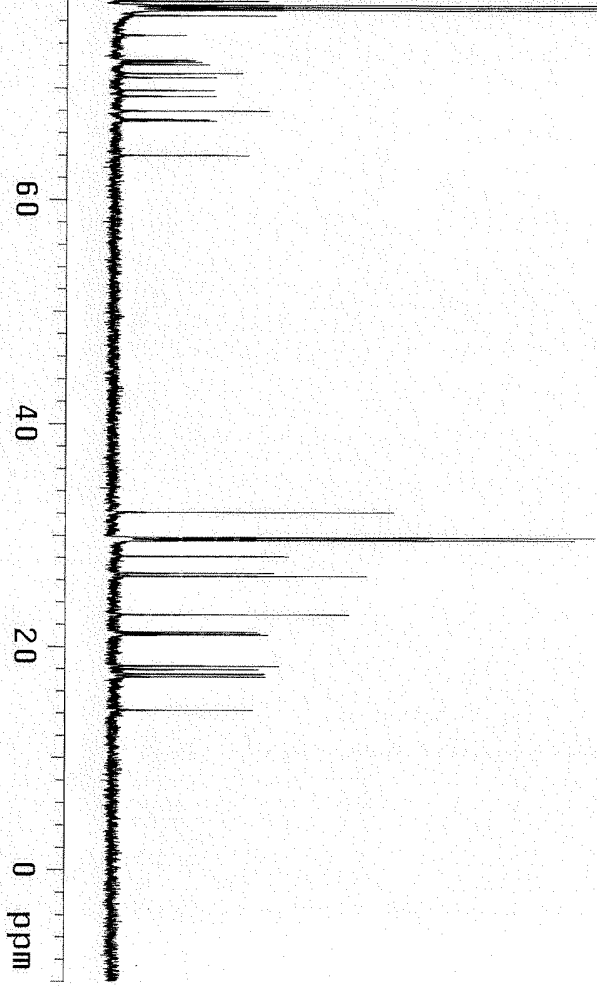




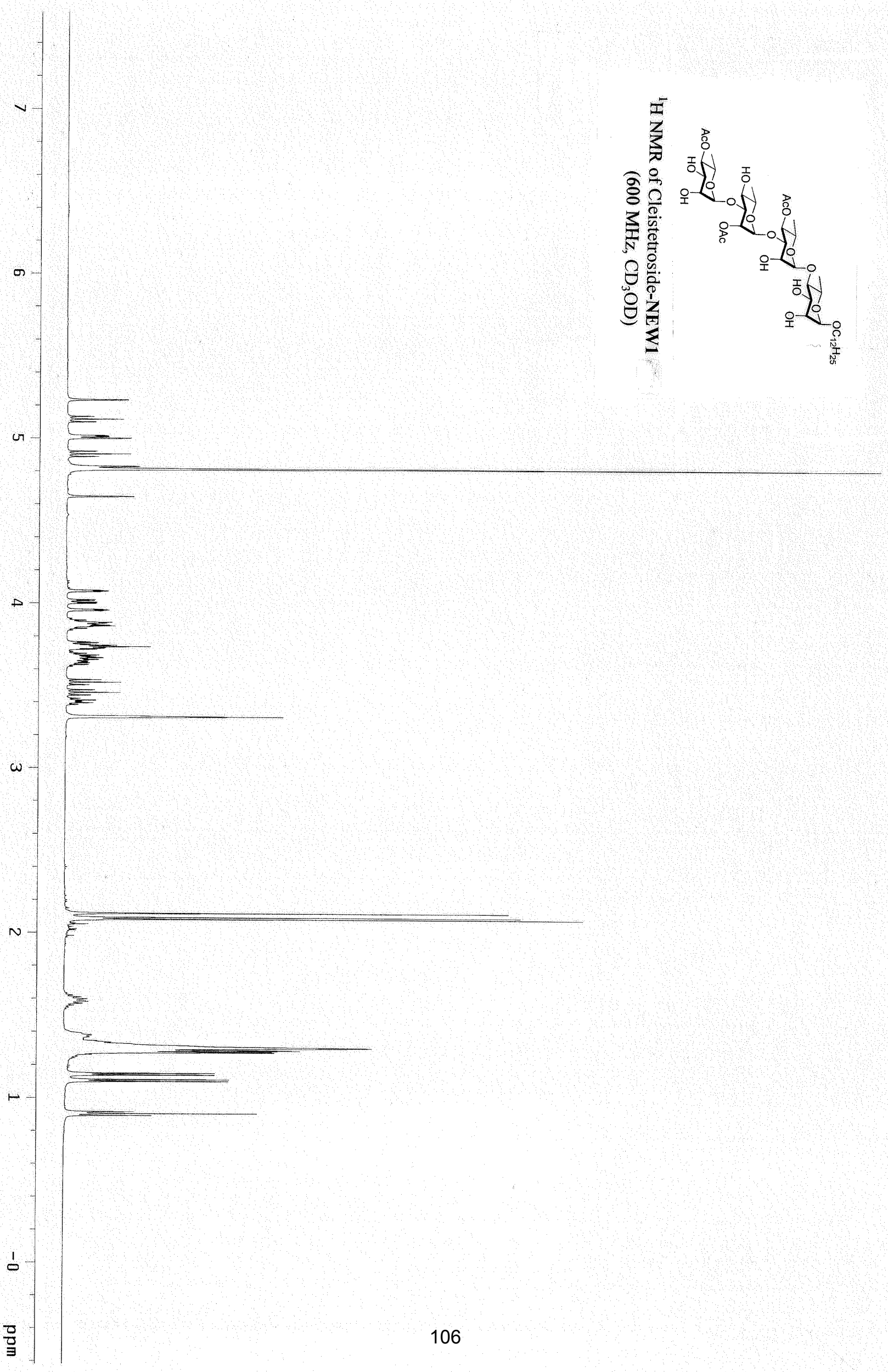




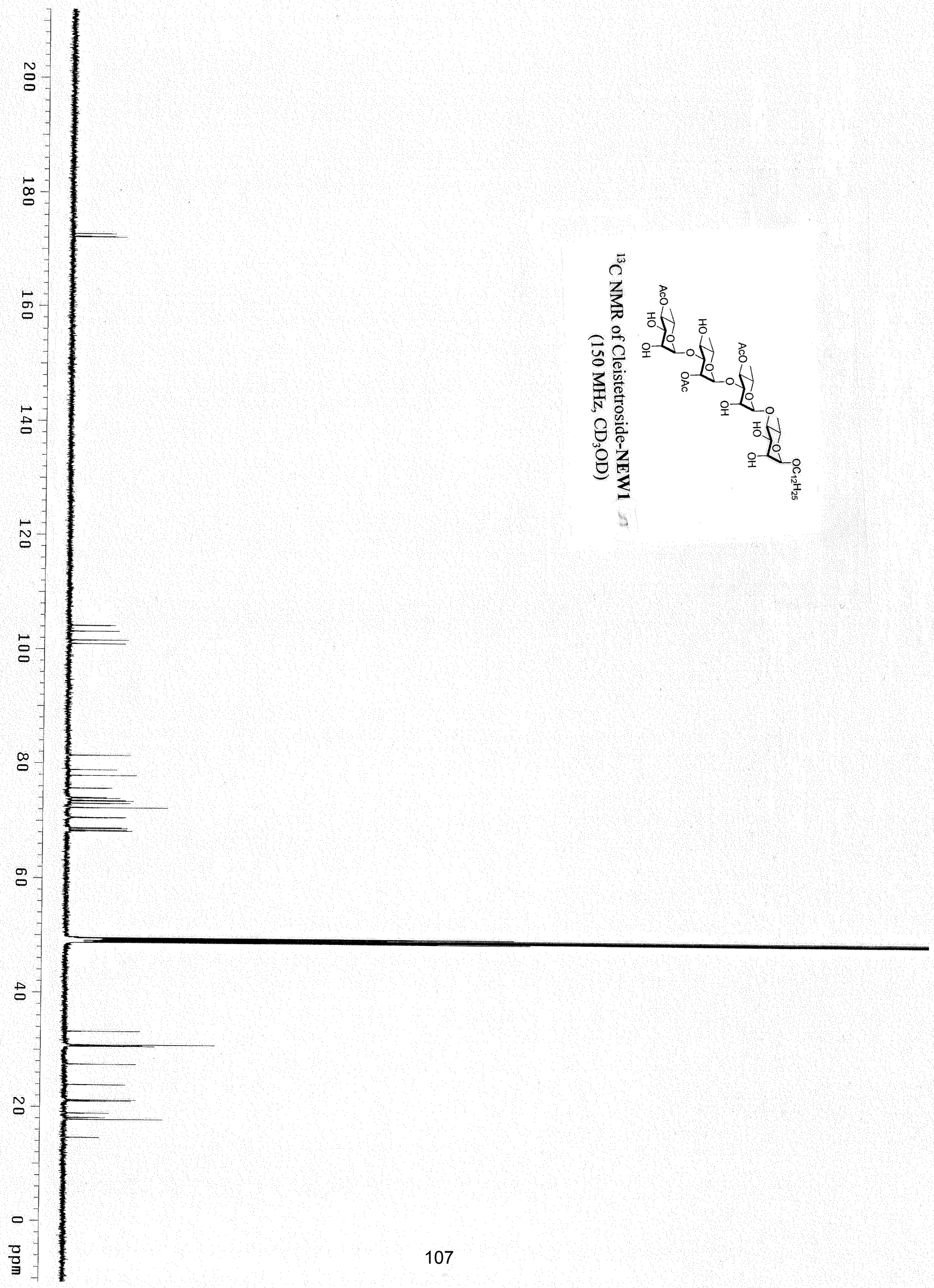




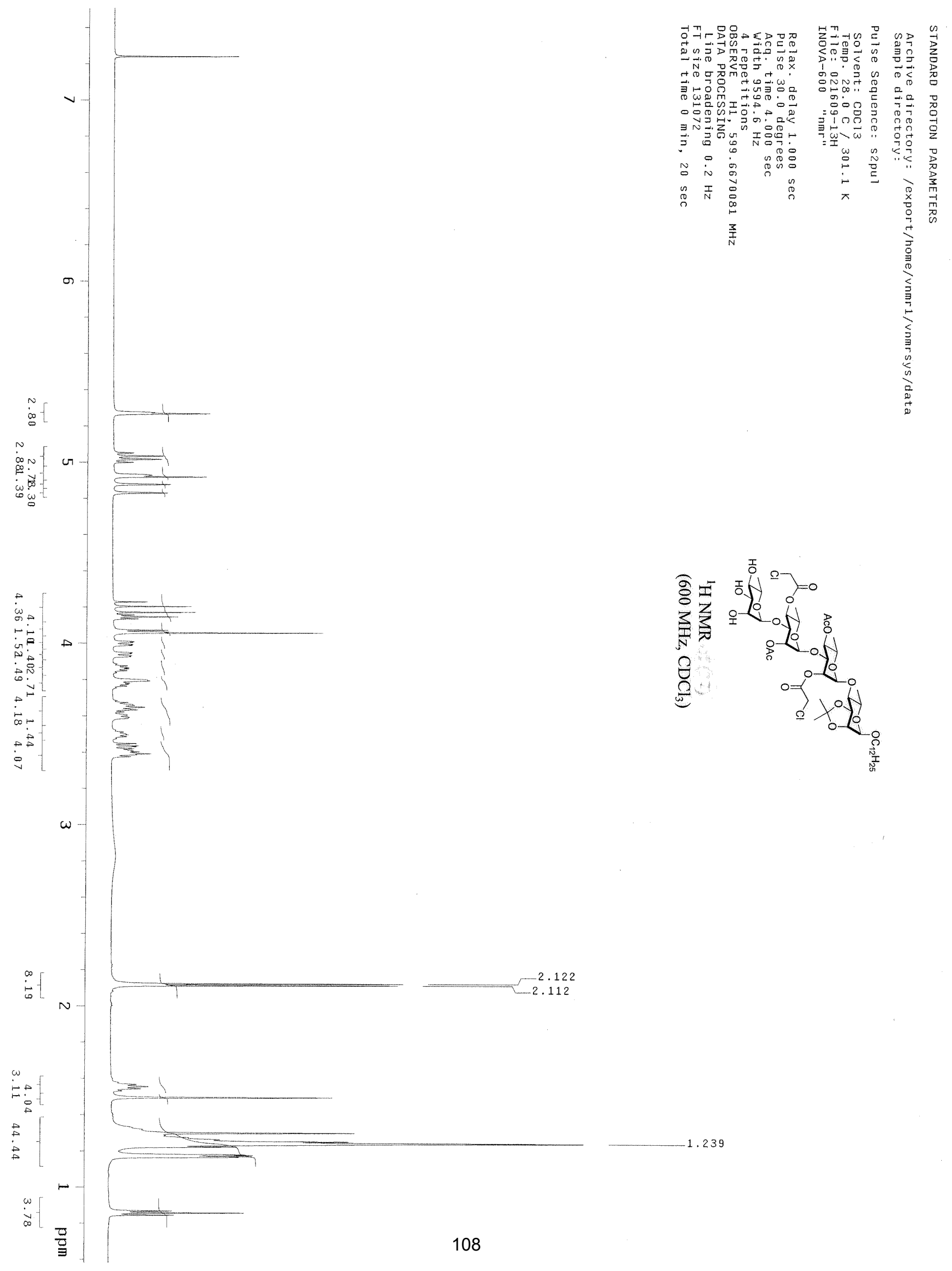



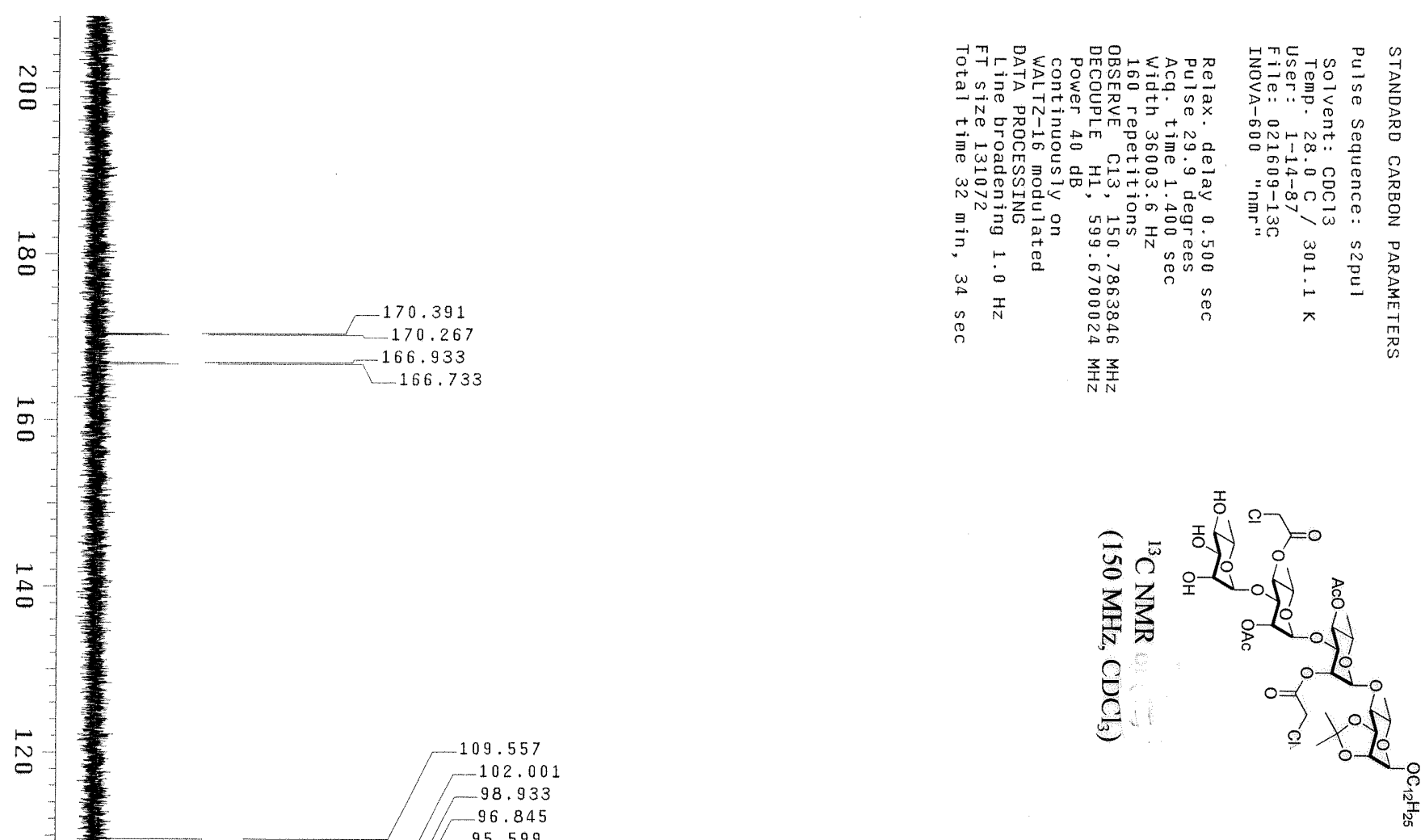

$\stackrel{\infty}{\infty}$

$\stackrel{N}{v}$

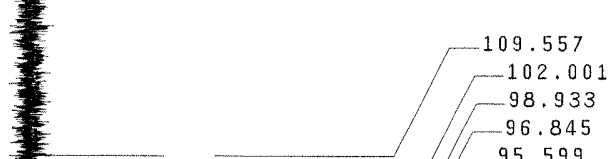

$\stackrel{\circ}{\circ}$

응

$\vec{B}$

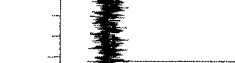

$-102.001$

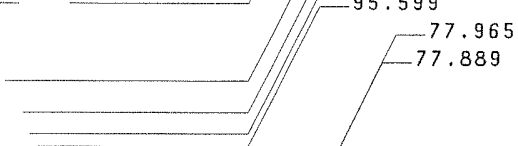

g

残

8

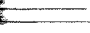

.
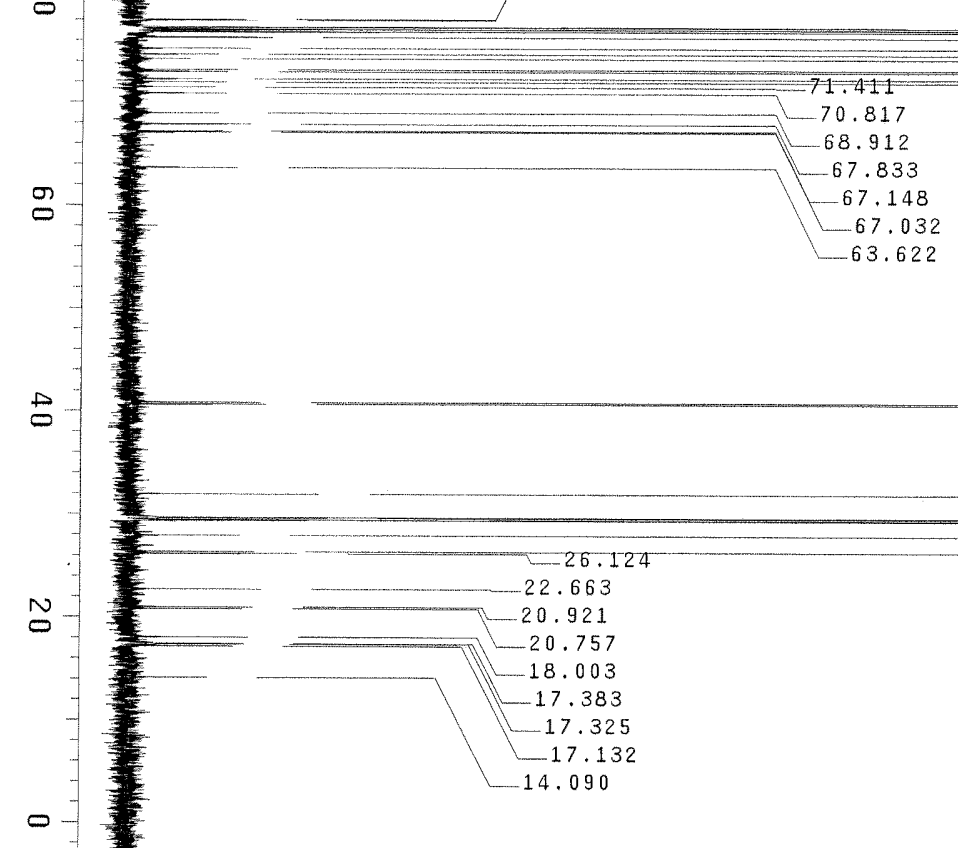

-
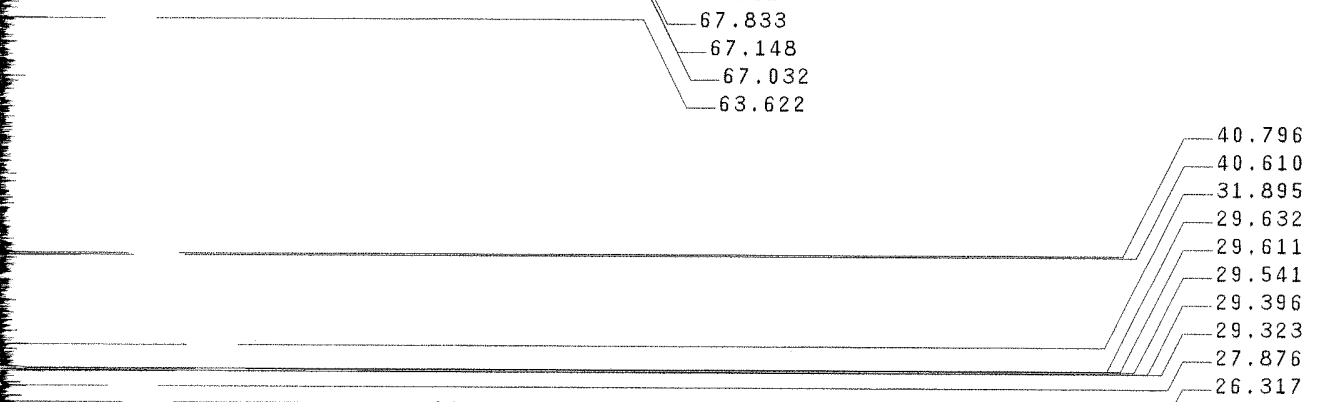

总 


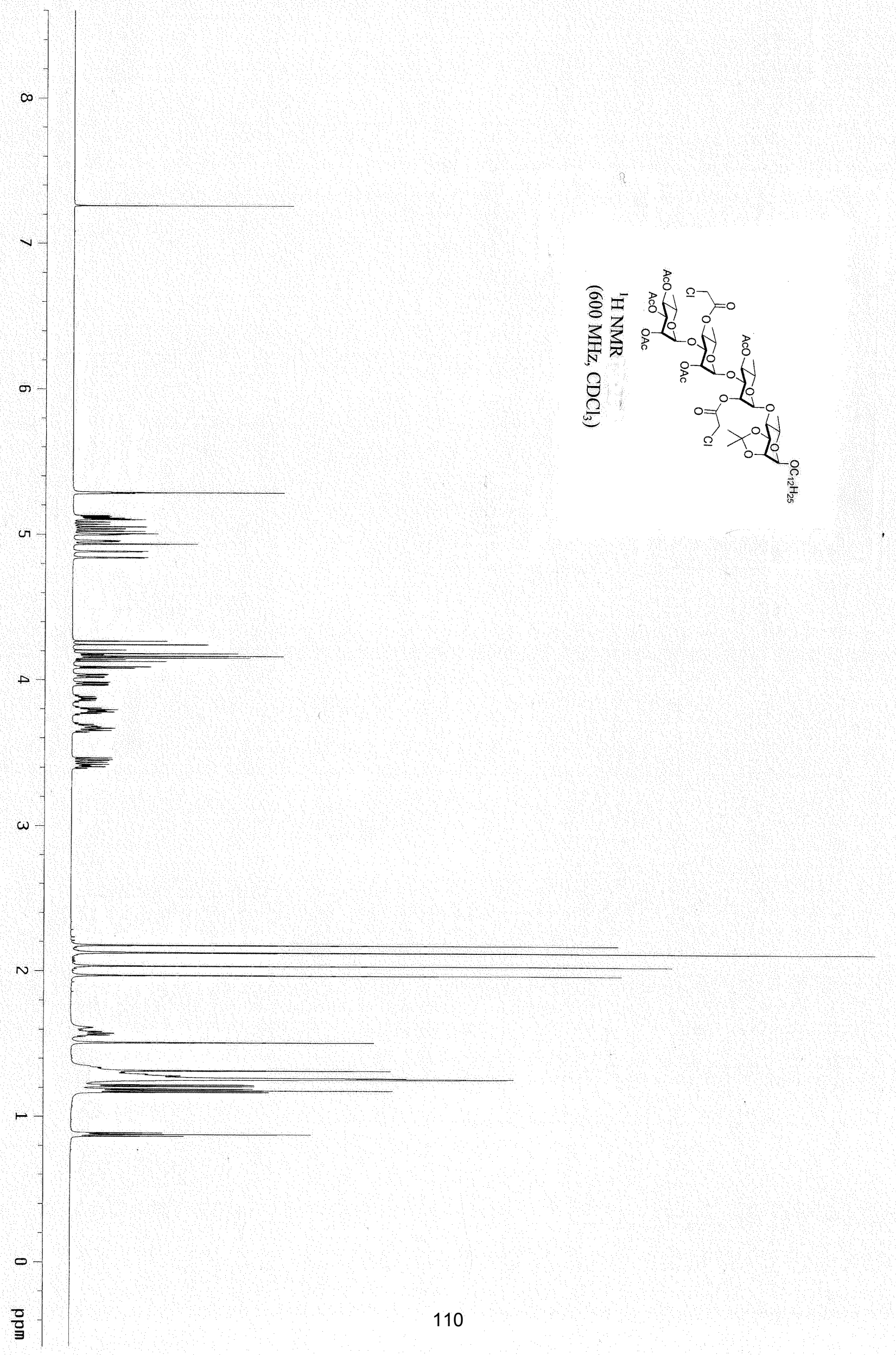




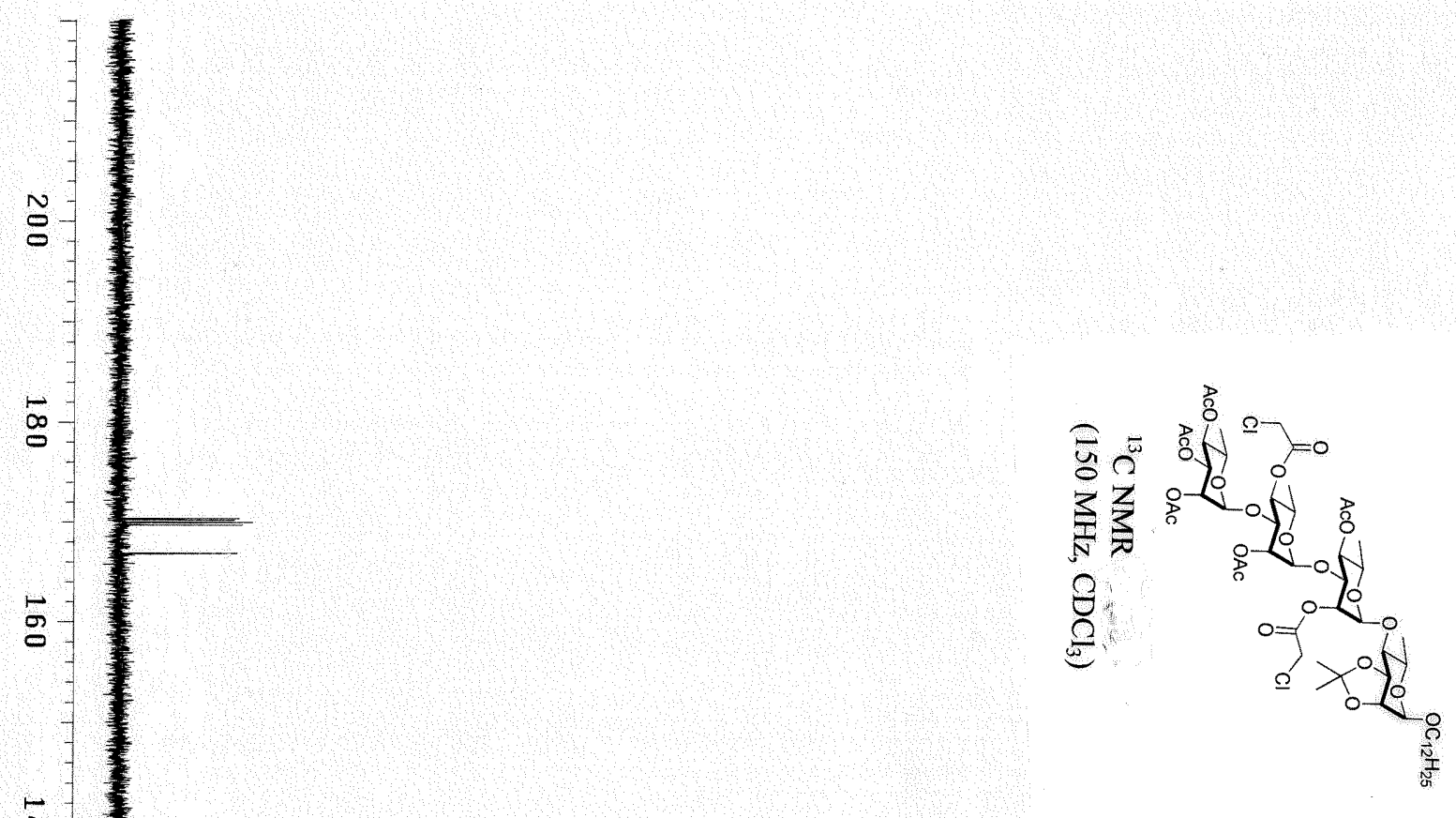




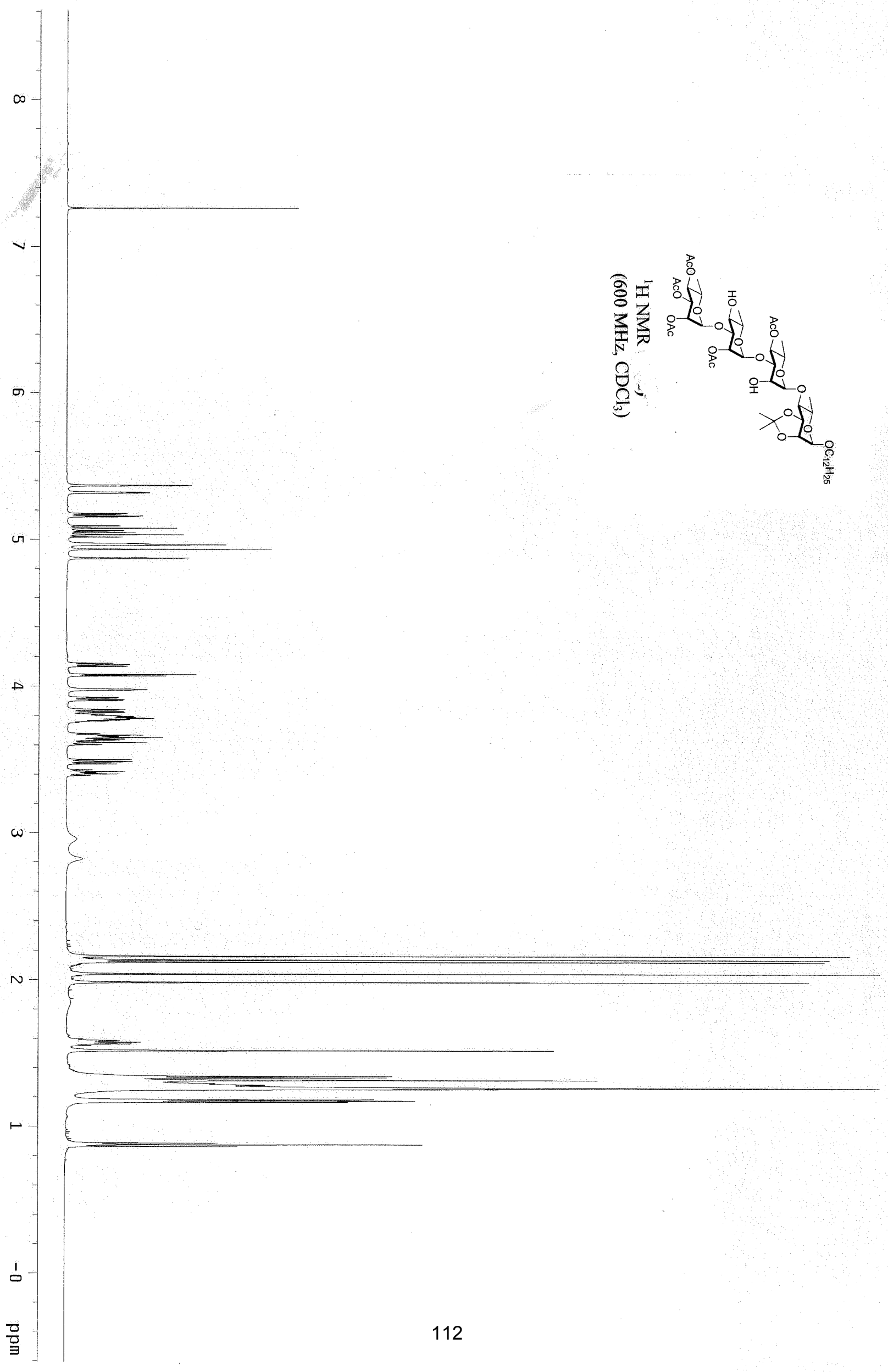




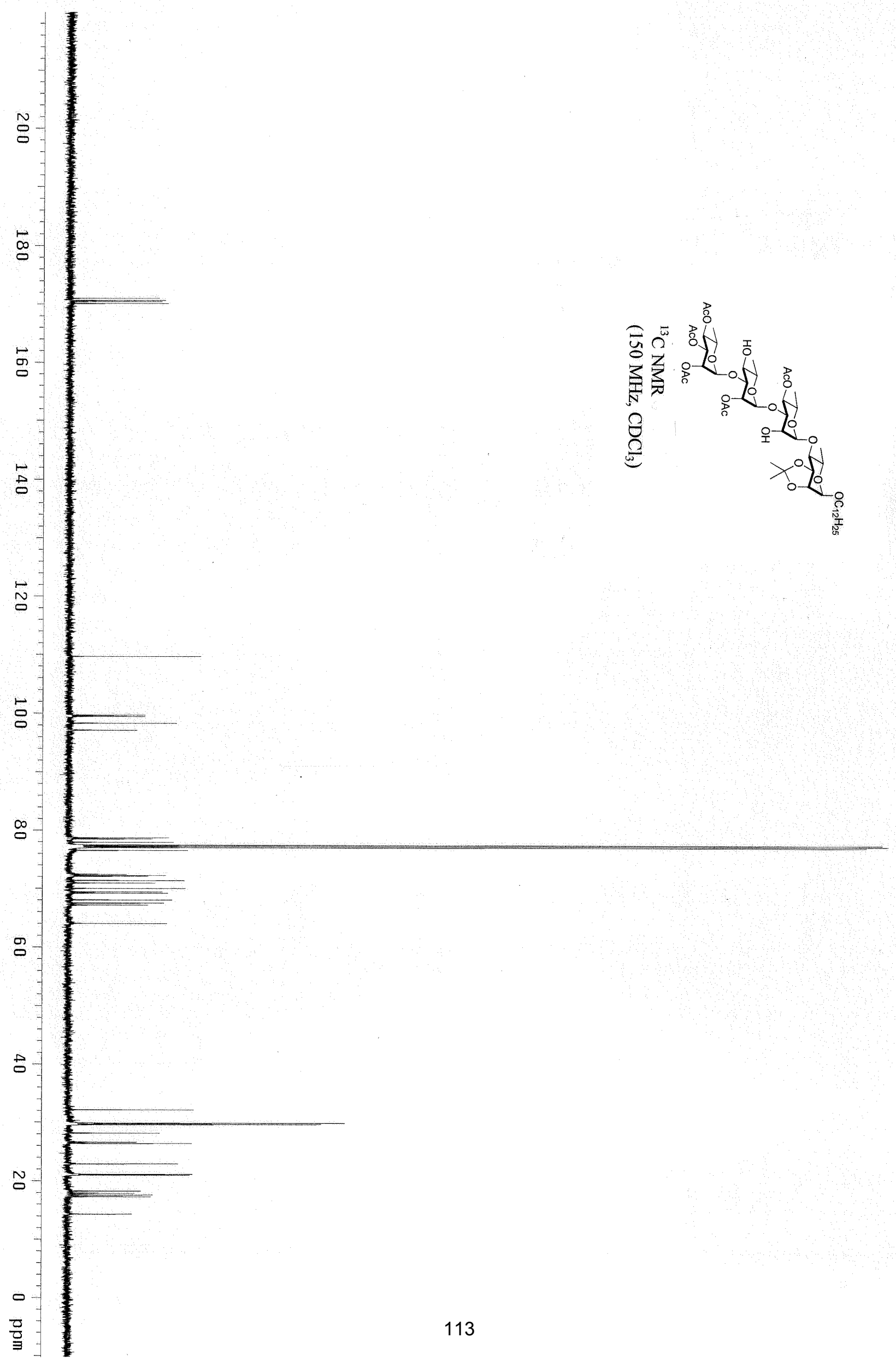




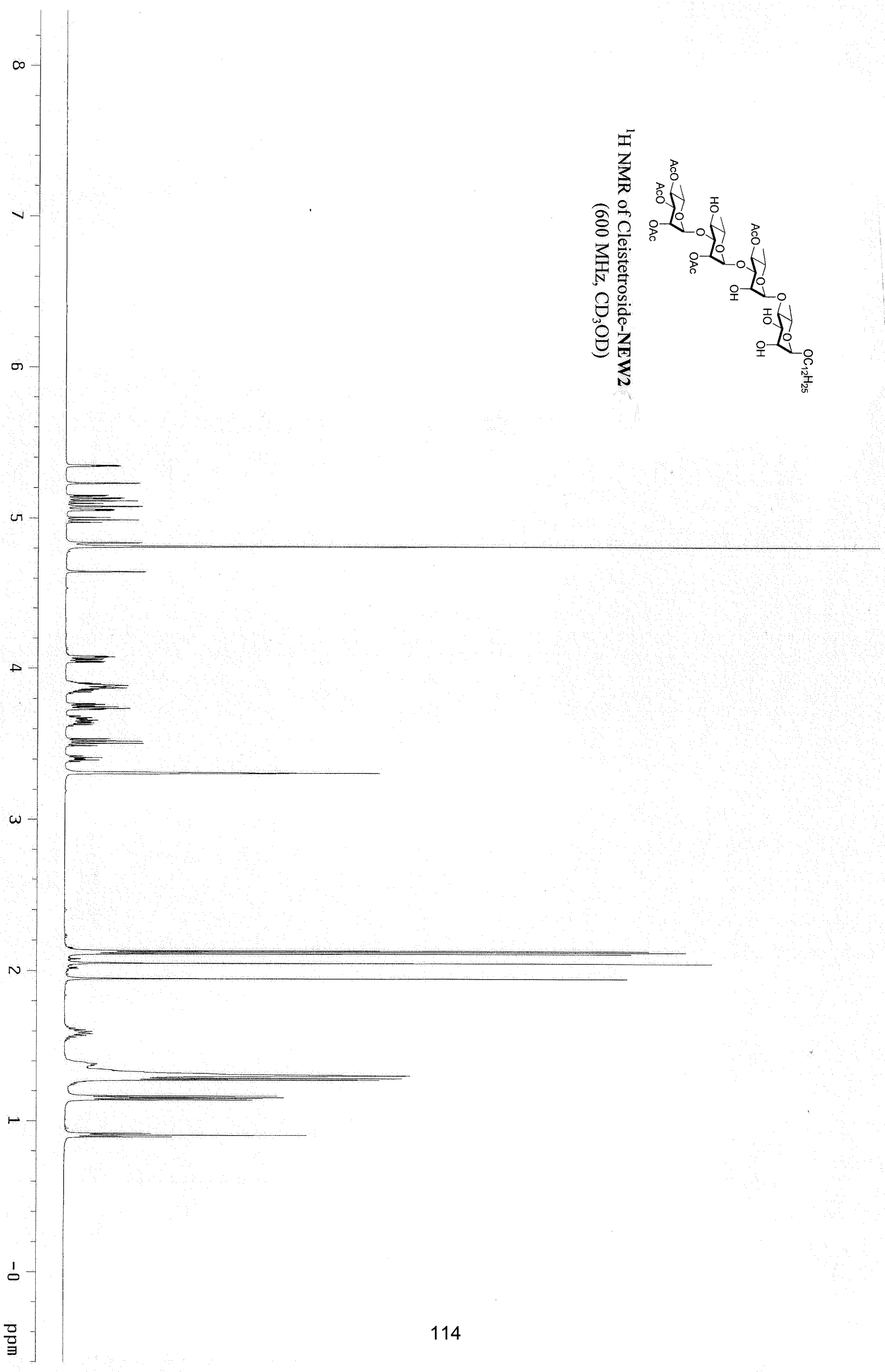




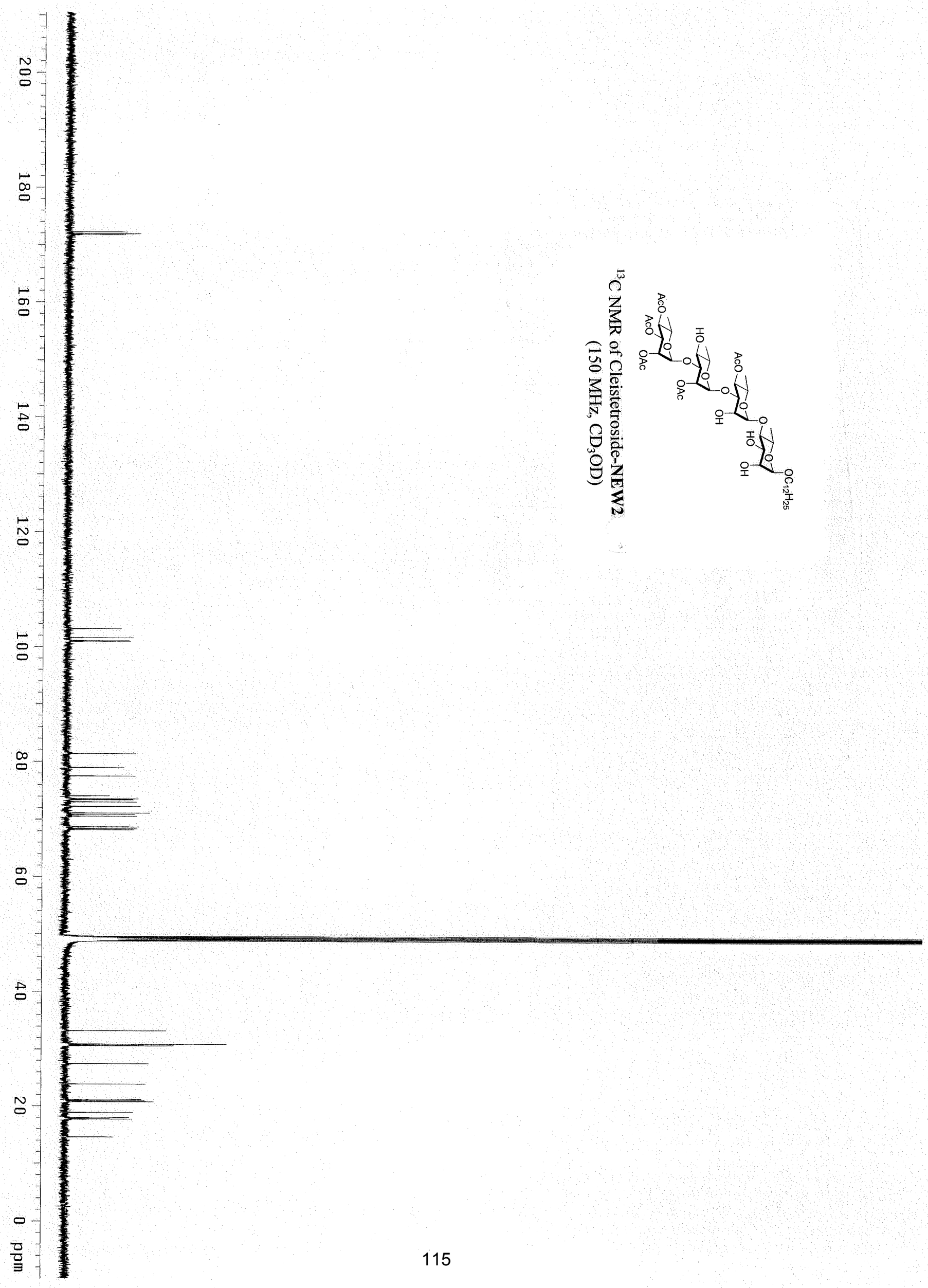




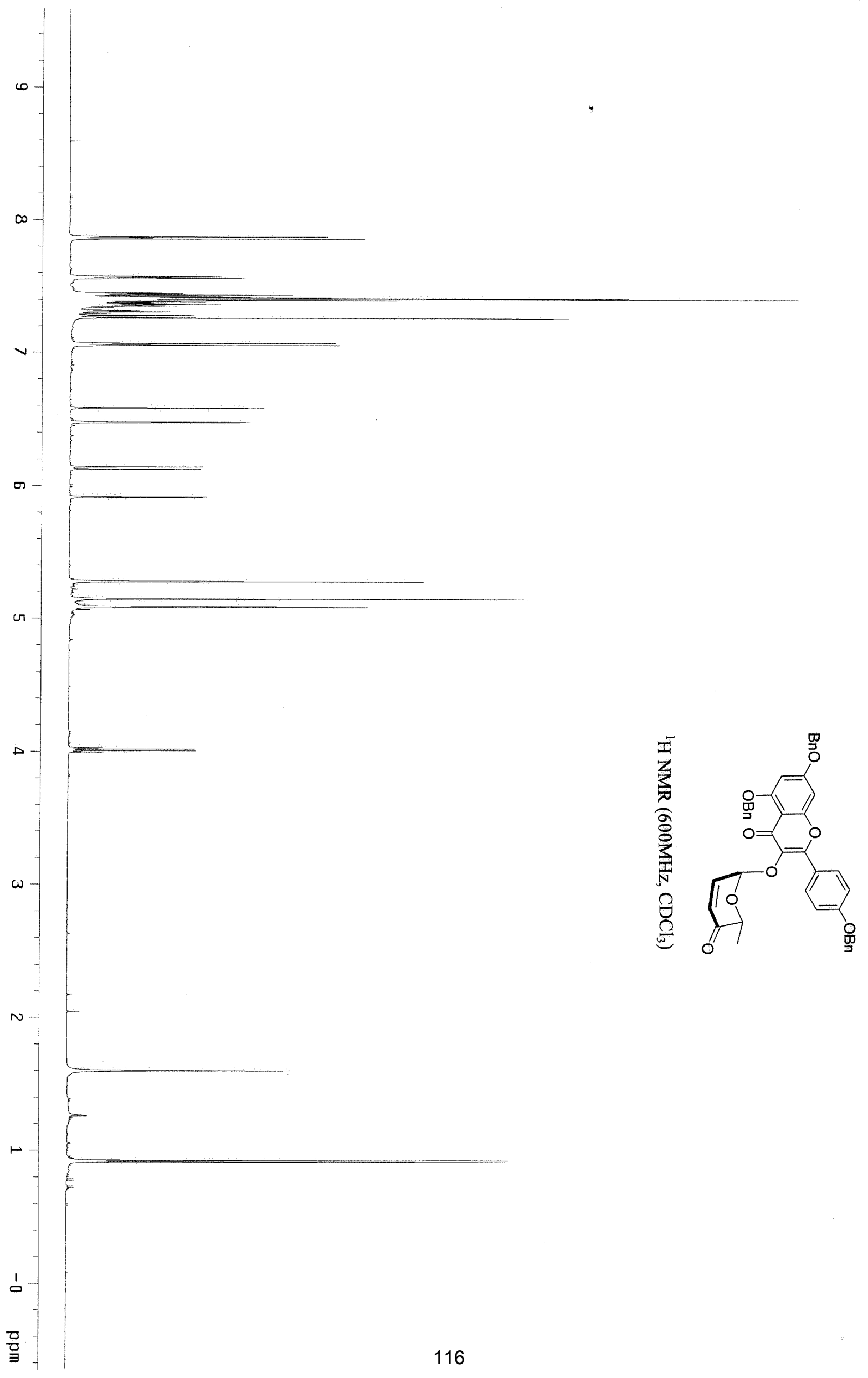




$$
\text { | " }
$$



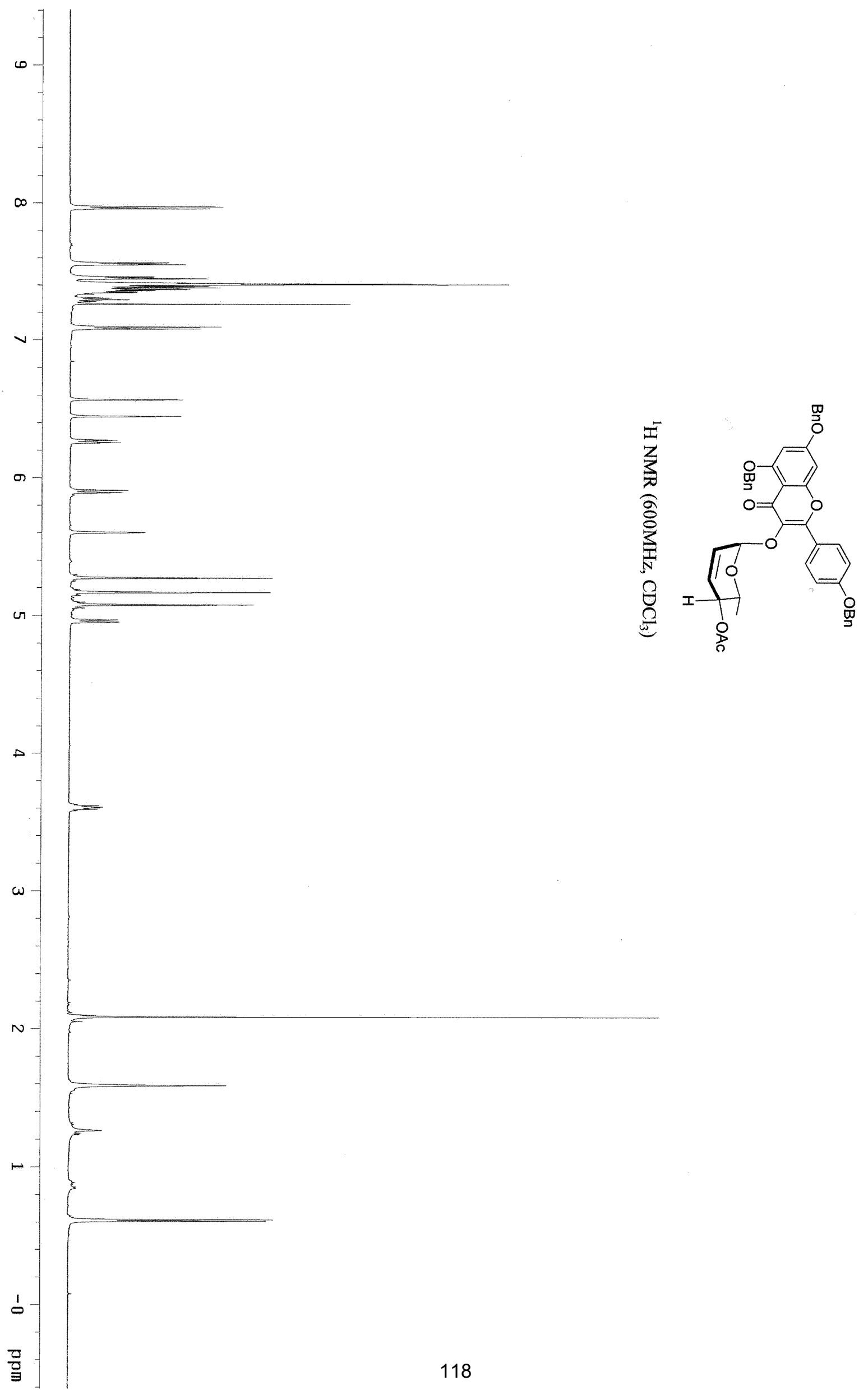


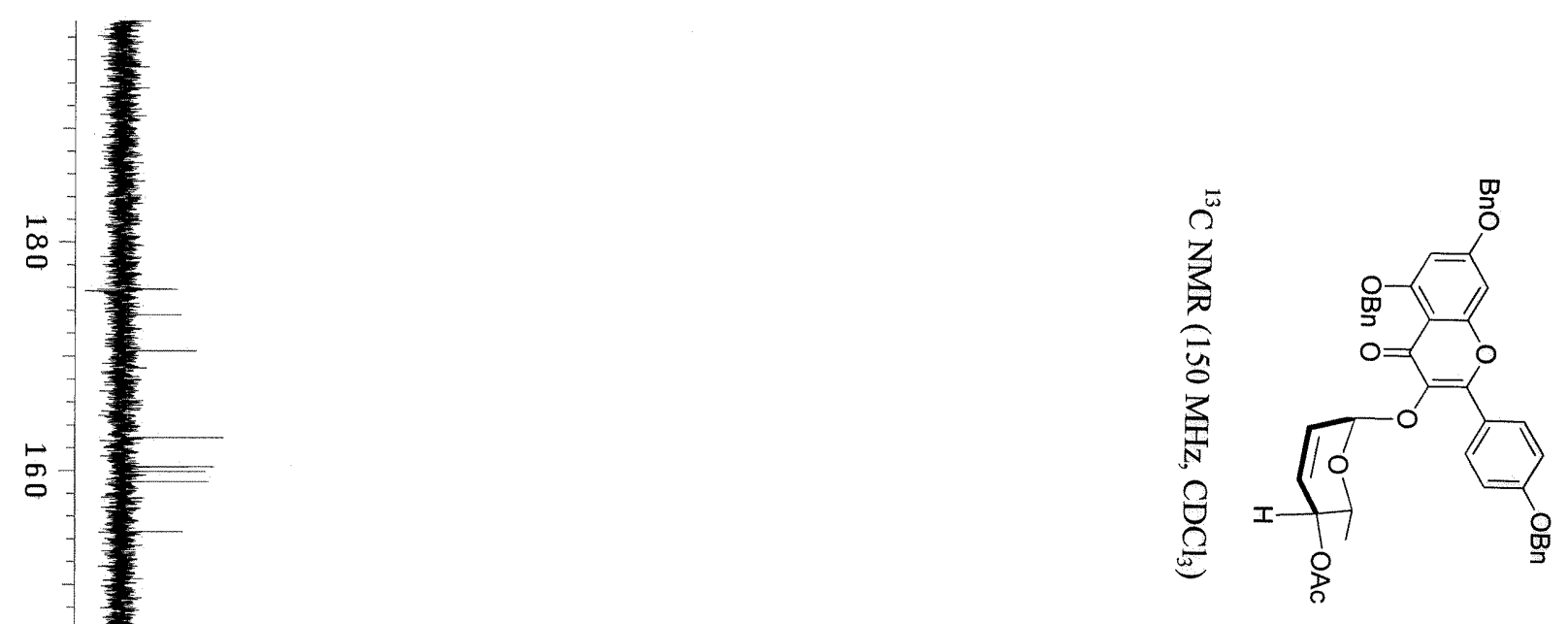

$\stackrel{\square}{\square}$

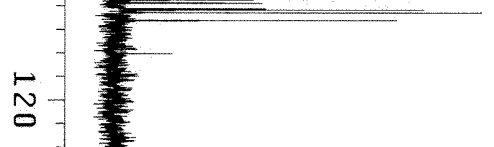

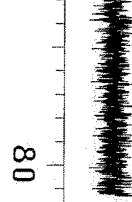

s.

g

$-$

.

ㄱ

$-$

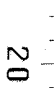

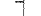

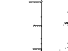

.

it

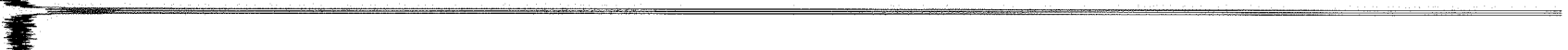

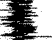

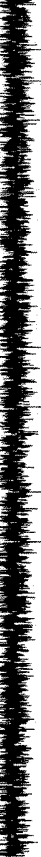




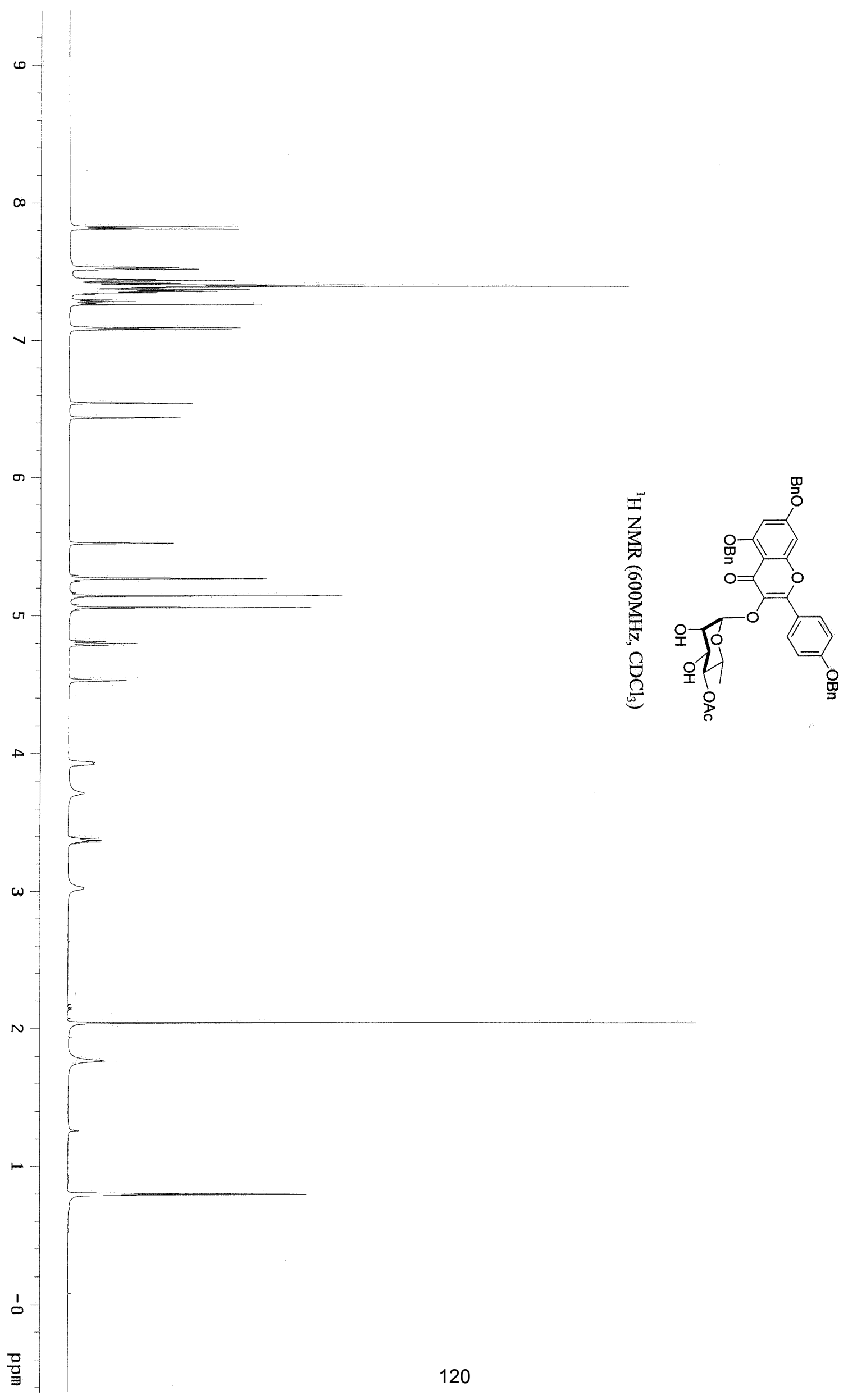




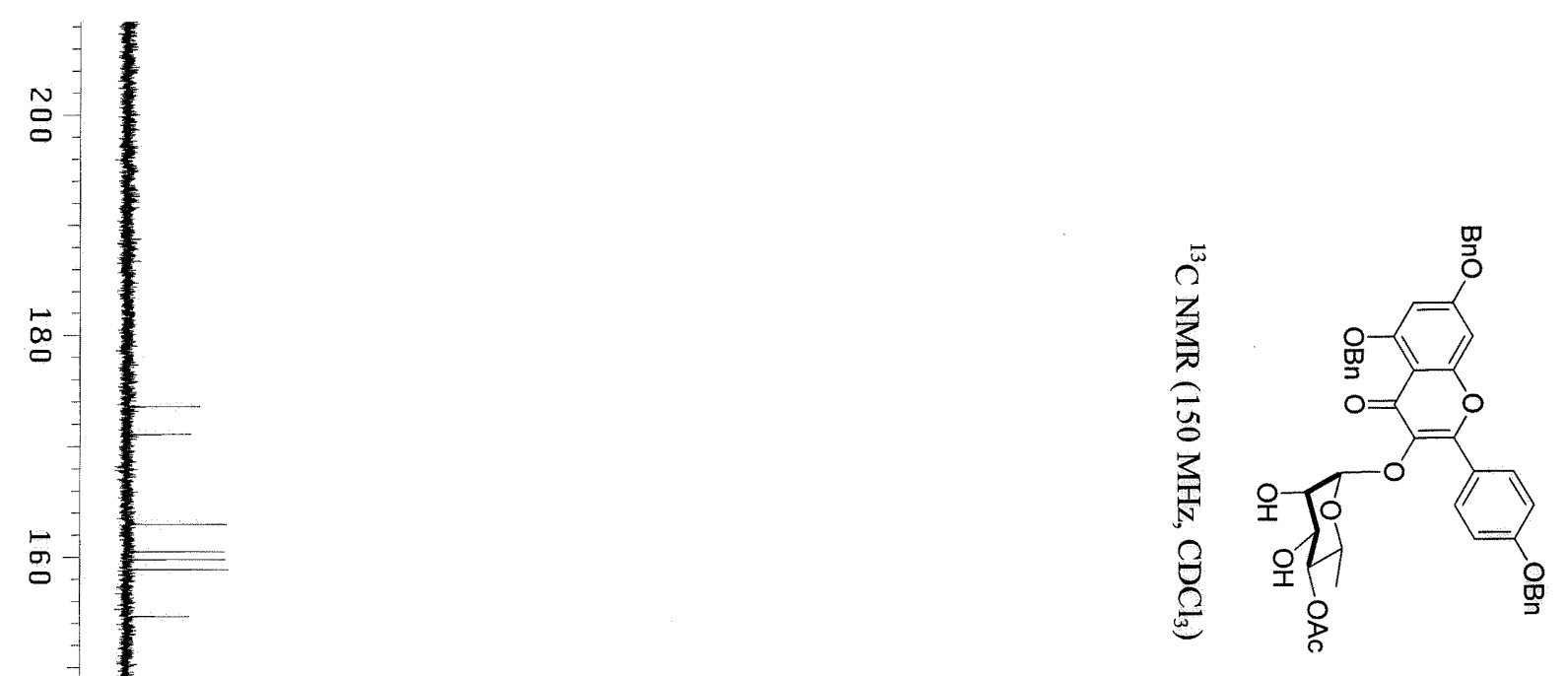

点

5

客

味
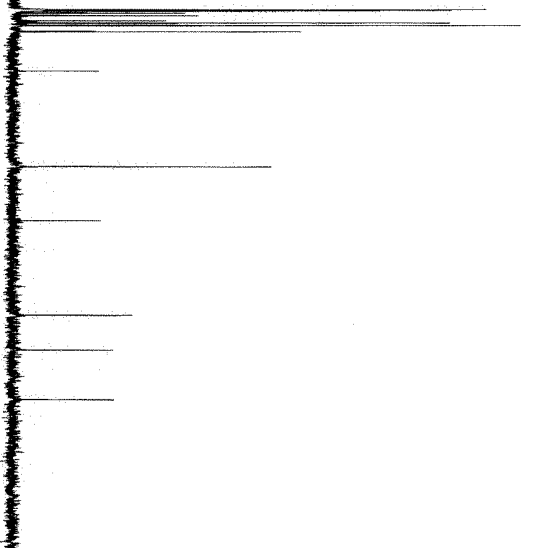

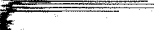

g-

$8-1$ $=$

$N=$

D

1

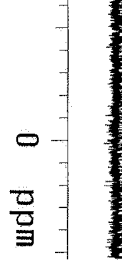



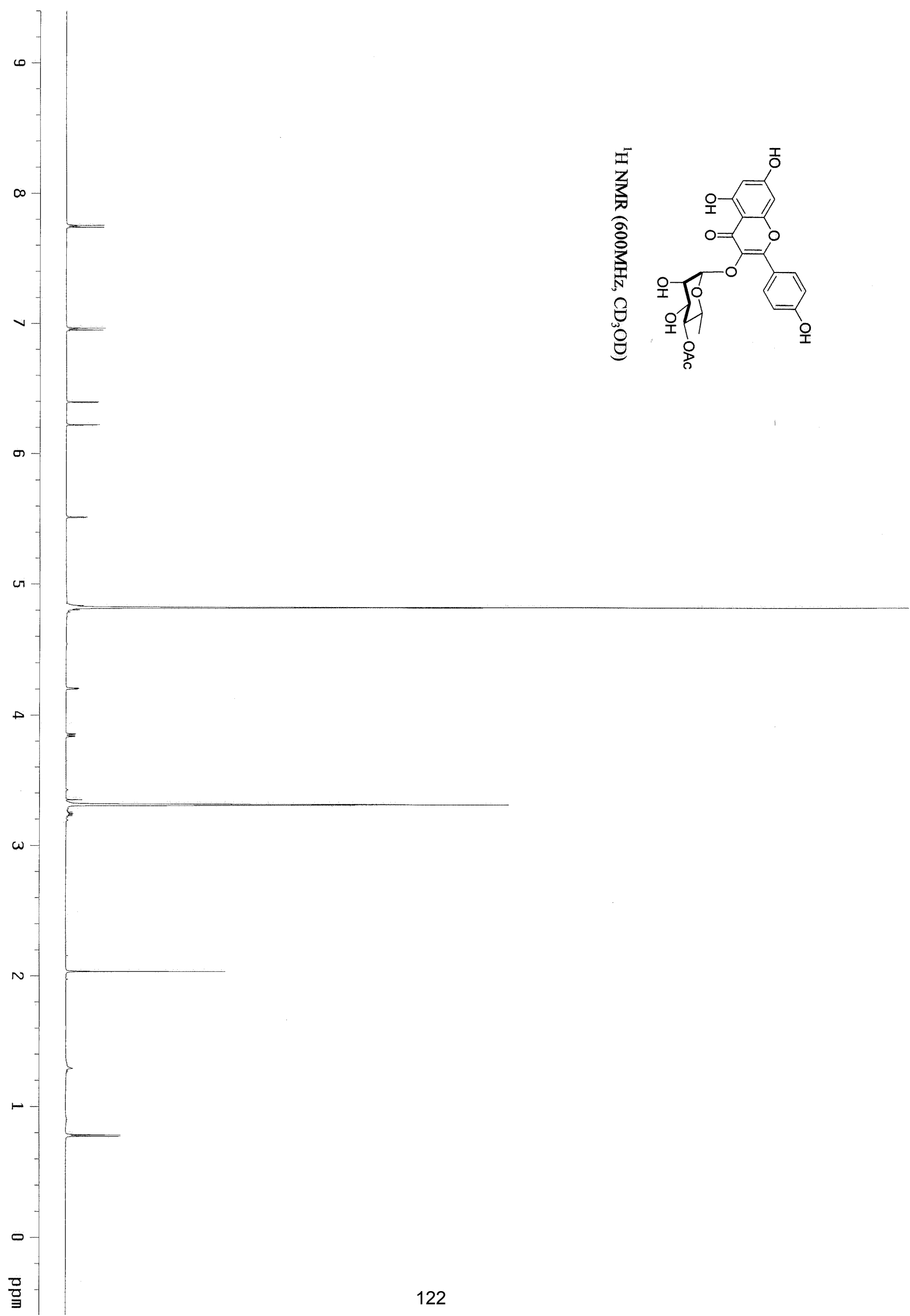


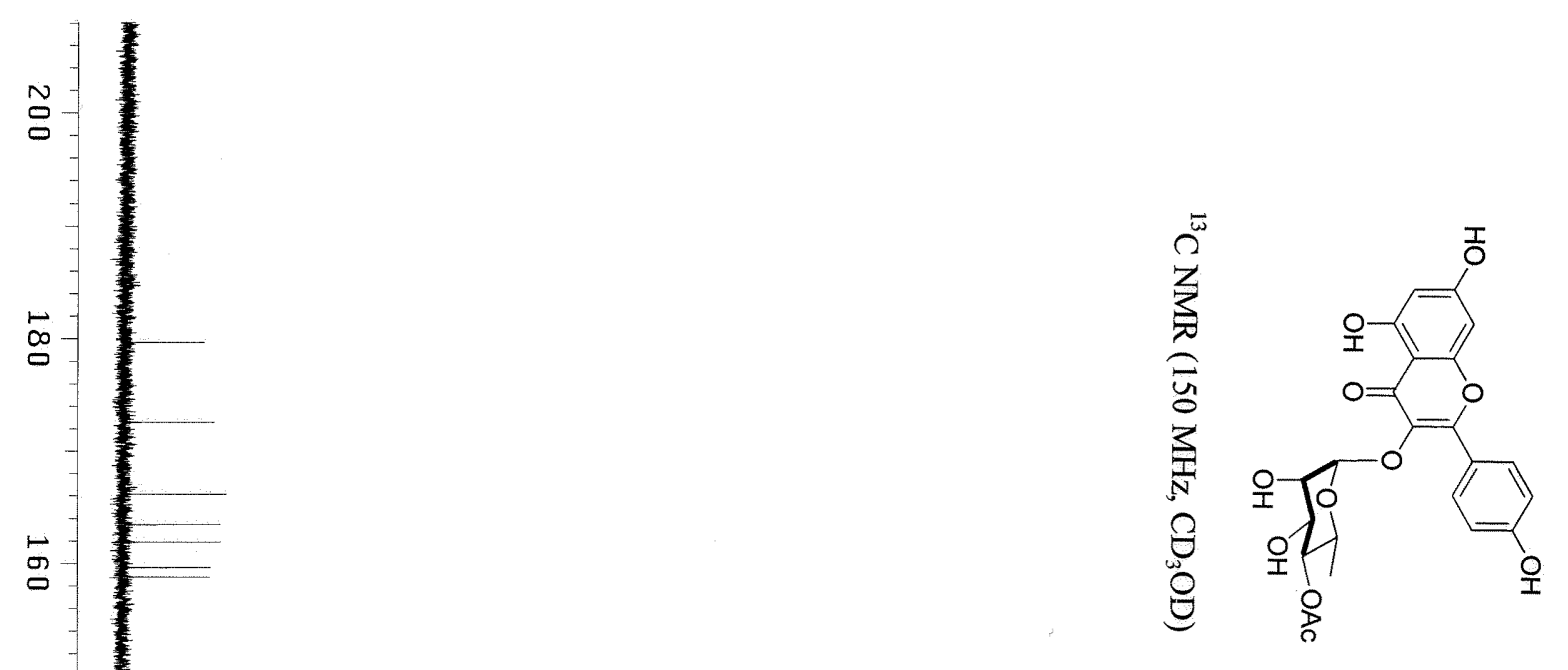

s

$\stackrel{s}{a}$

N-

-

음

ㅇ-

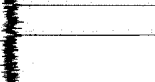

g

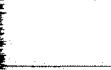

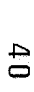

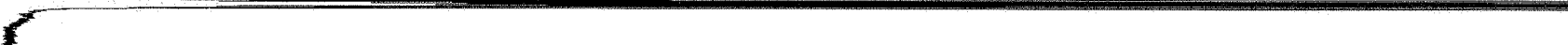

$\approx$

-

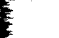




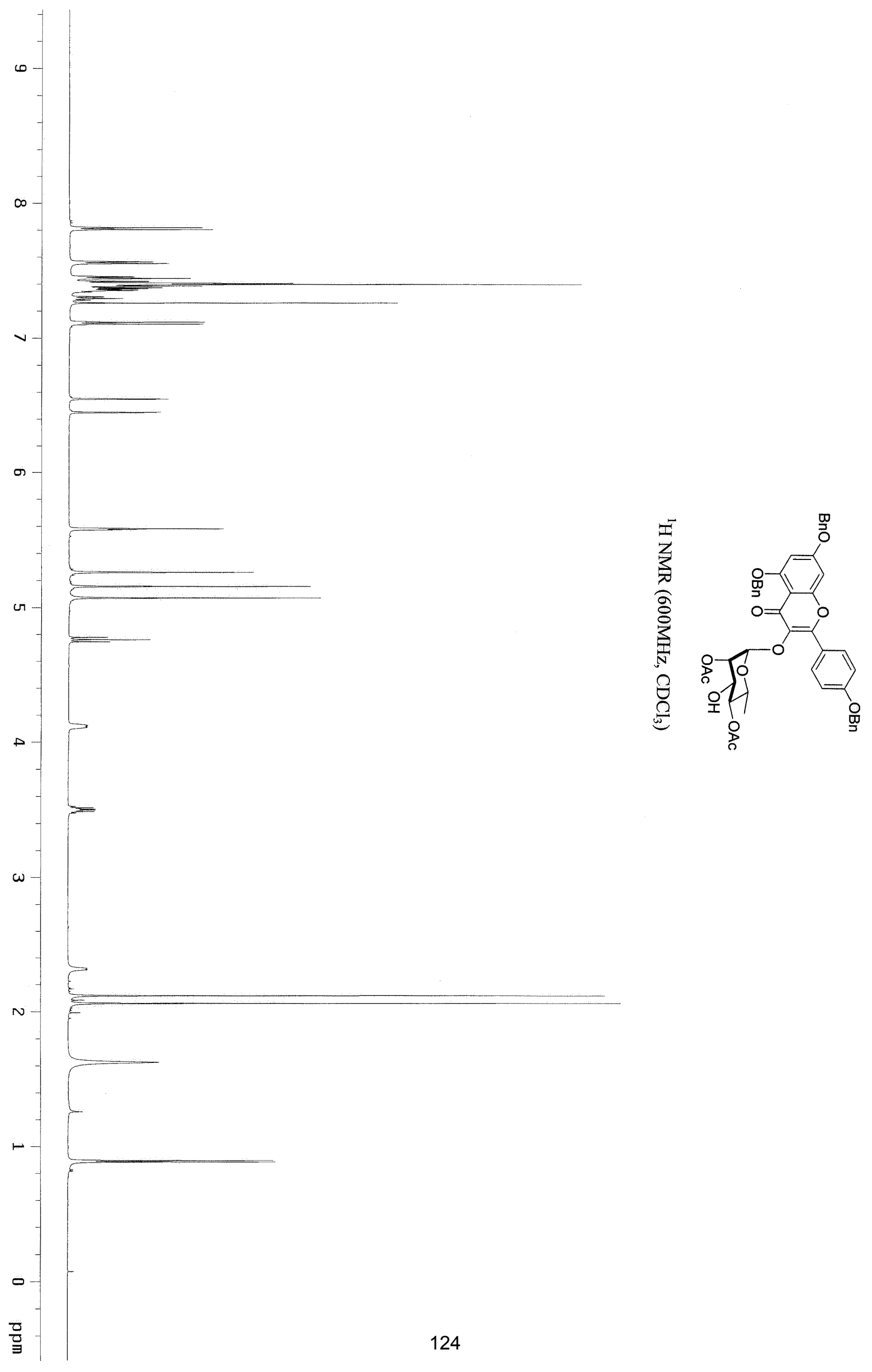



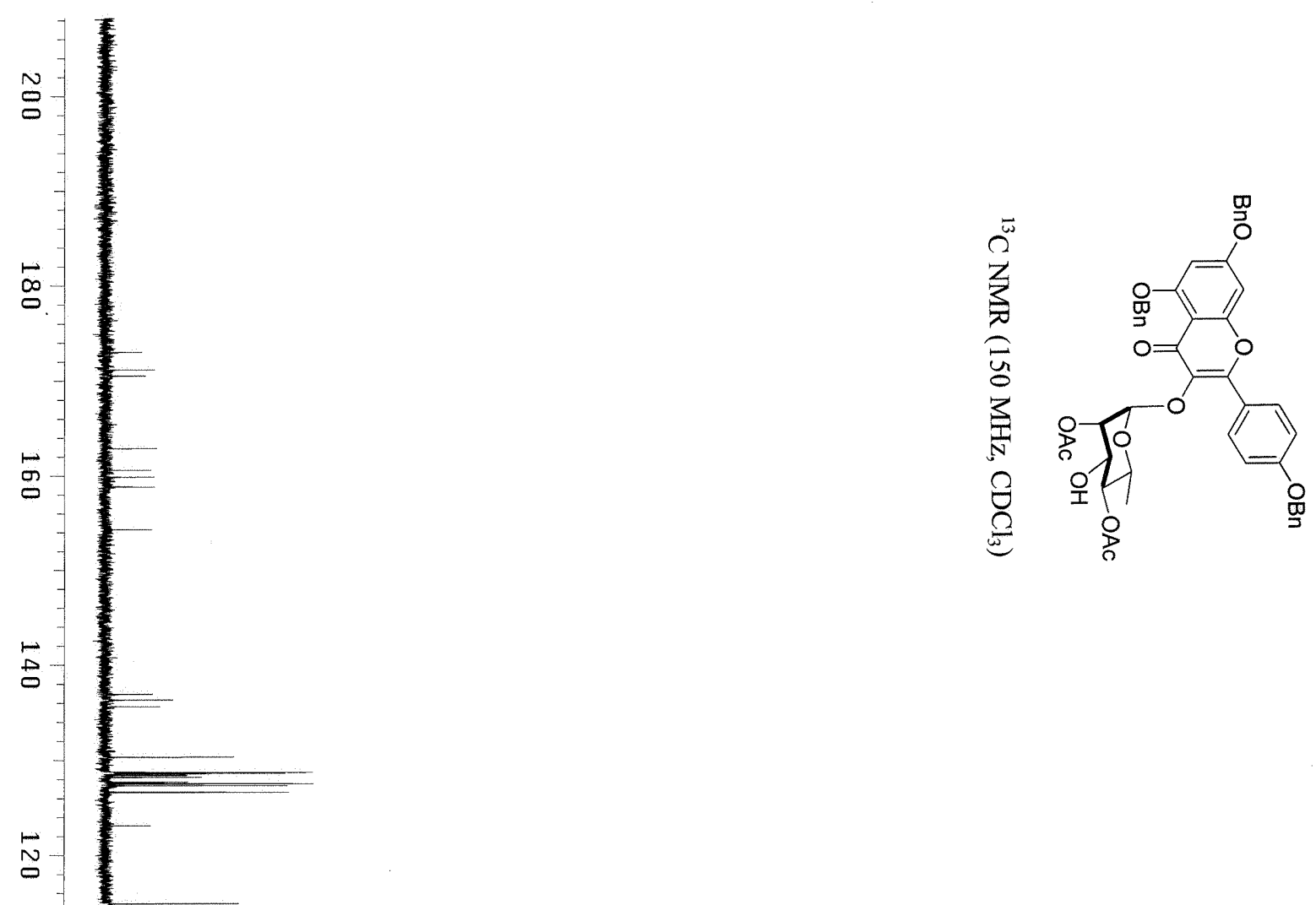

㝵 

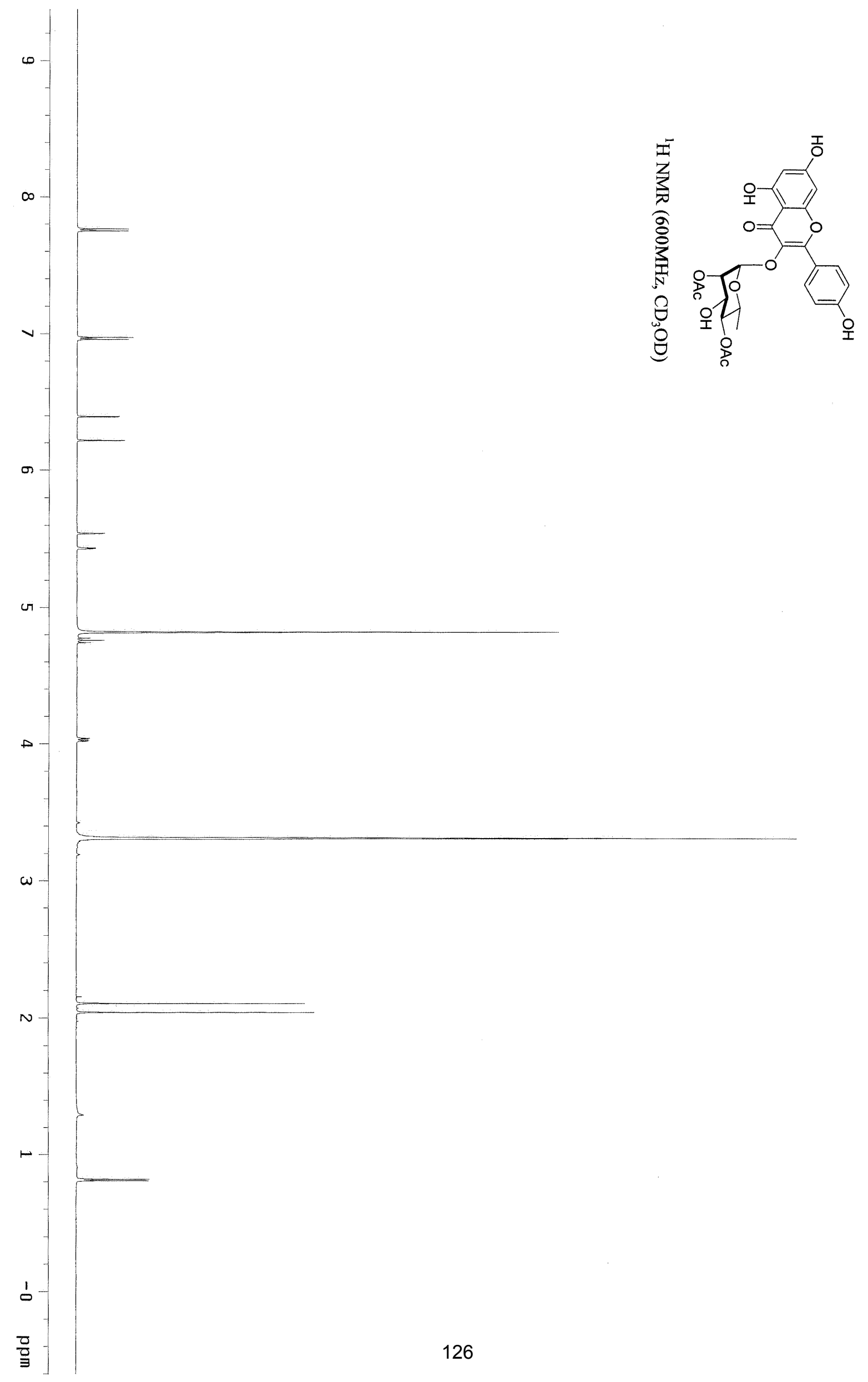


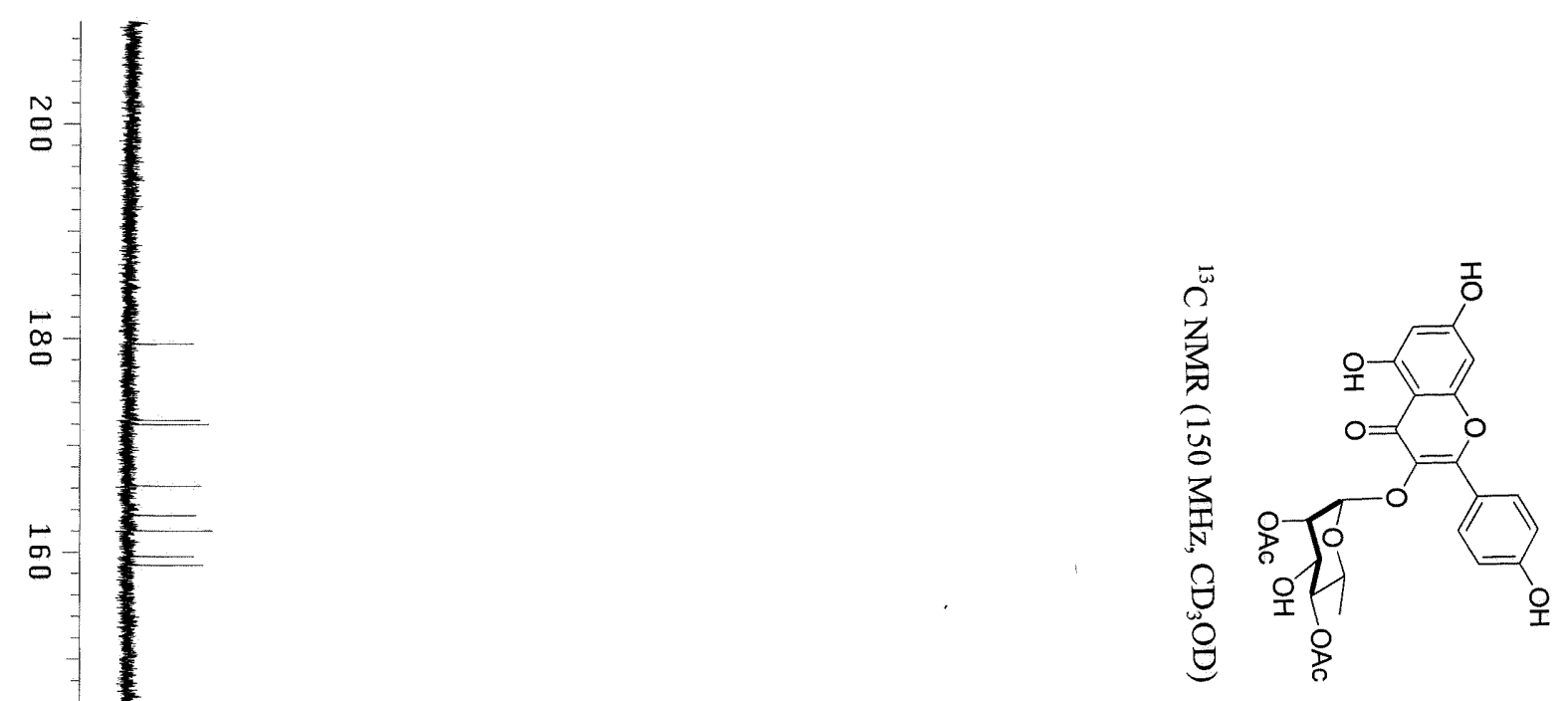

$\stackrel{1}{\circ}$

N

$\stackrel{N}{0}$

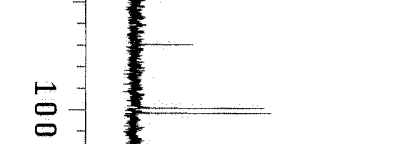

$\stackrel{\infty}{\square}$

。

-

N

$\stackrel{N}{0}$
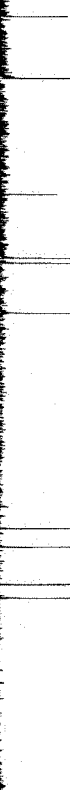

列 


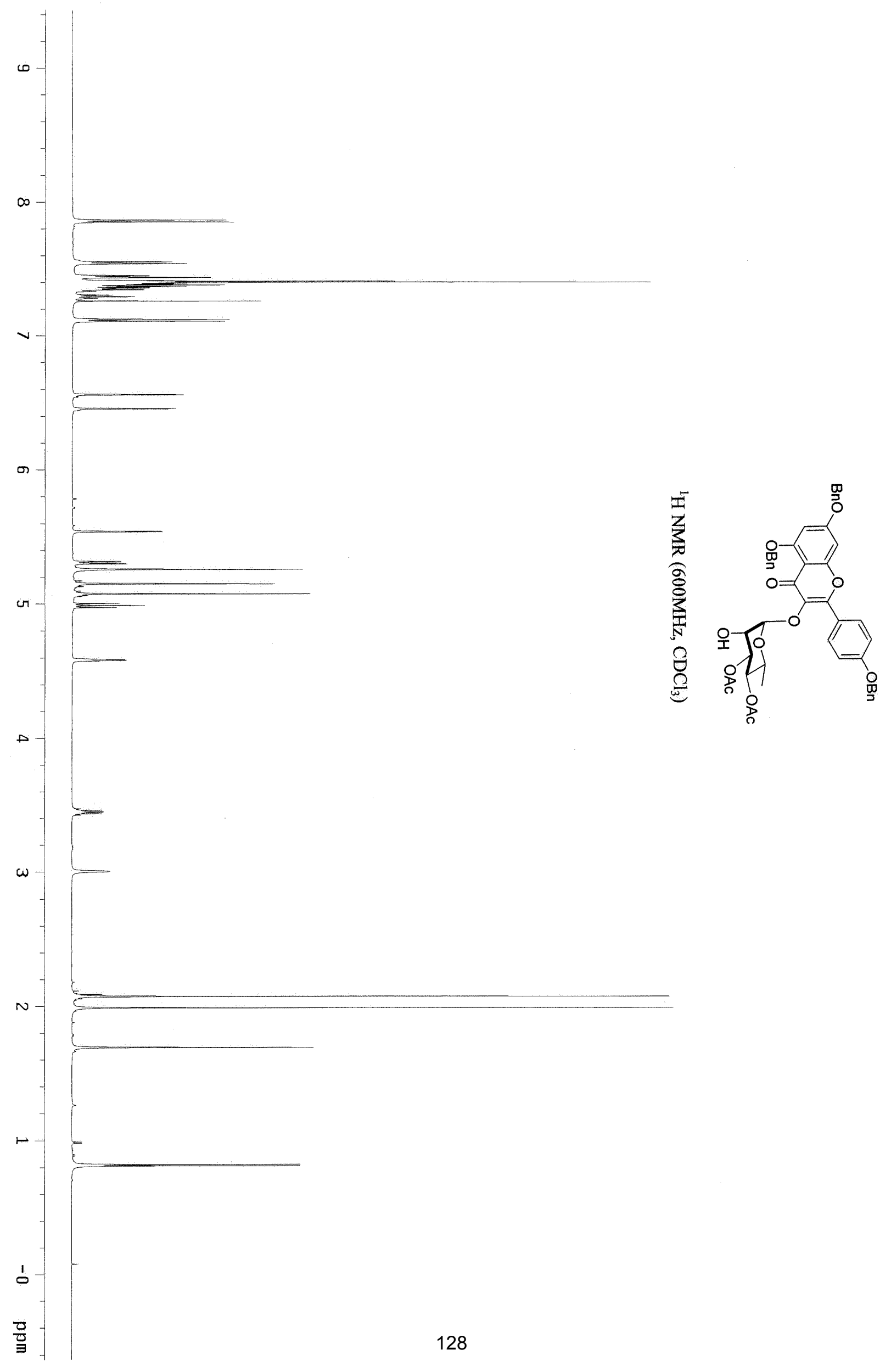




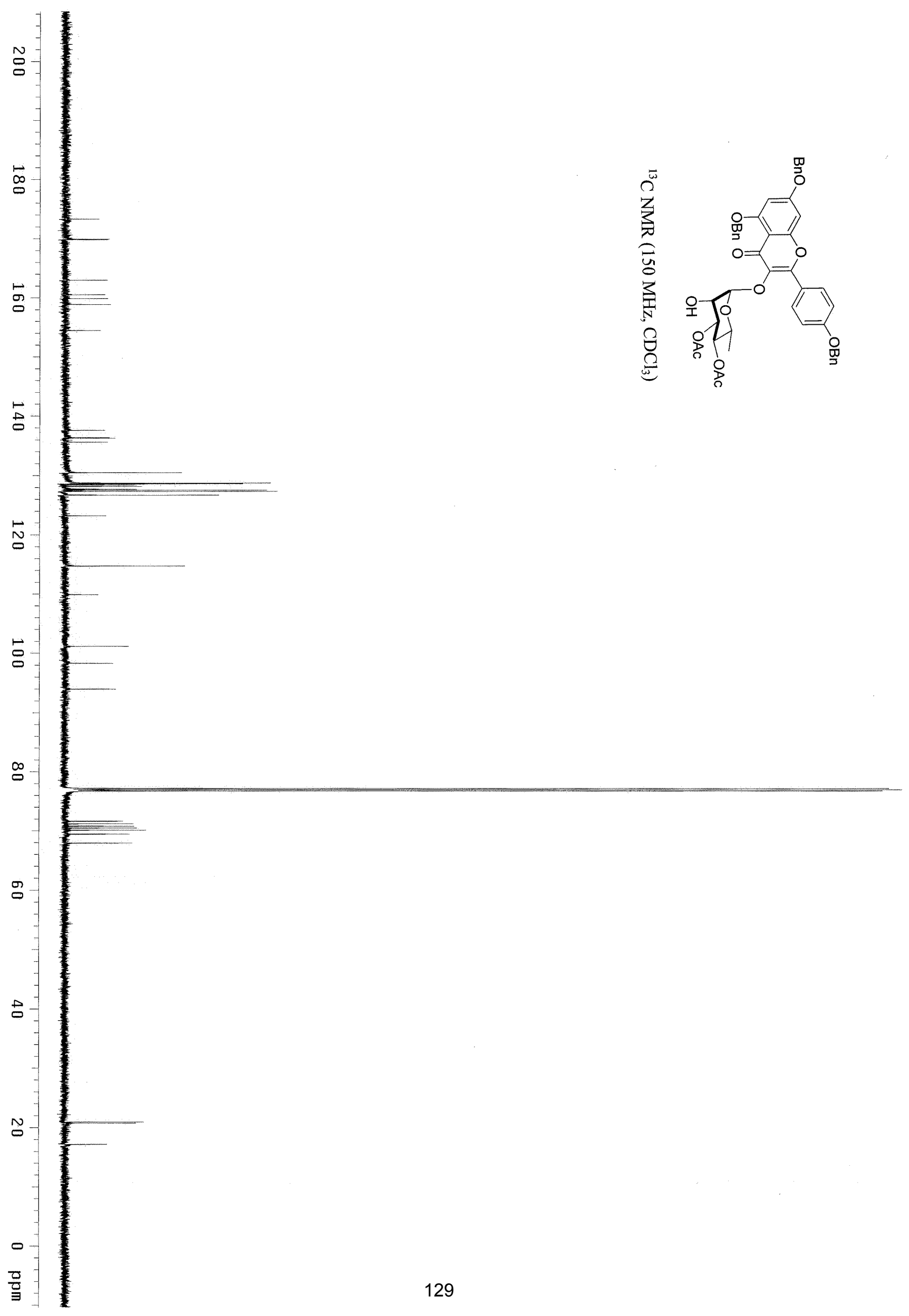



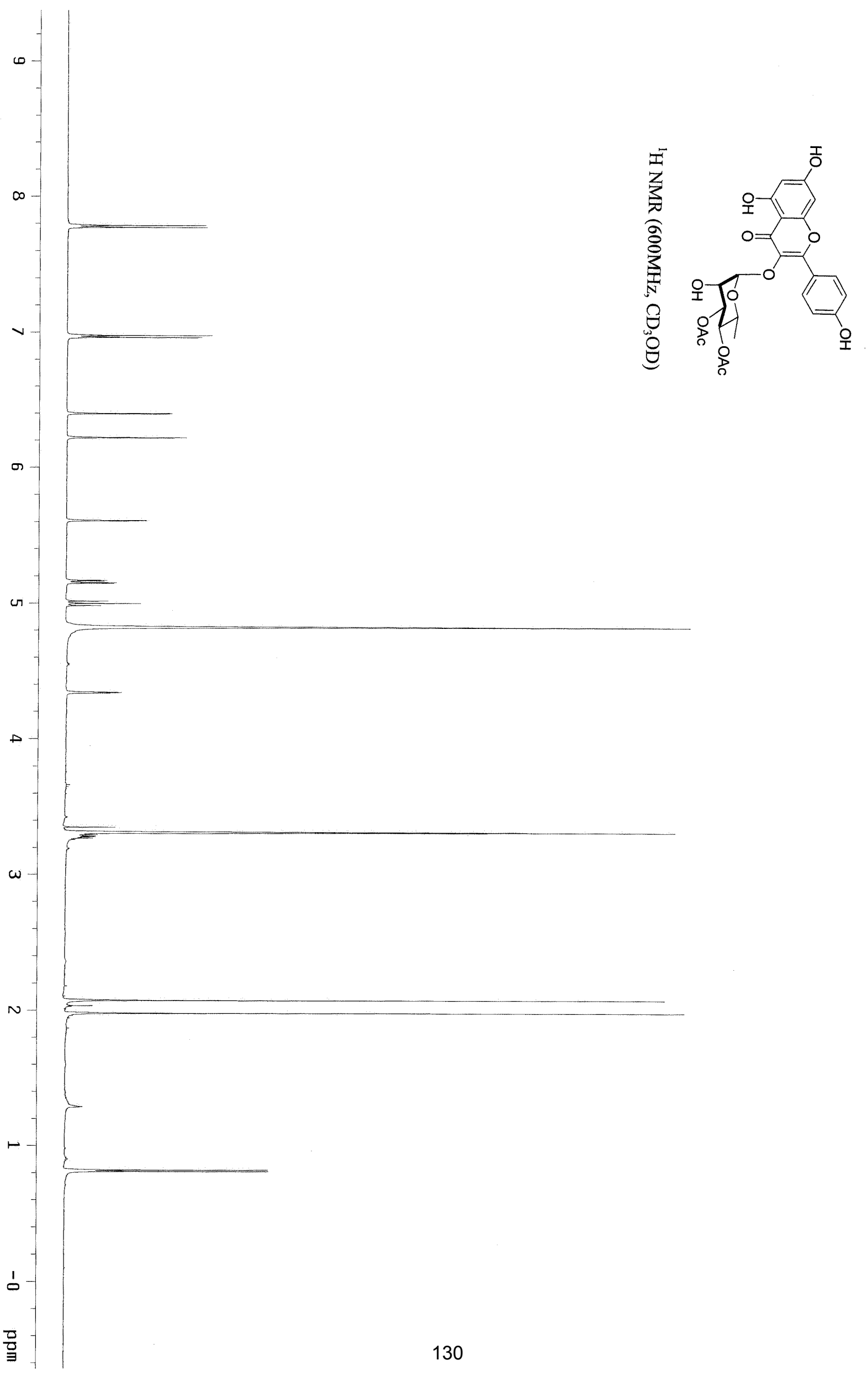


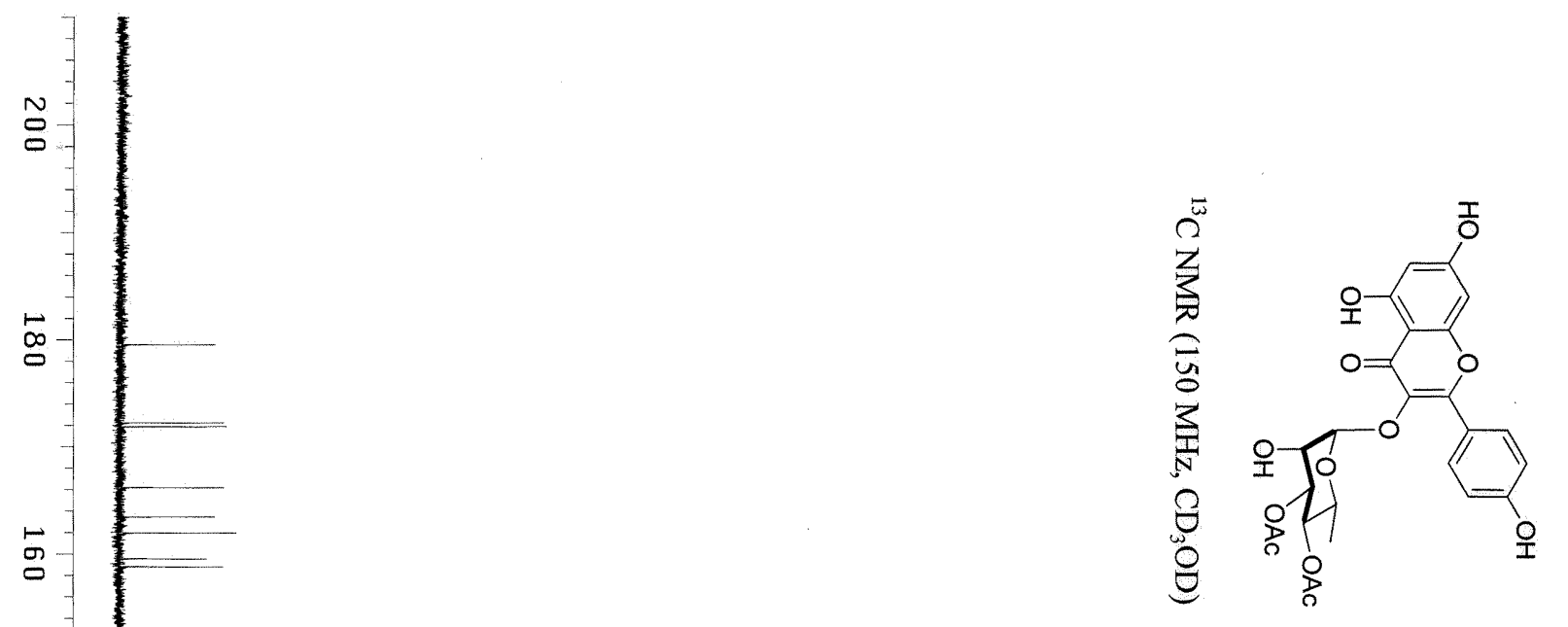

$$
\text { 点 }
$$$$
\text { 产 }
$$

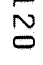

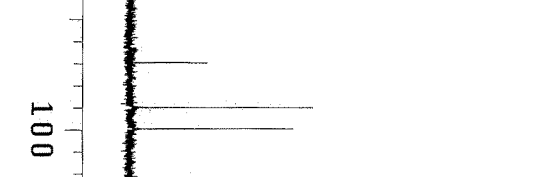

$\stackrel{\infty}{\circ}$

뭉
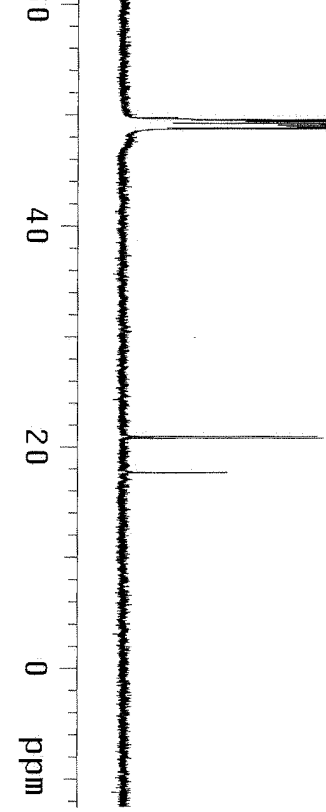


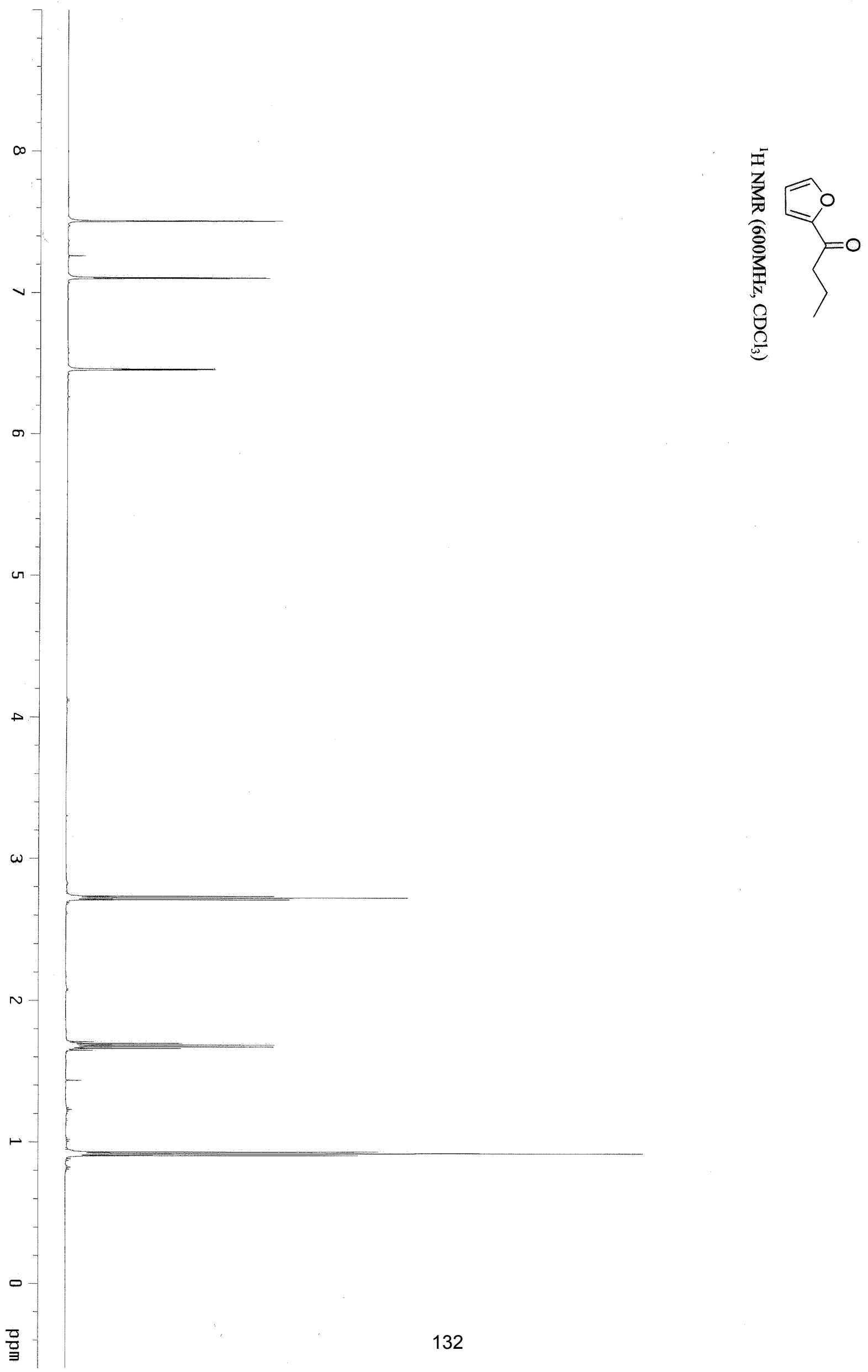




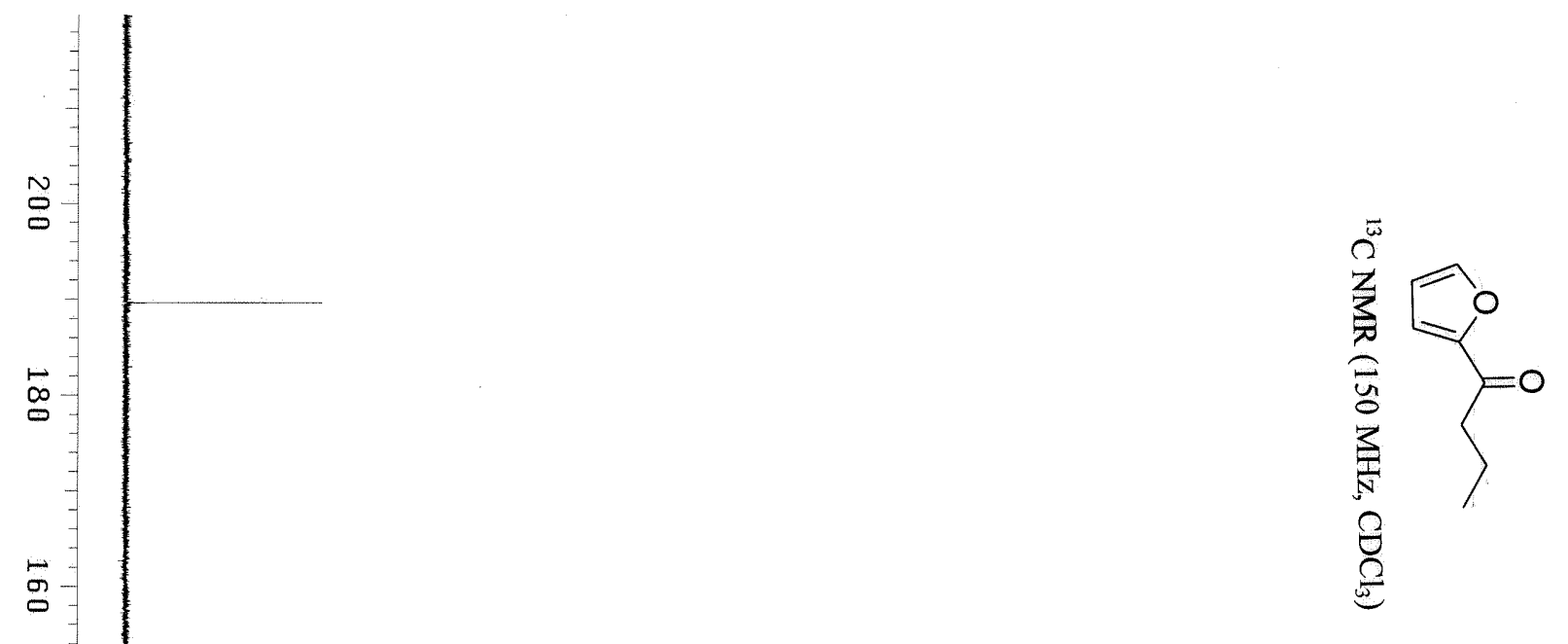

음

5
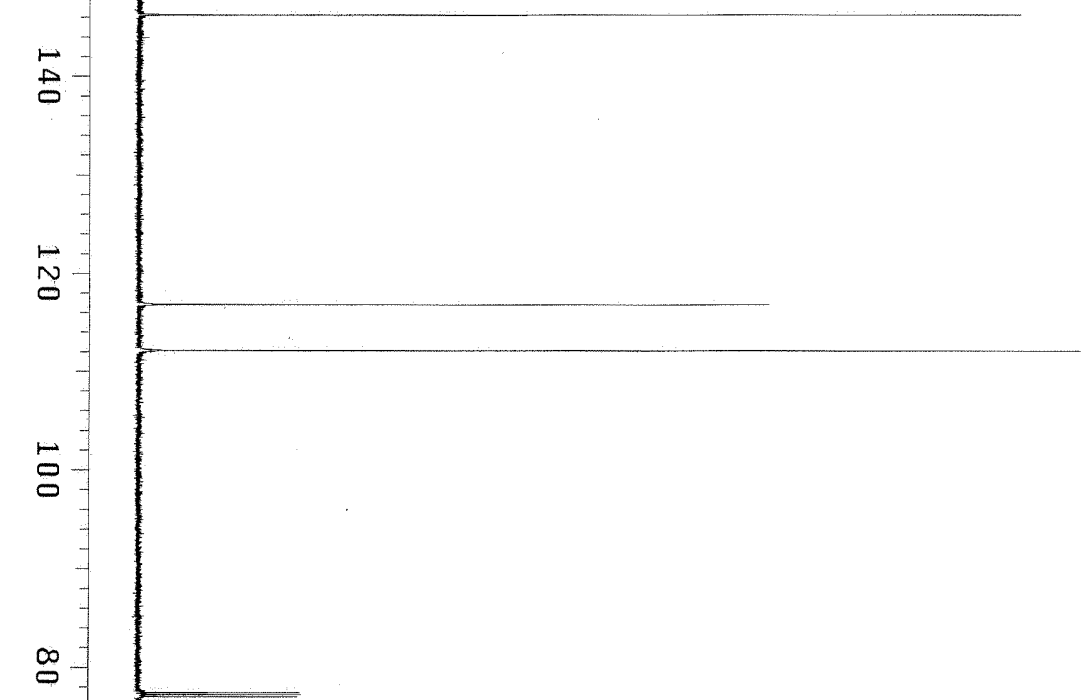

0 


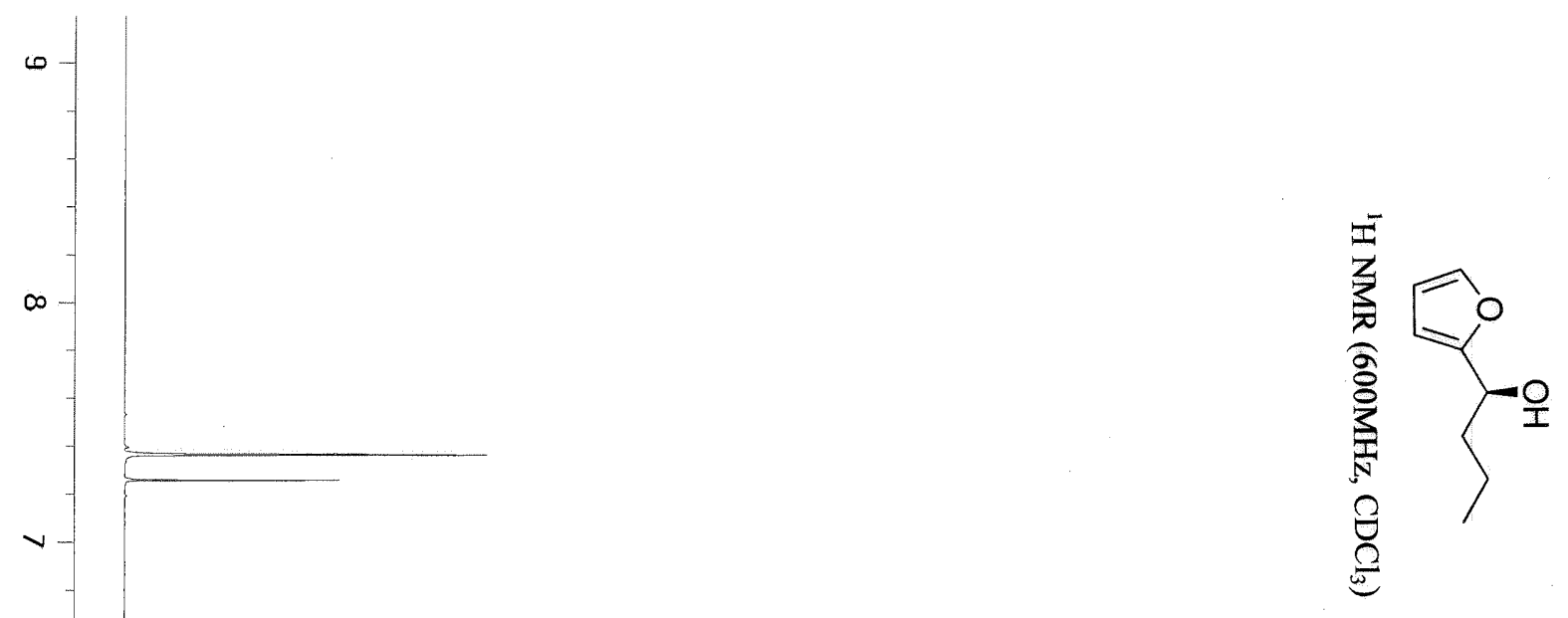

0

$\omega$
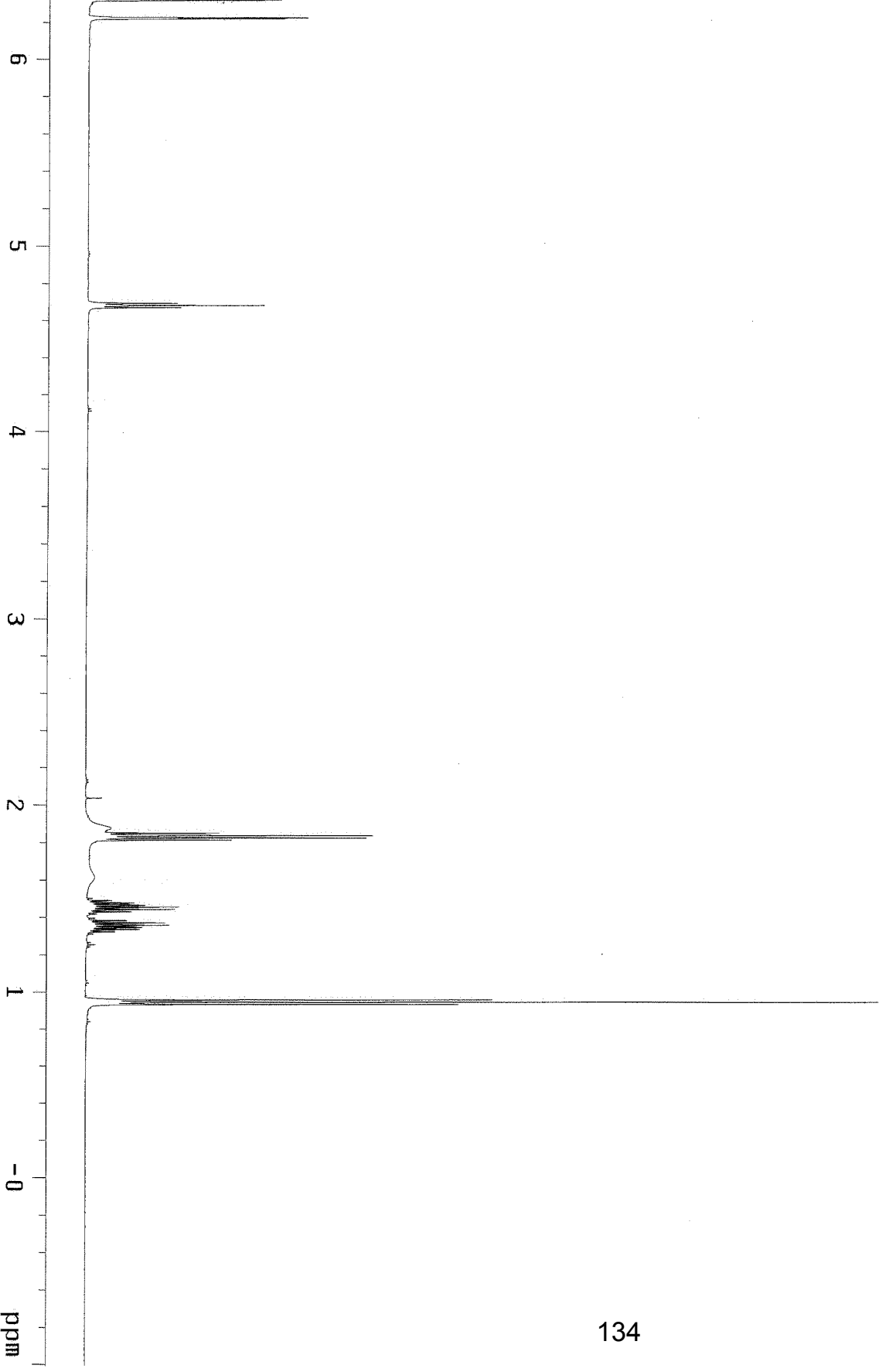

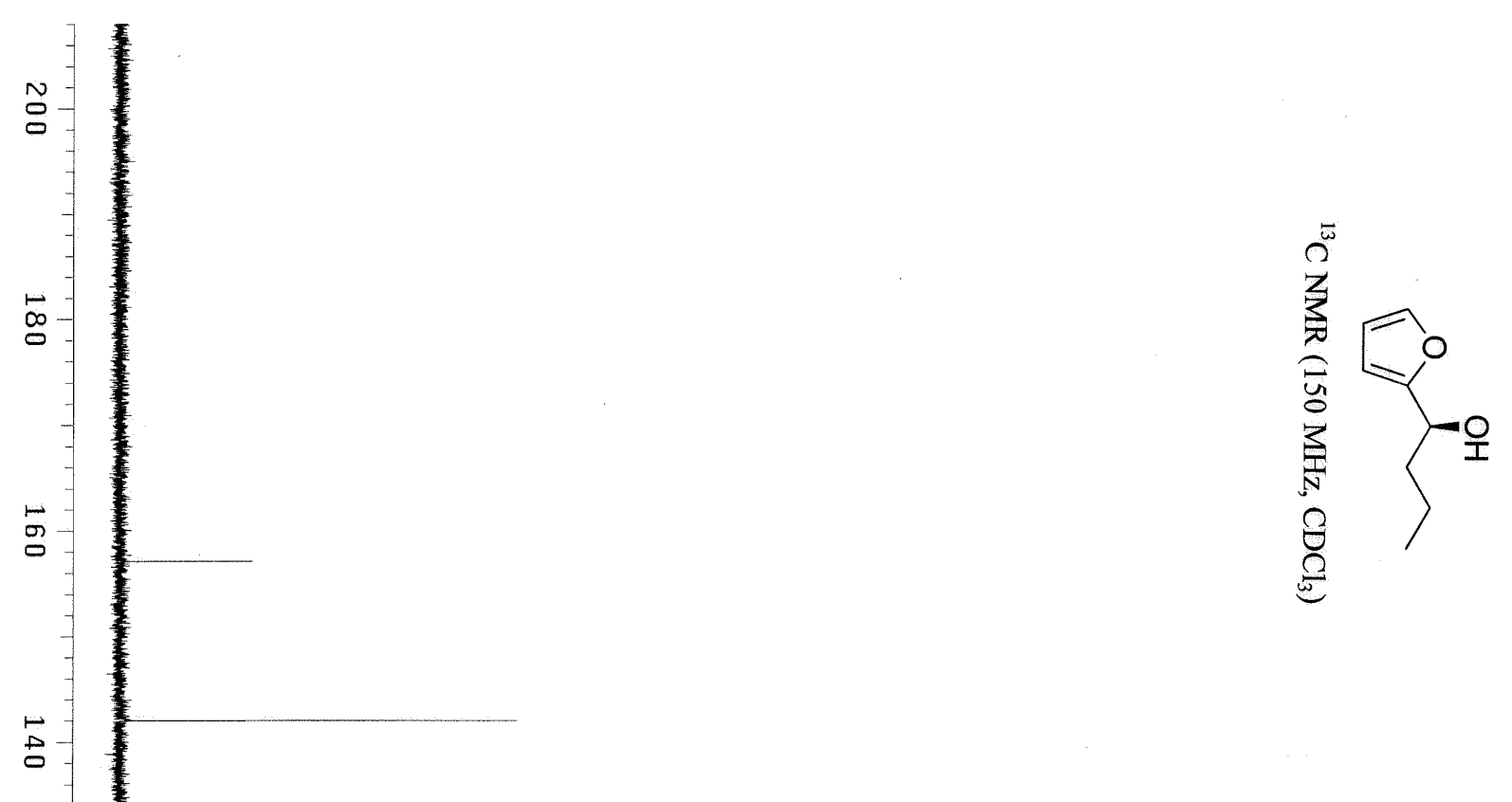

N

ڤ̃

吕-1

$\infty$

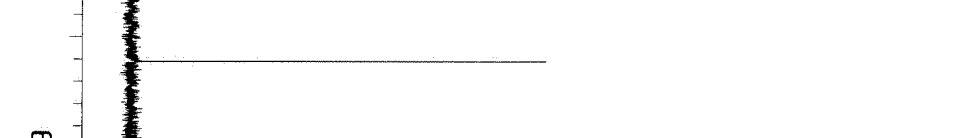

\%

$B$

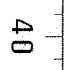

$-$

N

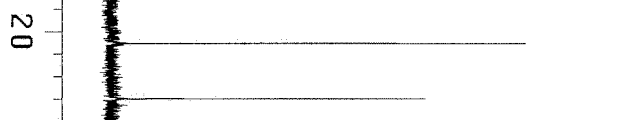

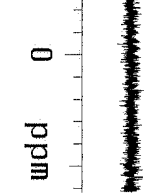




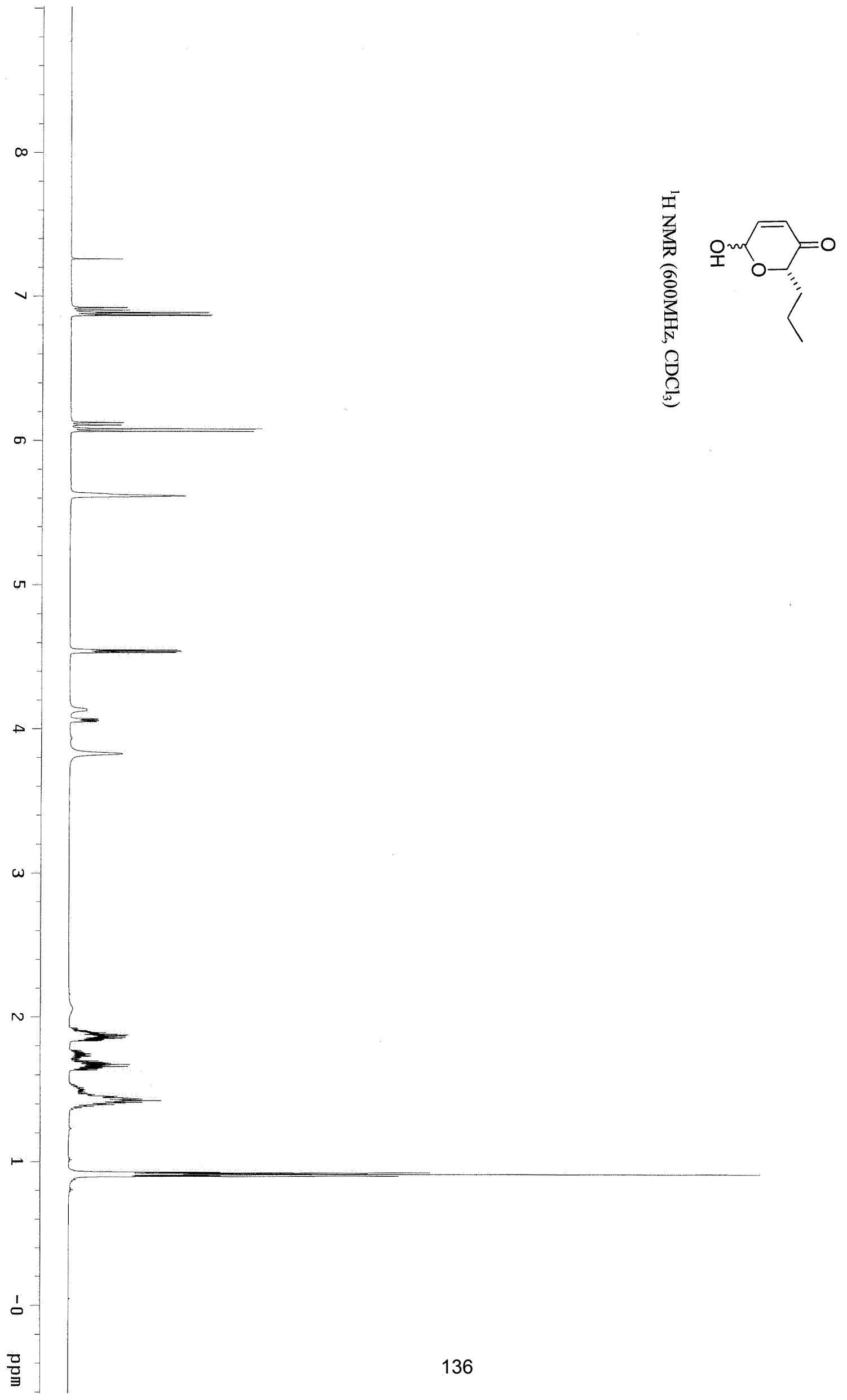




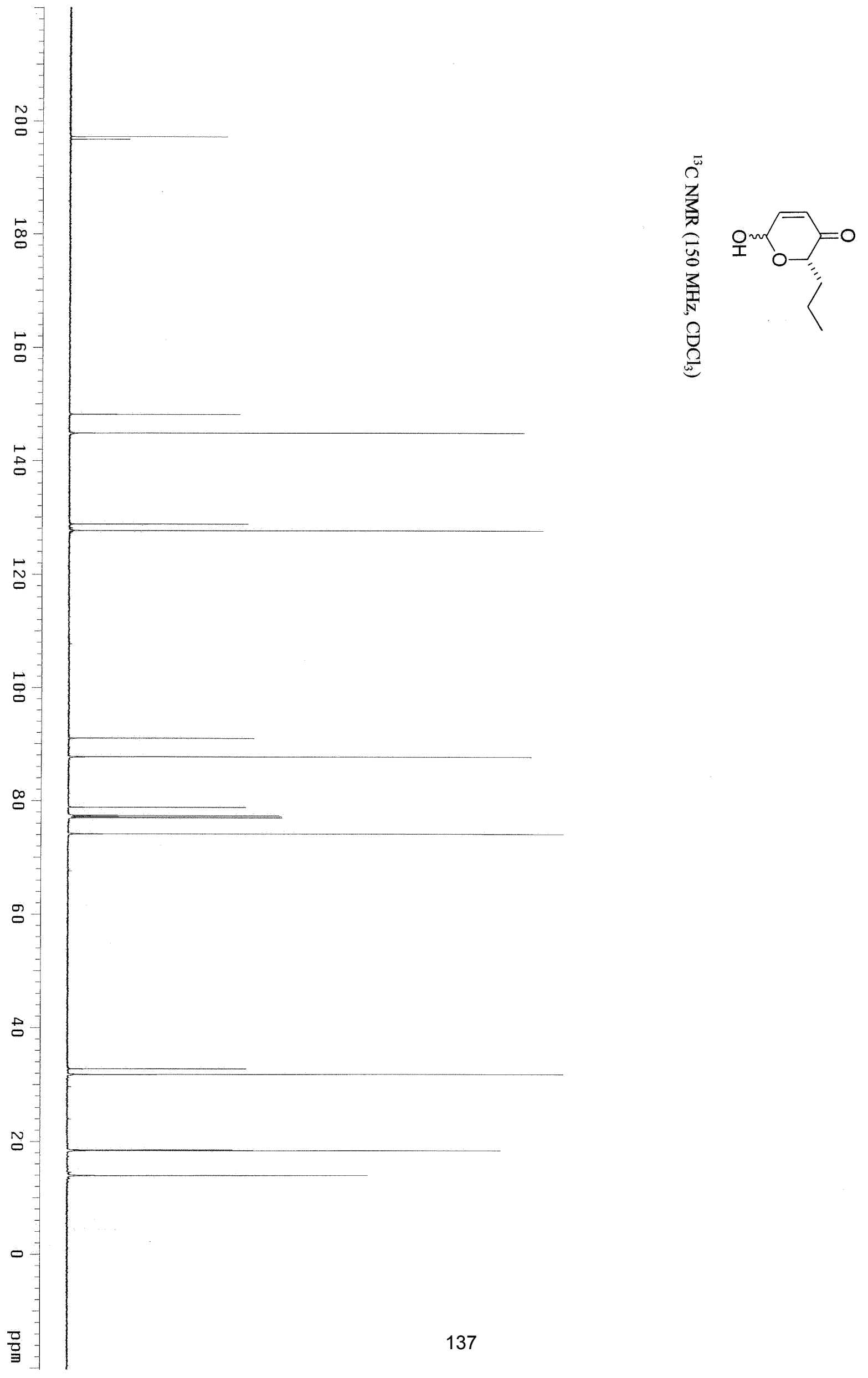



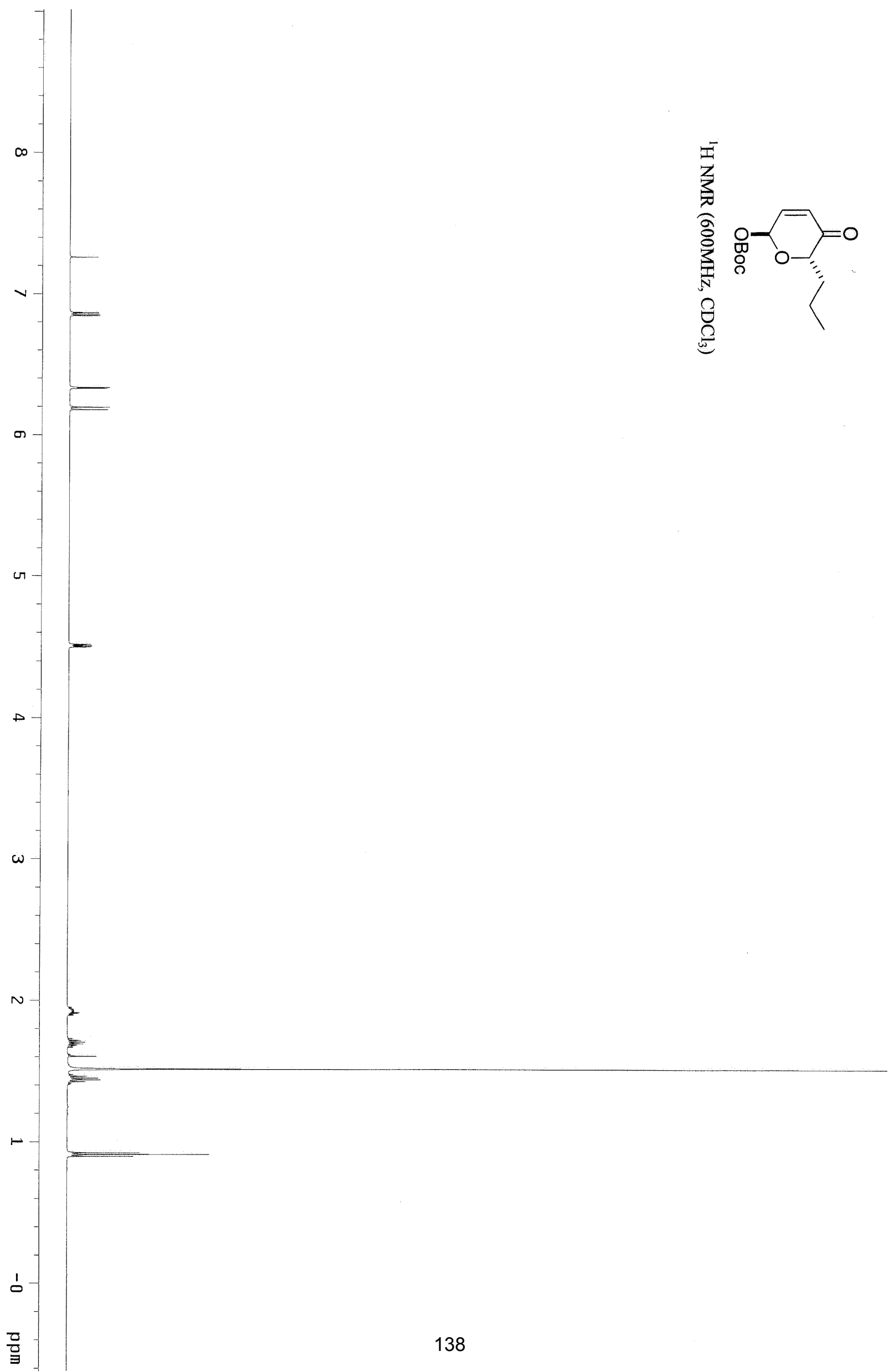


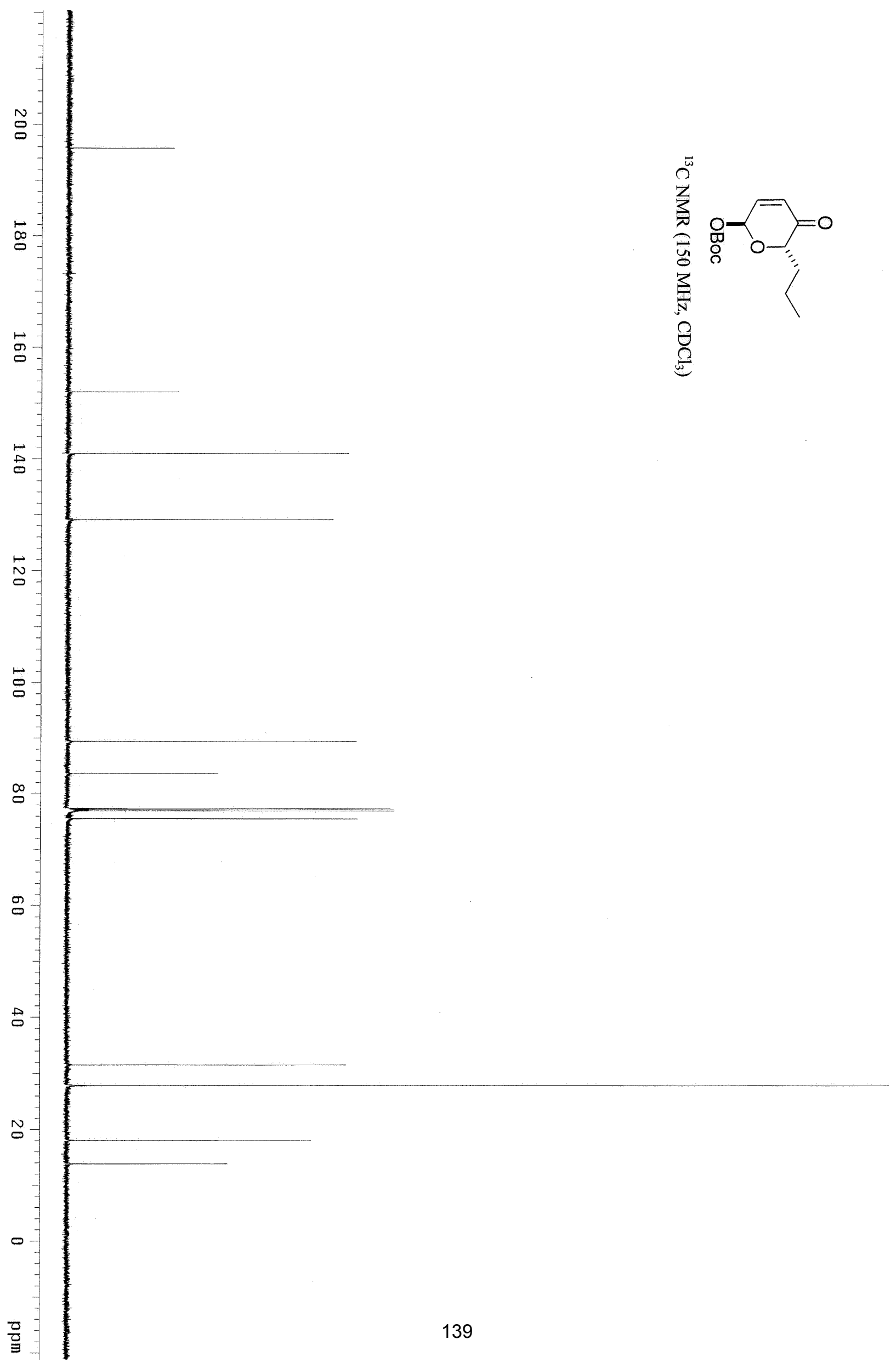




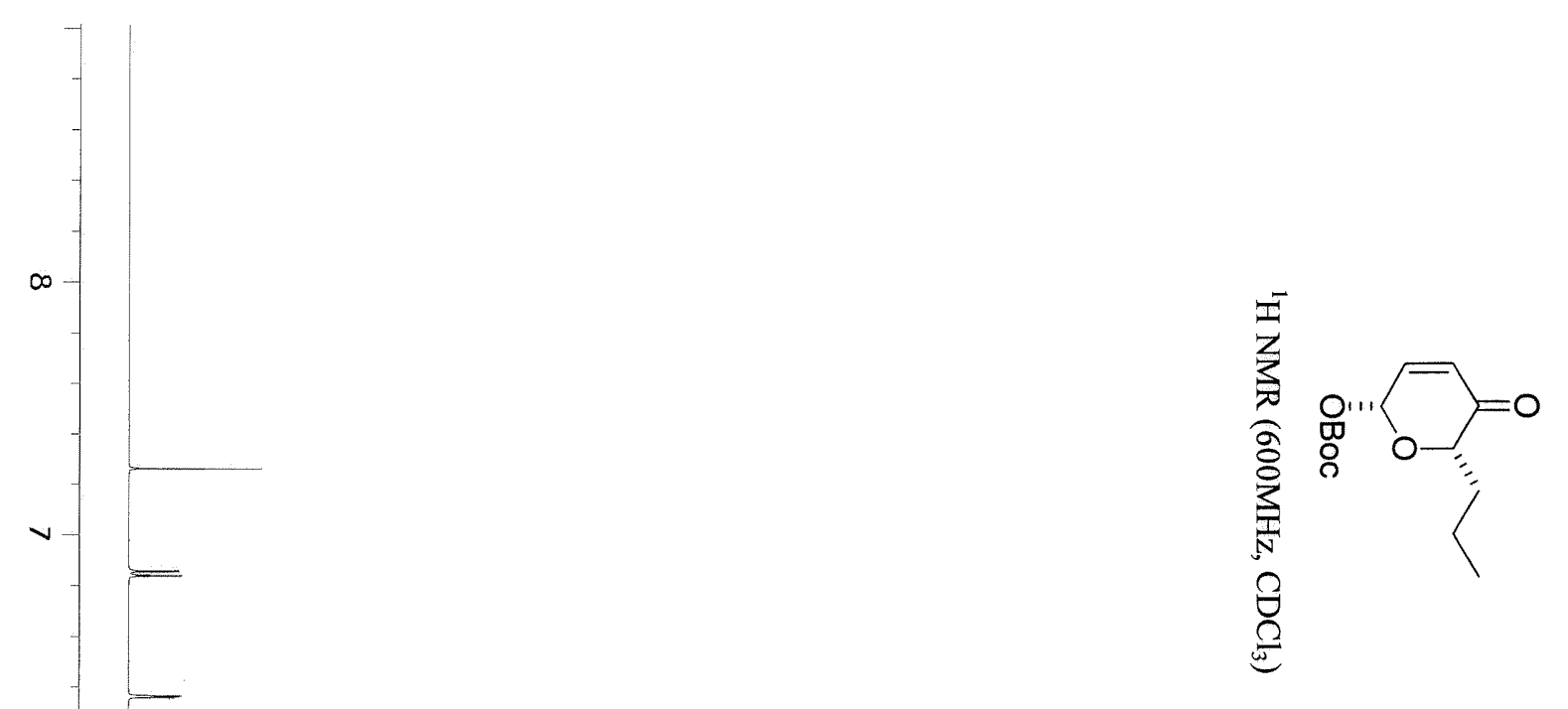



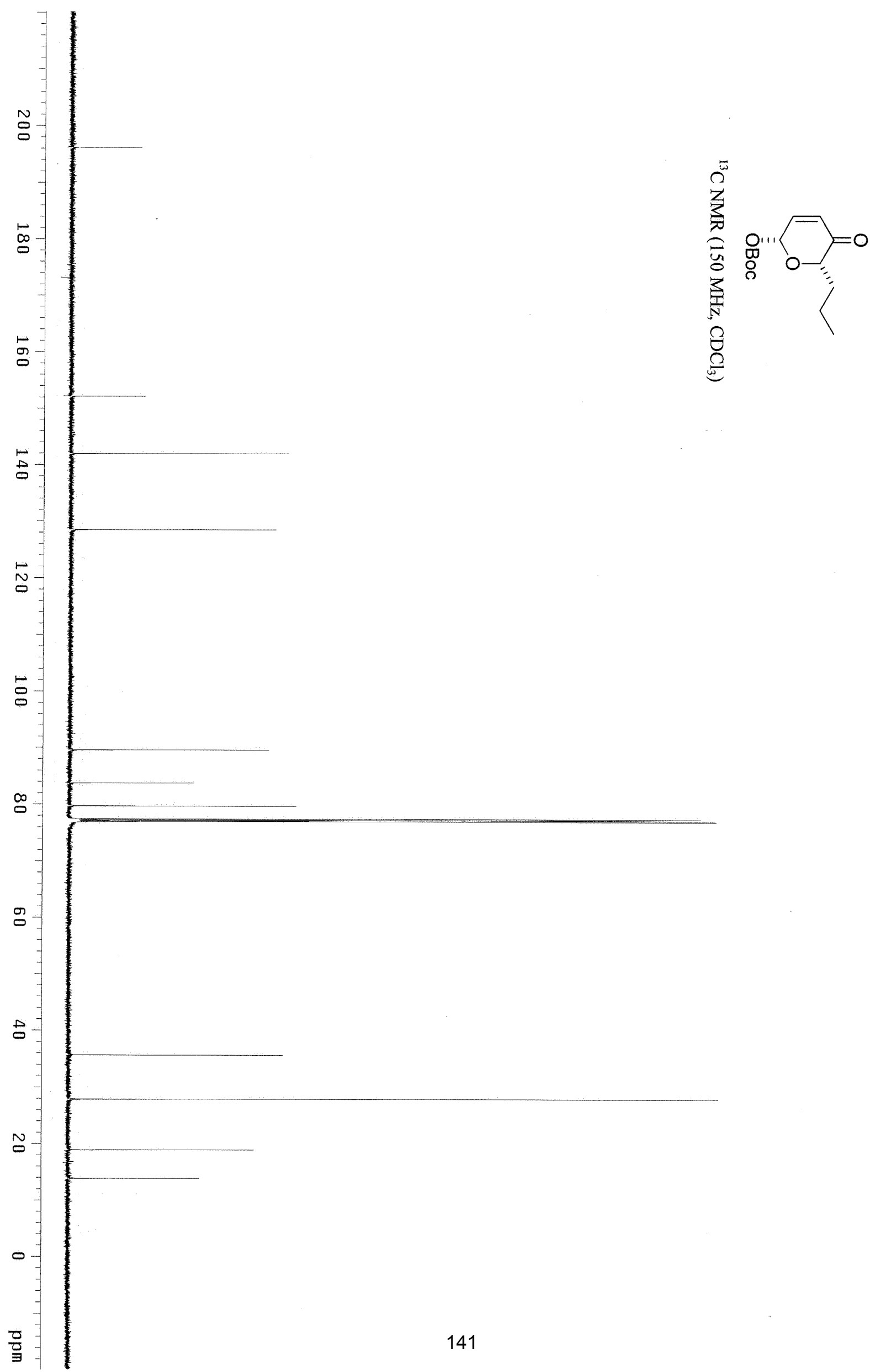


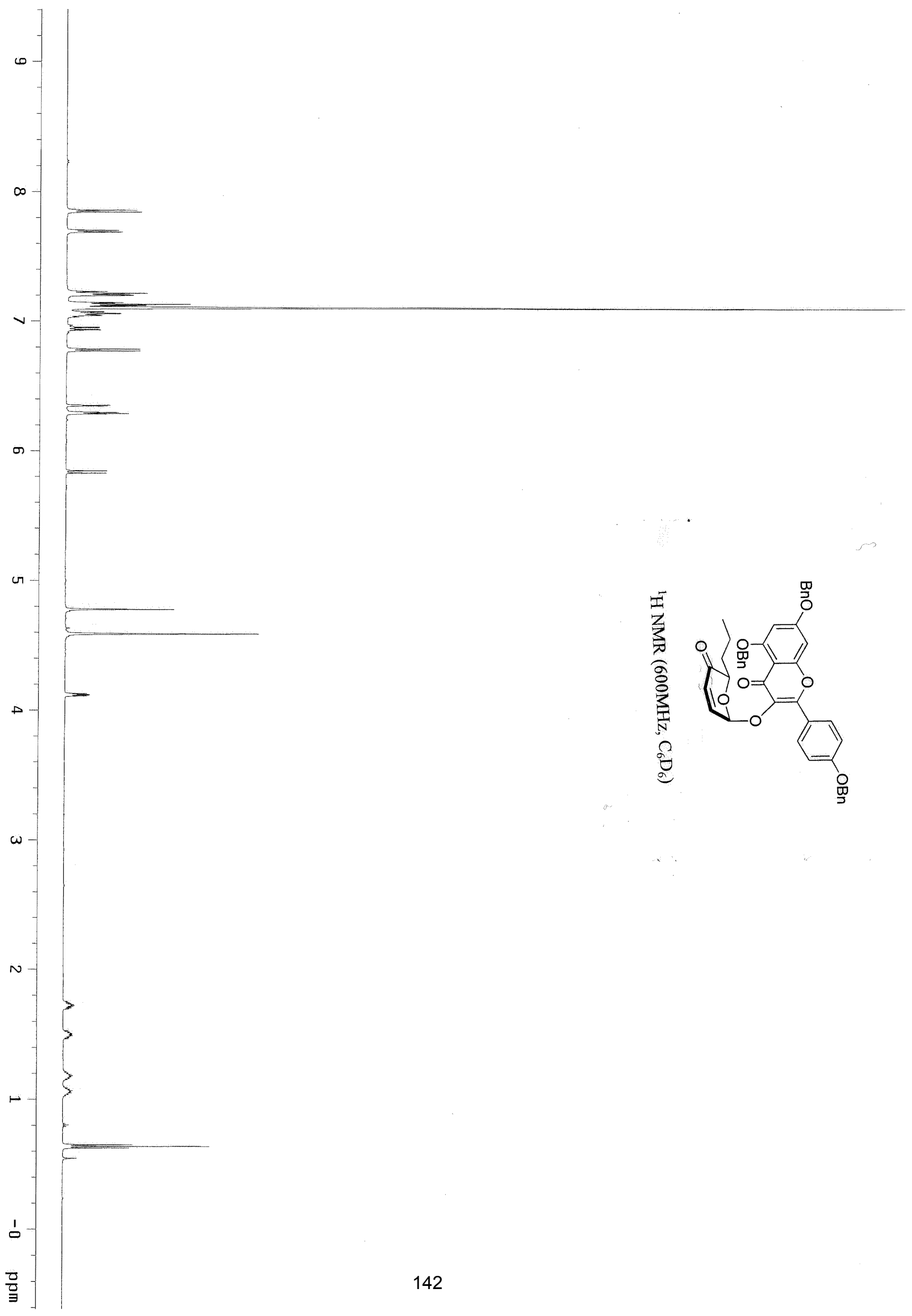




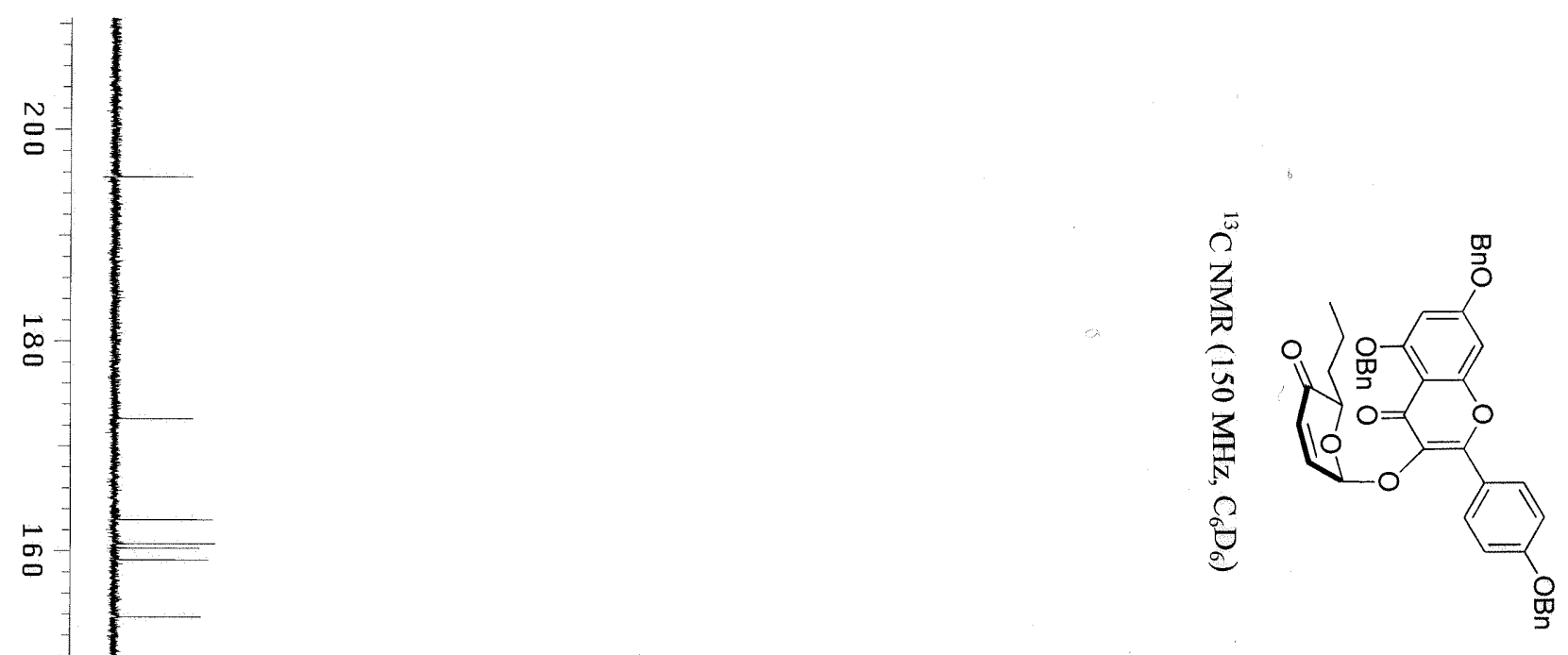




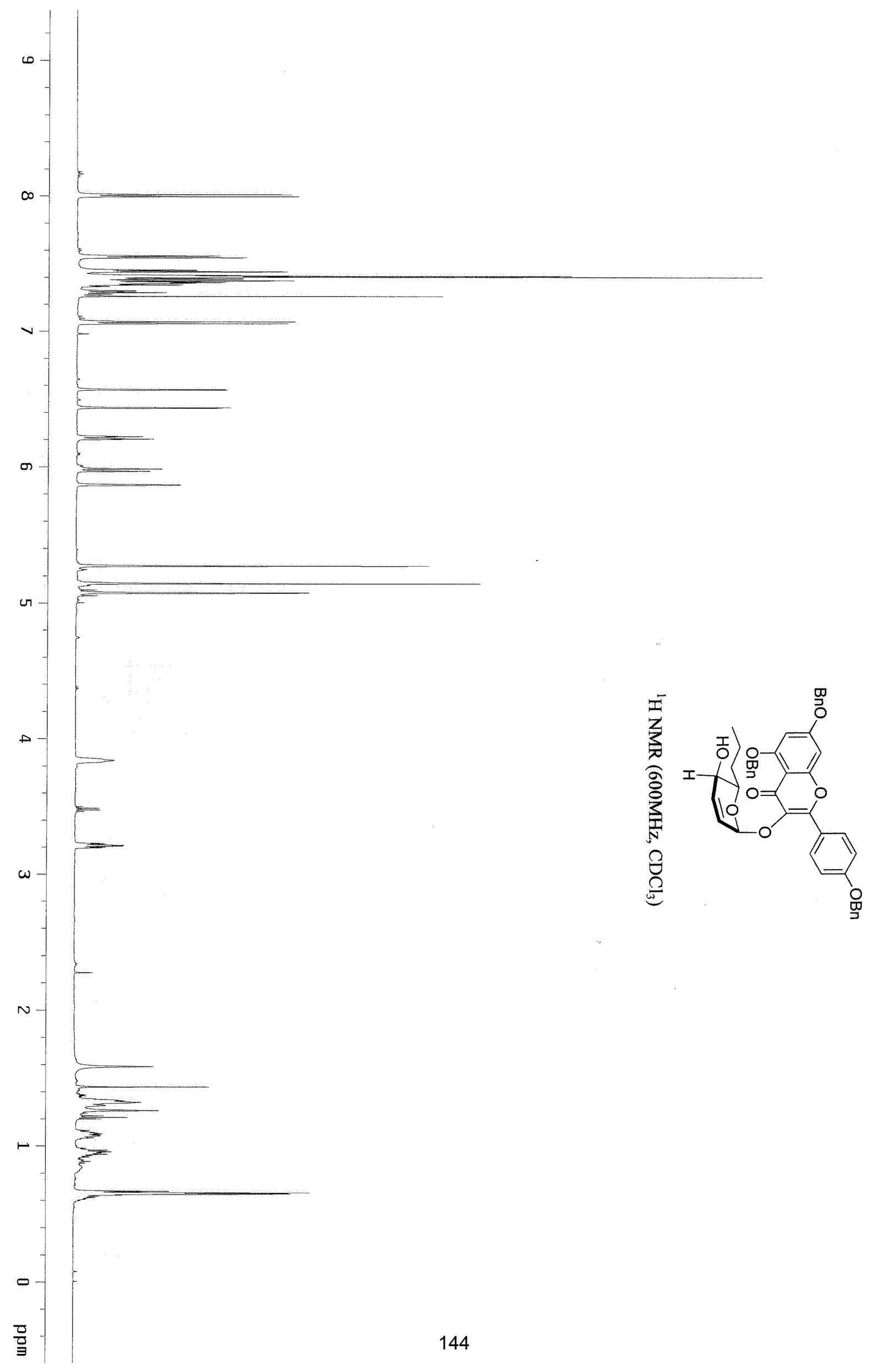




$$
\left.\right|^{*}
$$



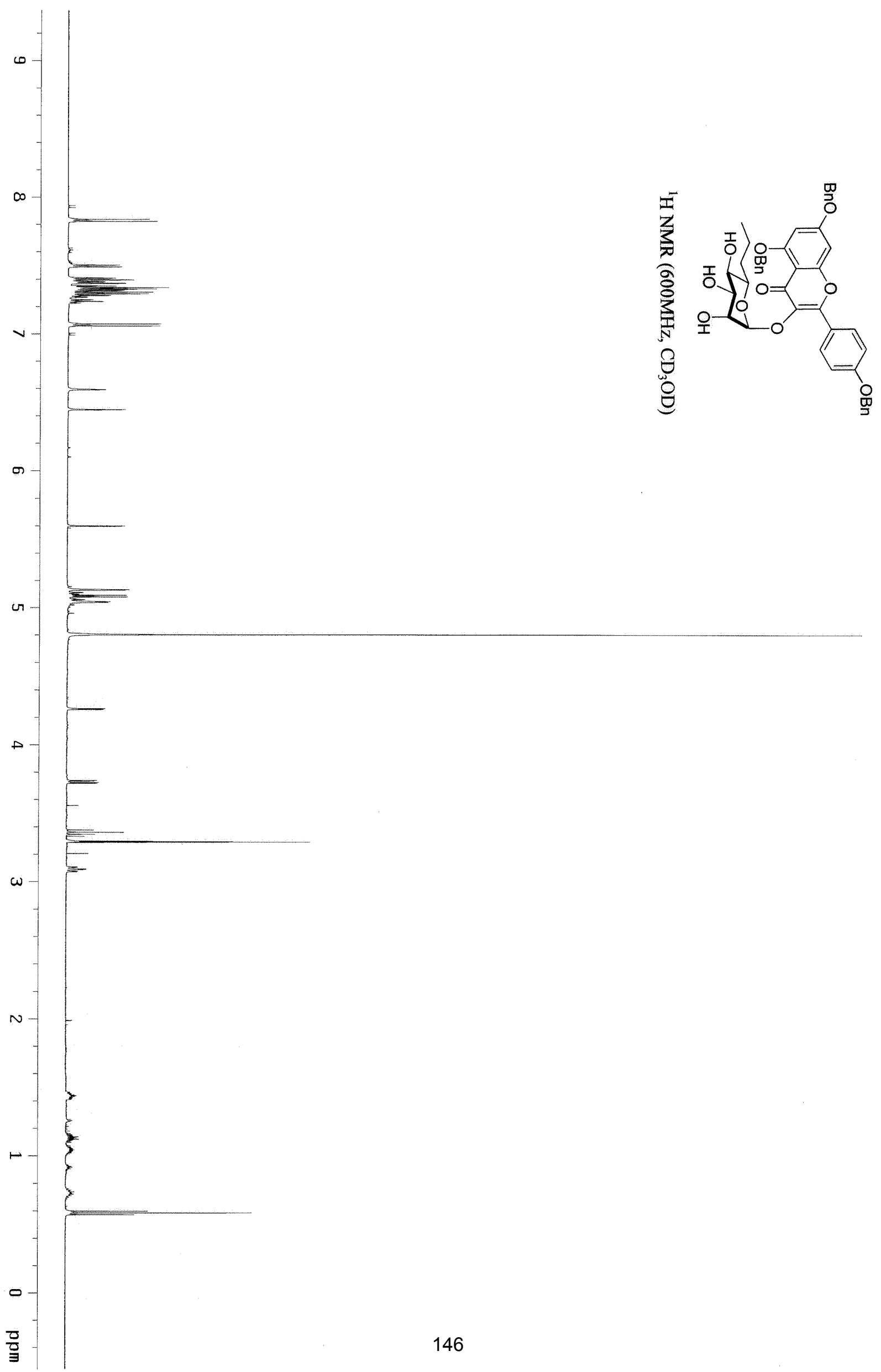


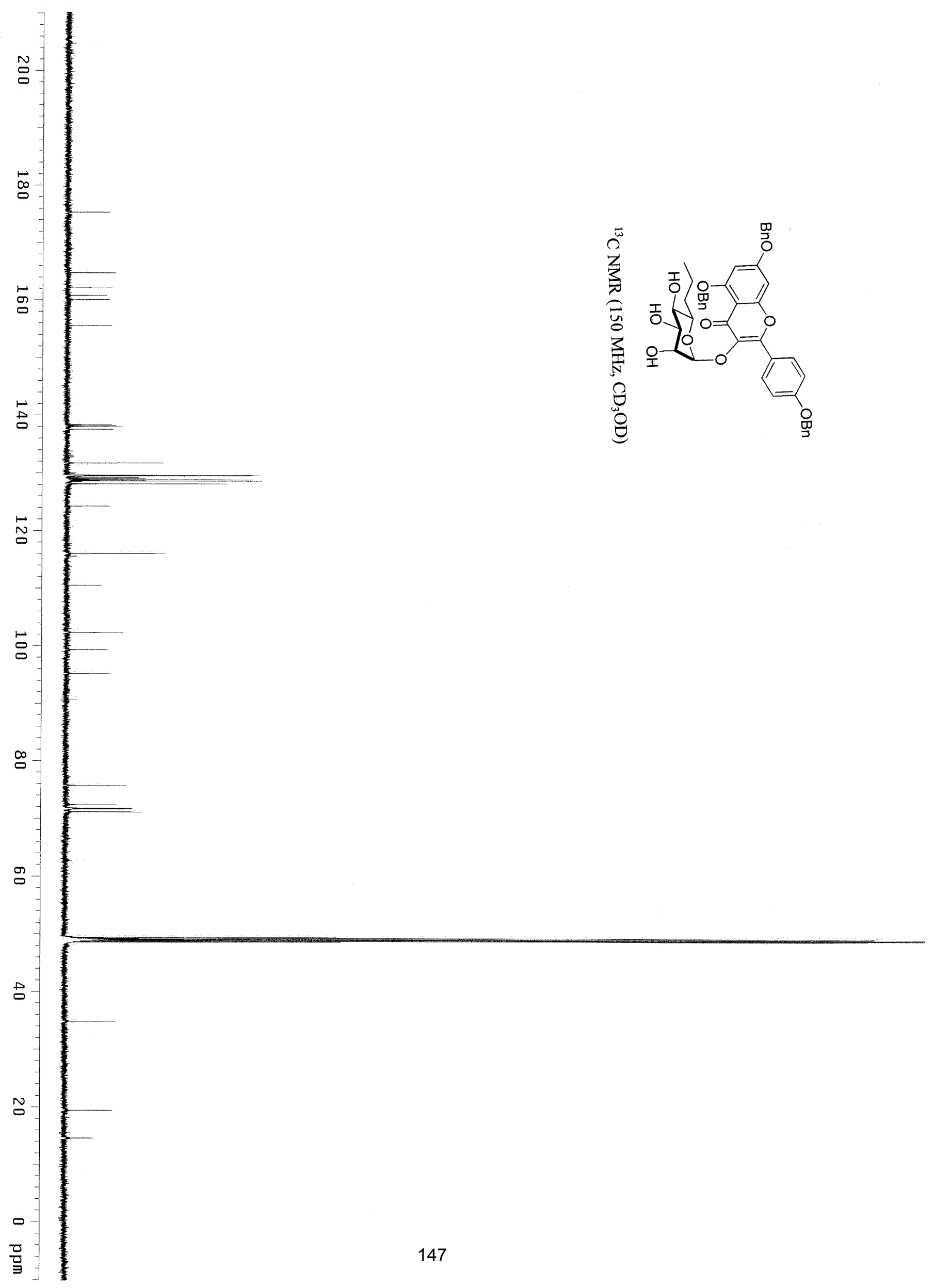




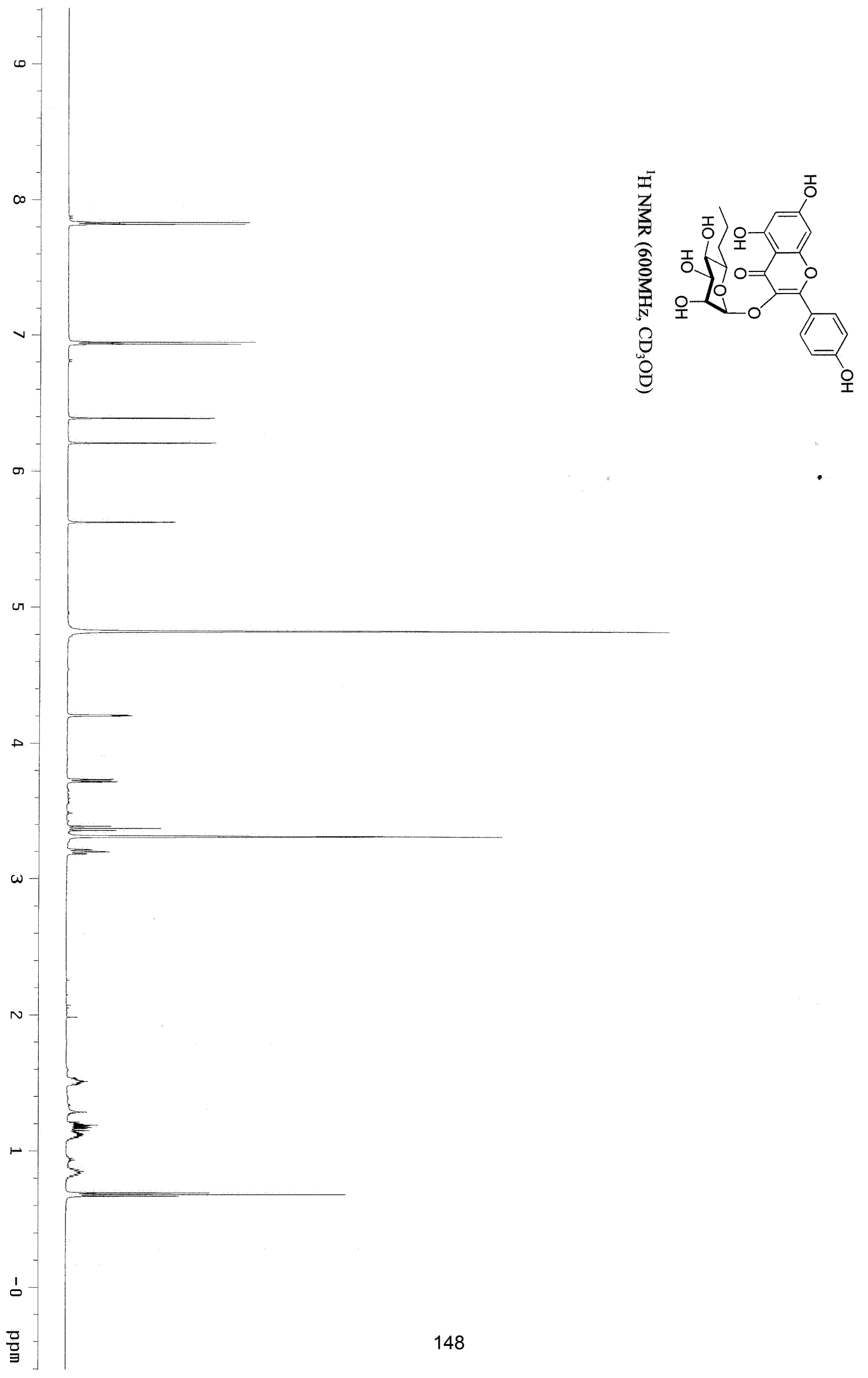




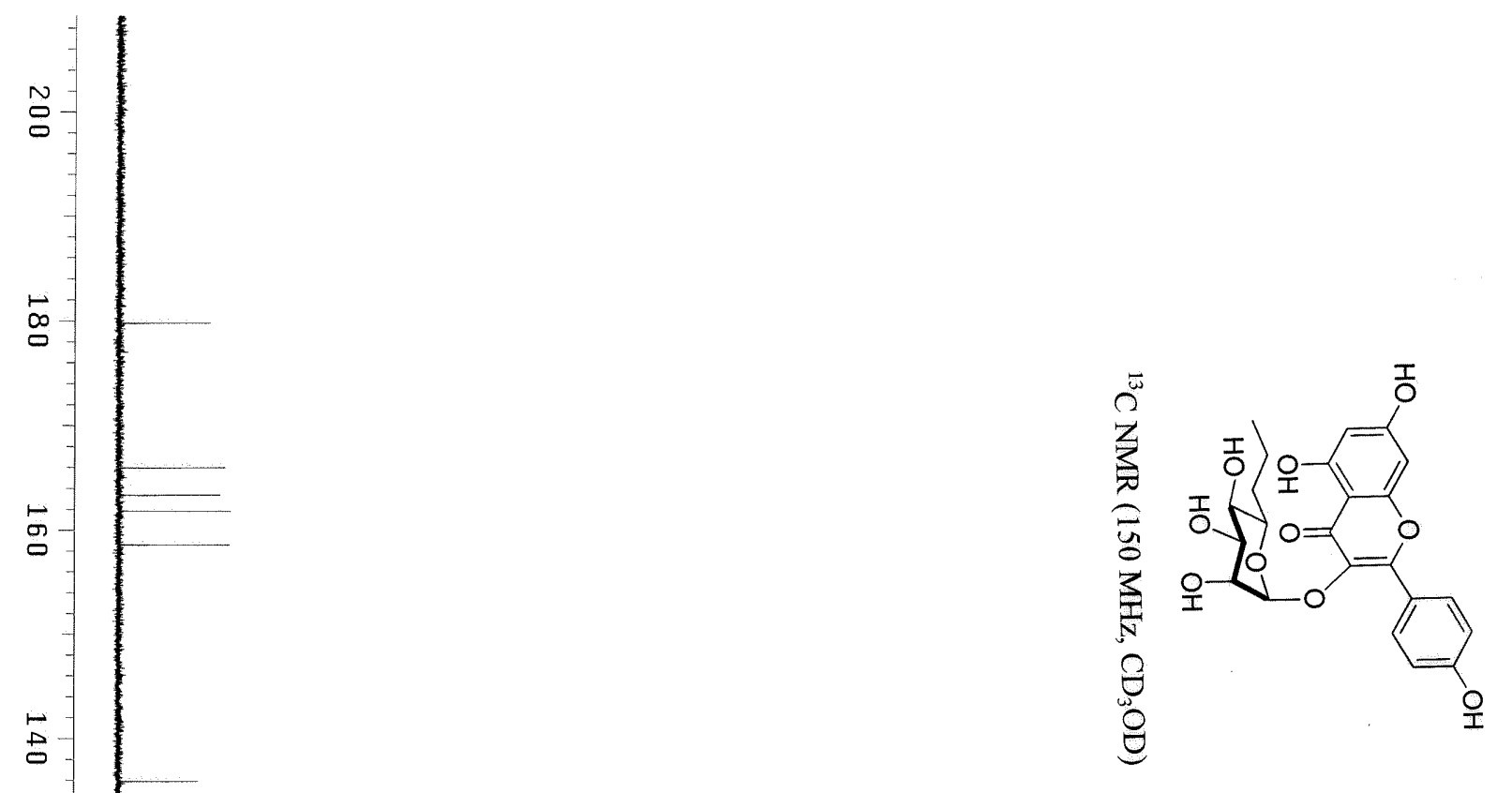

$\stackrel{\infty}{\circ}$

옹

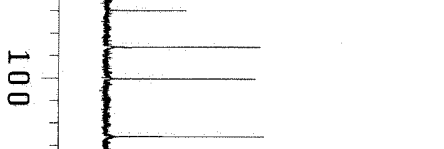

$\stackrel{\mathfrak{N}}{\circ}$

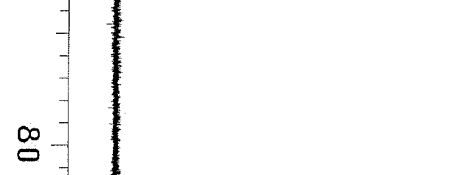

8

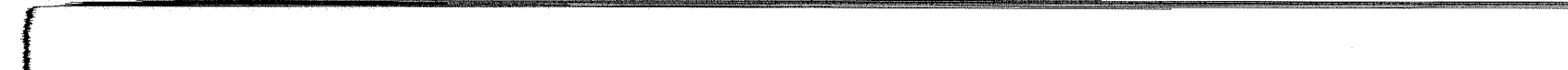

N

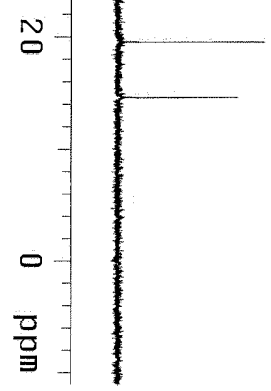



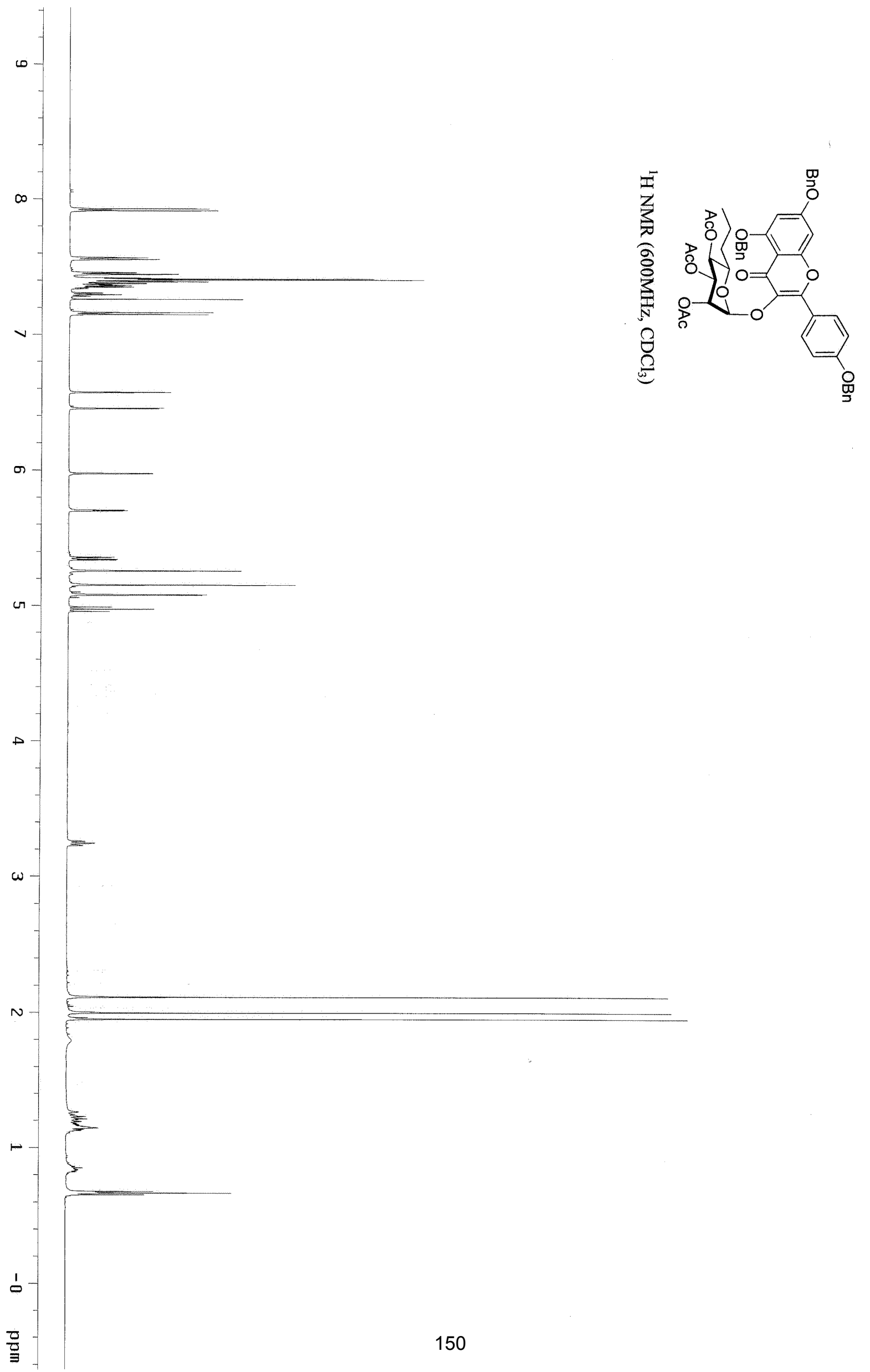


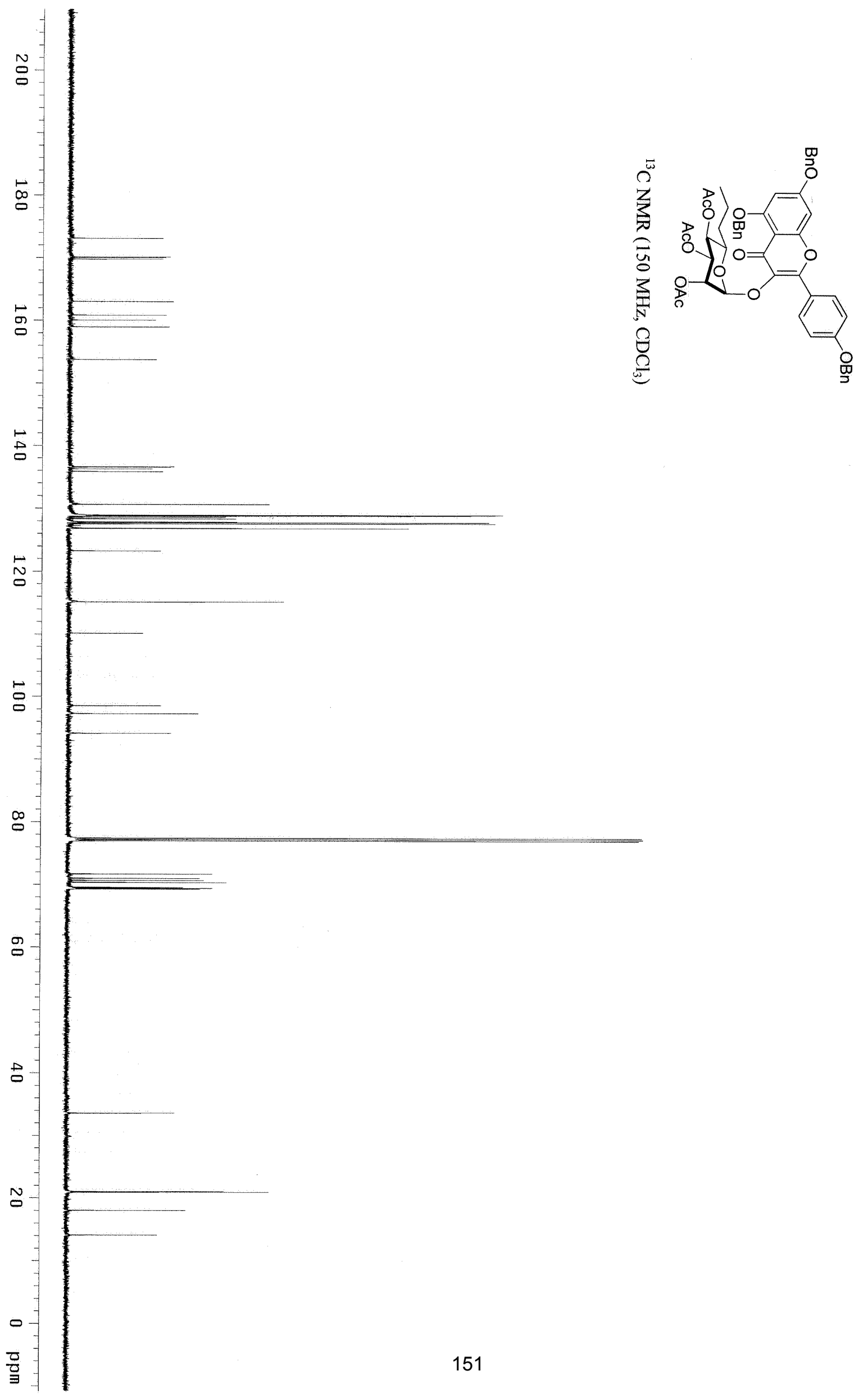



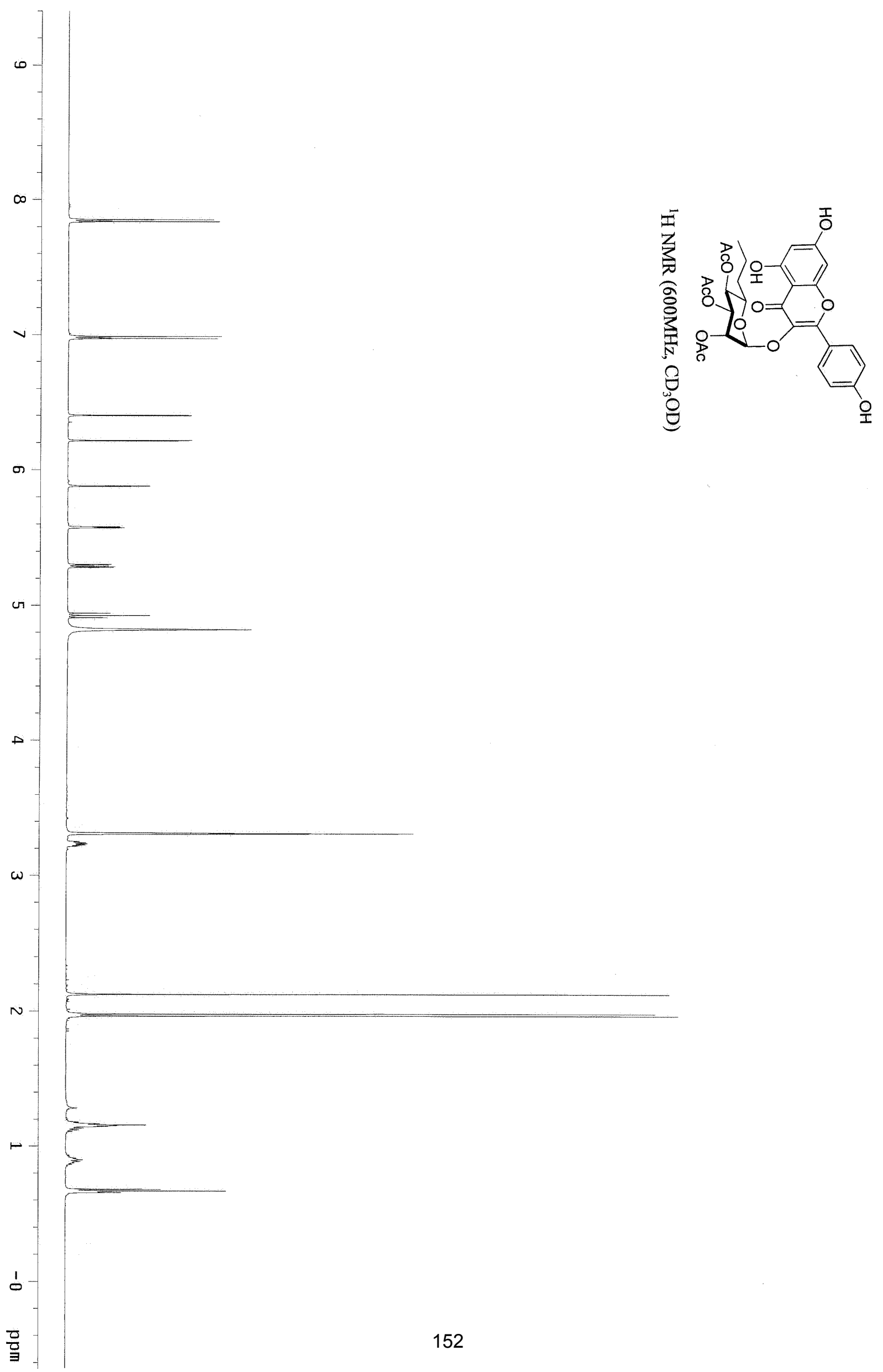


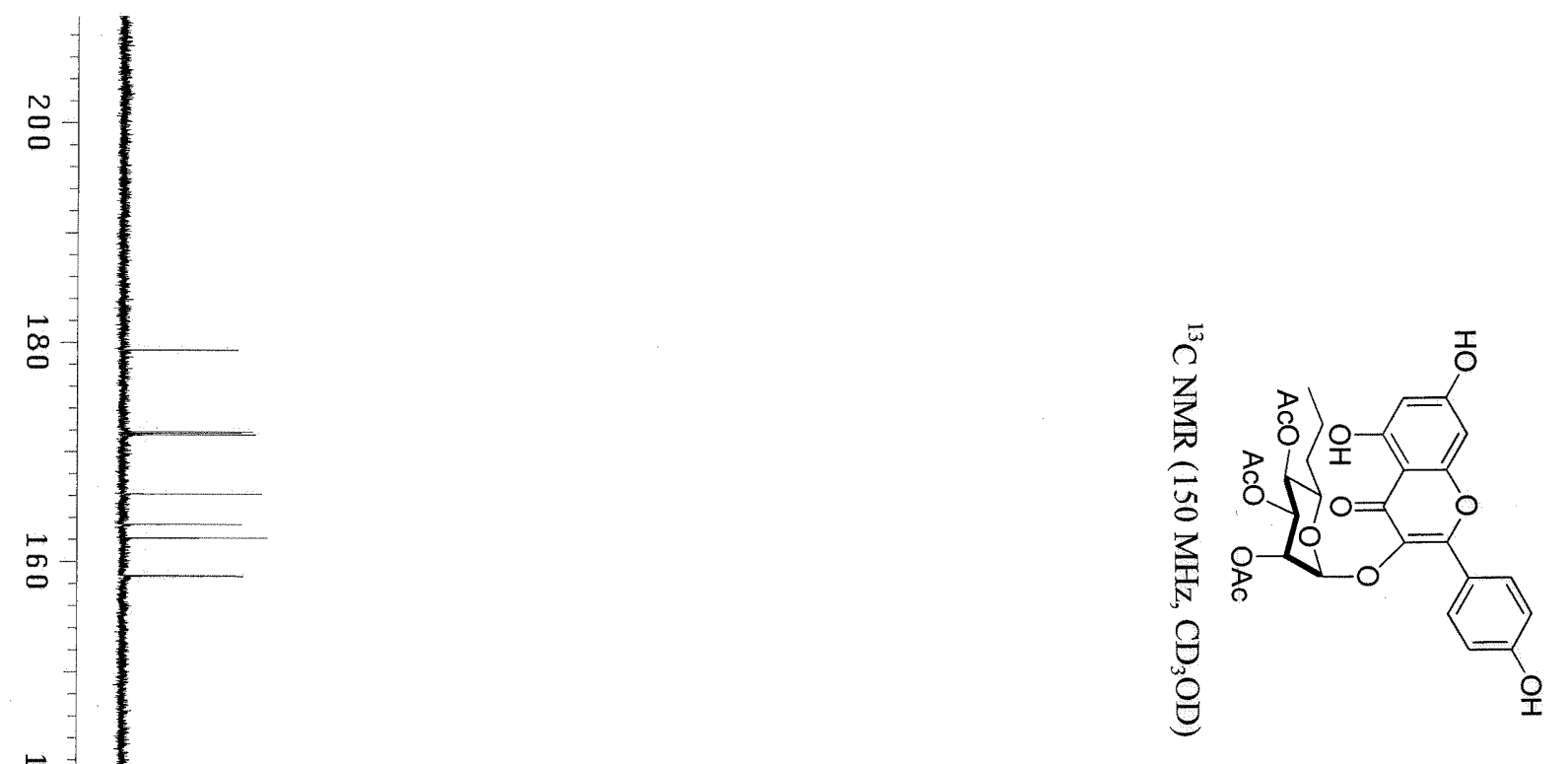

$\infty$

동

$\stackrel{\sim}{0}$

$D$
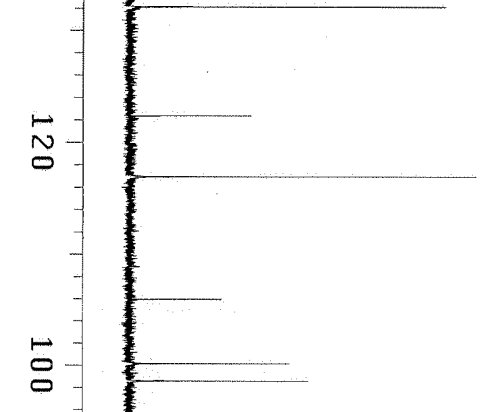

$\stackrel{\infty}{\circ}$

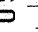

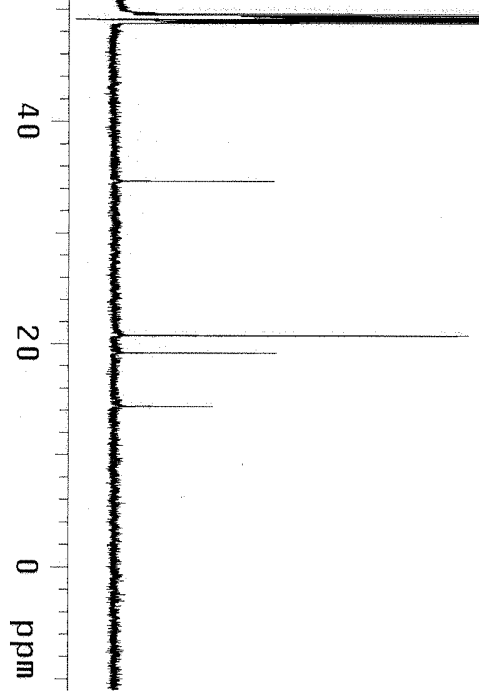




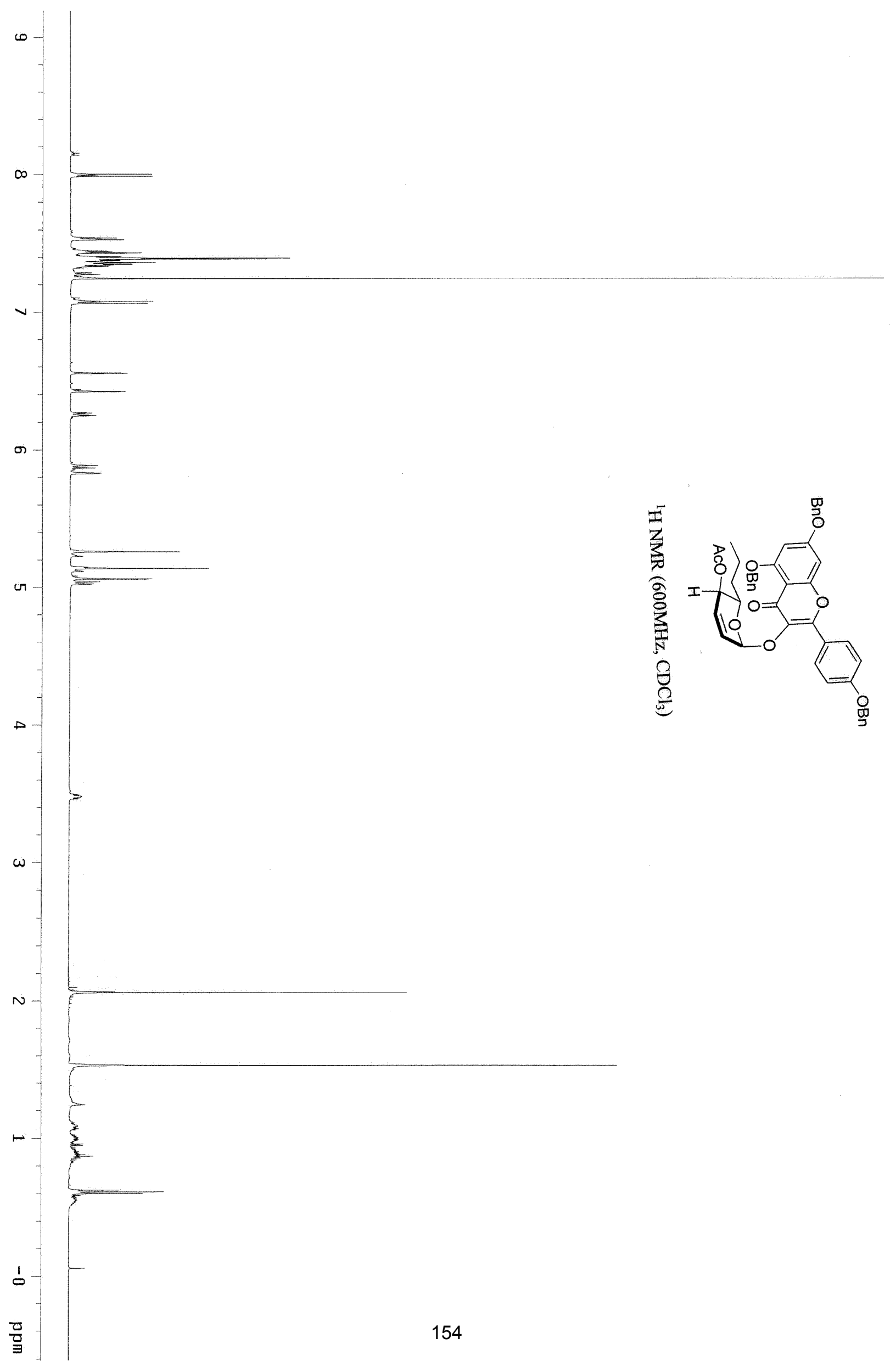




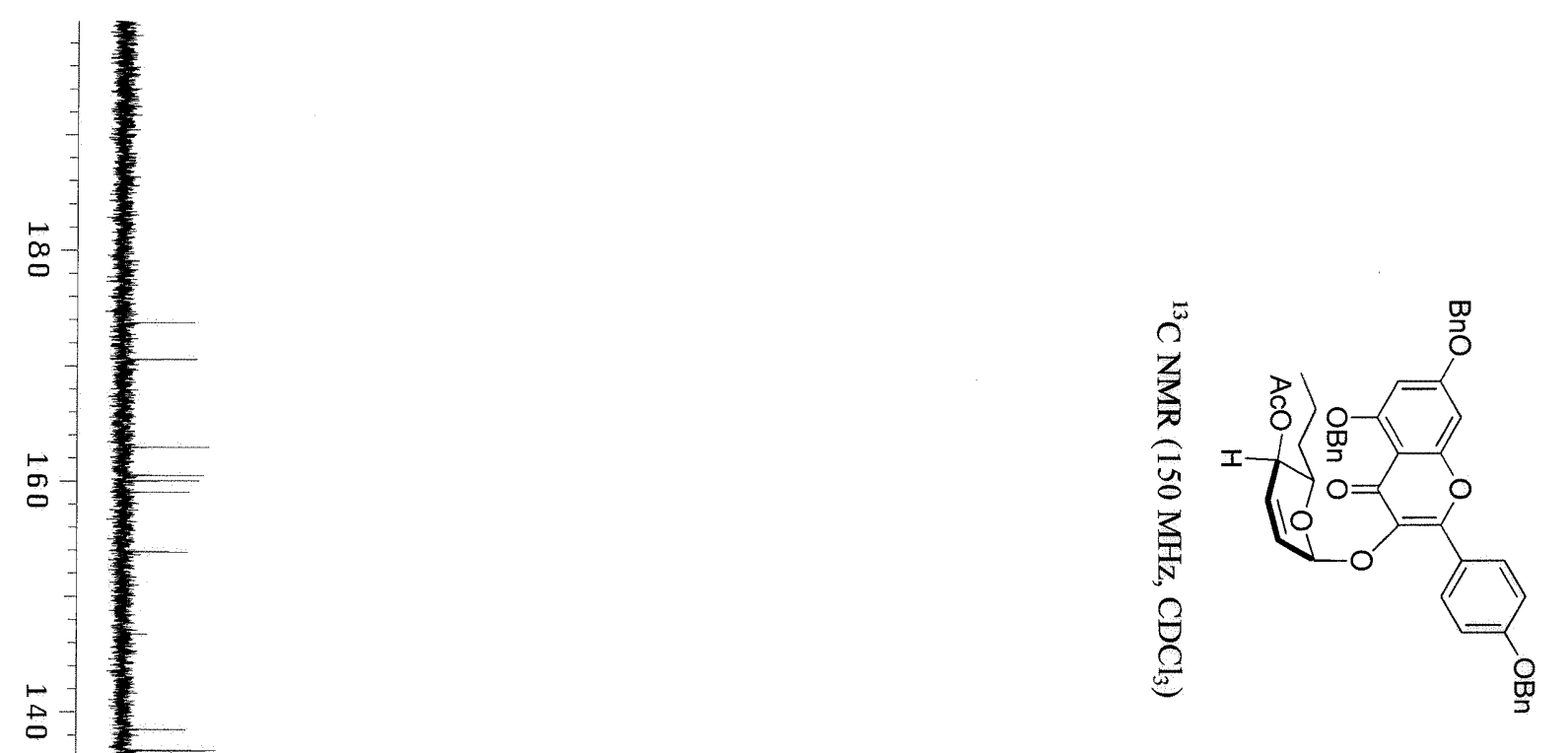




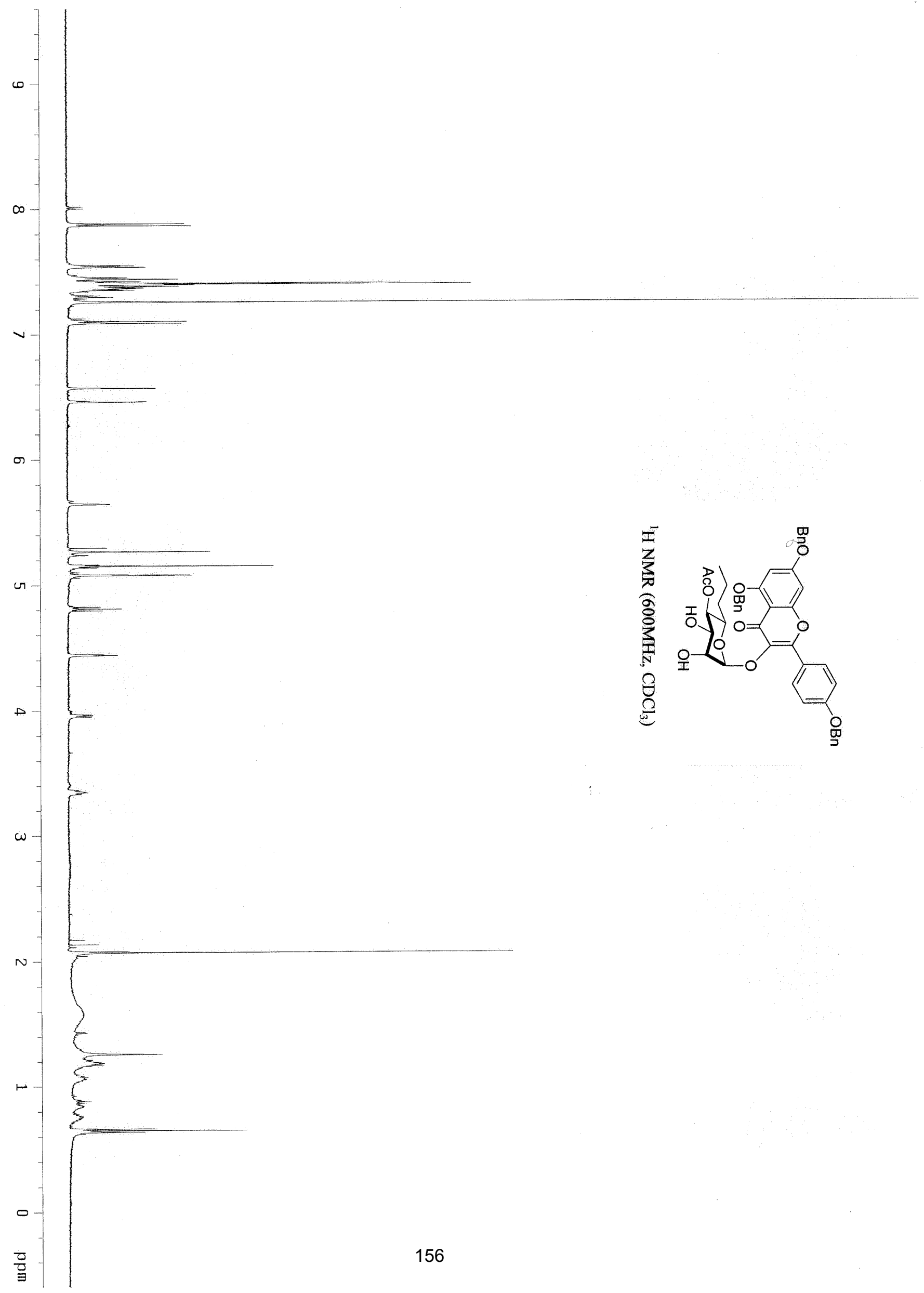




$$
\mid \text { |" }
$$




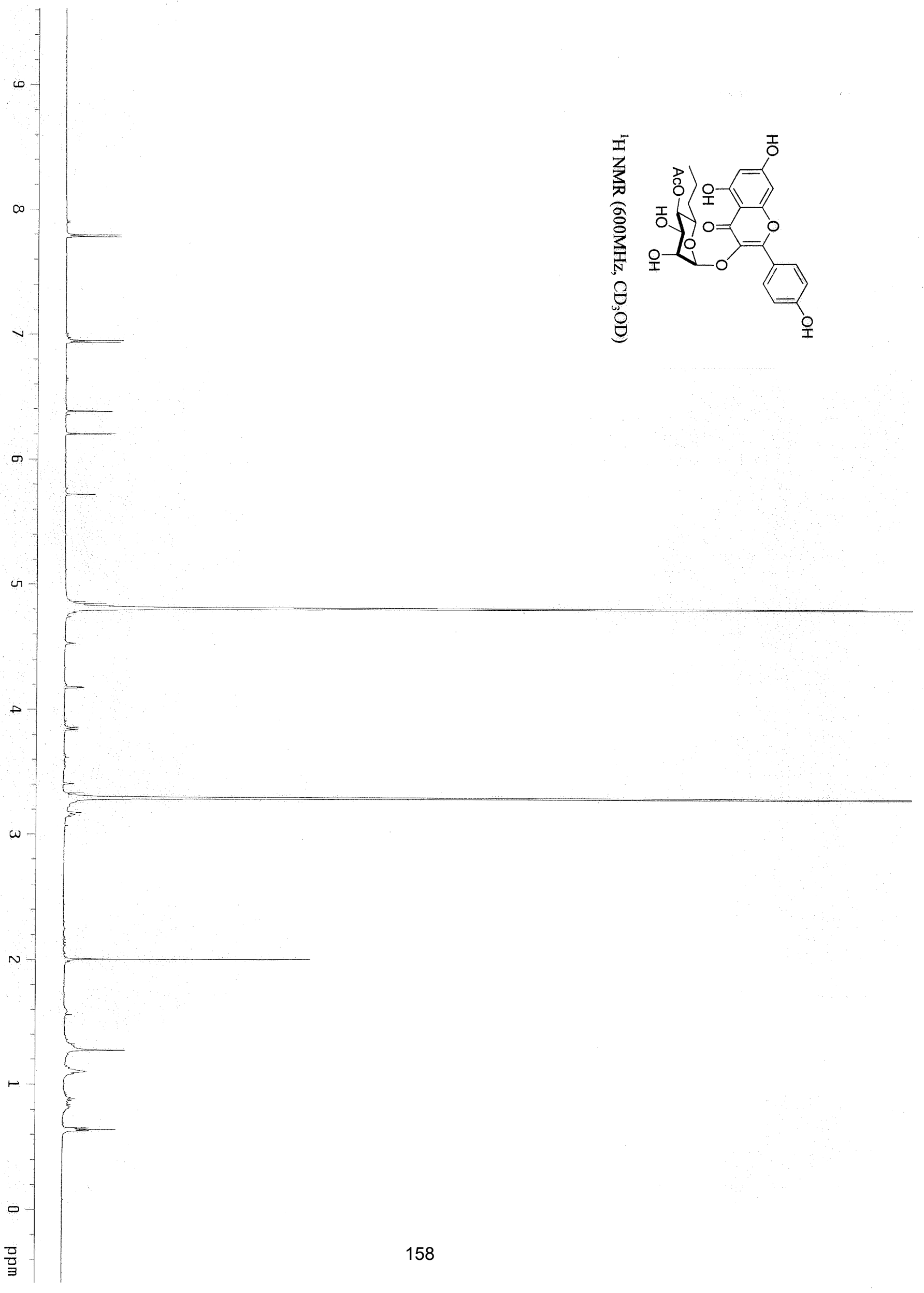




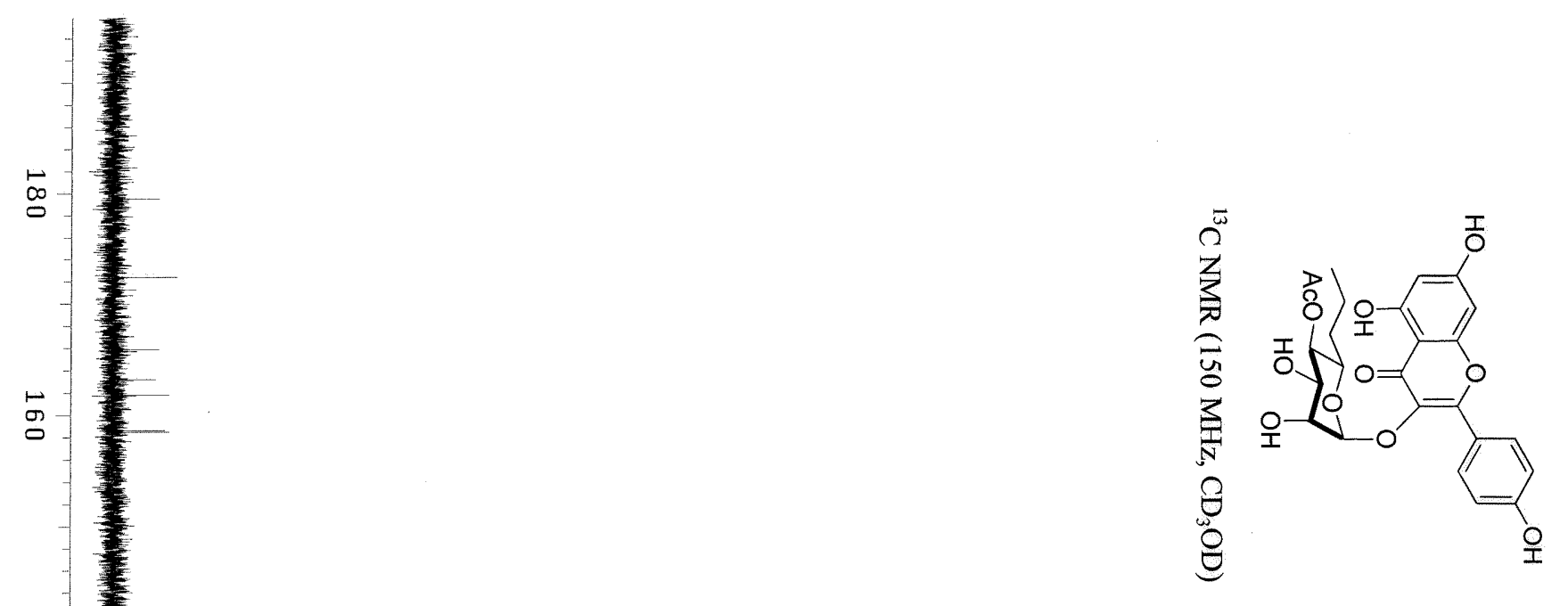

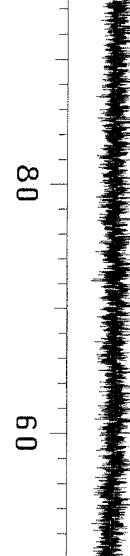

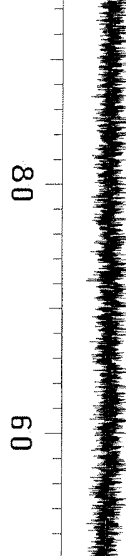

N

号

음

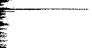

等旁



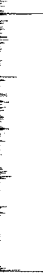




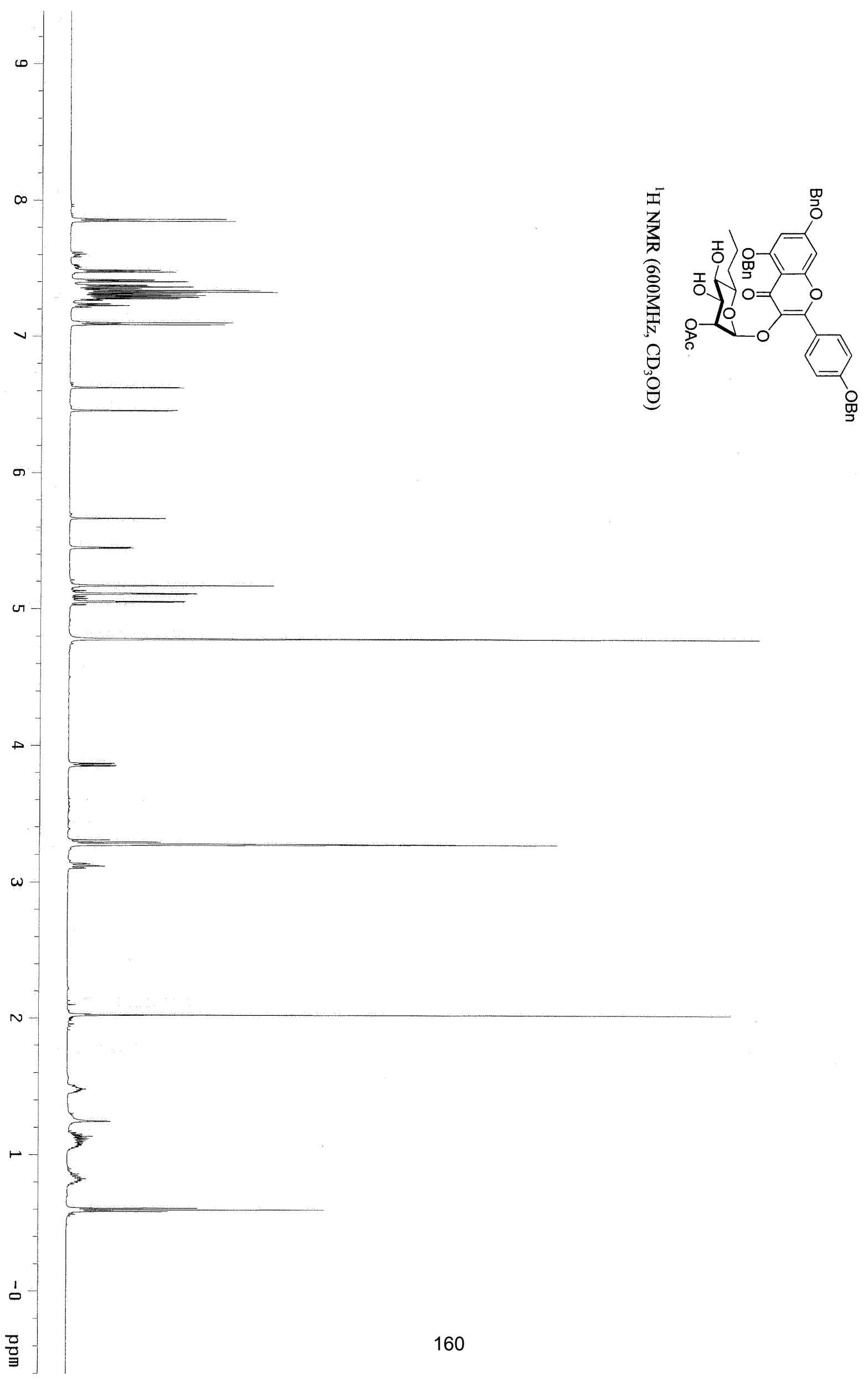



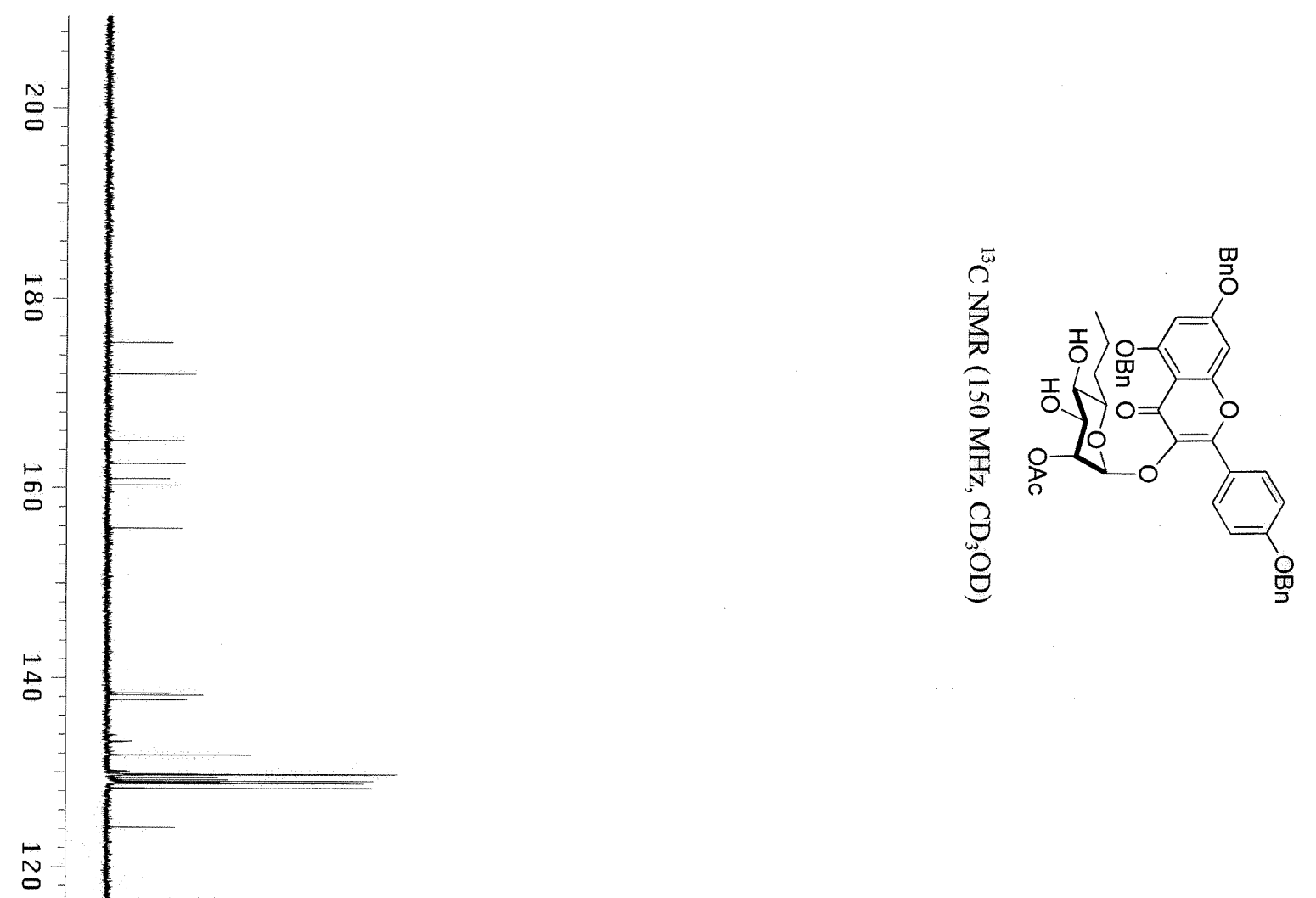

$$
\stackrel{\infty}{\circ}
$$

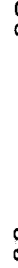

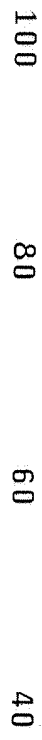
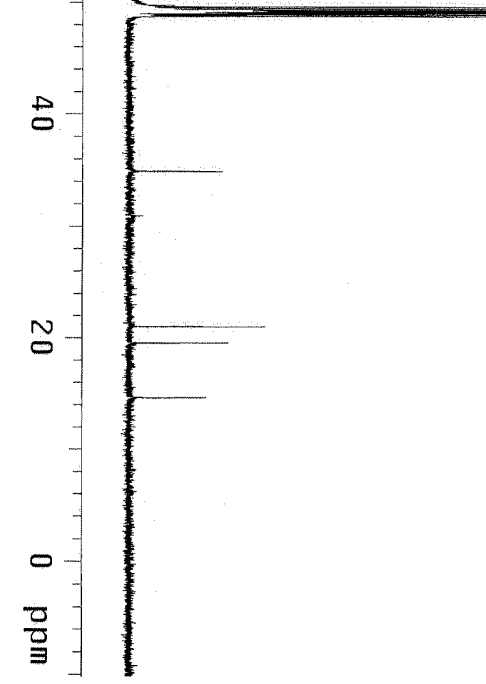

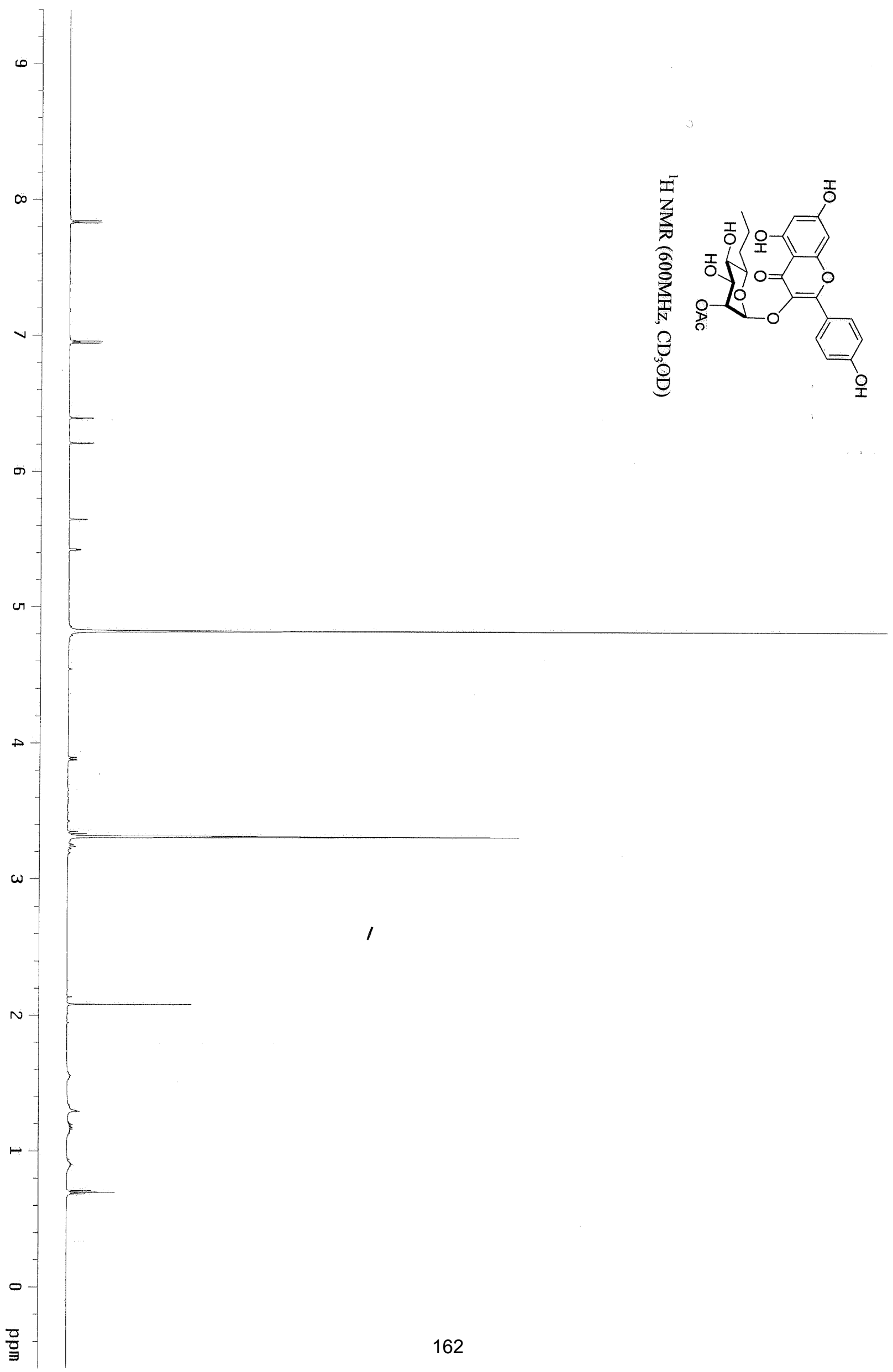


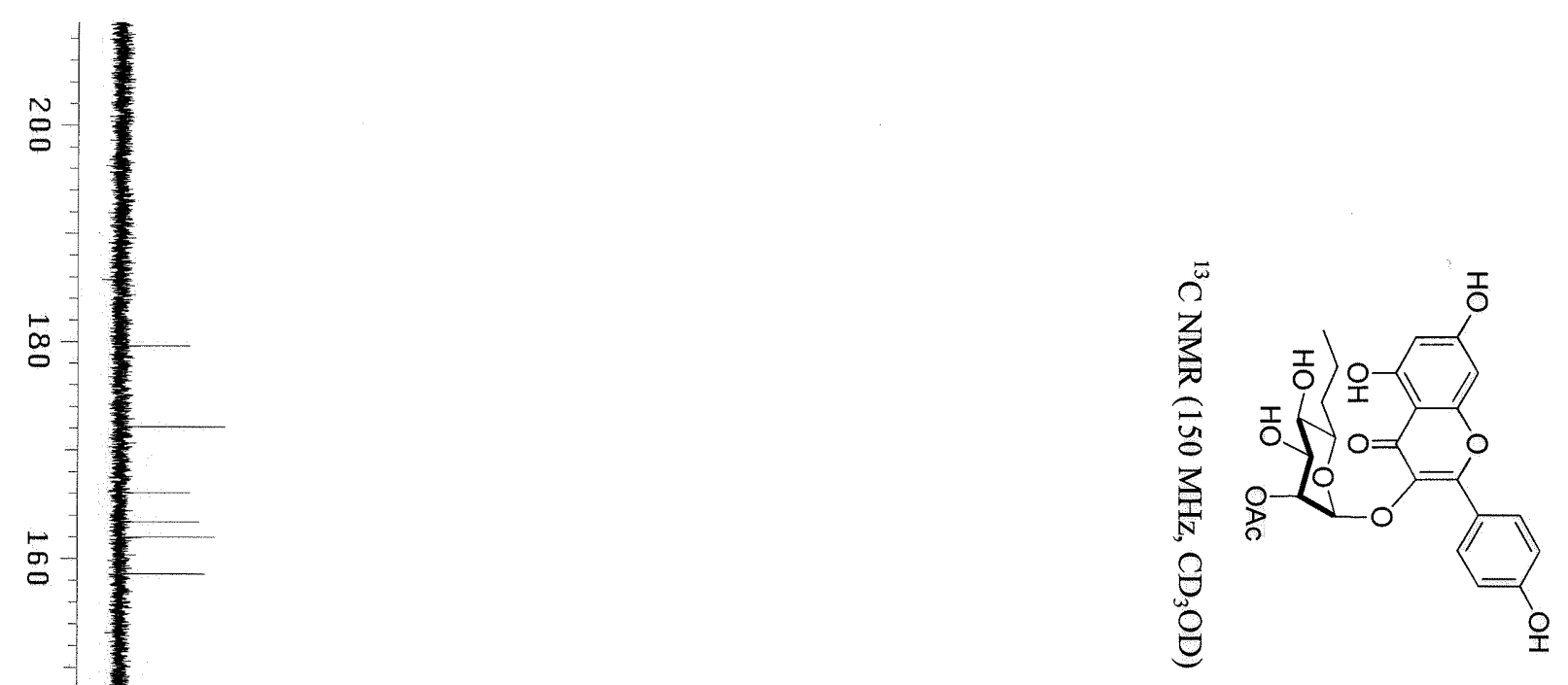

$\stackrel{\circ}{0}$

N

Of

등

0

$\stackrel{\infty}{\varnothing}$

g

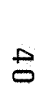

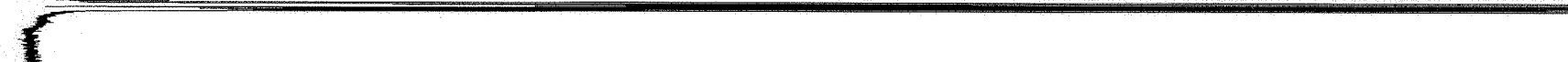

ㅁ

-

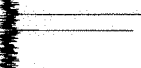

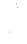

青毫 


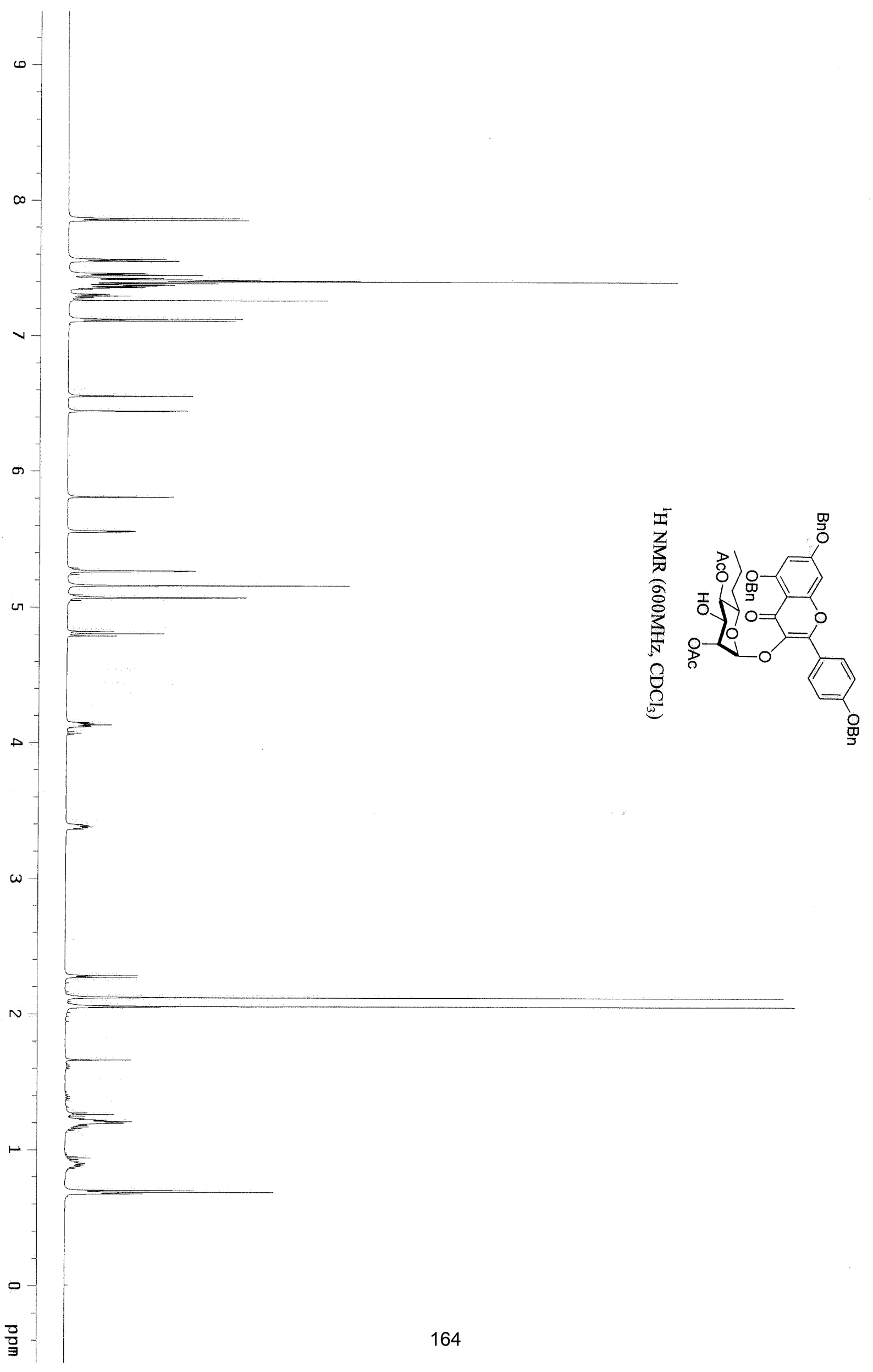




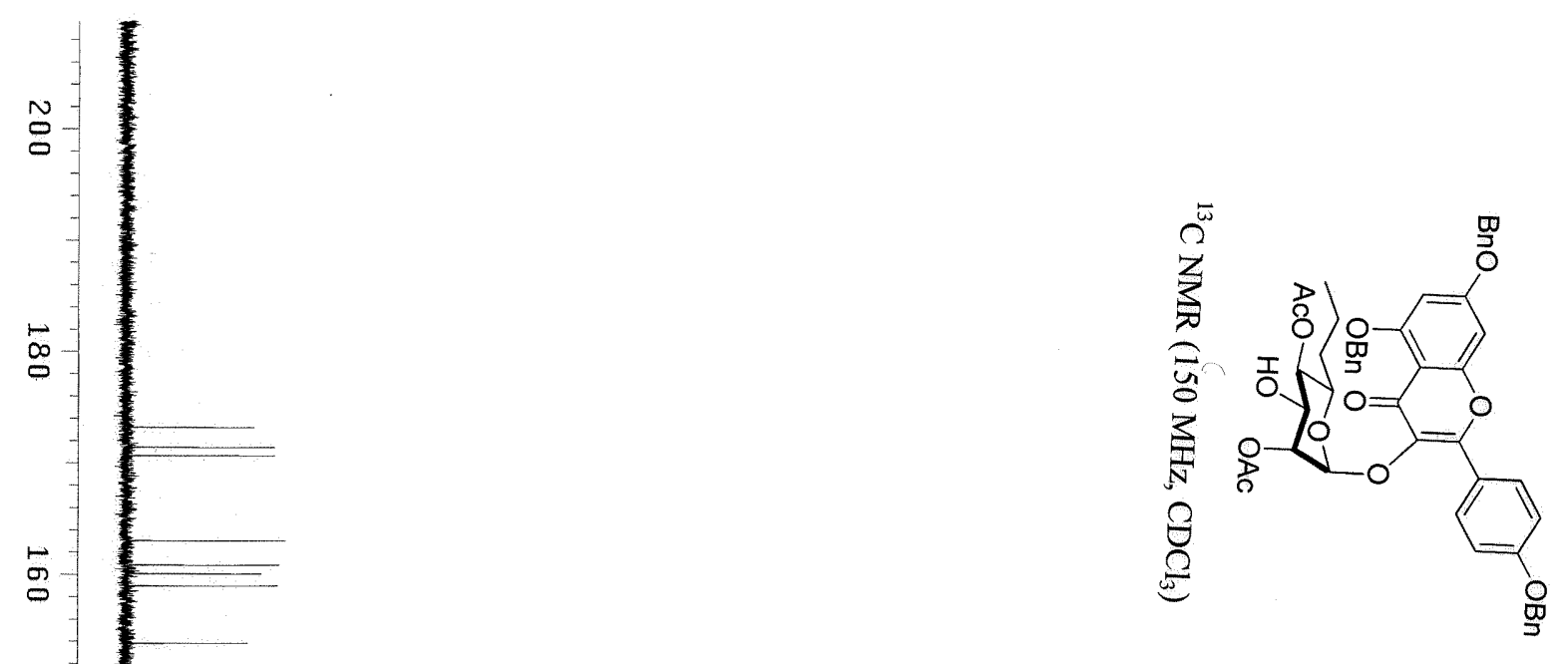

-

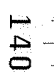

$\stackrel{\sim}{\sim}$

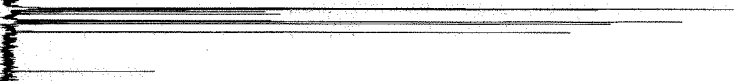

01

$-1$

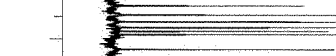

g.

i

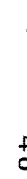

$\stackrel{8}{\circ}$

.

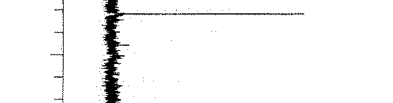



$\circ$.

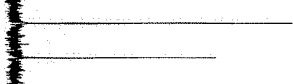

$+$

$\circ$

믑 


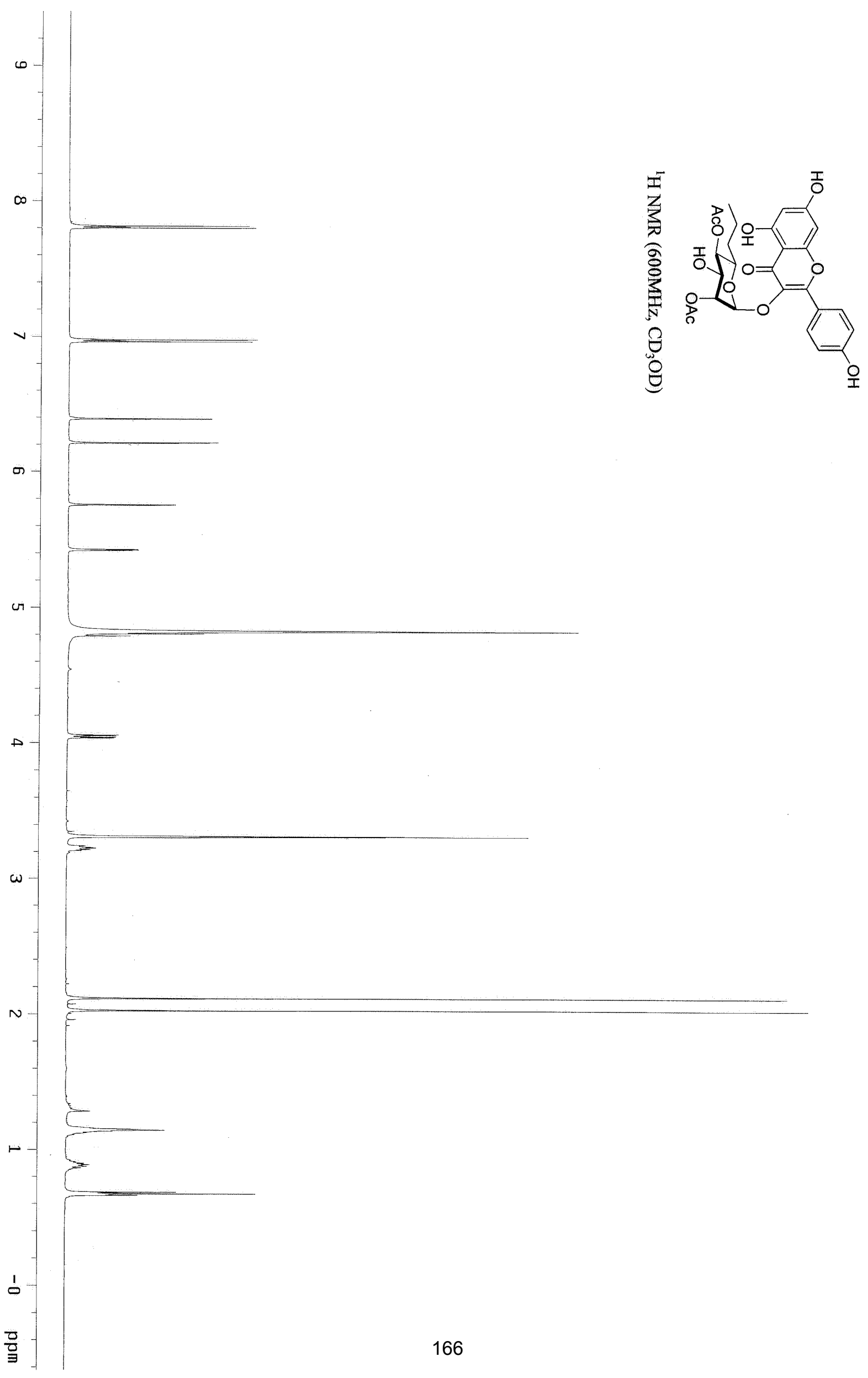




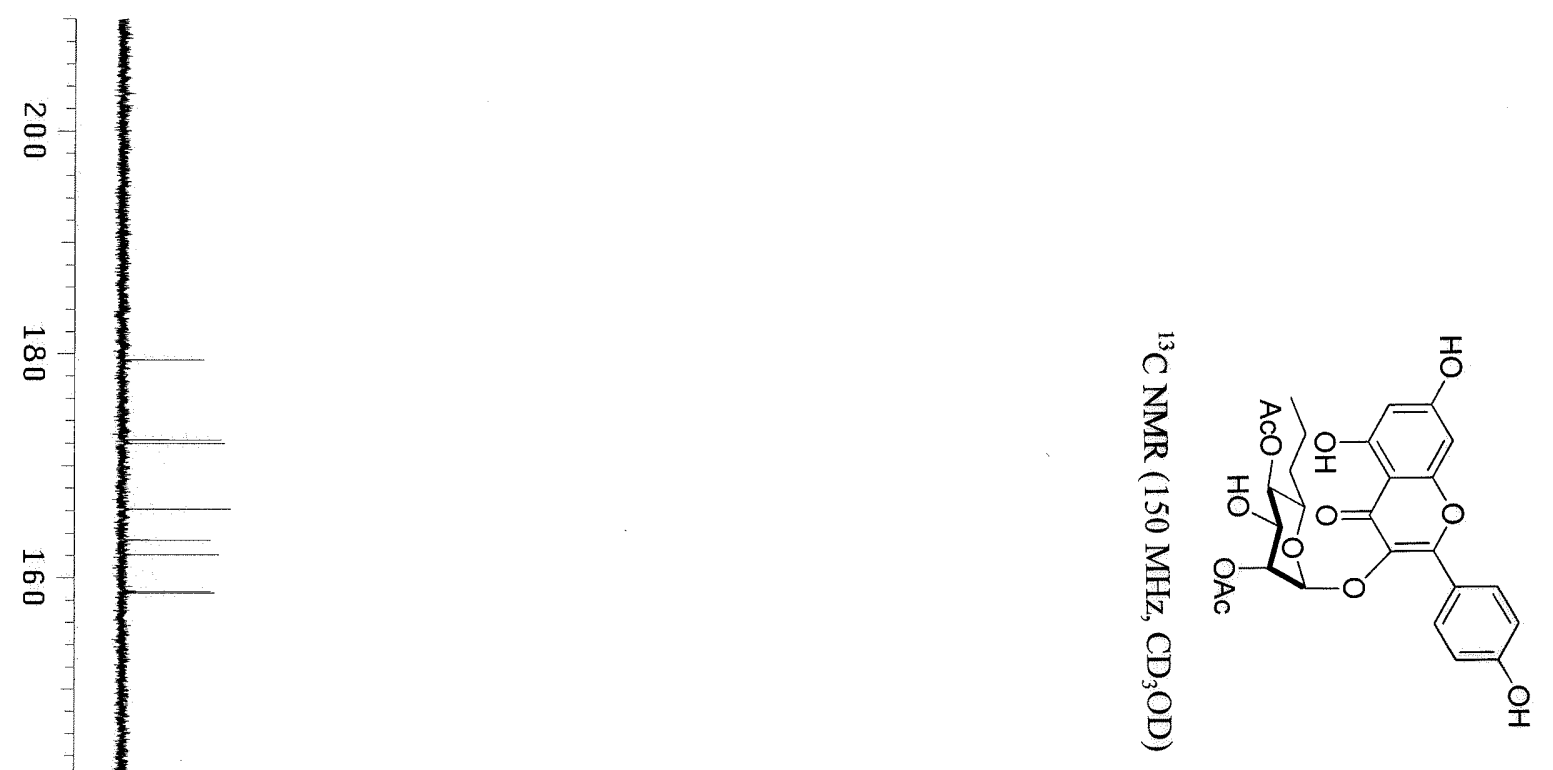

$\stackrel{\infty}{\circ}$

D

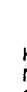

$\stackrel{N}{0}$

5

응-

$+$

$\infty$

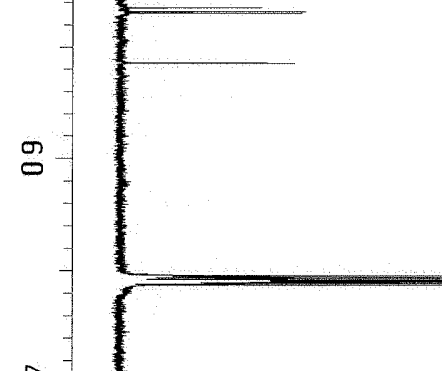

음

$\stackrel{\sim}{\Xi}$

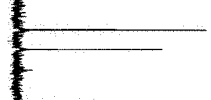

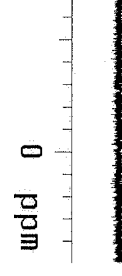




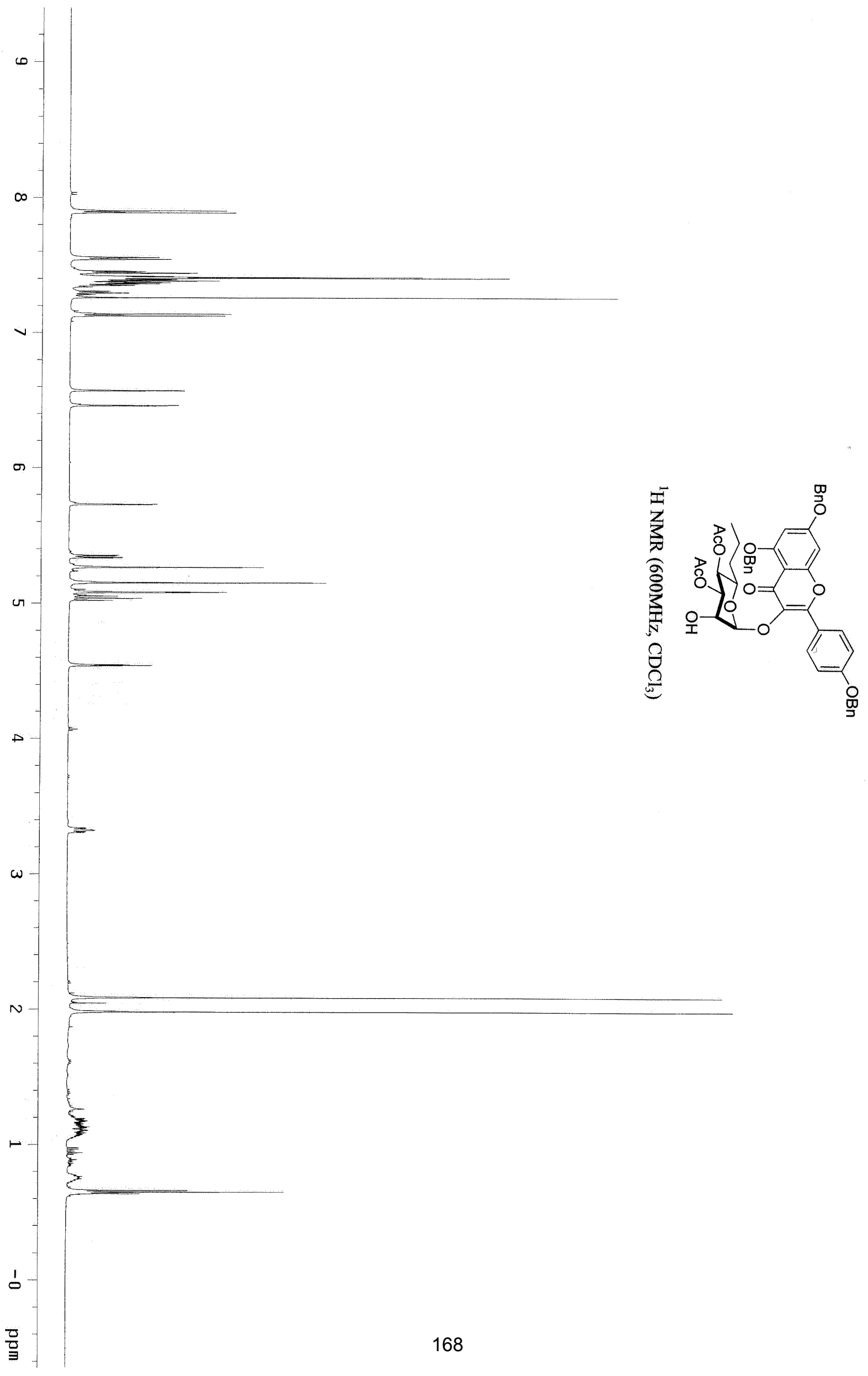




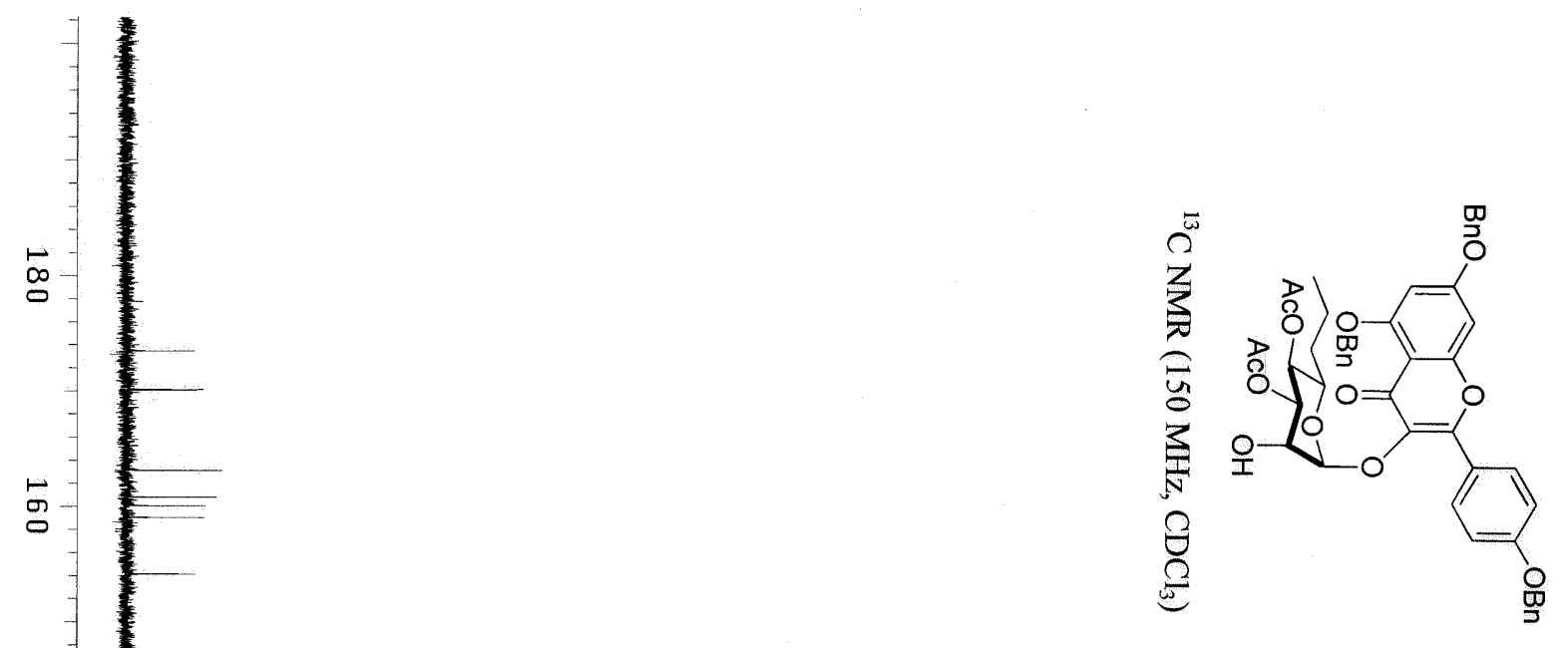

$\stackrel{\bullet}{\circ}$

:

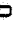

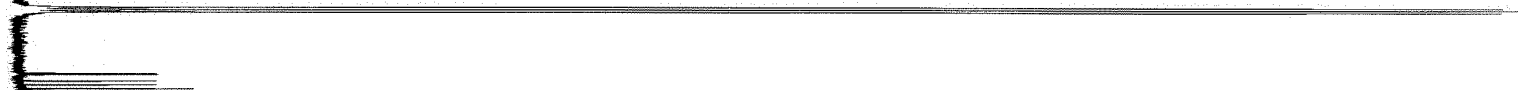

क

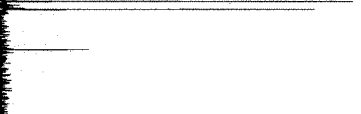

$\Xi$

ס

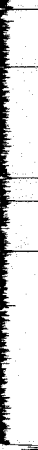




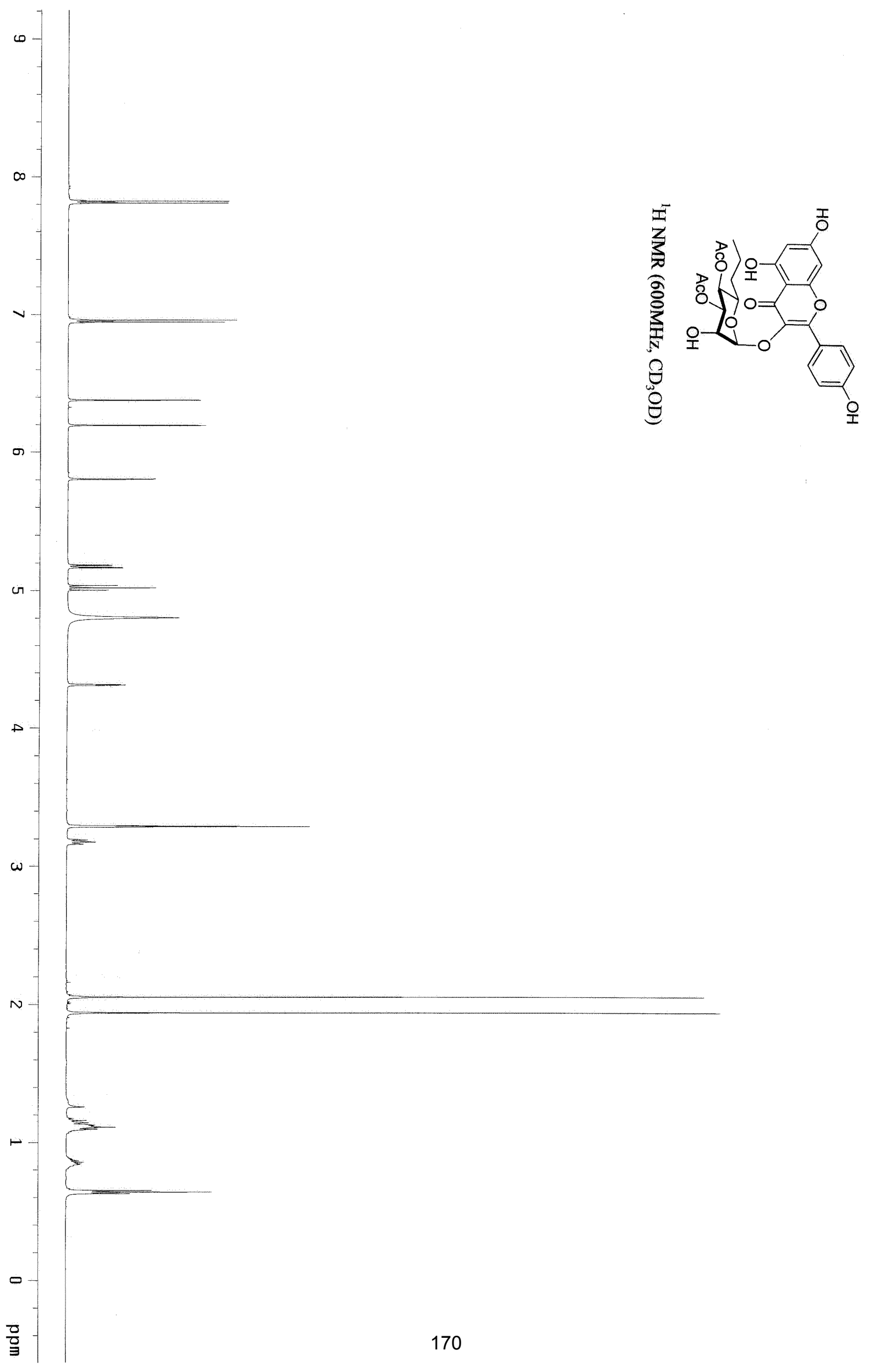




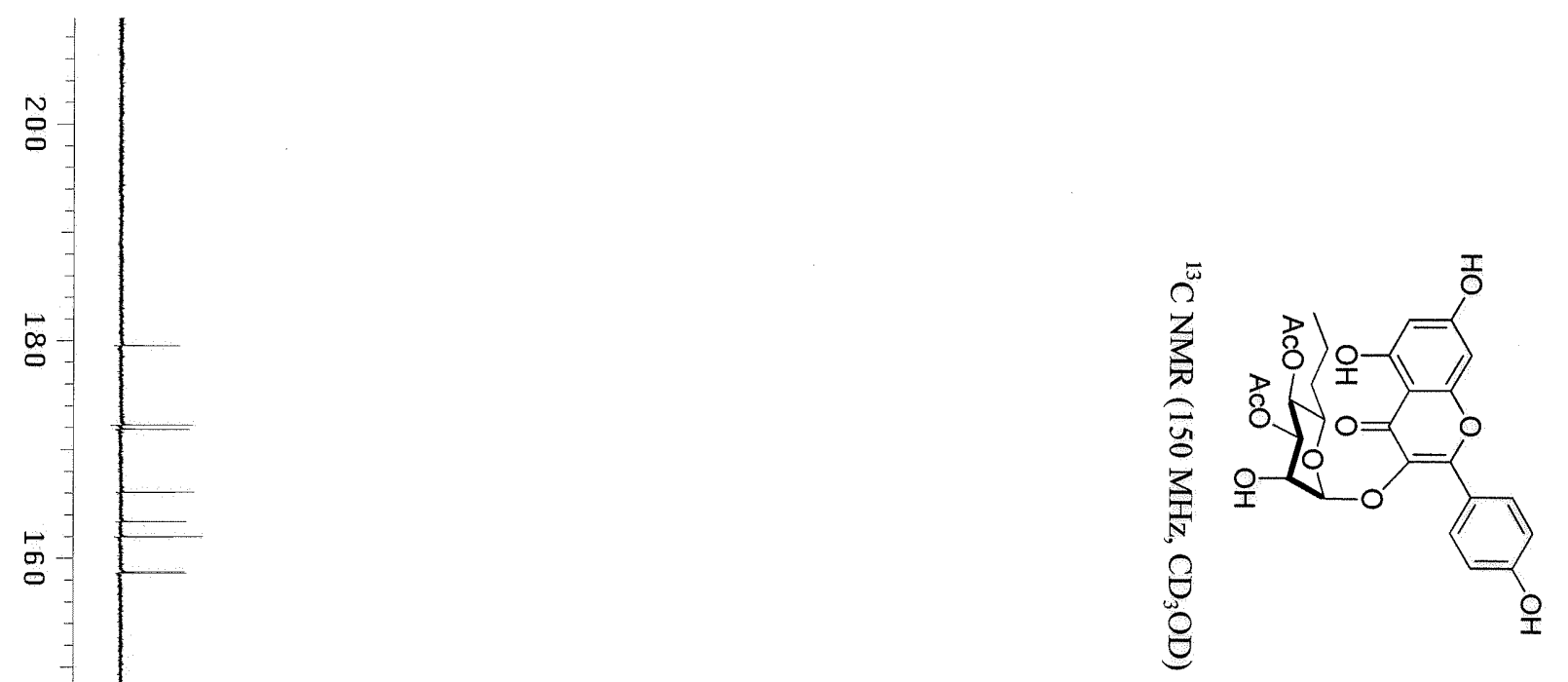

虽
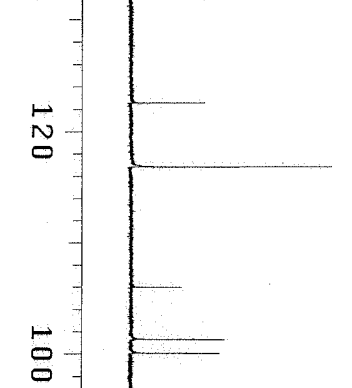

$\stackrel{\infty}{\circ}$

g

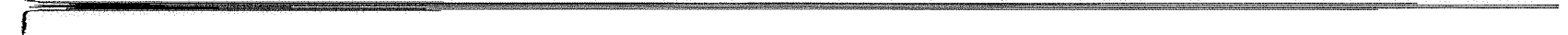

$+$

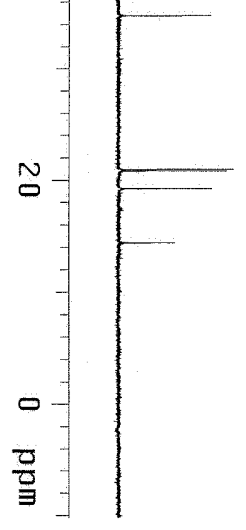




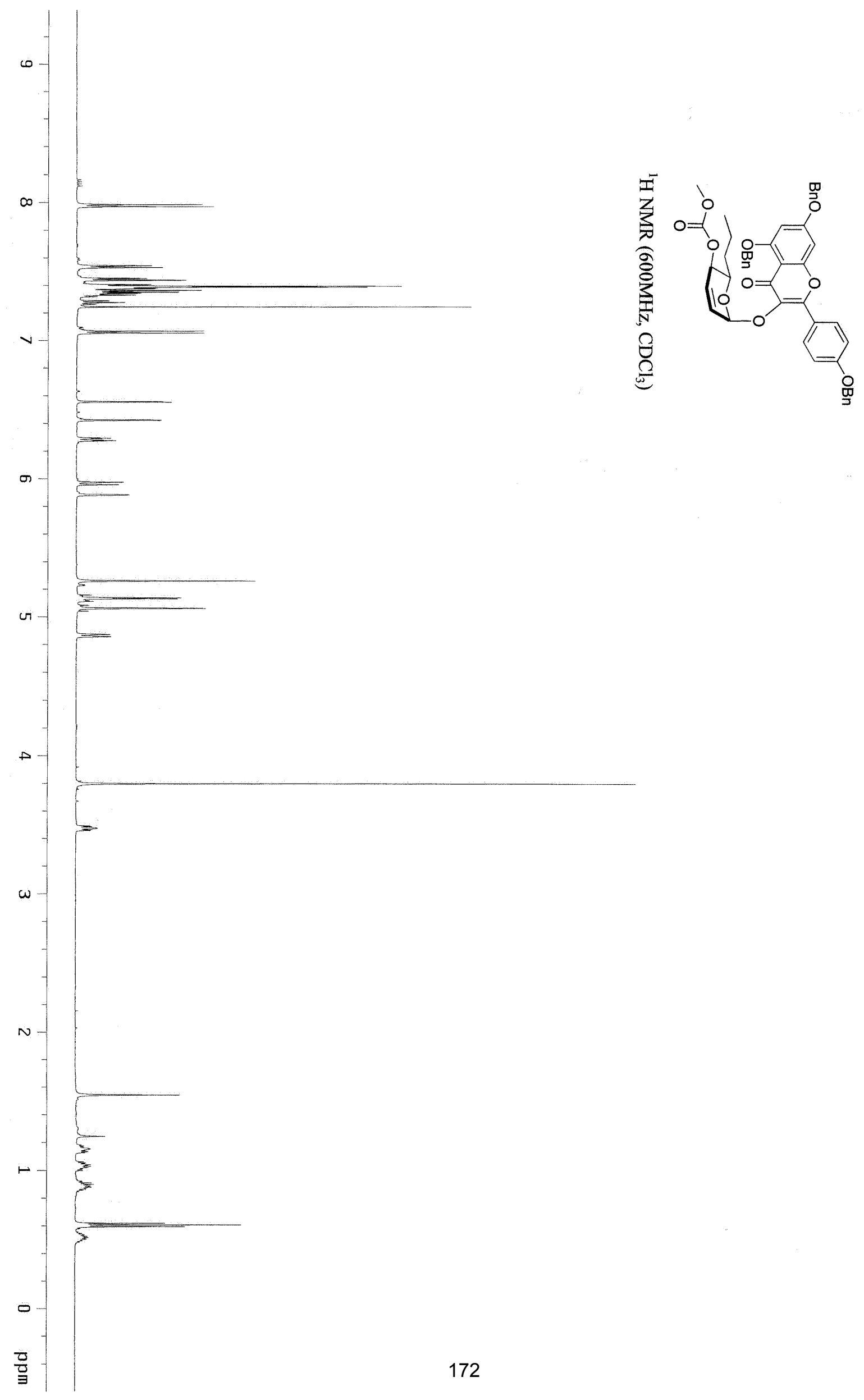




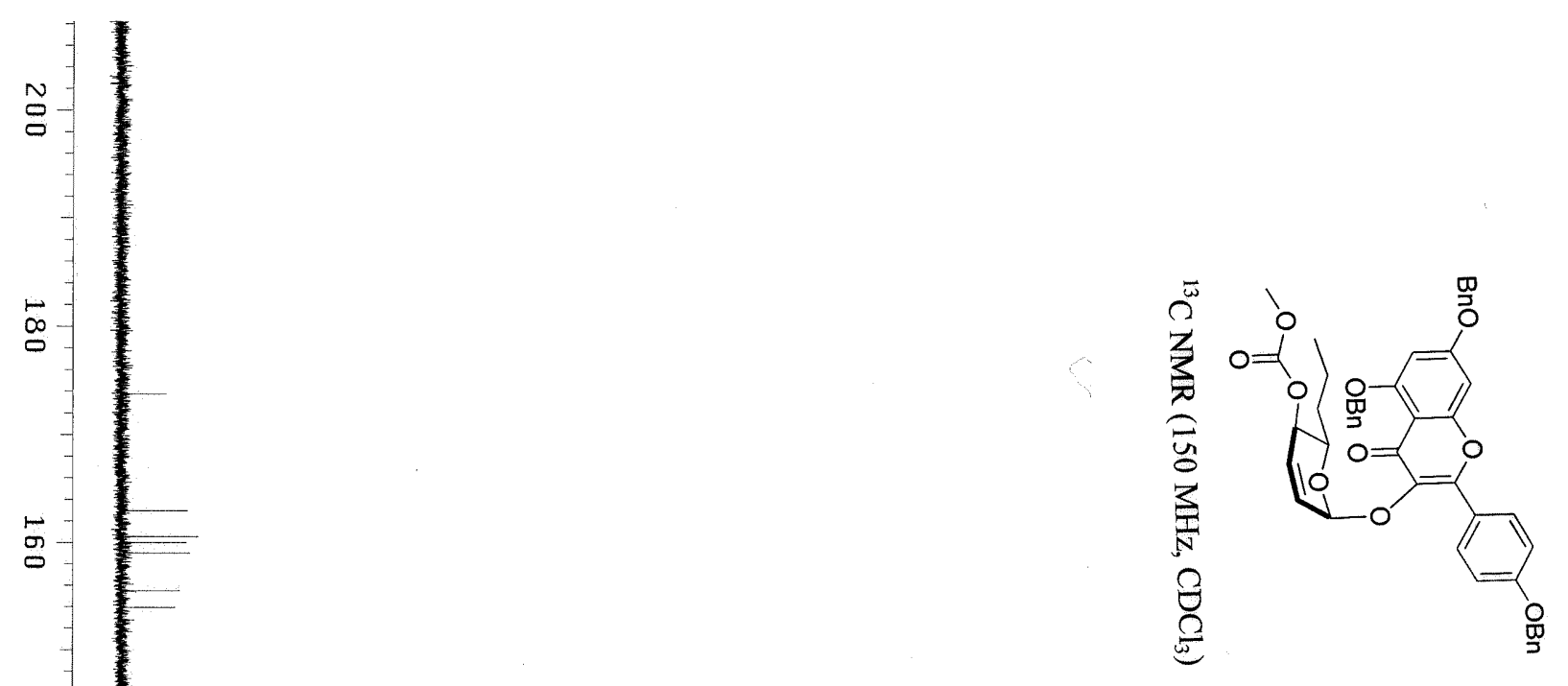

8

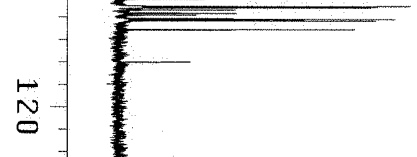




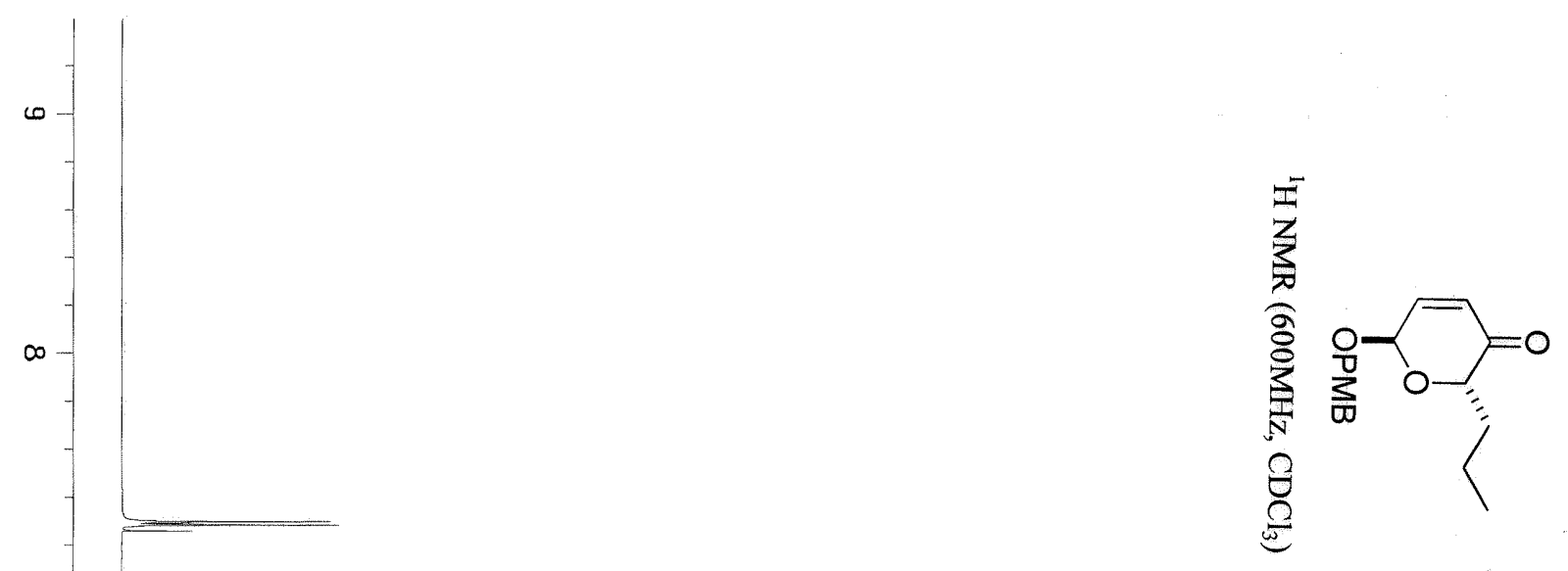

$\omega$

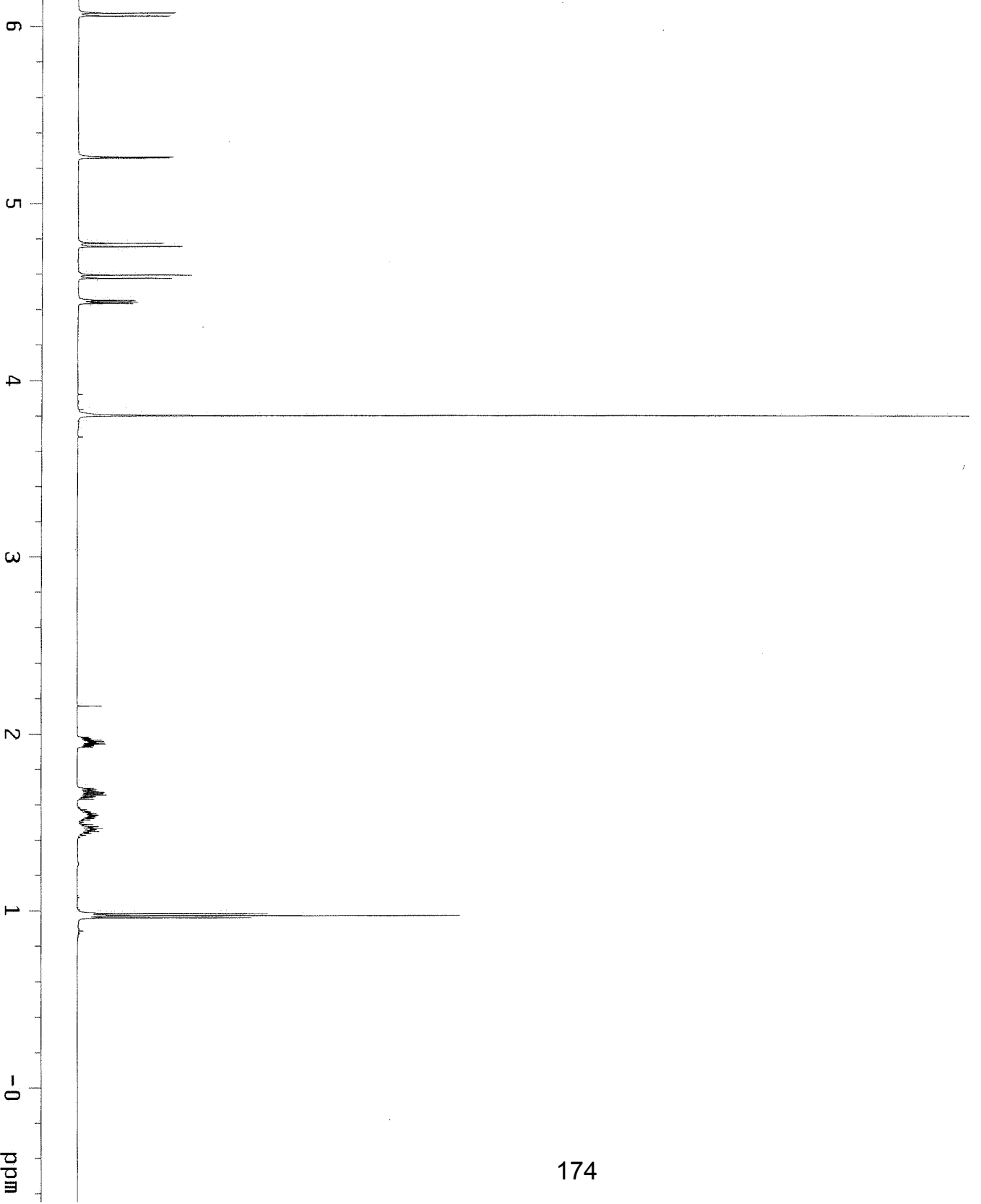




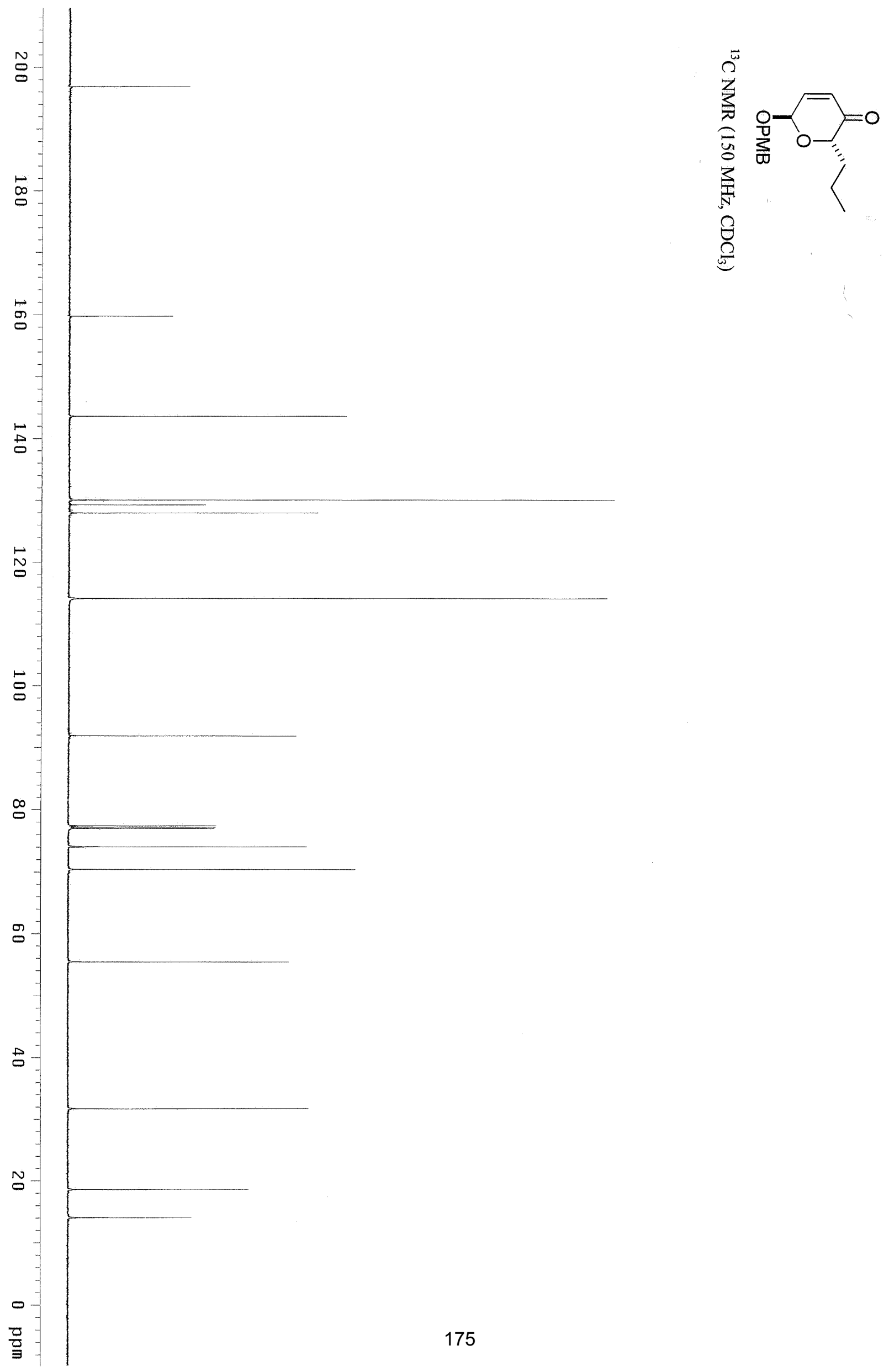



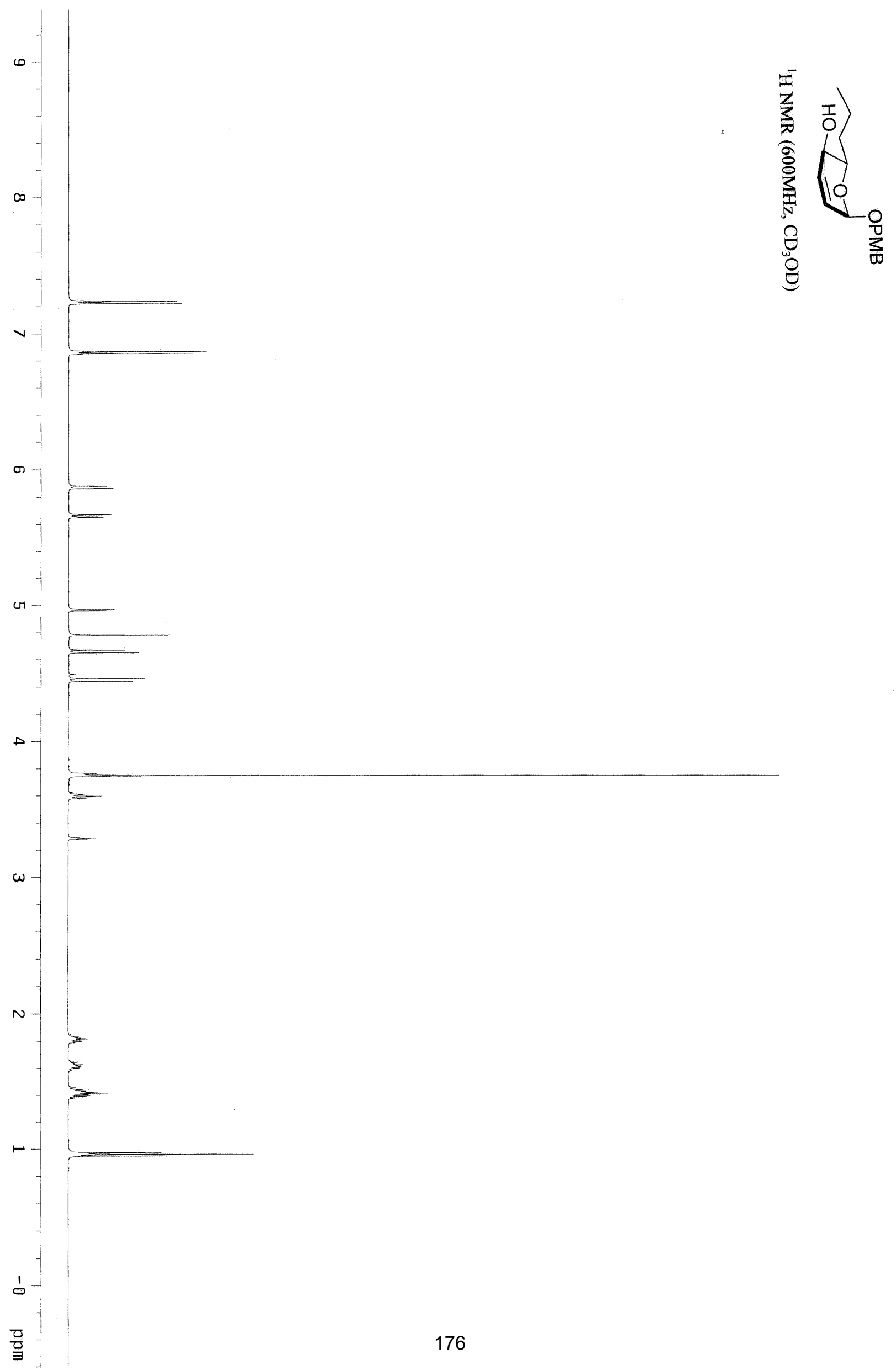


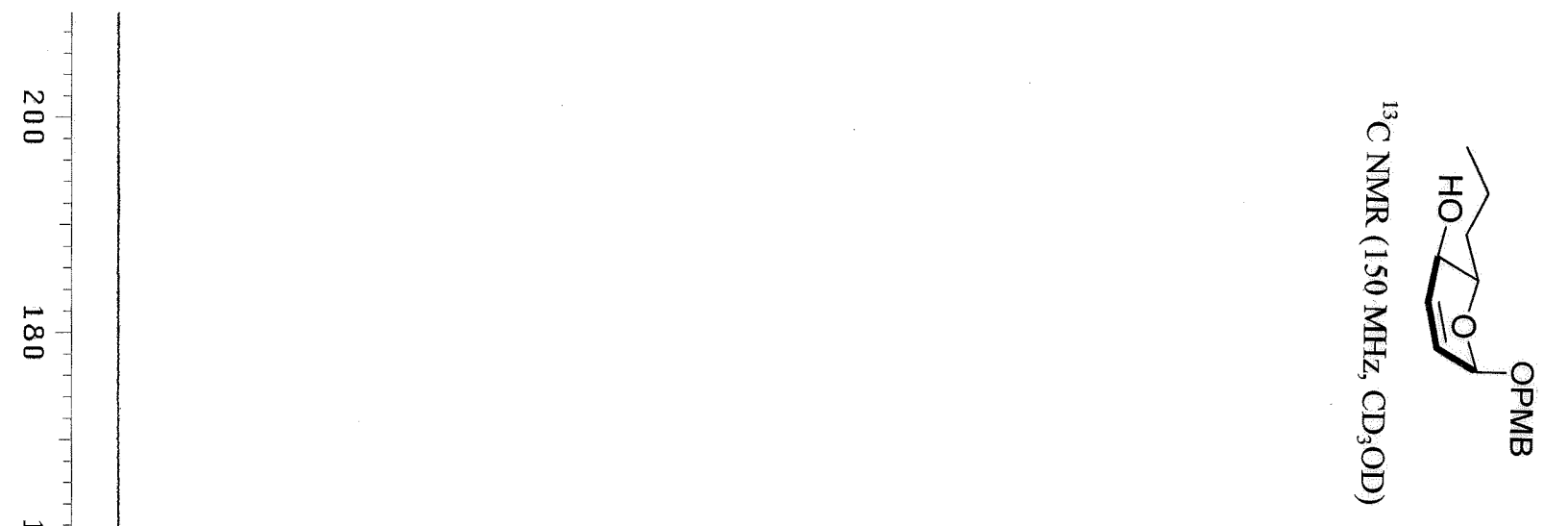

宁

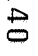

$\stackrel{0}{0}$

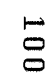

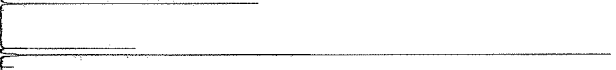

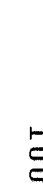

$\infty$

g

0

$\dot{0}$

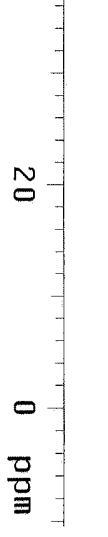




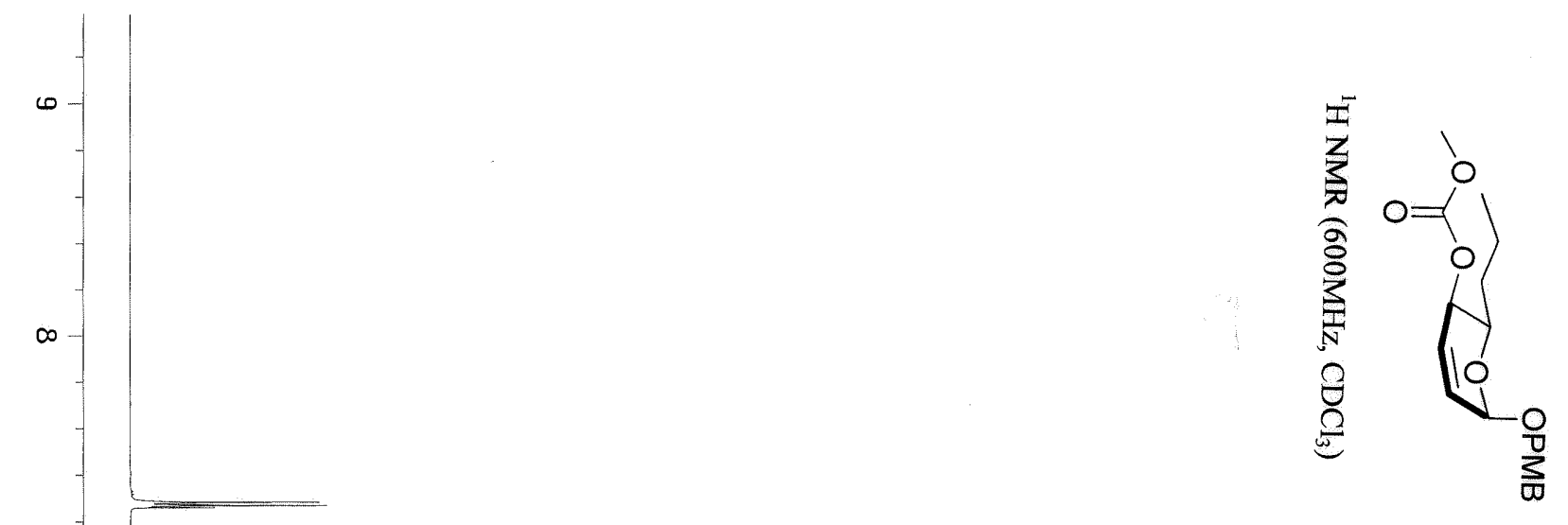




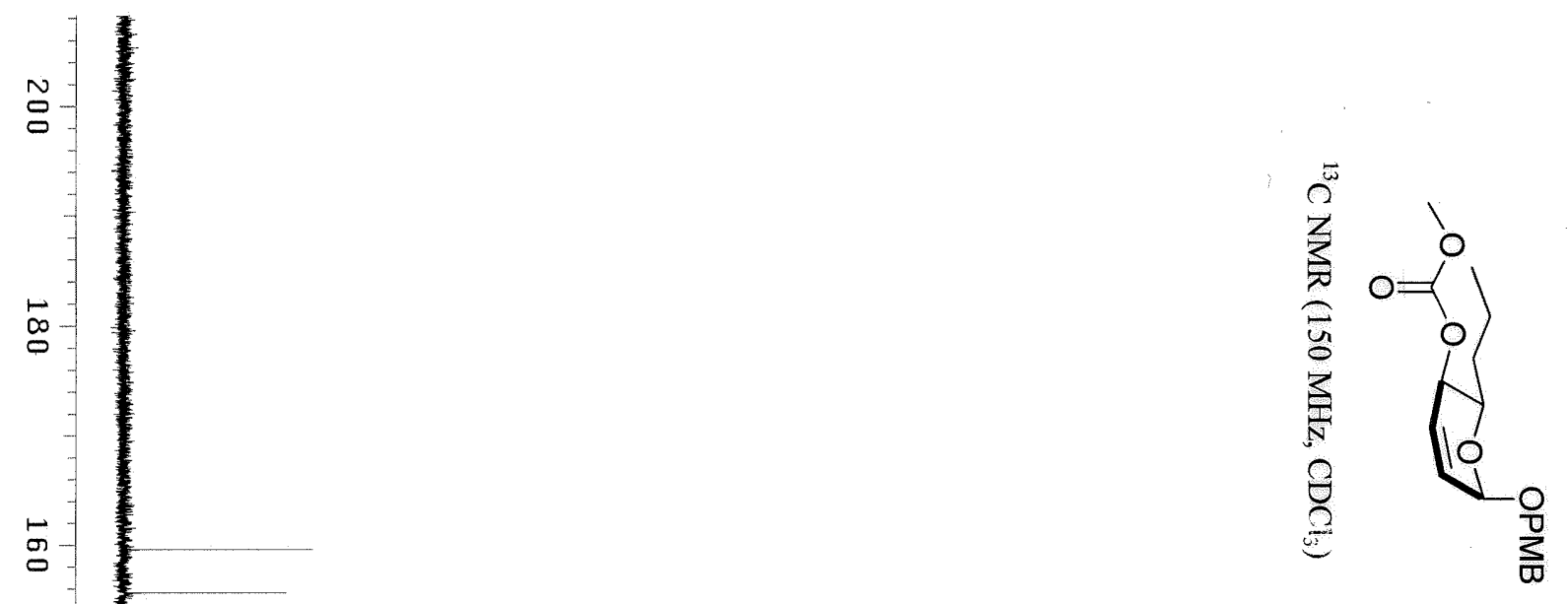

$\infty$

$\circ$

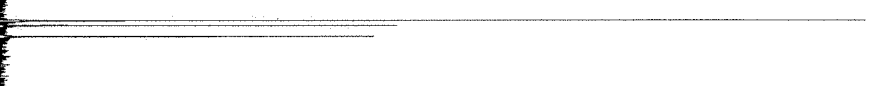

$\stackrel{5}{0}$

N-

$B$

官-

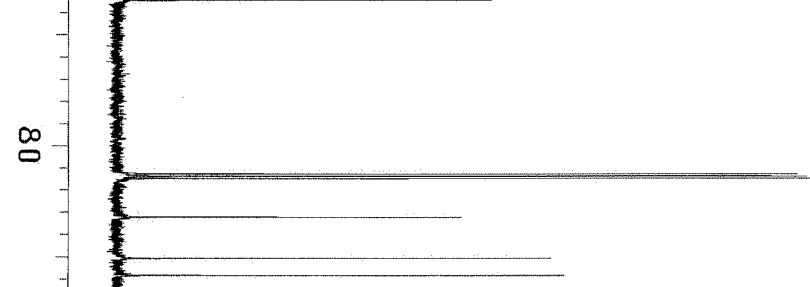

o

0

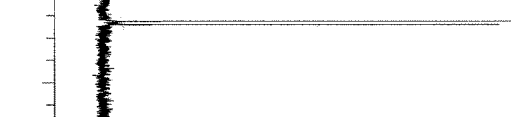

:
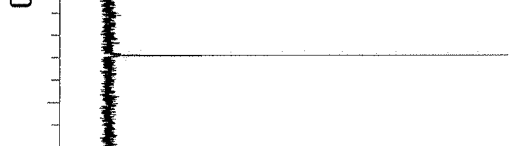

N

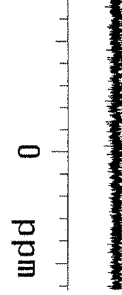




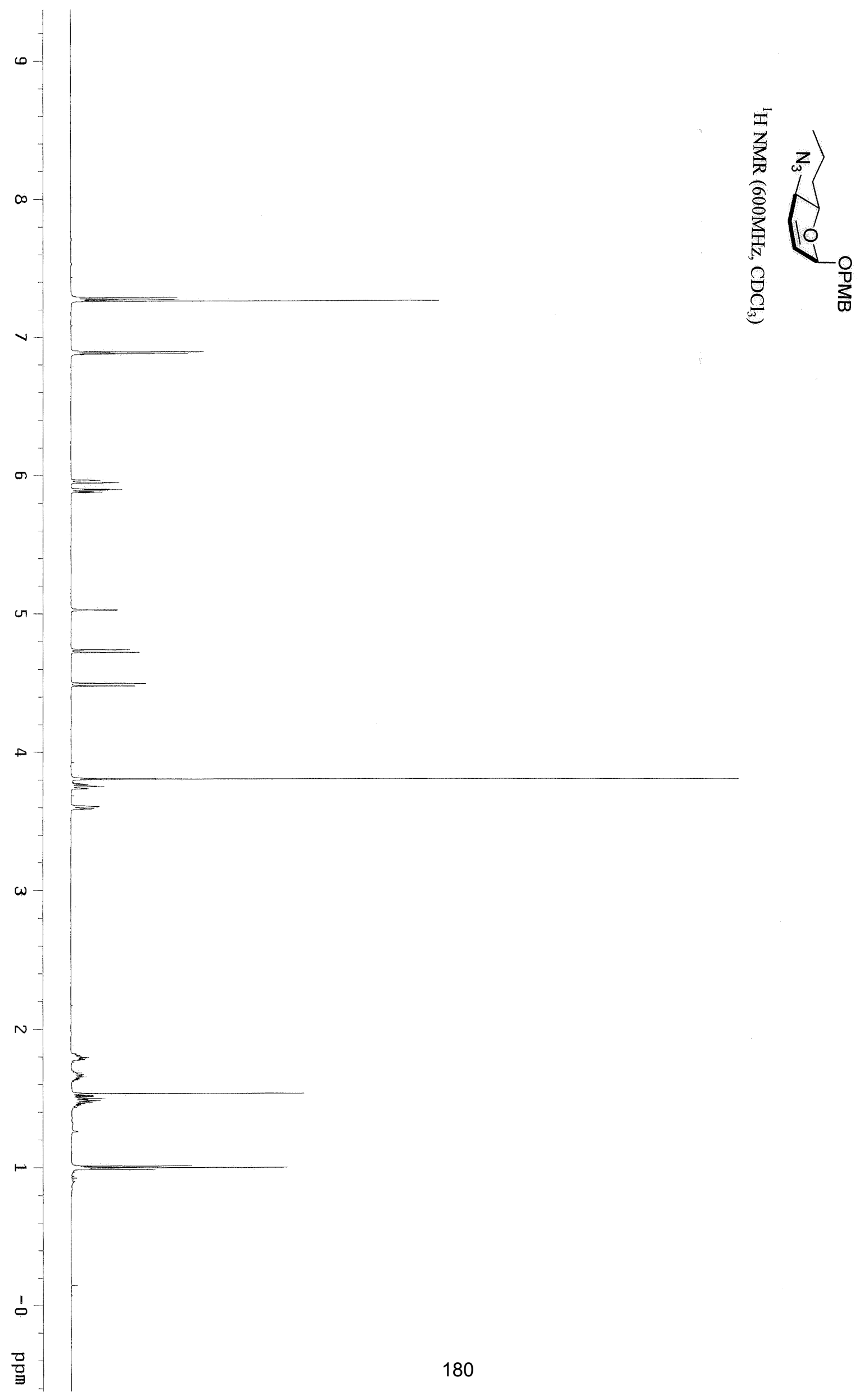




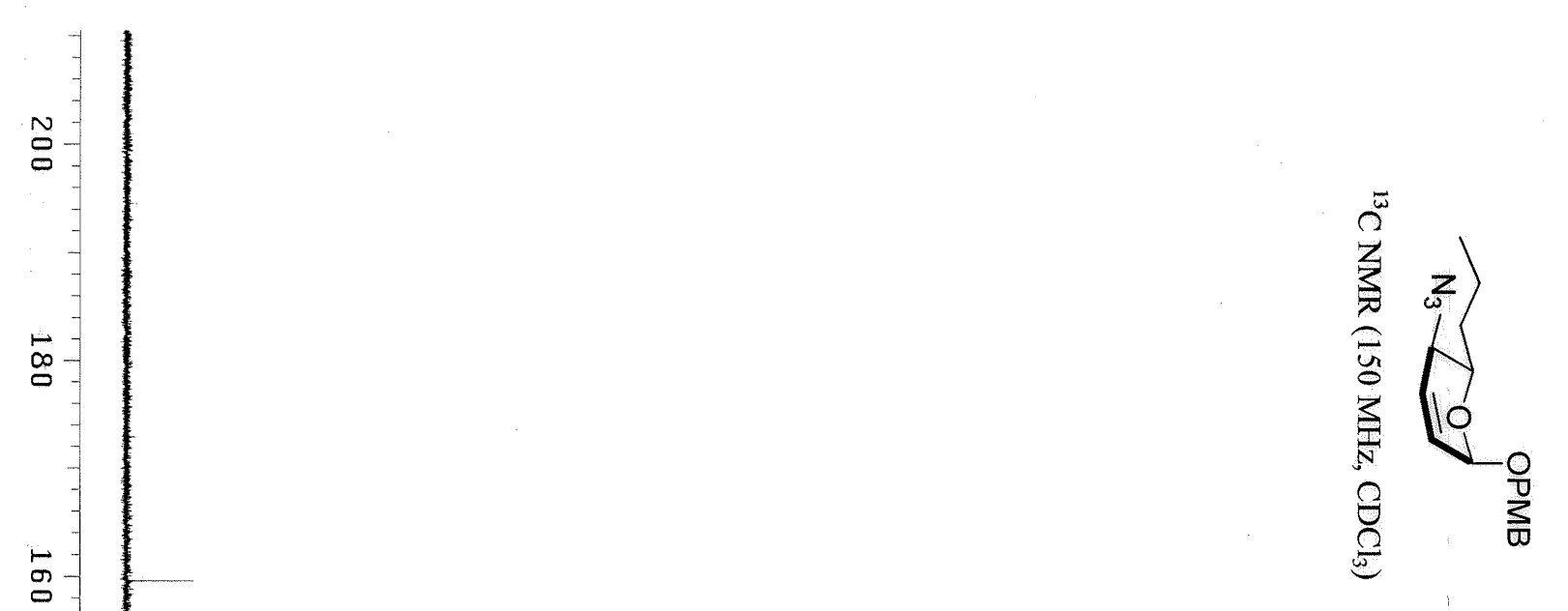

$\stackrel{\infty}{\infty}$

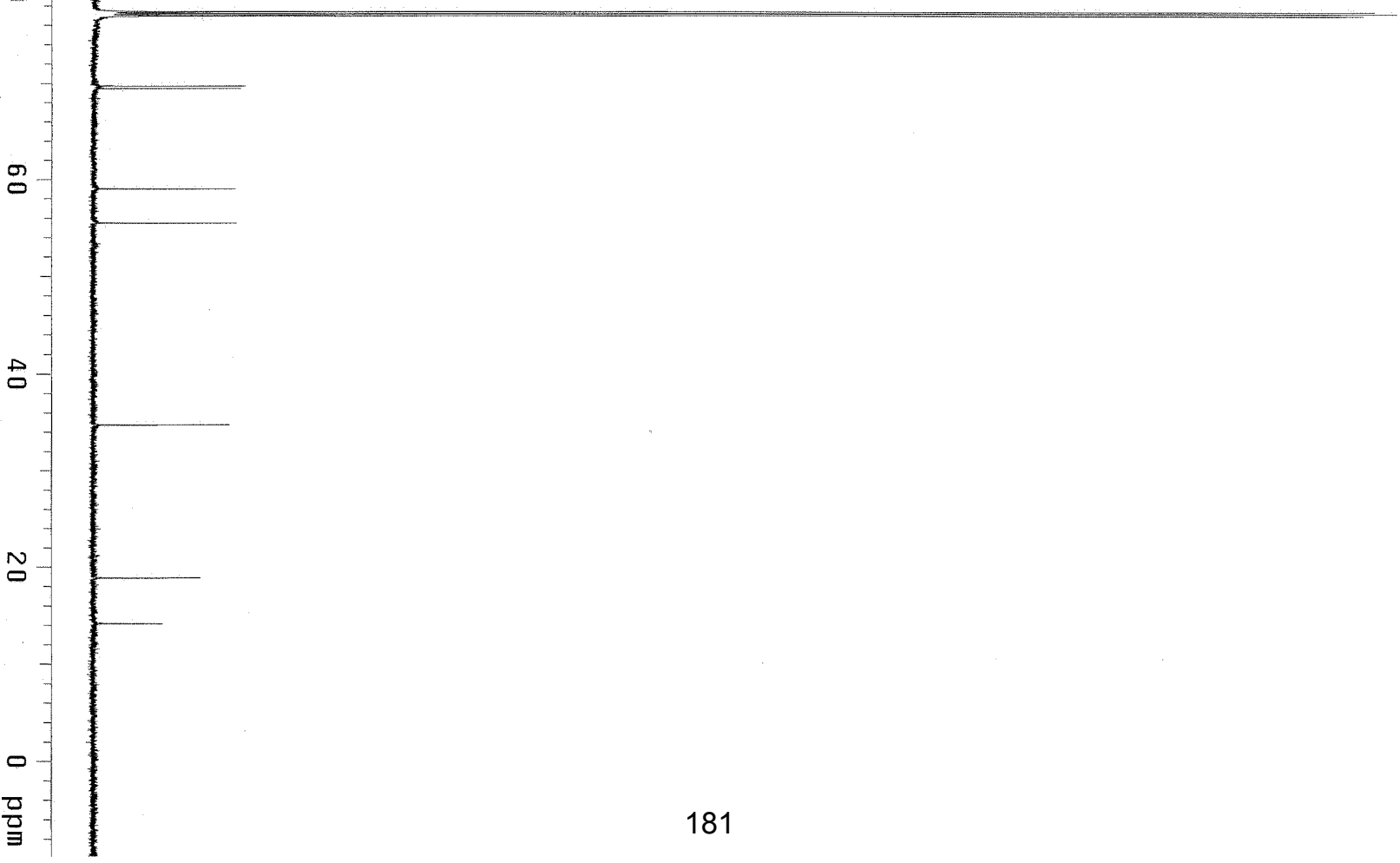




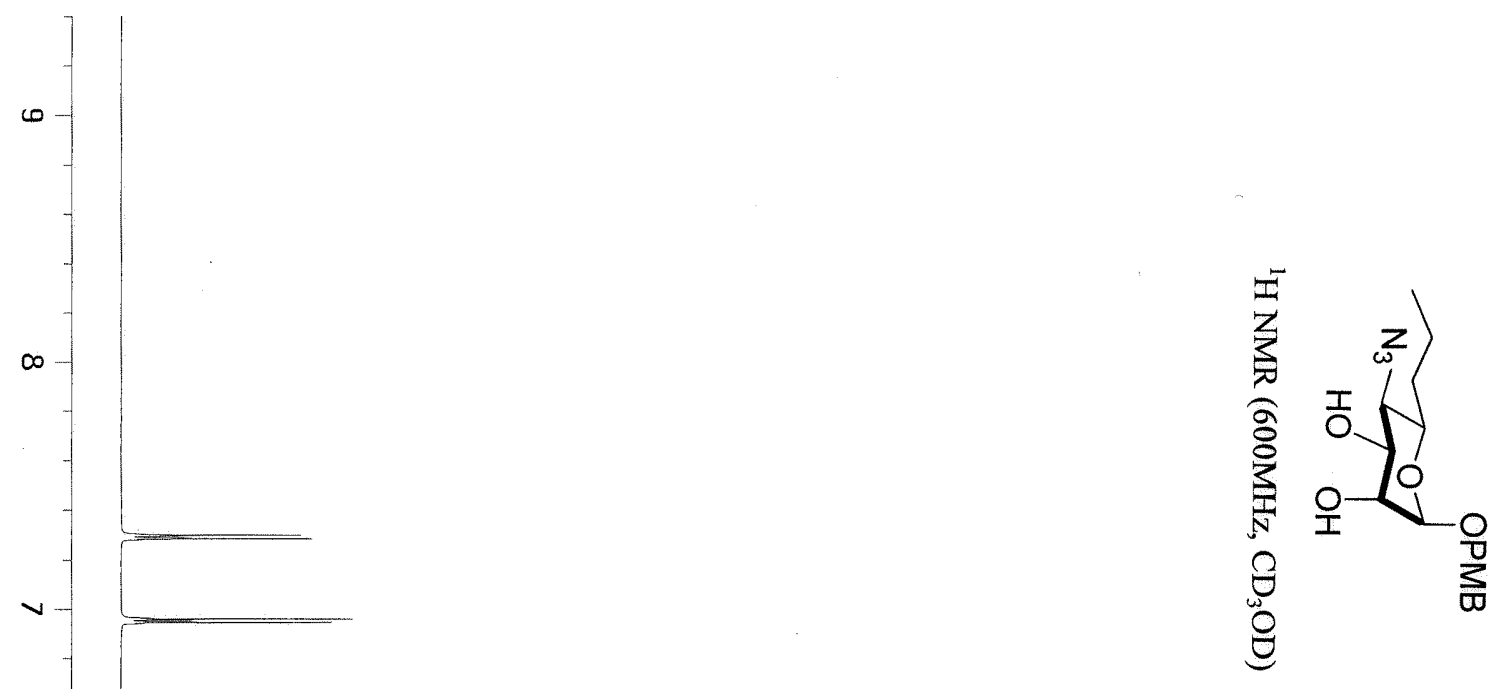

$\omega$ 

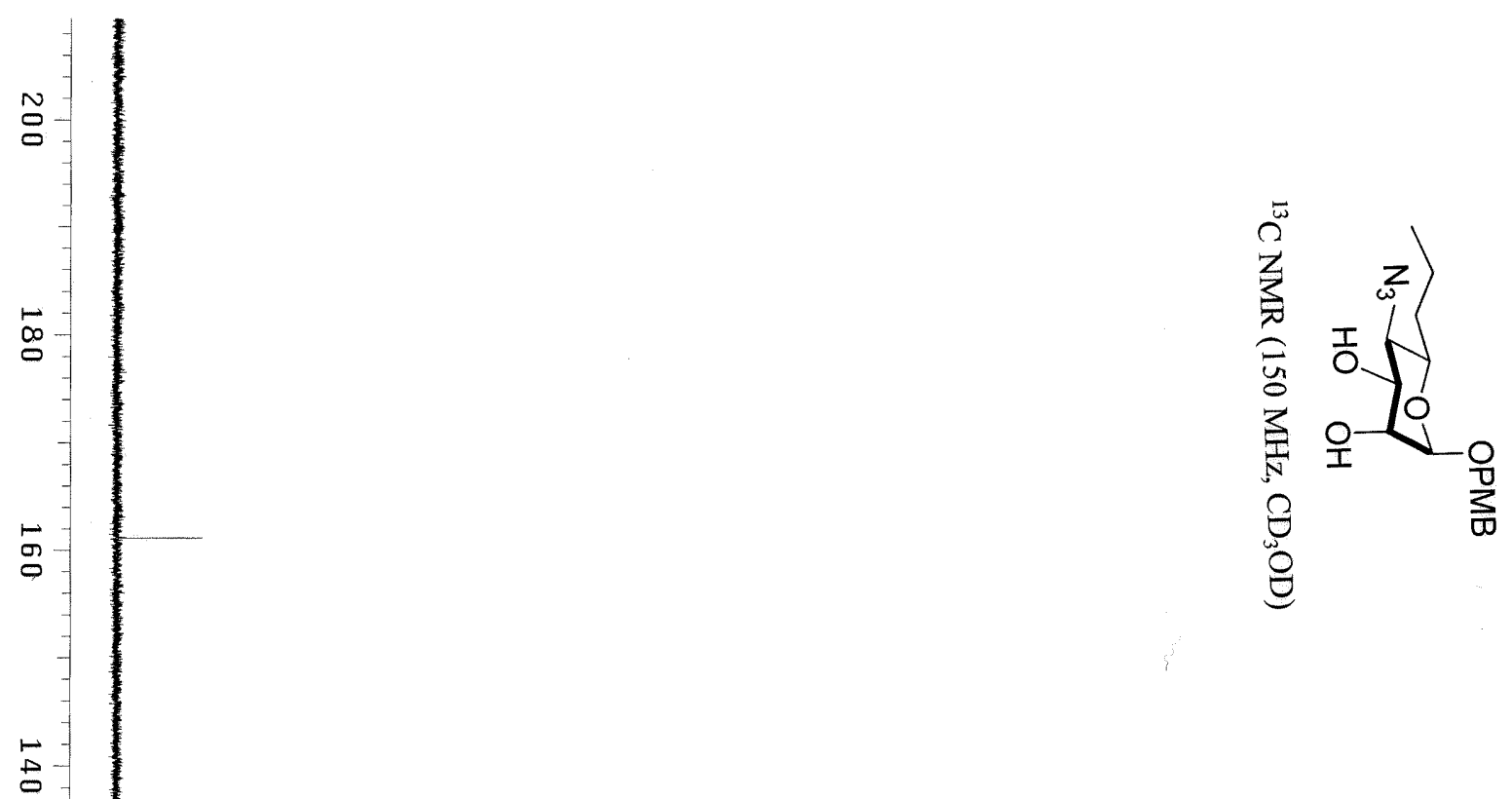

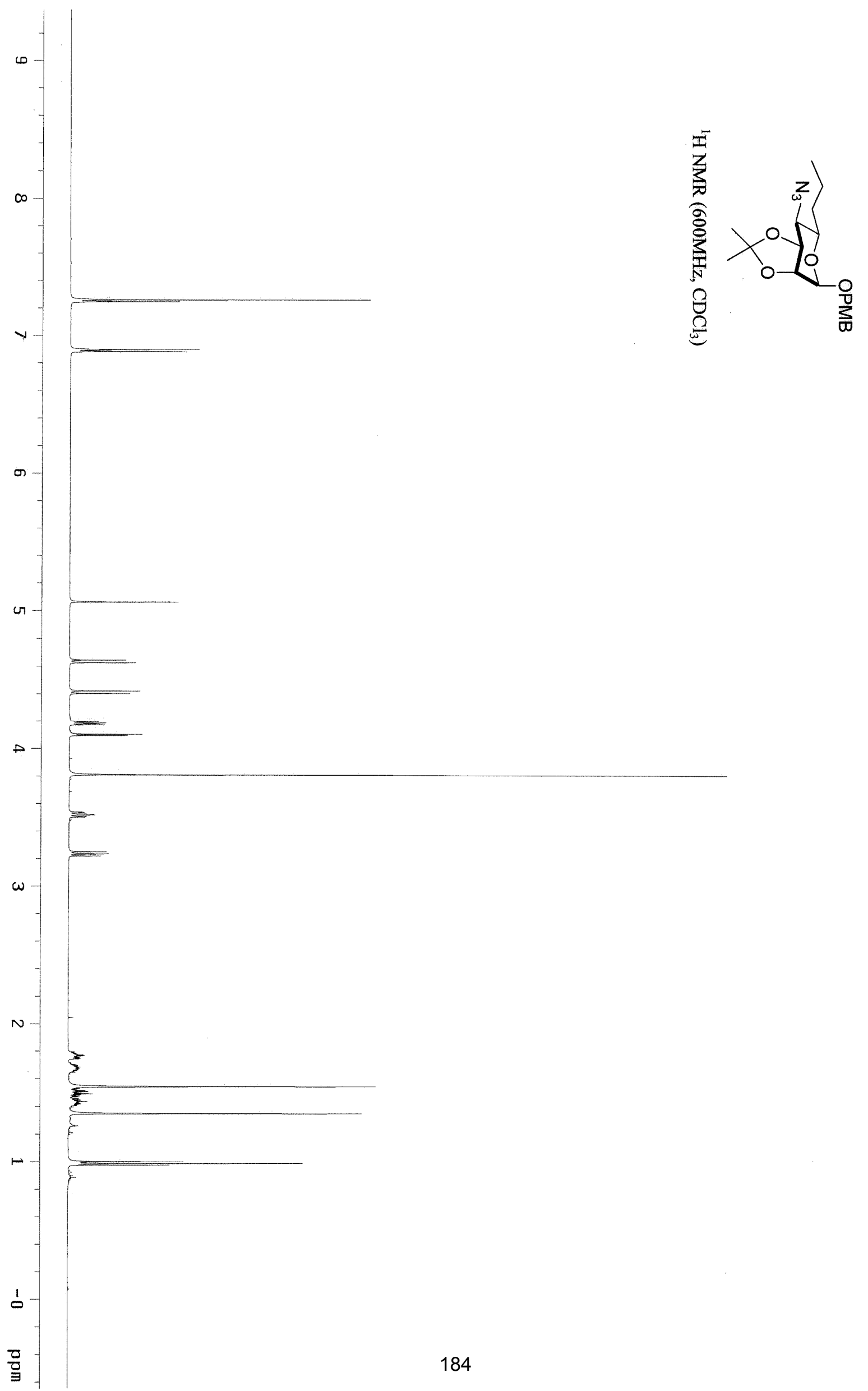


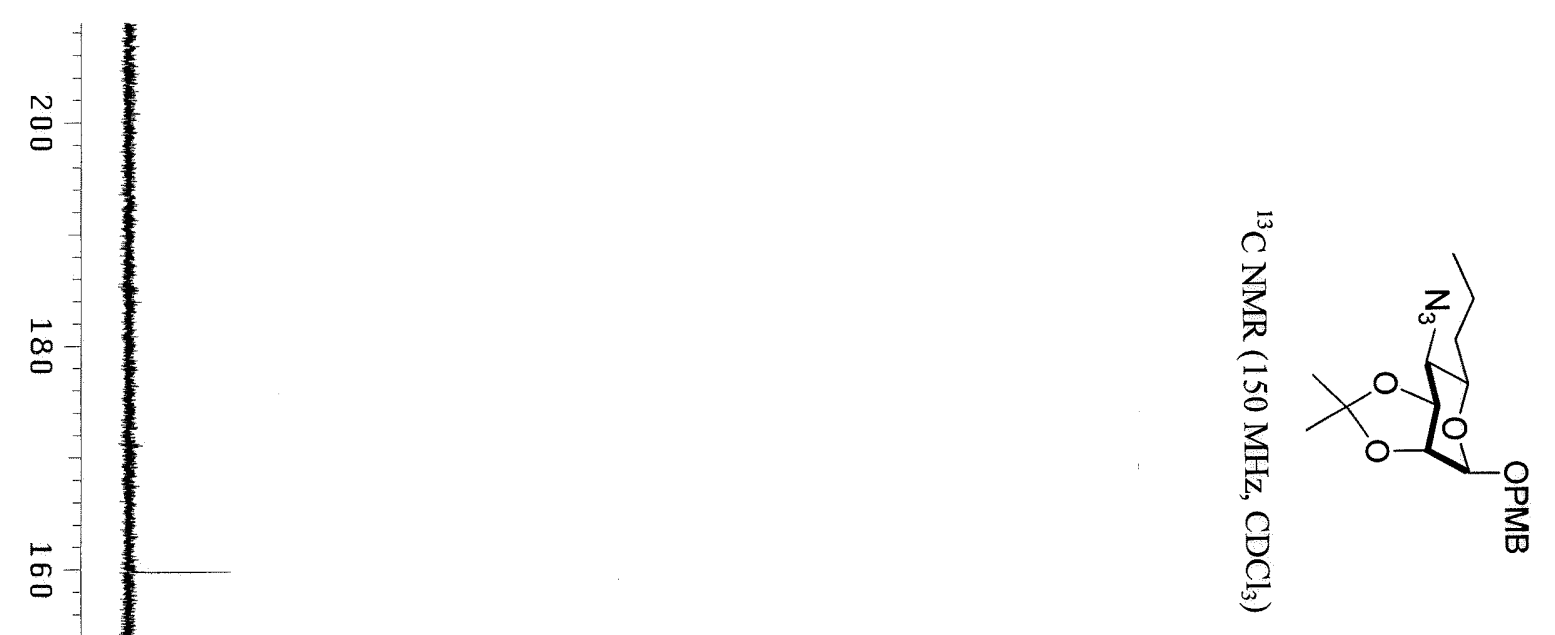

5

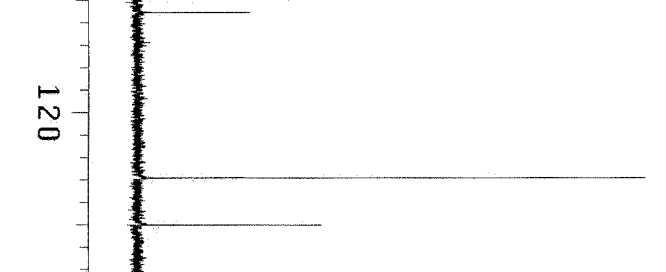

5

$\infty$
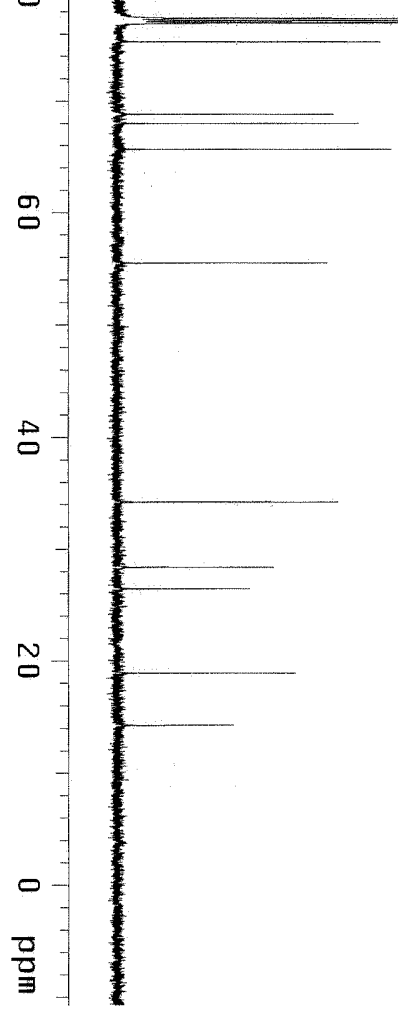


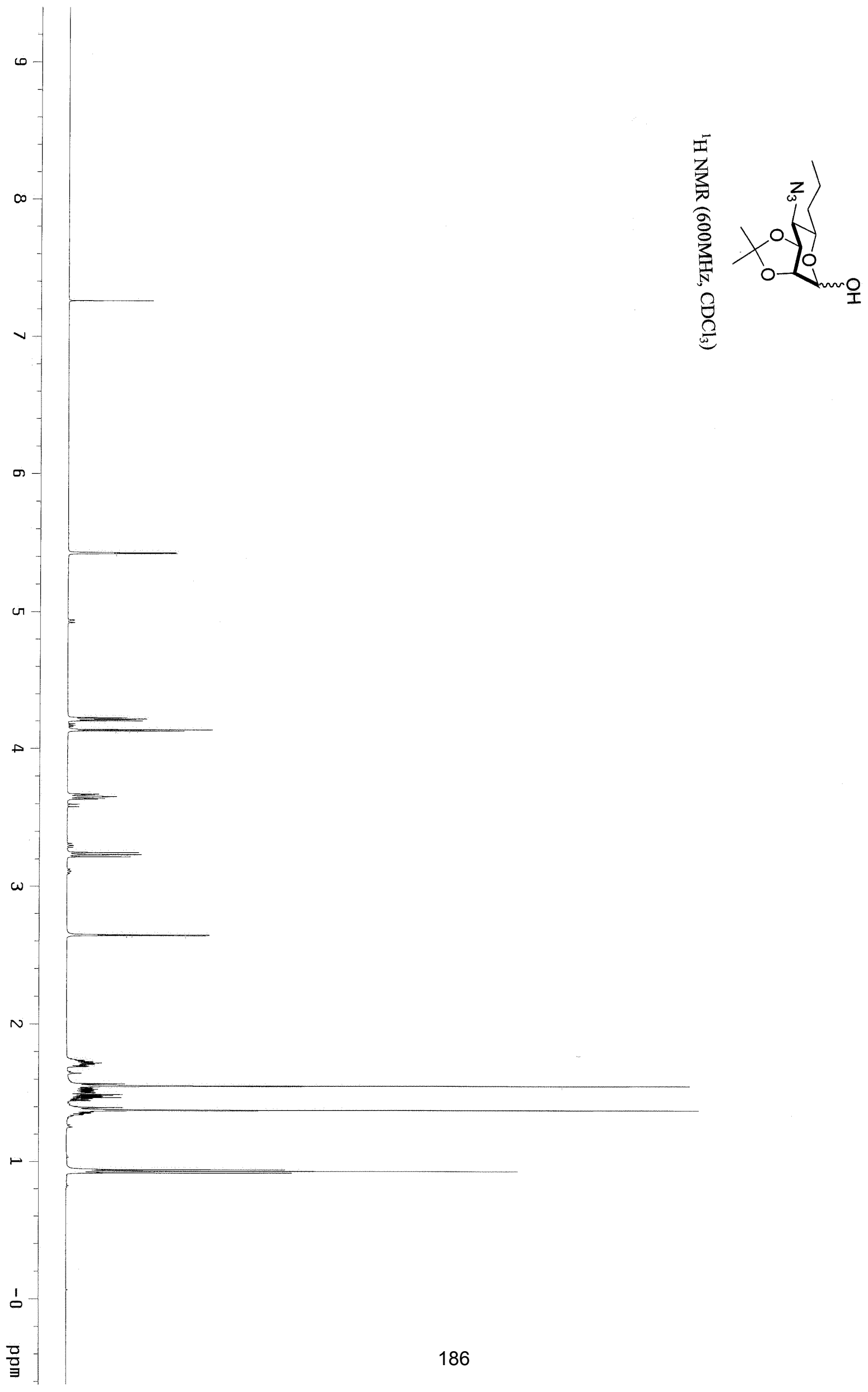




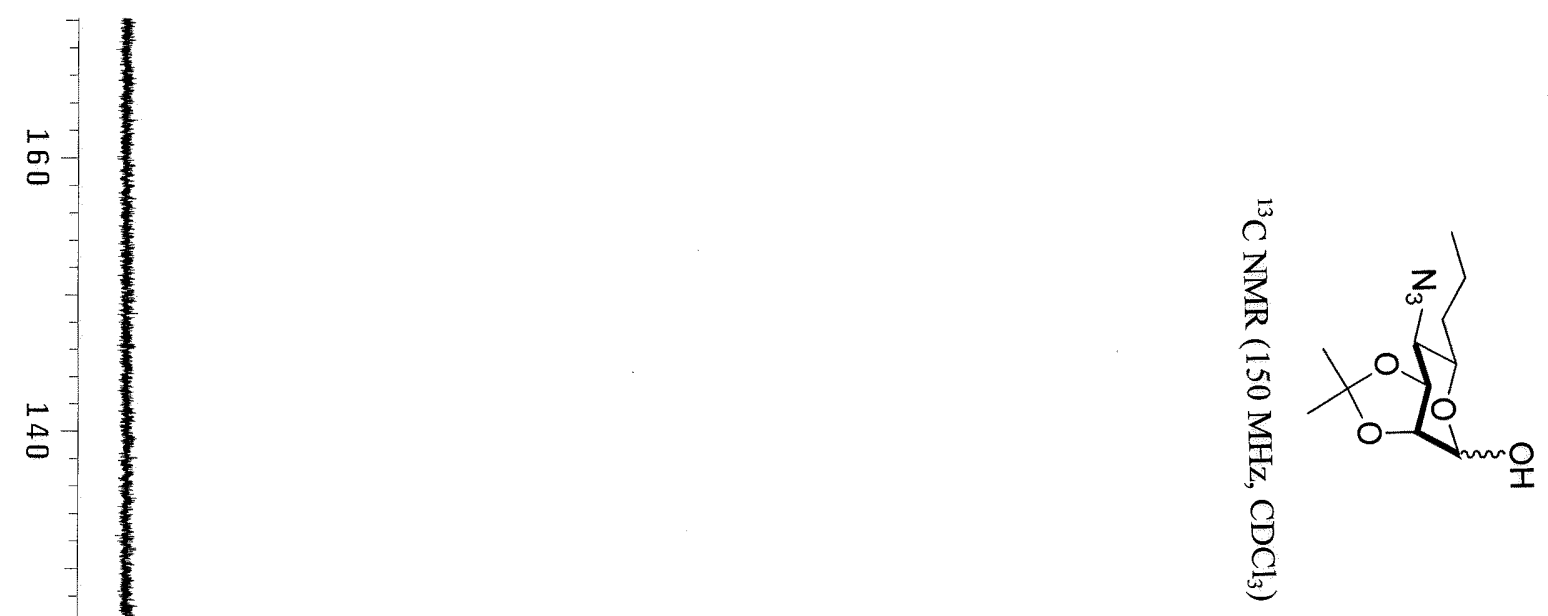

$\stackrel{\infty}{\circ}$

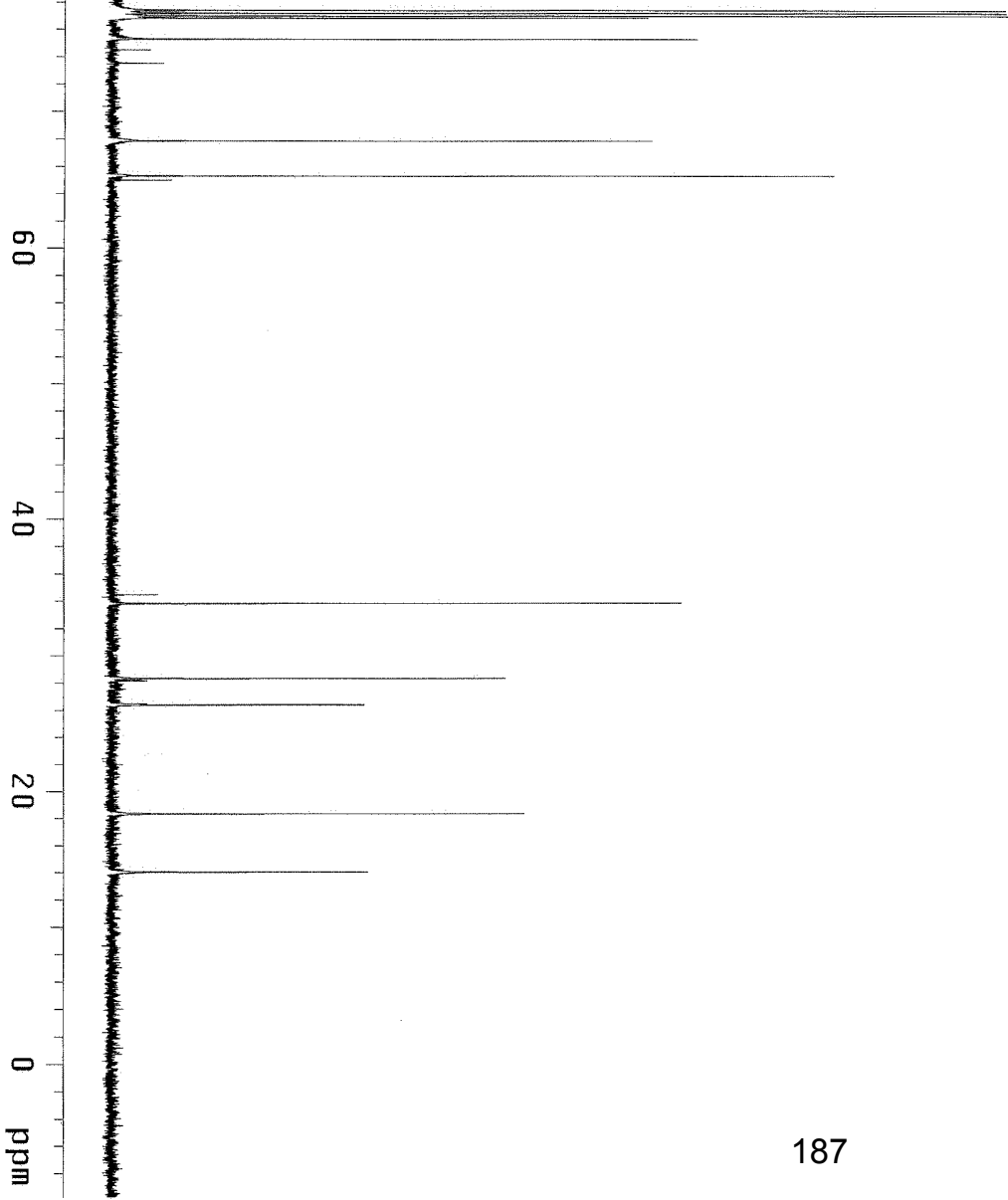




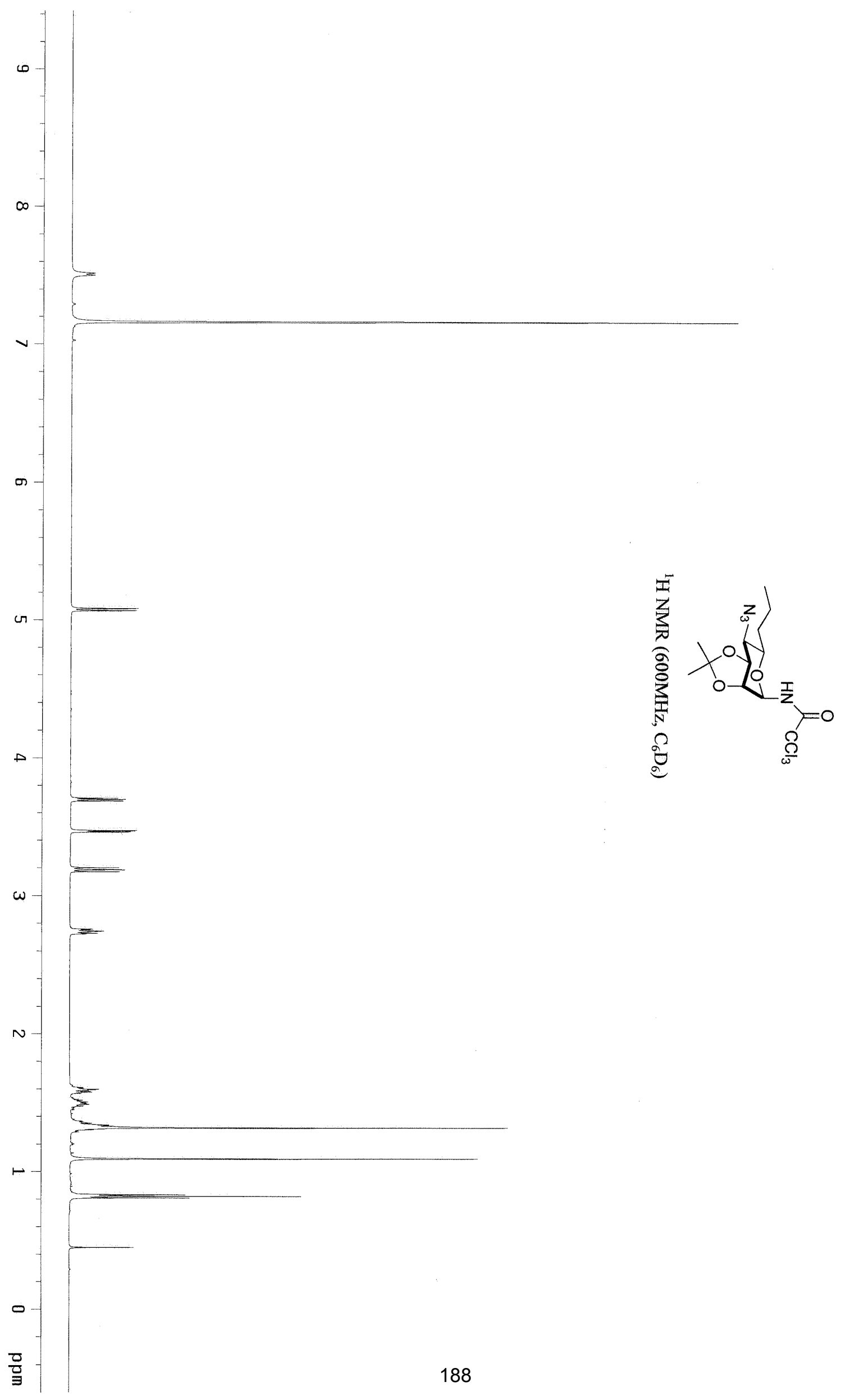




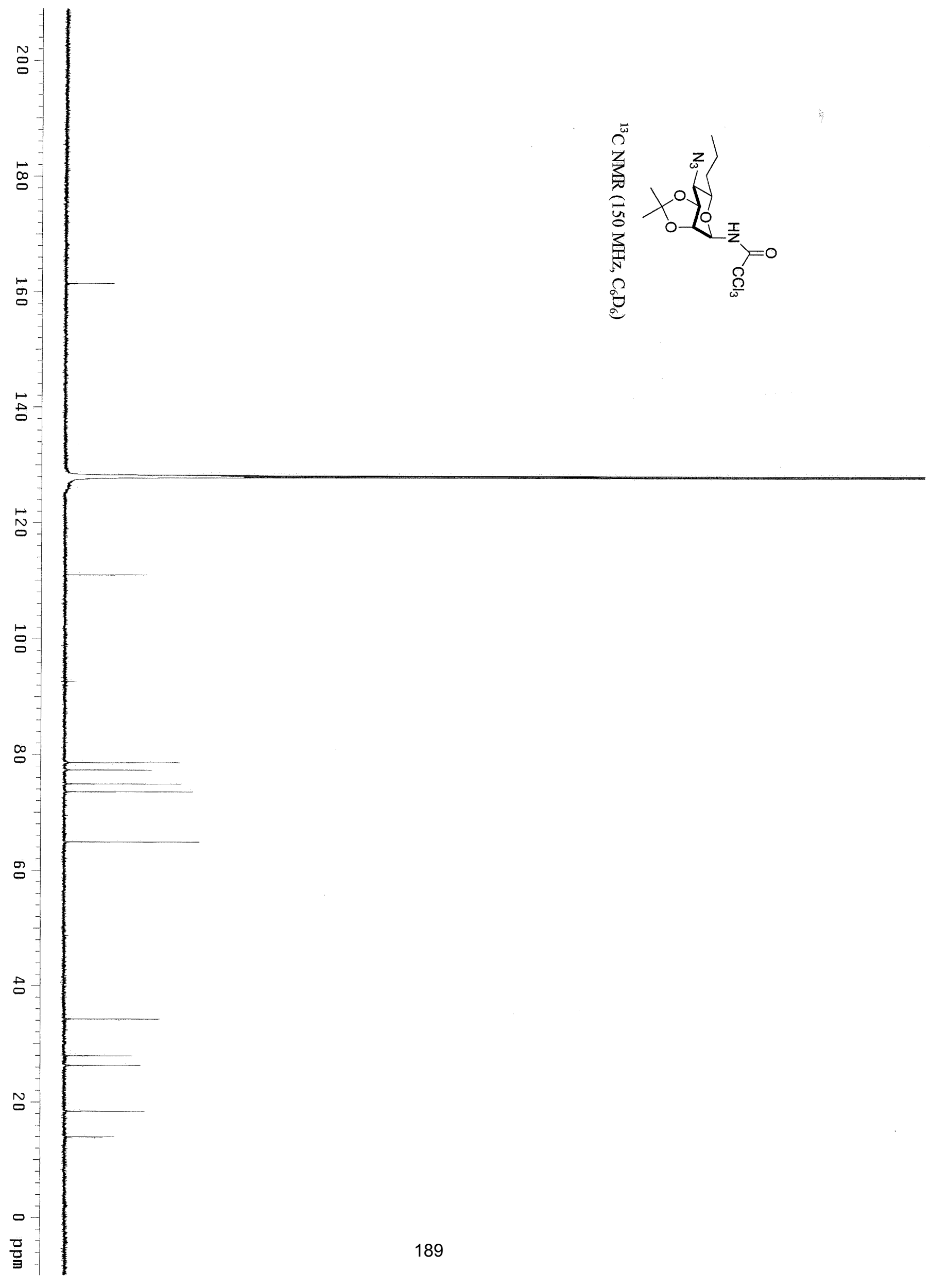




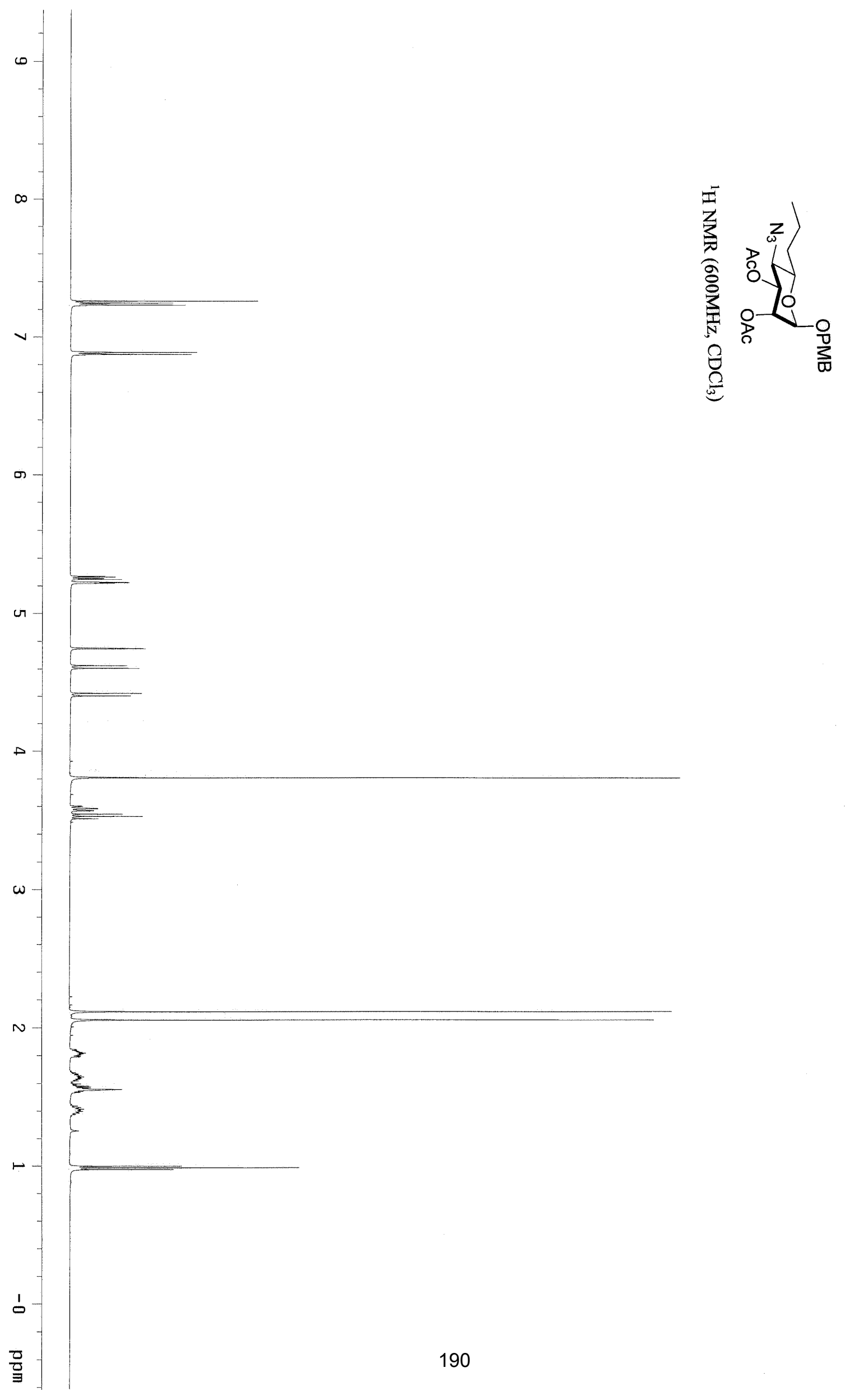




$$
\|^{k}
$$




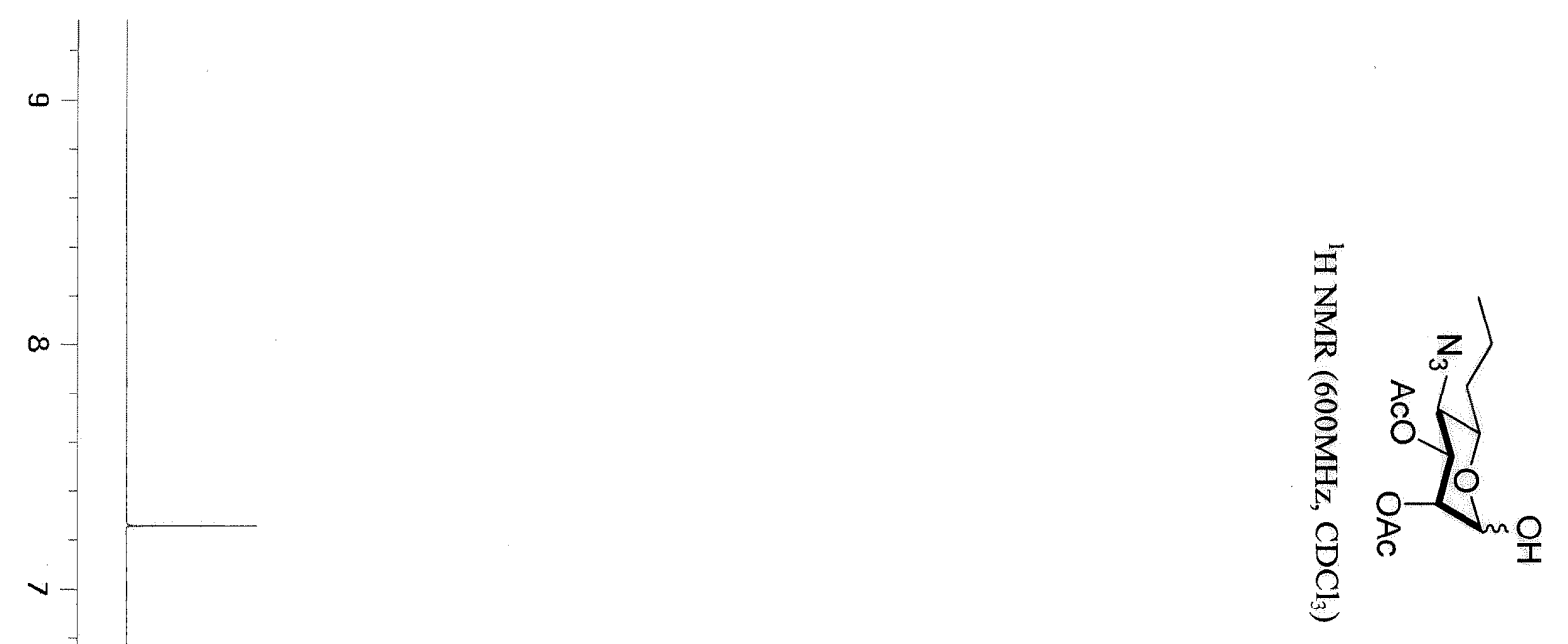




$$
I^{k}
$$




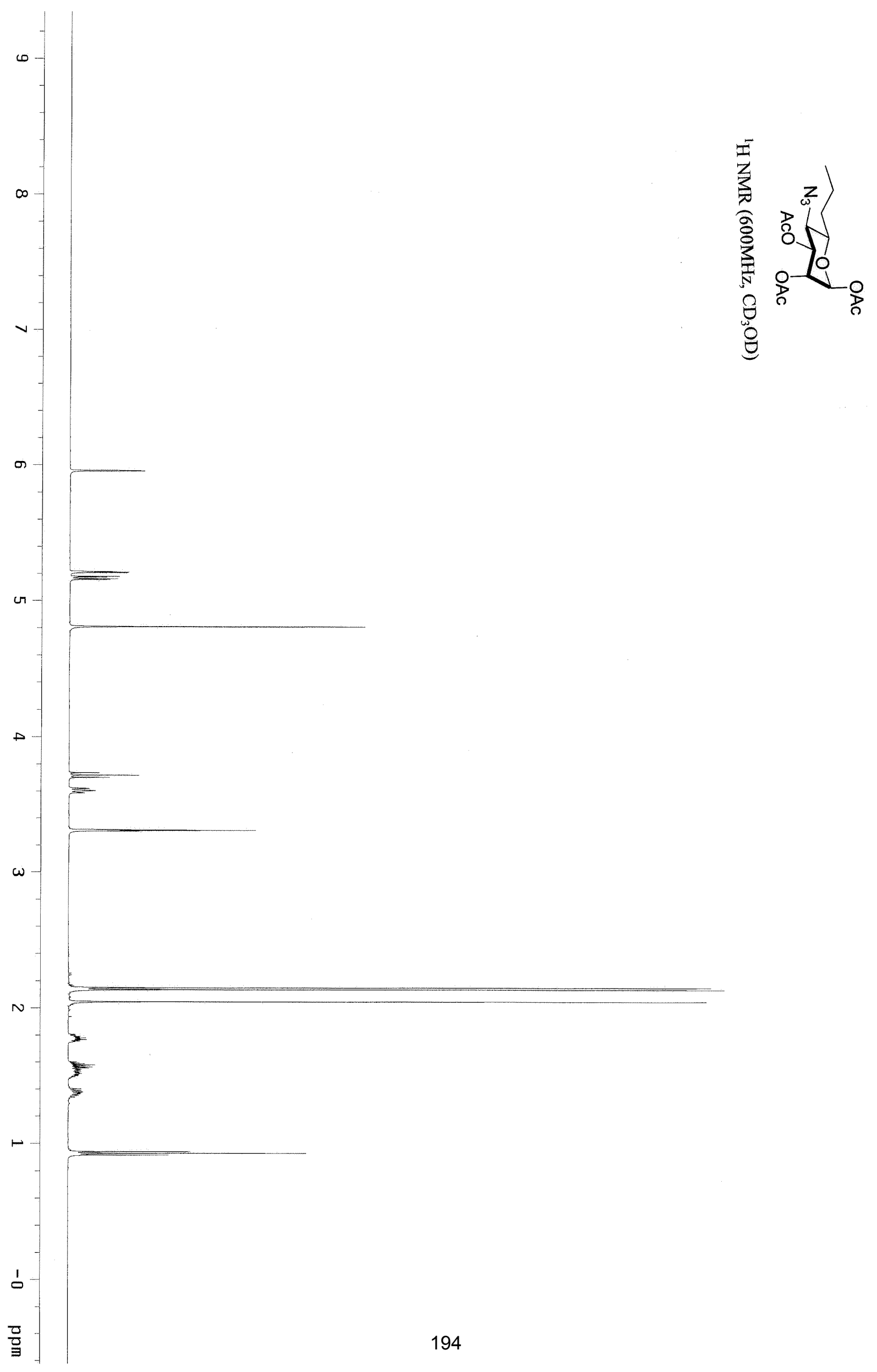




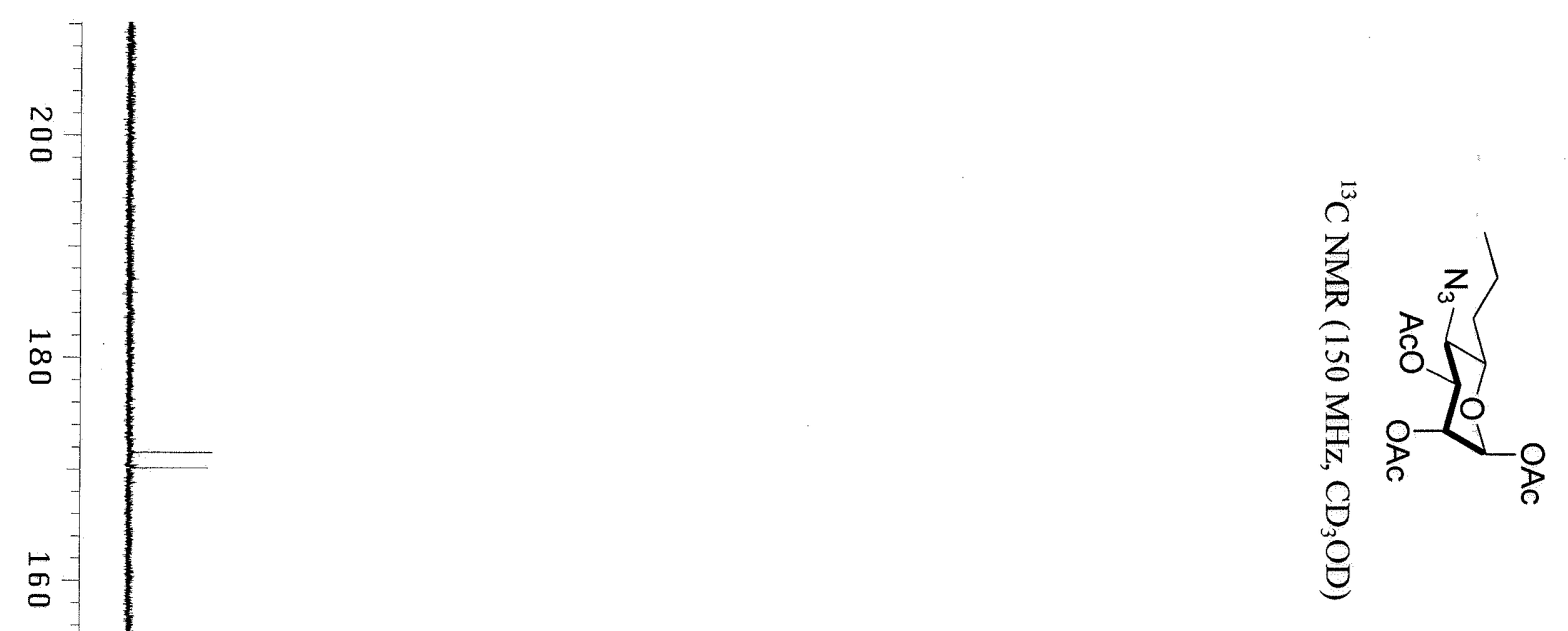




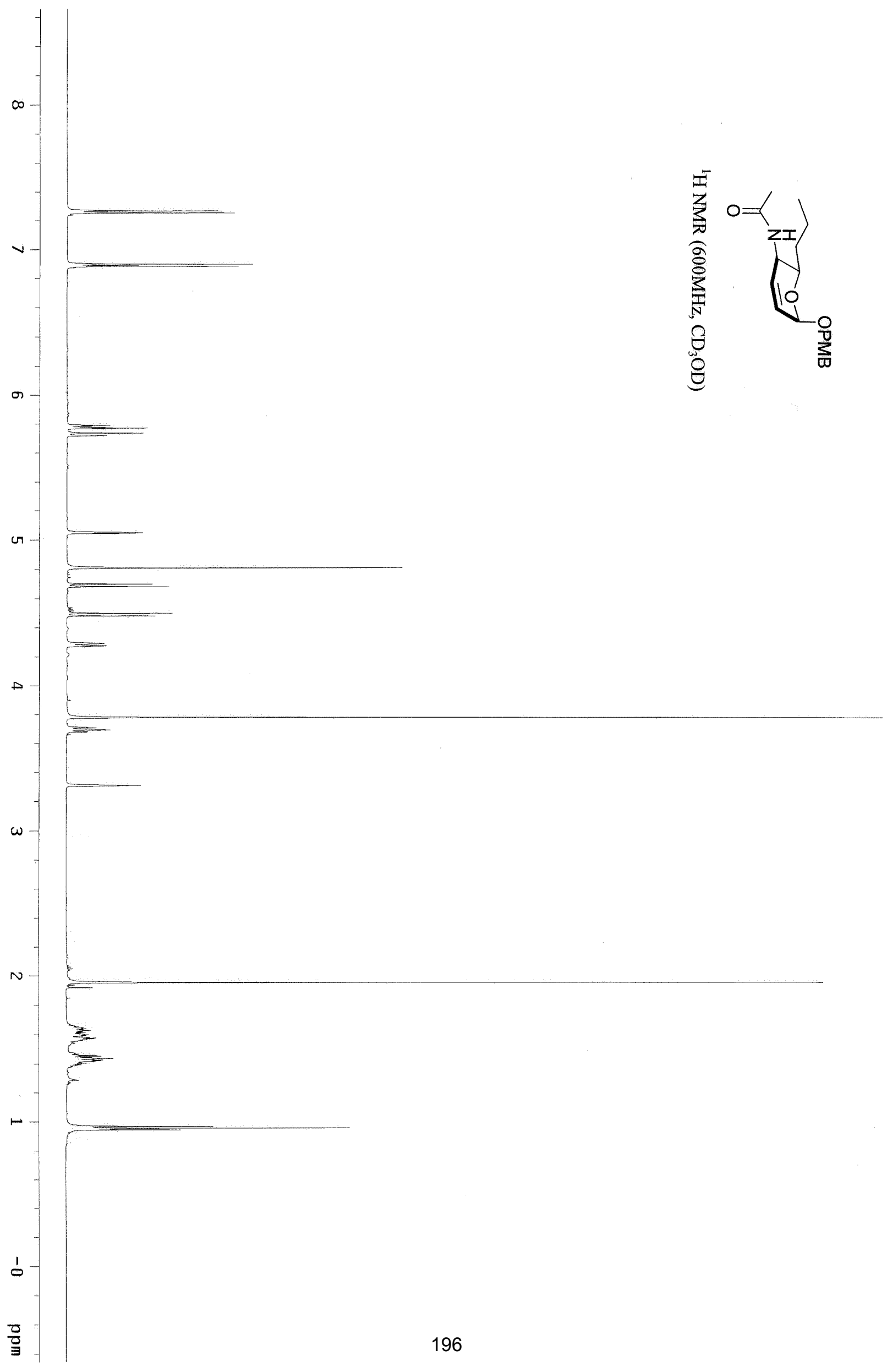




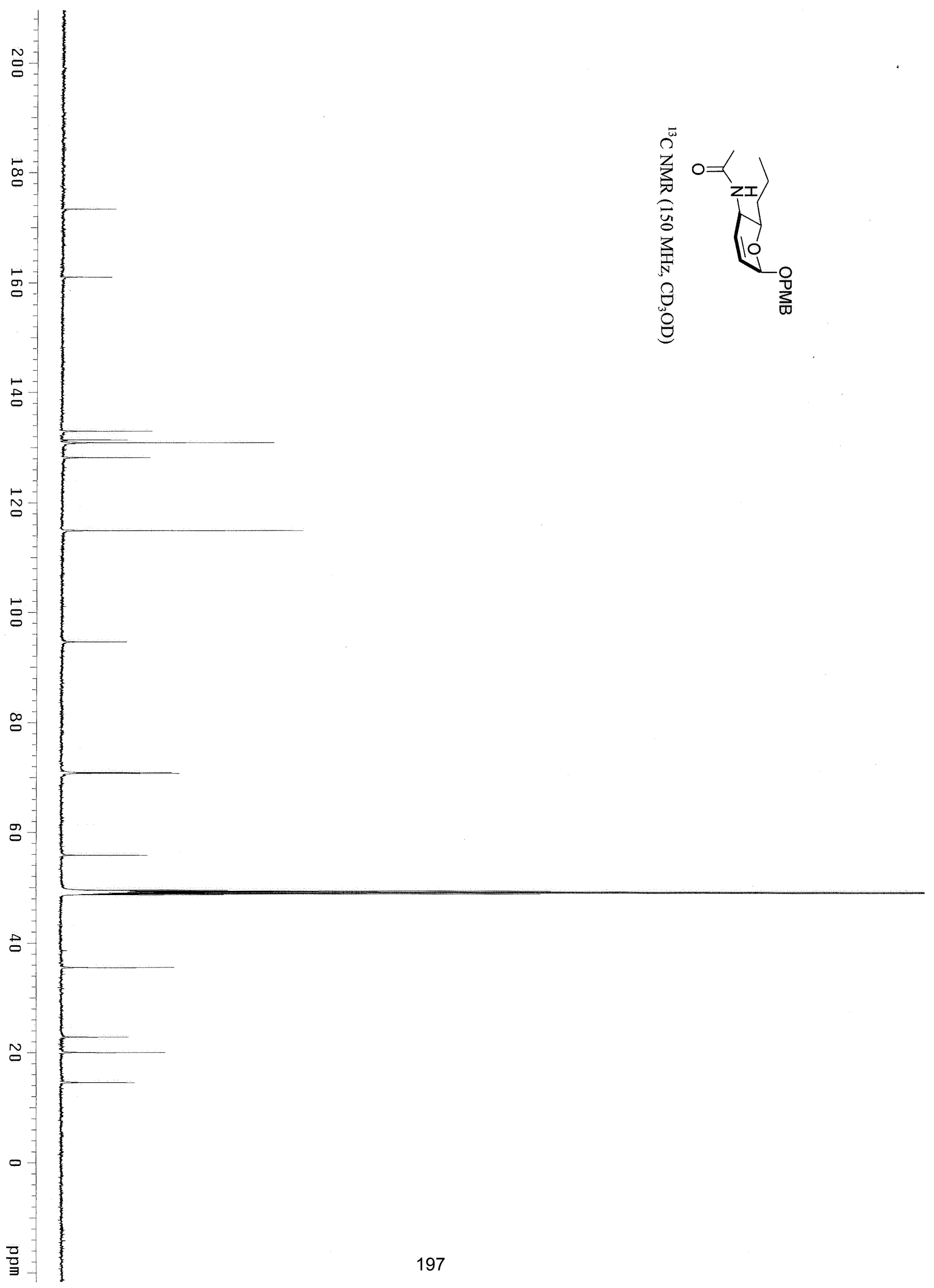




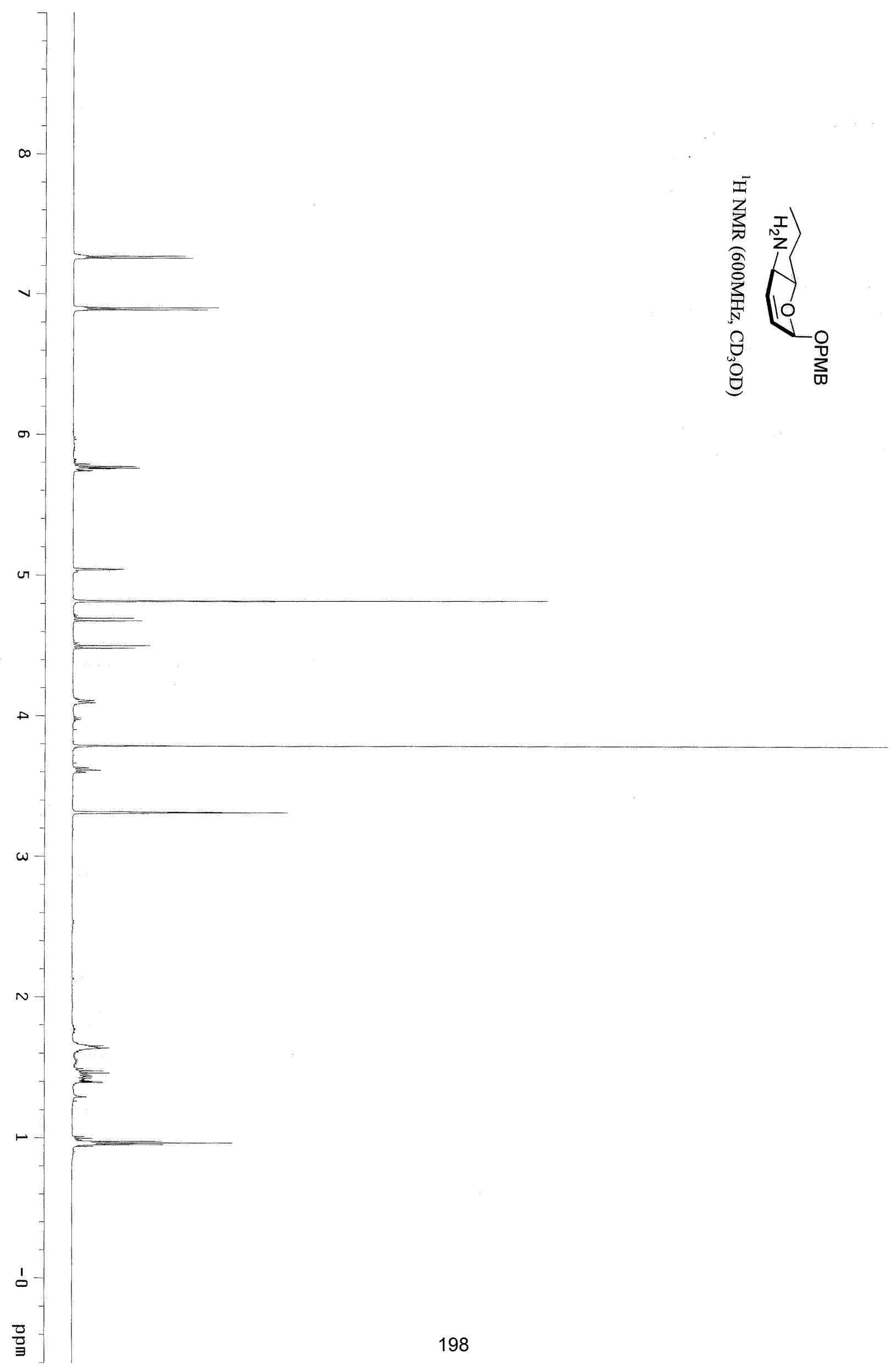




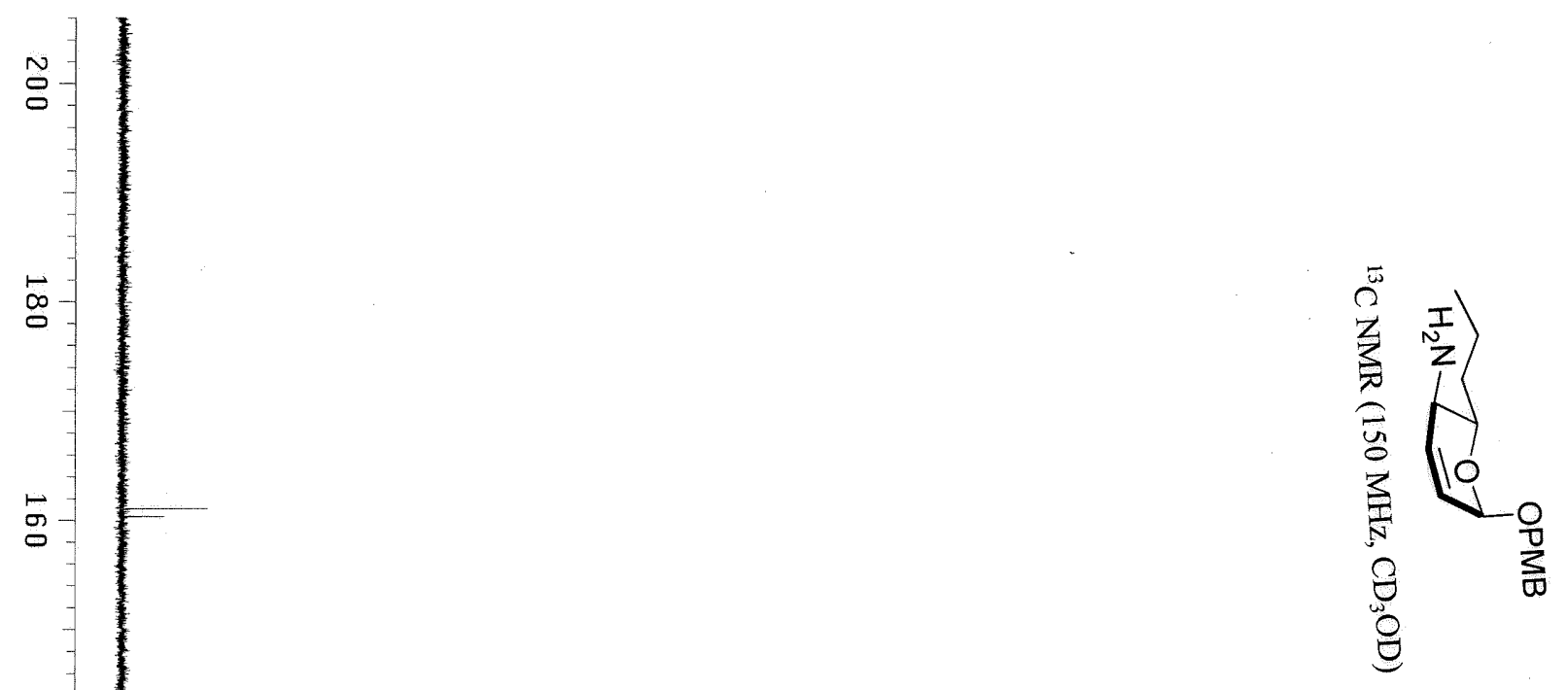

5
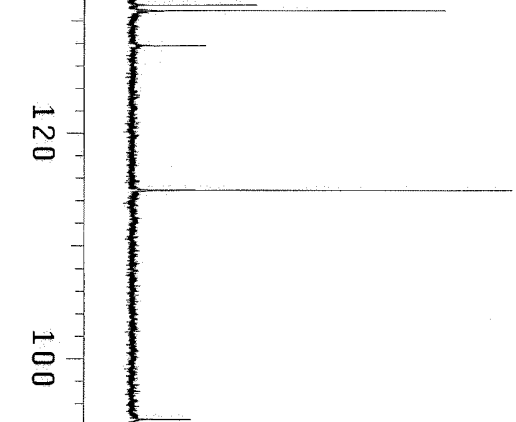

$\infty$

g
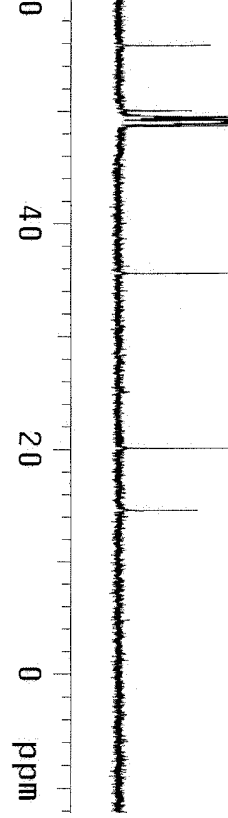


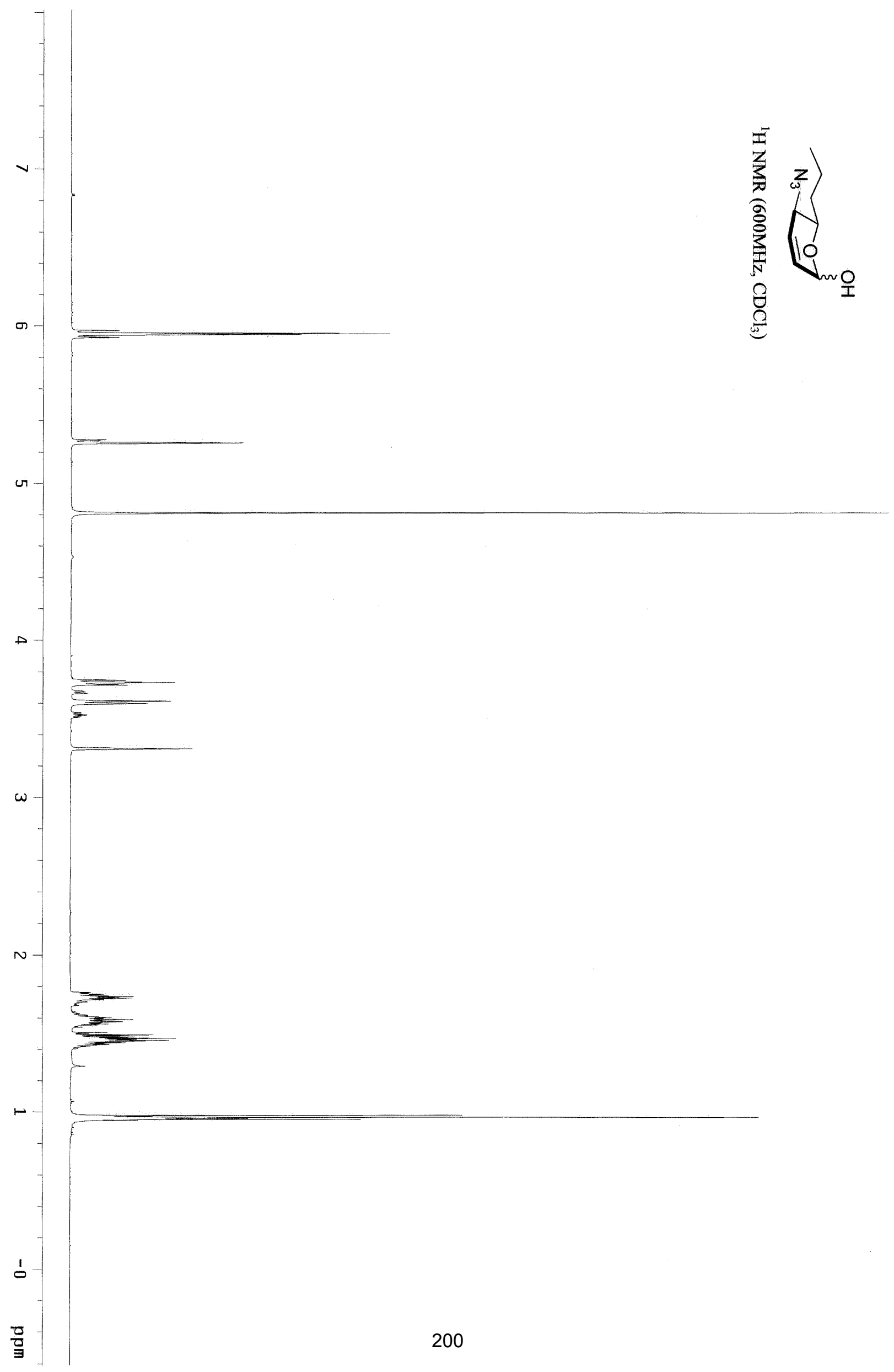




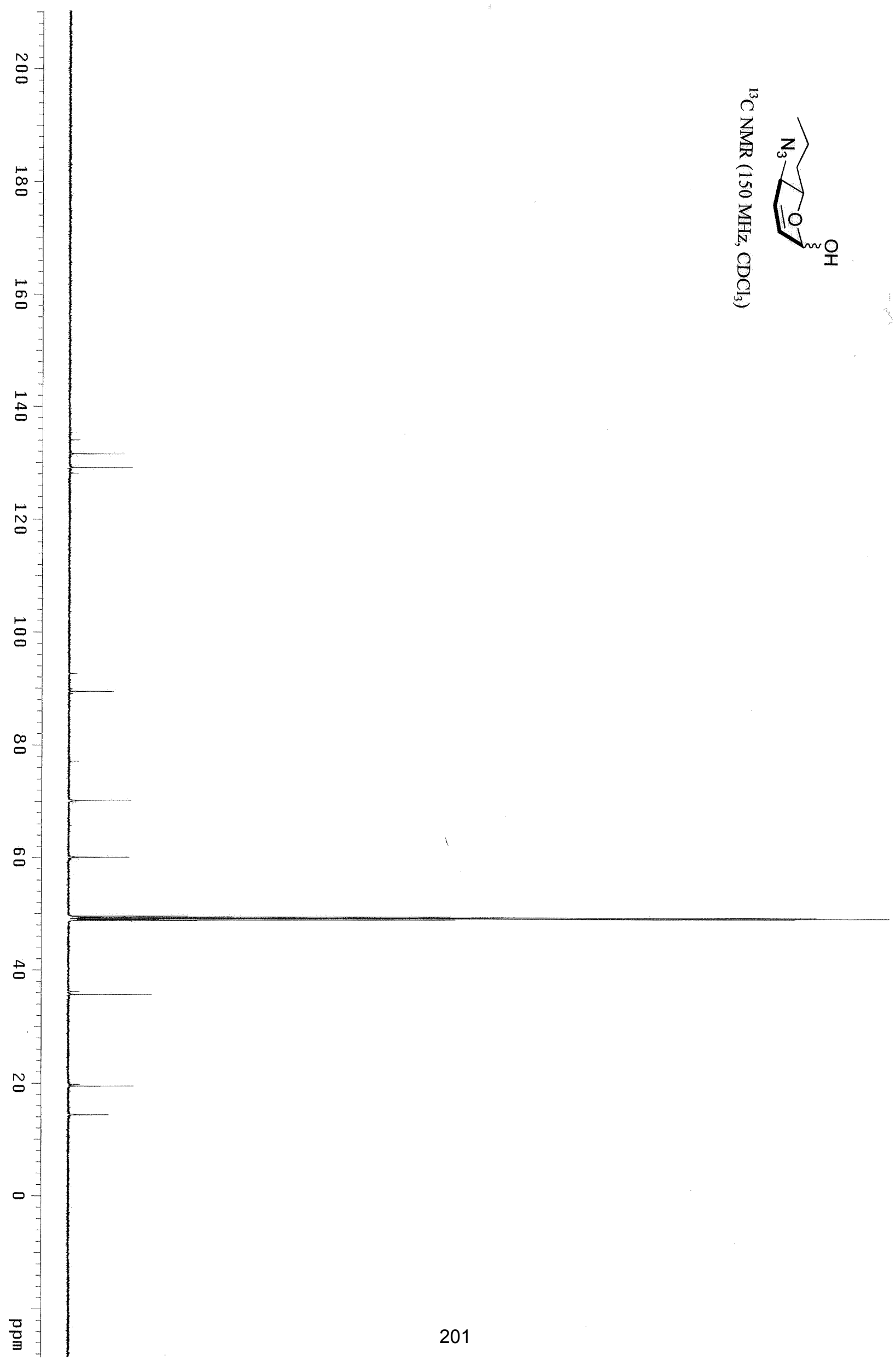




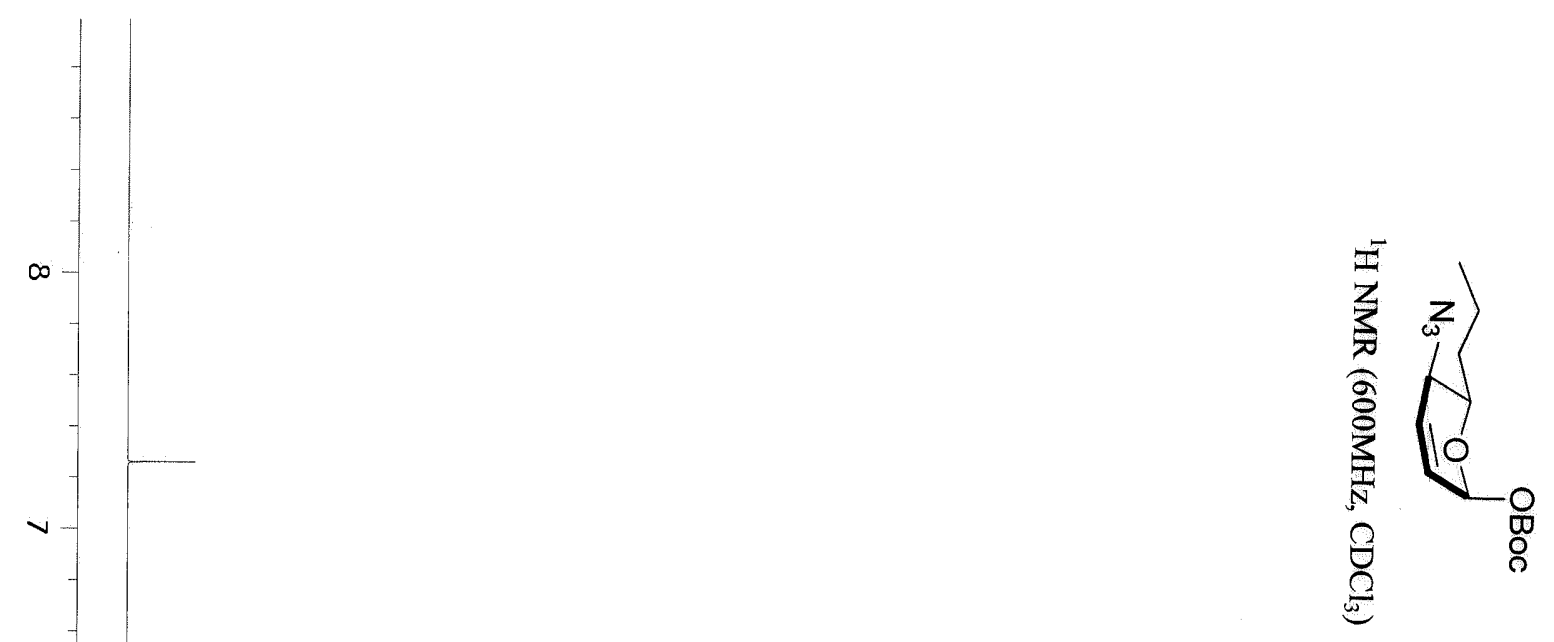




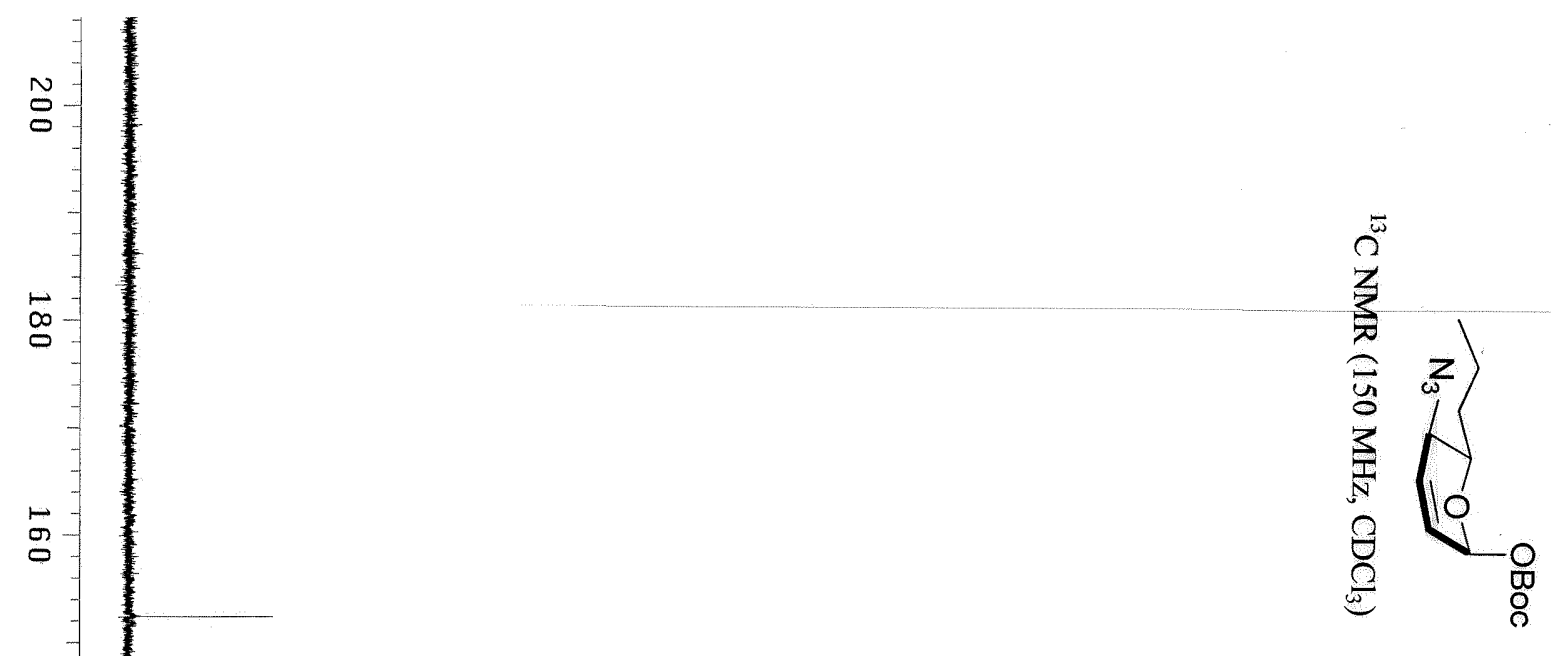

$\stackrel{0}{0}$

$\stackrel{N}{0}$

둥

$\infty$

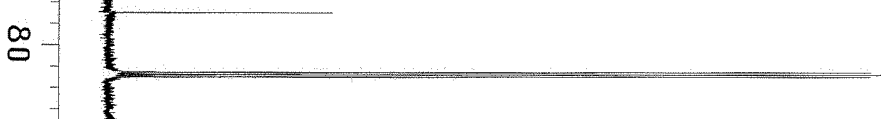

g.

-

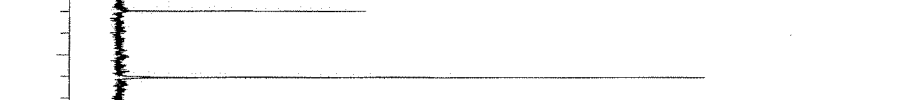

ㄴ-

$=1$ 


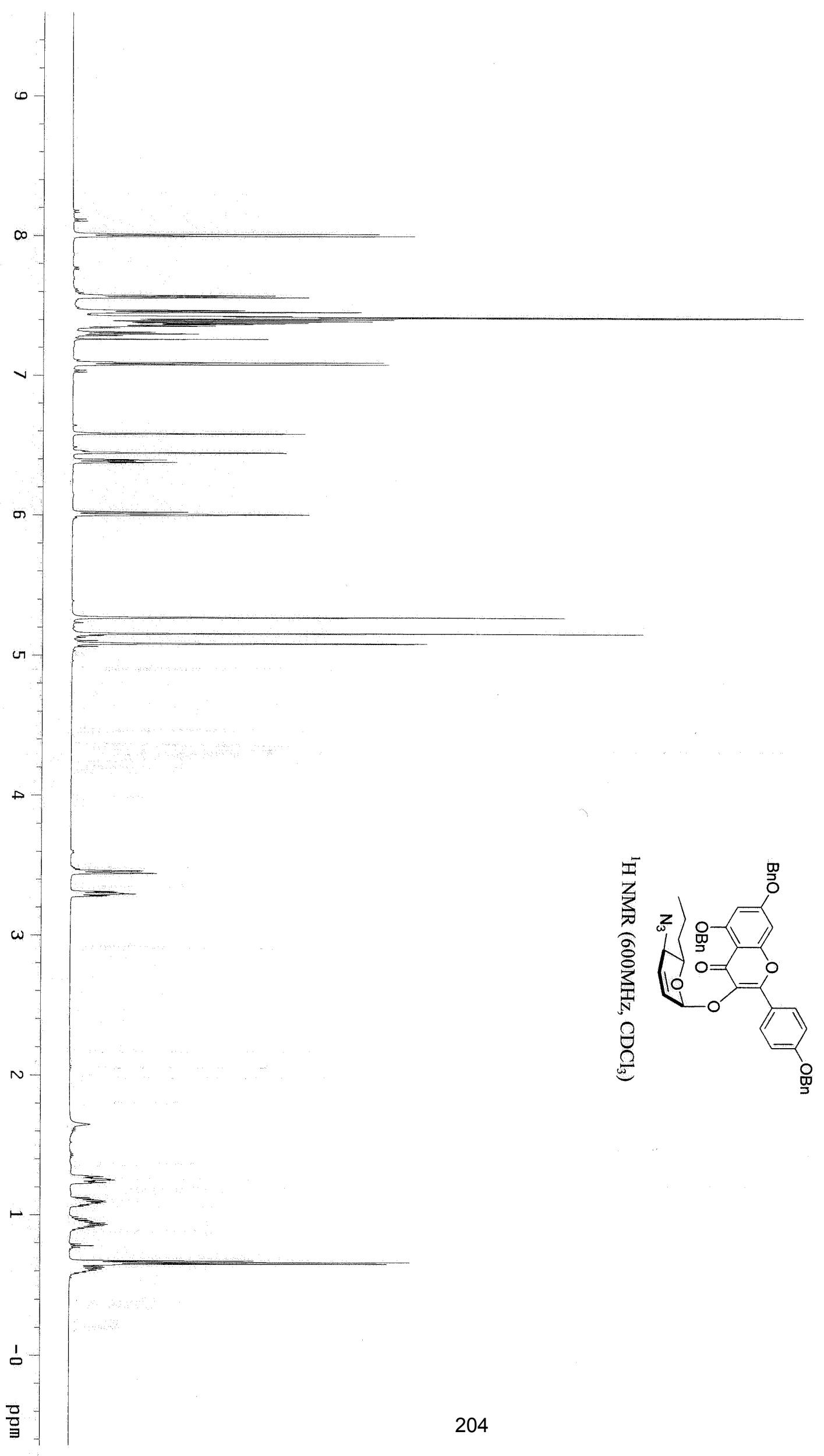



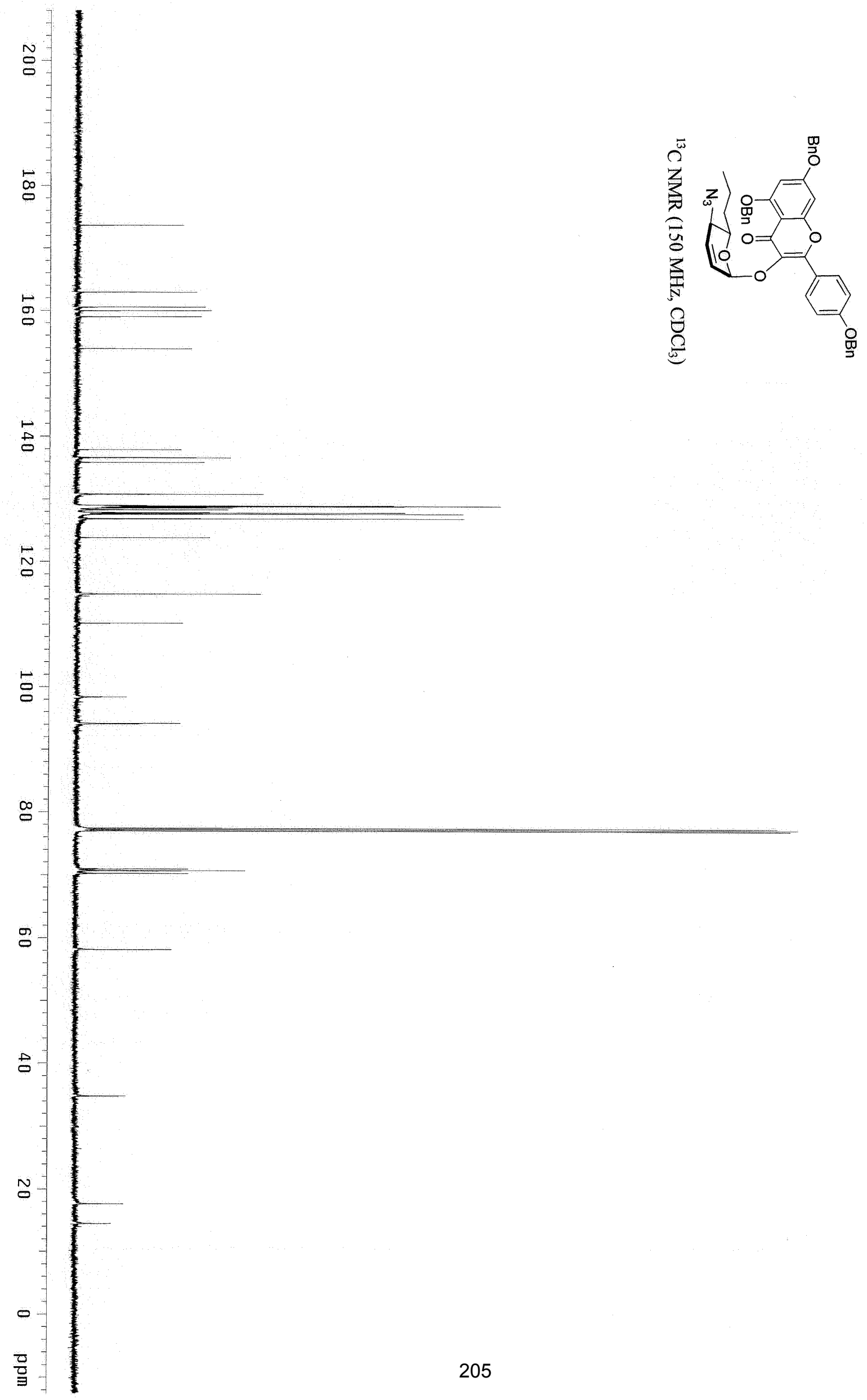


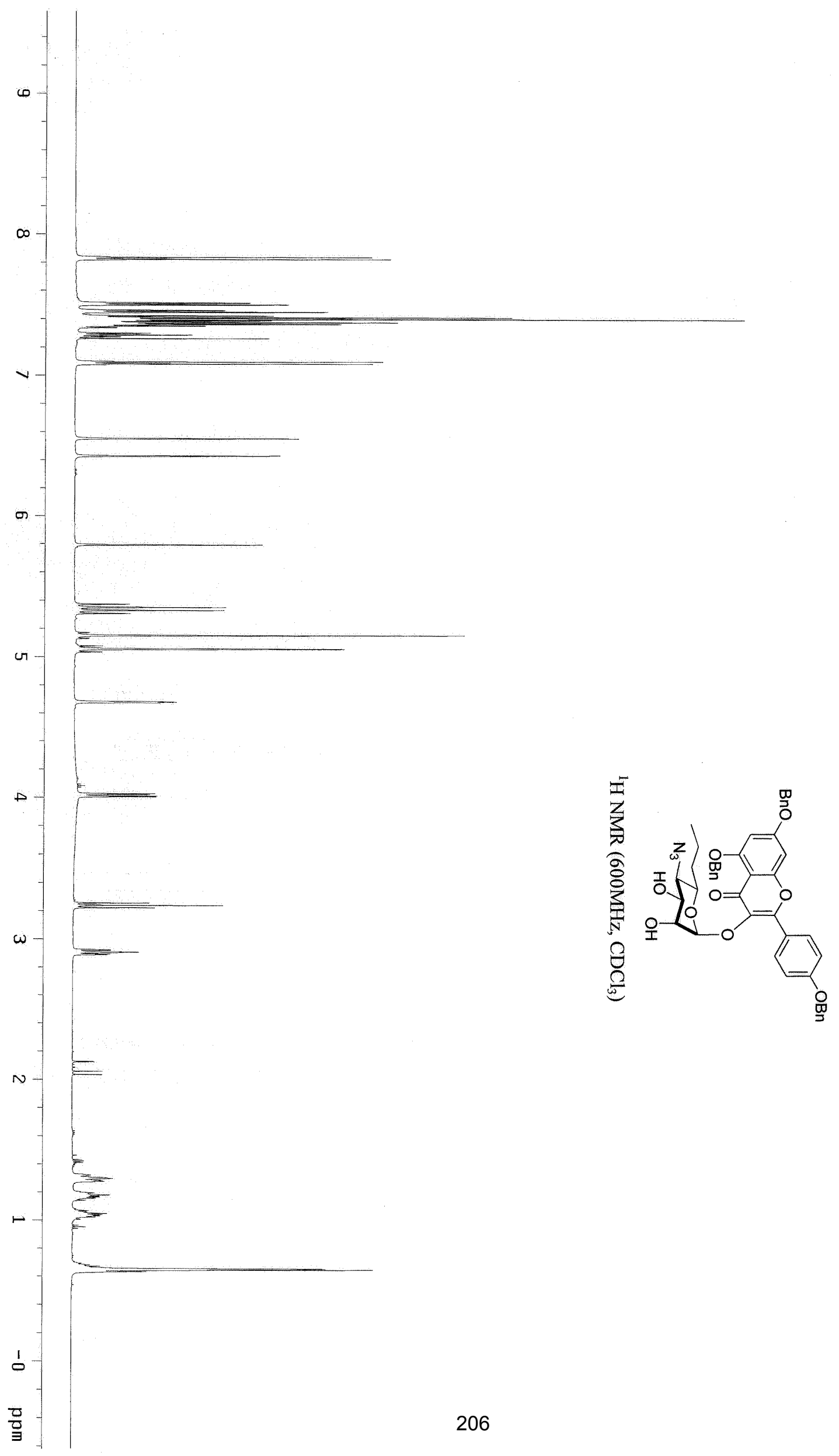




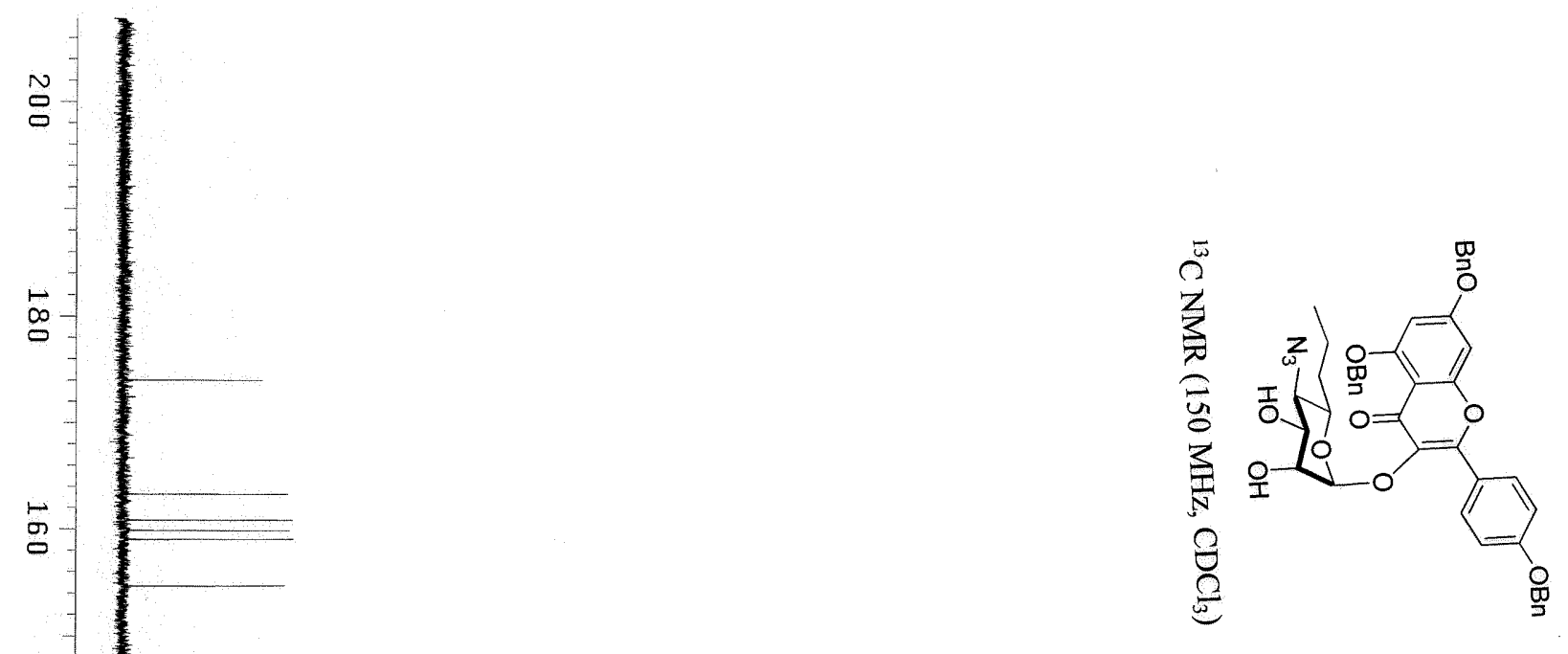

$\infty$

$\stackrel{B}{\circ}$

$\stackrel{N}{0}$

등

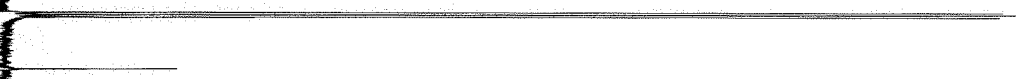

$0-\overline{1}$

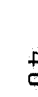

$D$

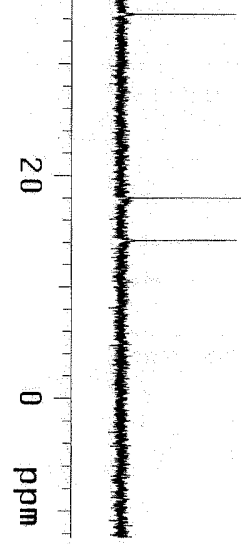




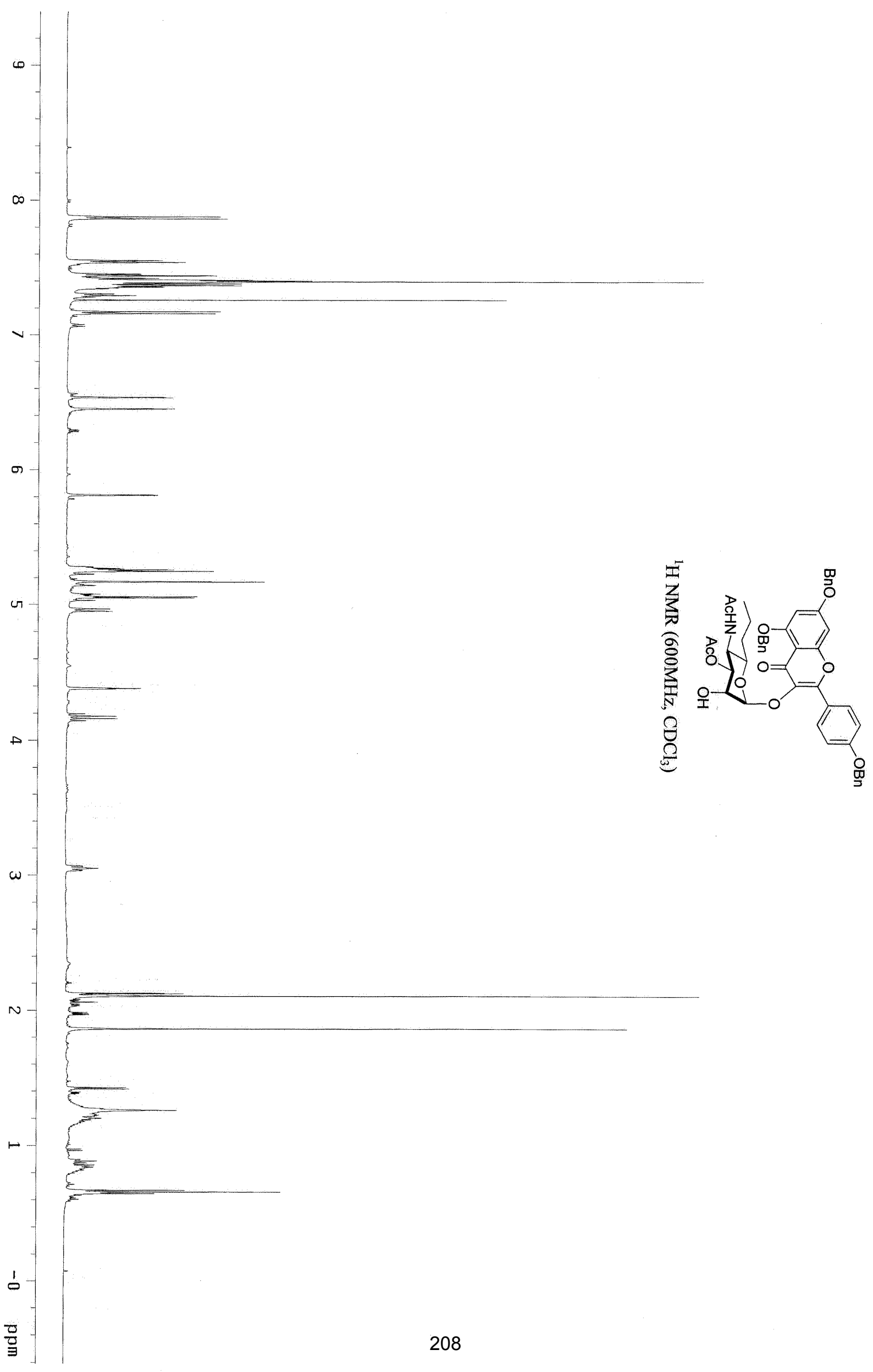




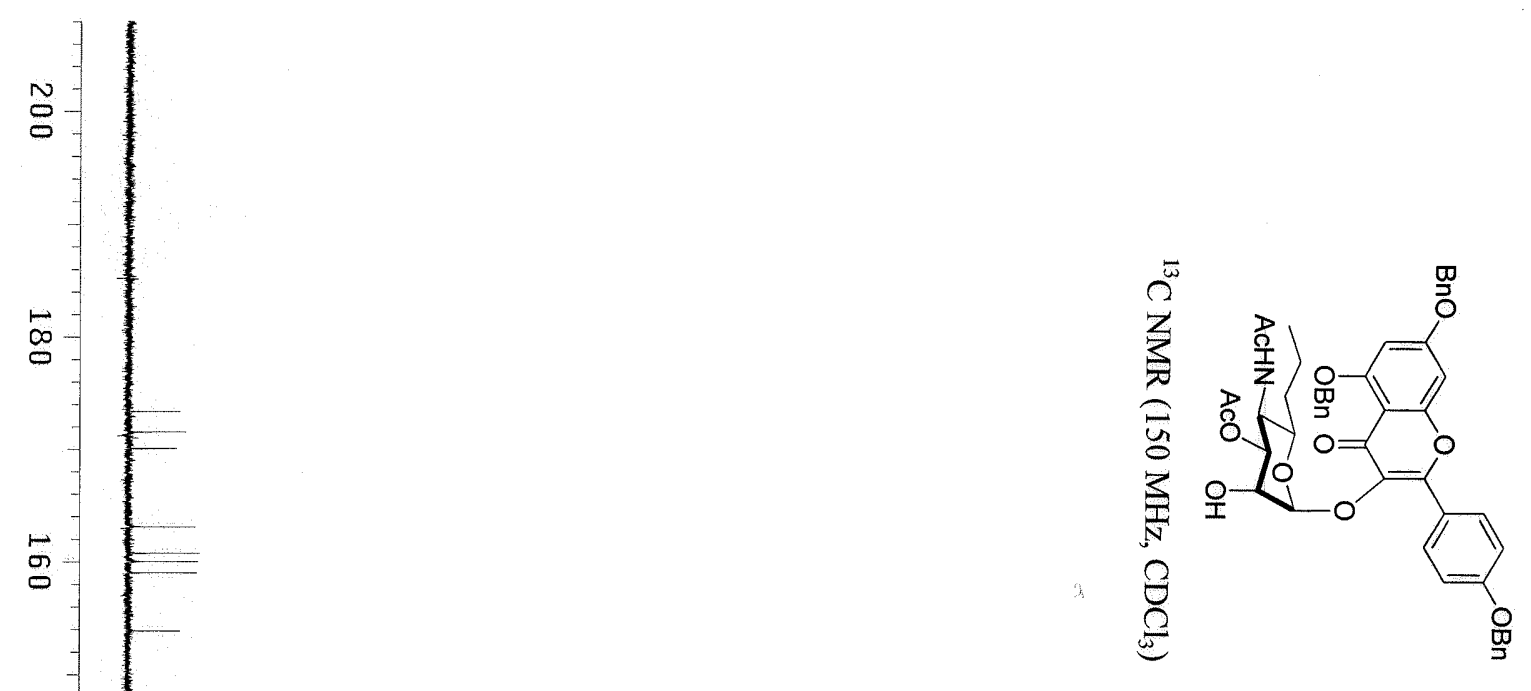

용

过

N=

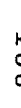

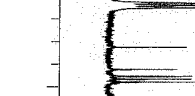

용

o)

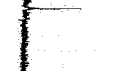

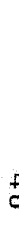

8

1

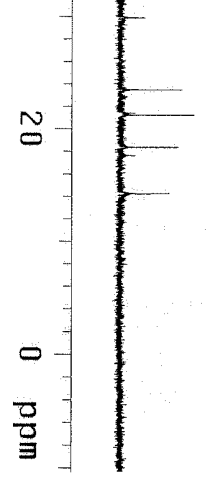

윸 


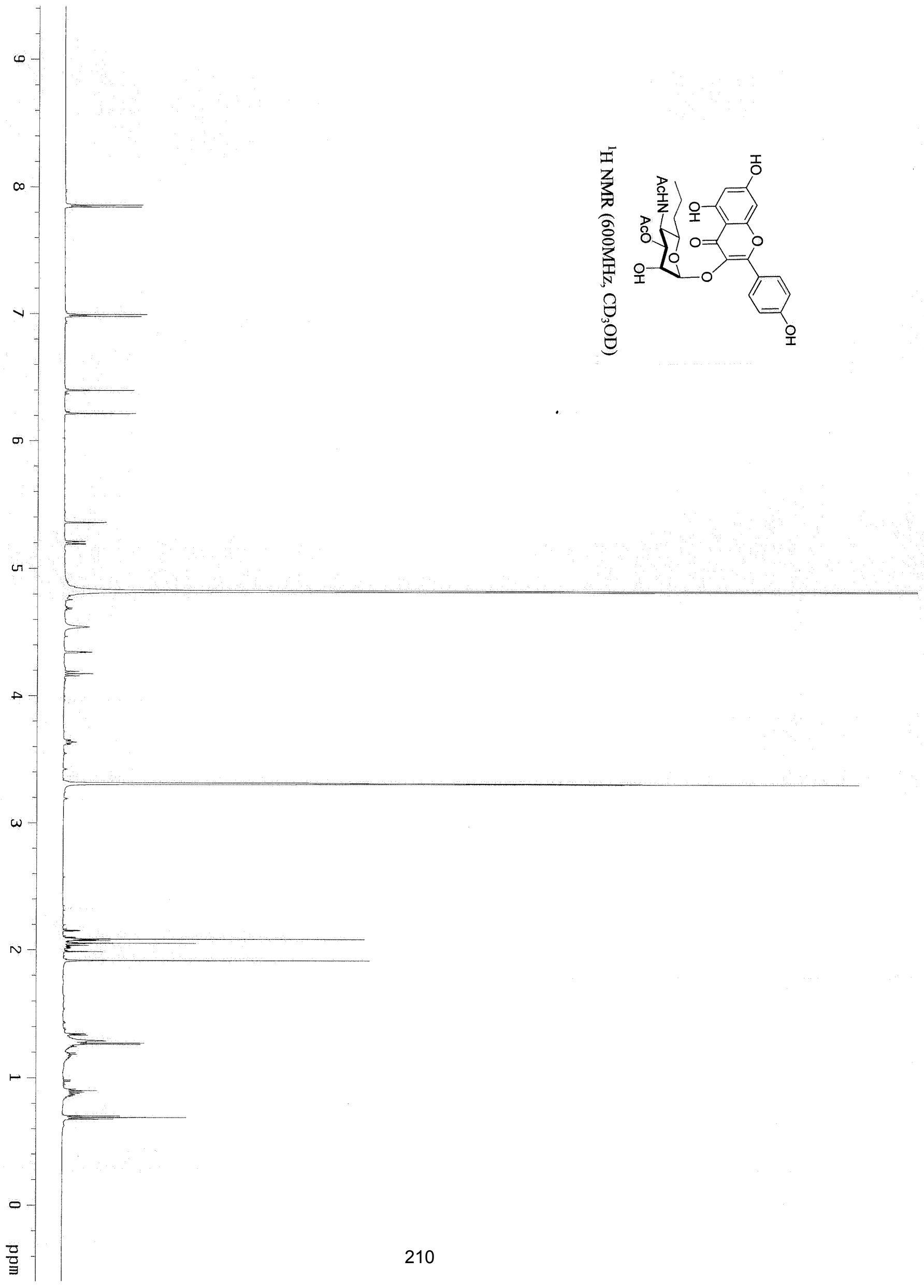




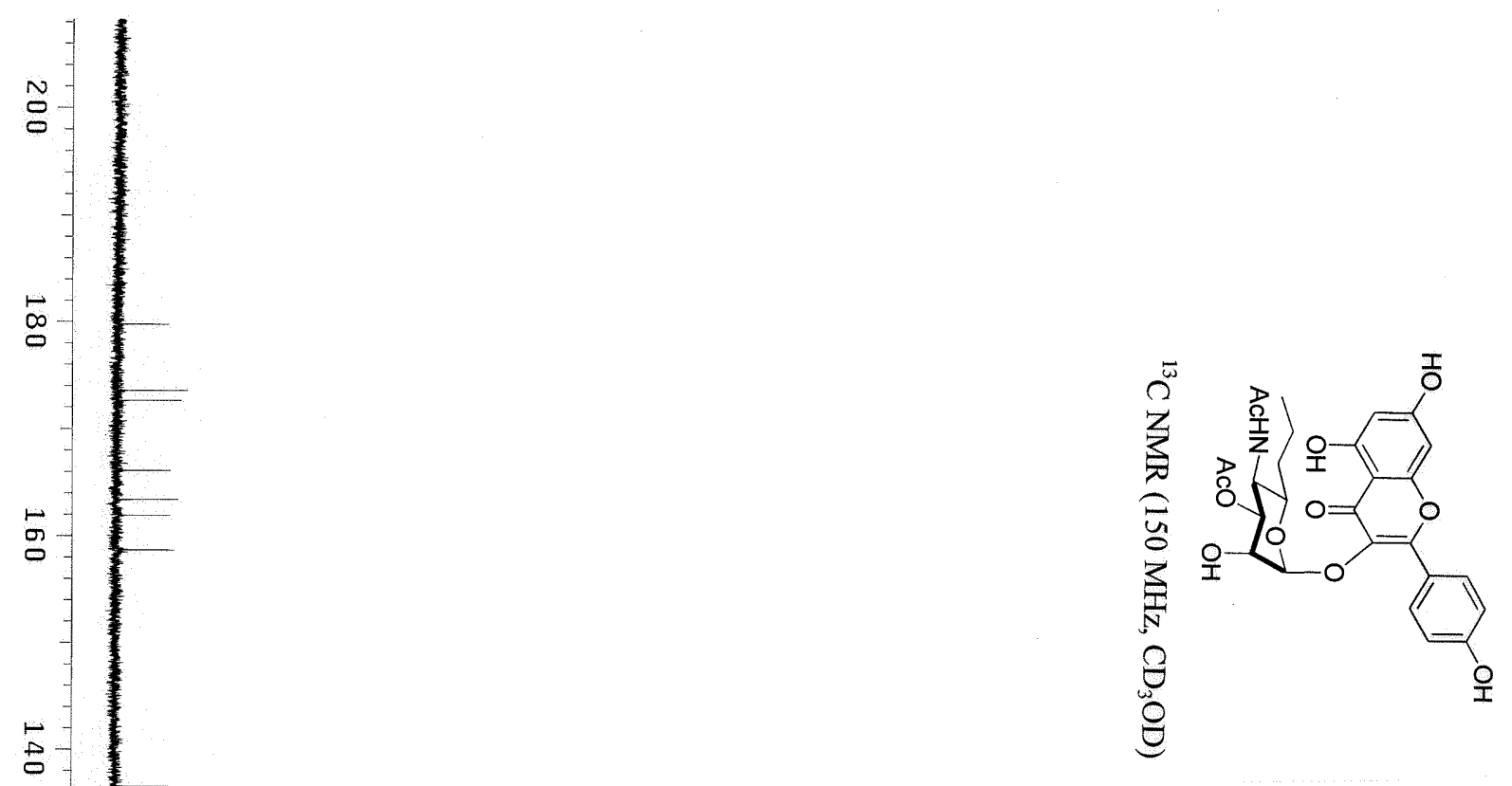




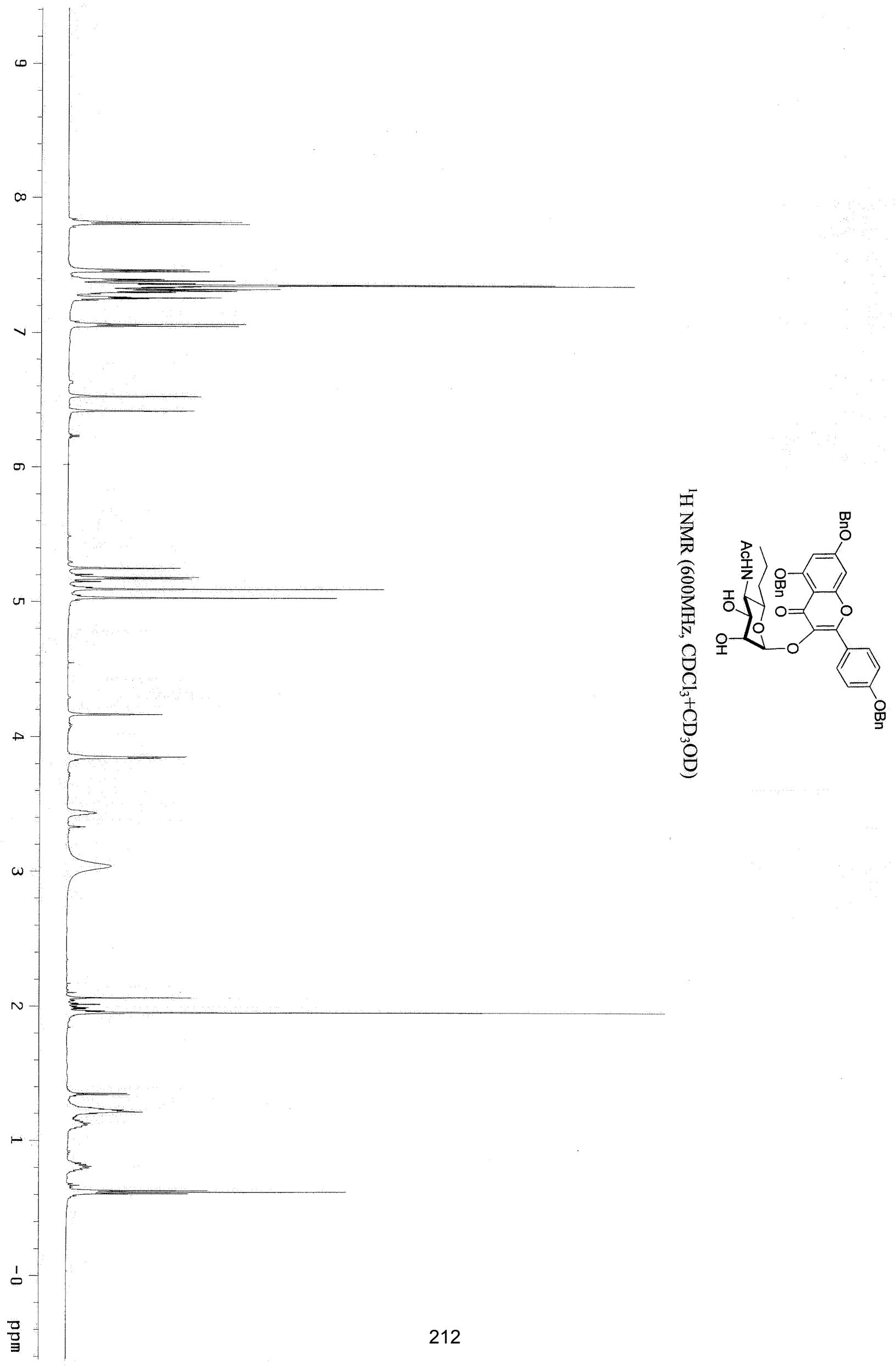



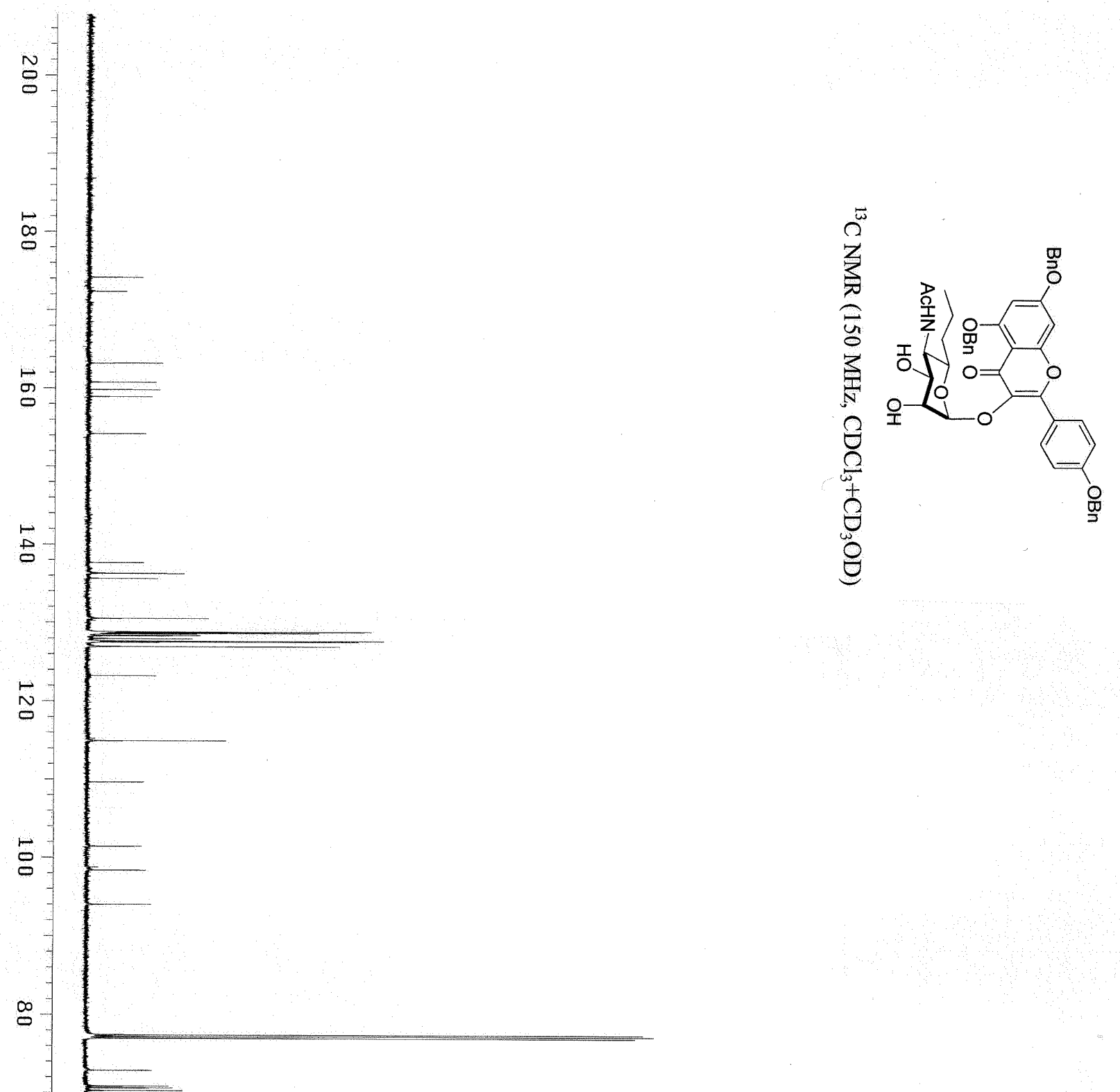

g

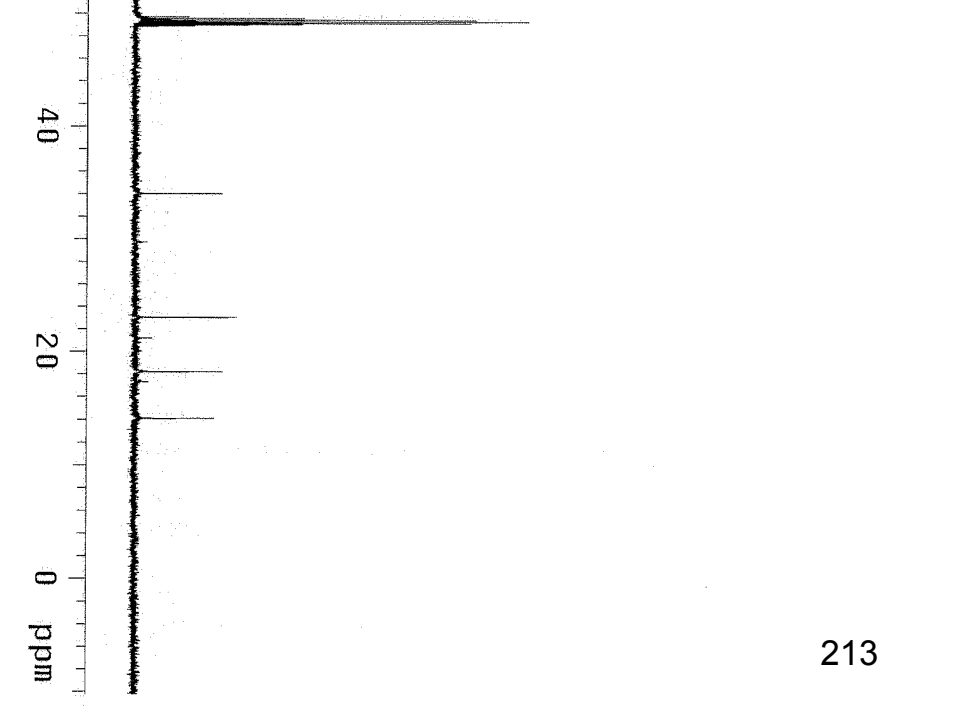




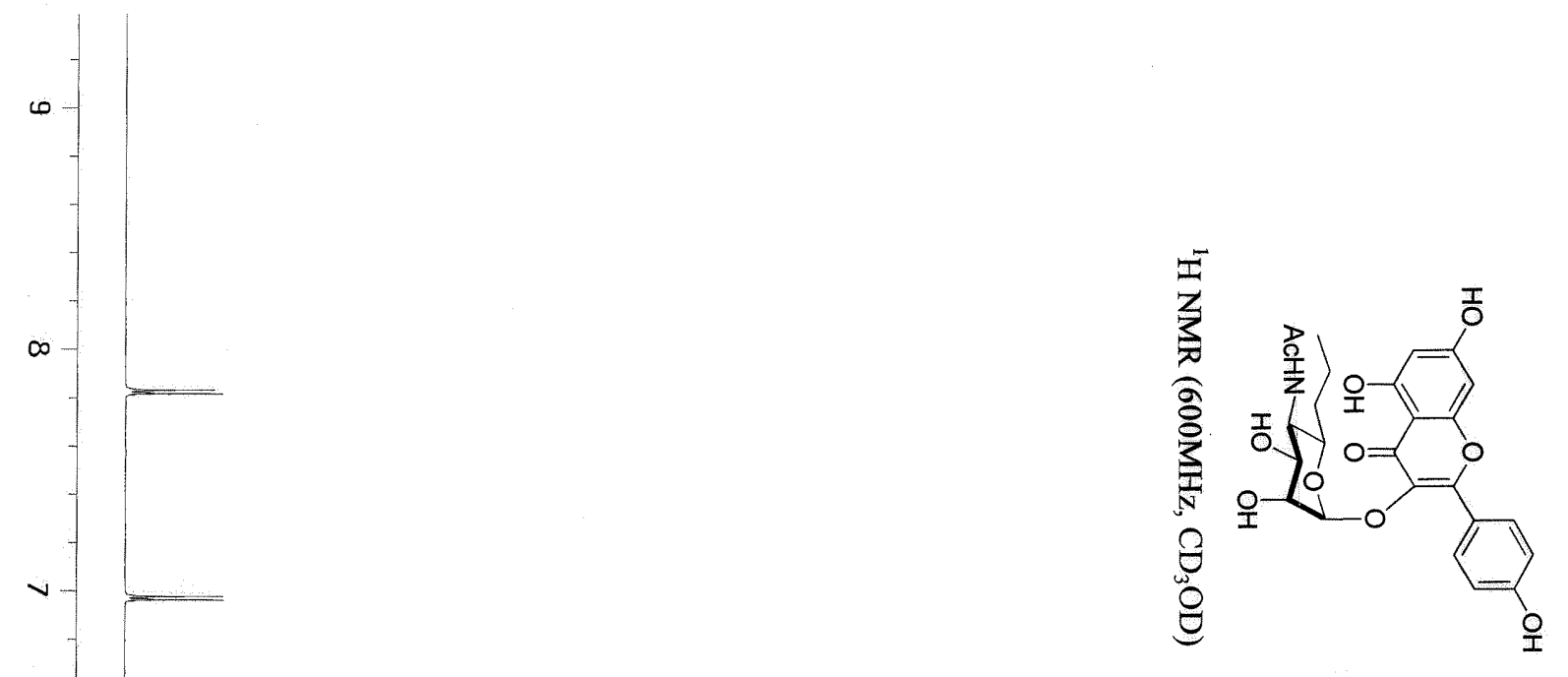




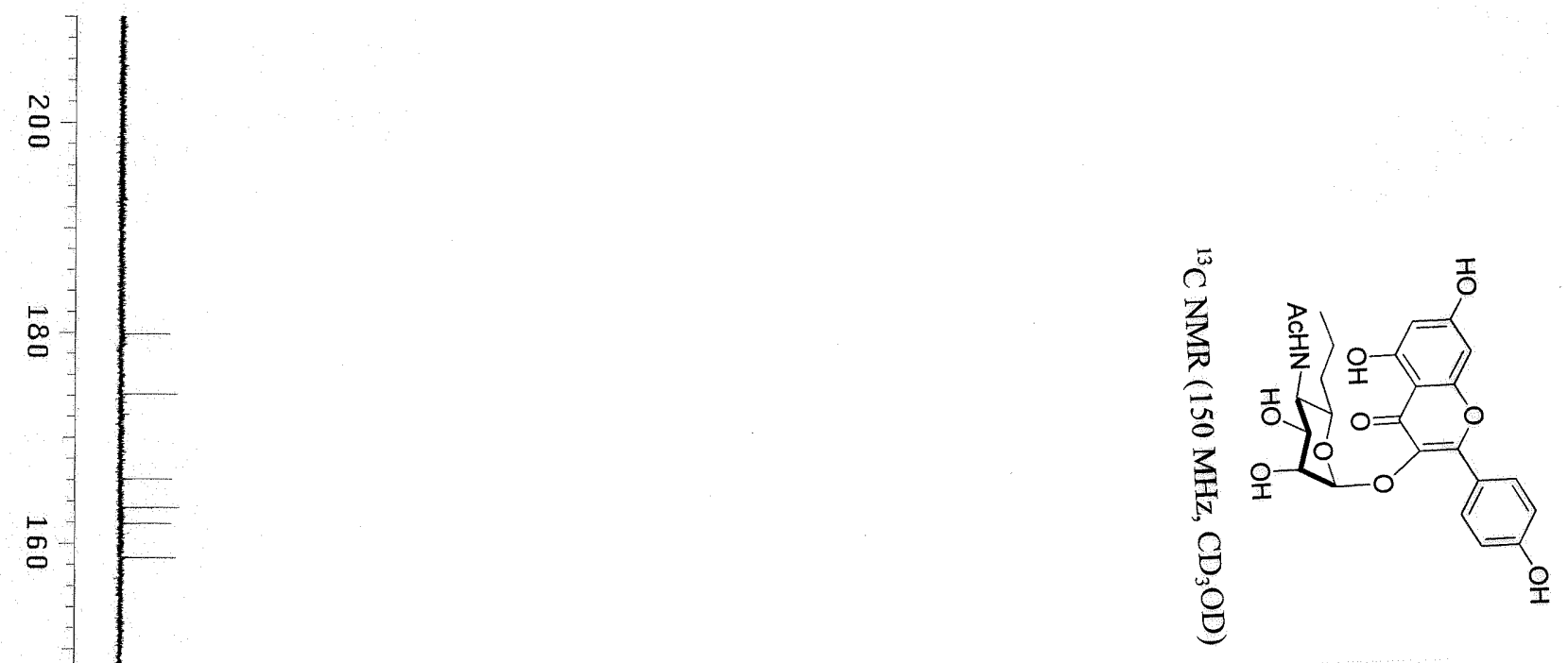

$\infty$

官:

a

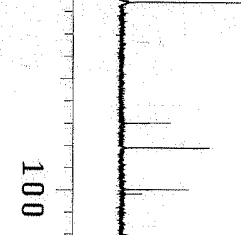

0

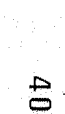

$B$

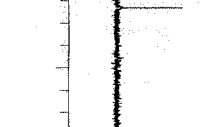

ㅁ

E

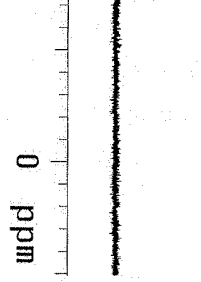




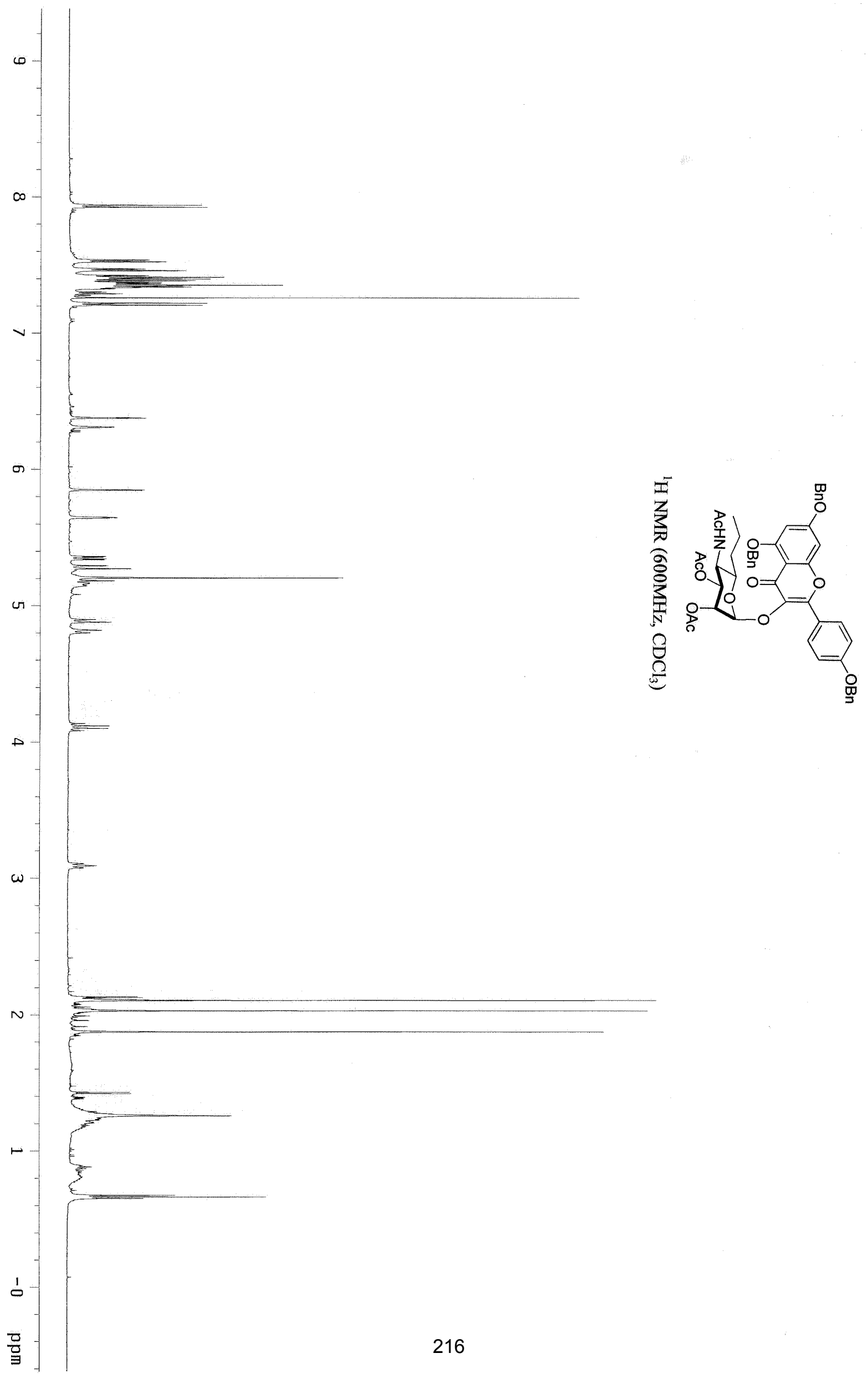




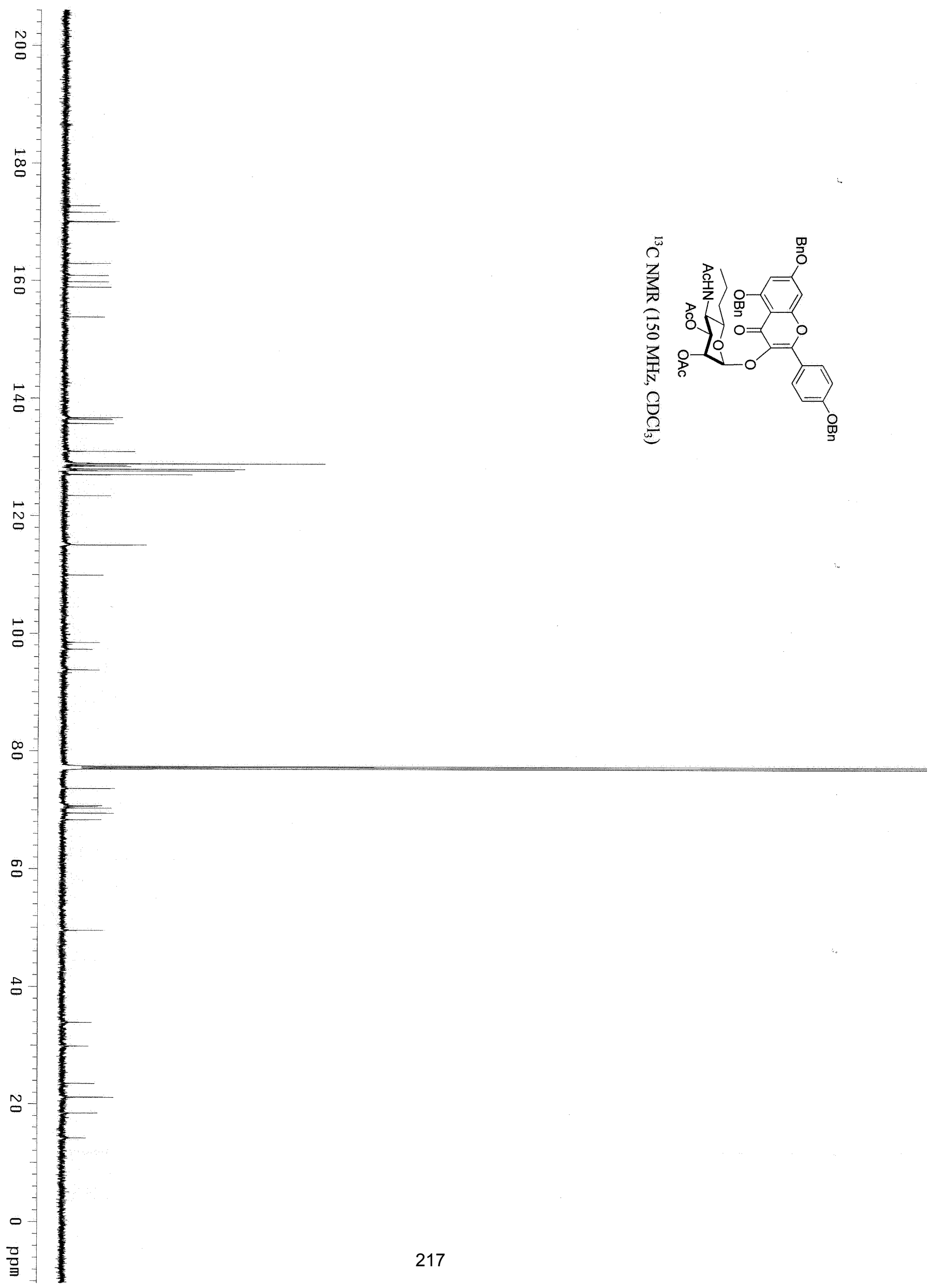




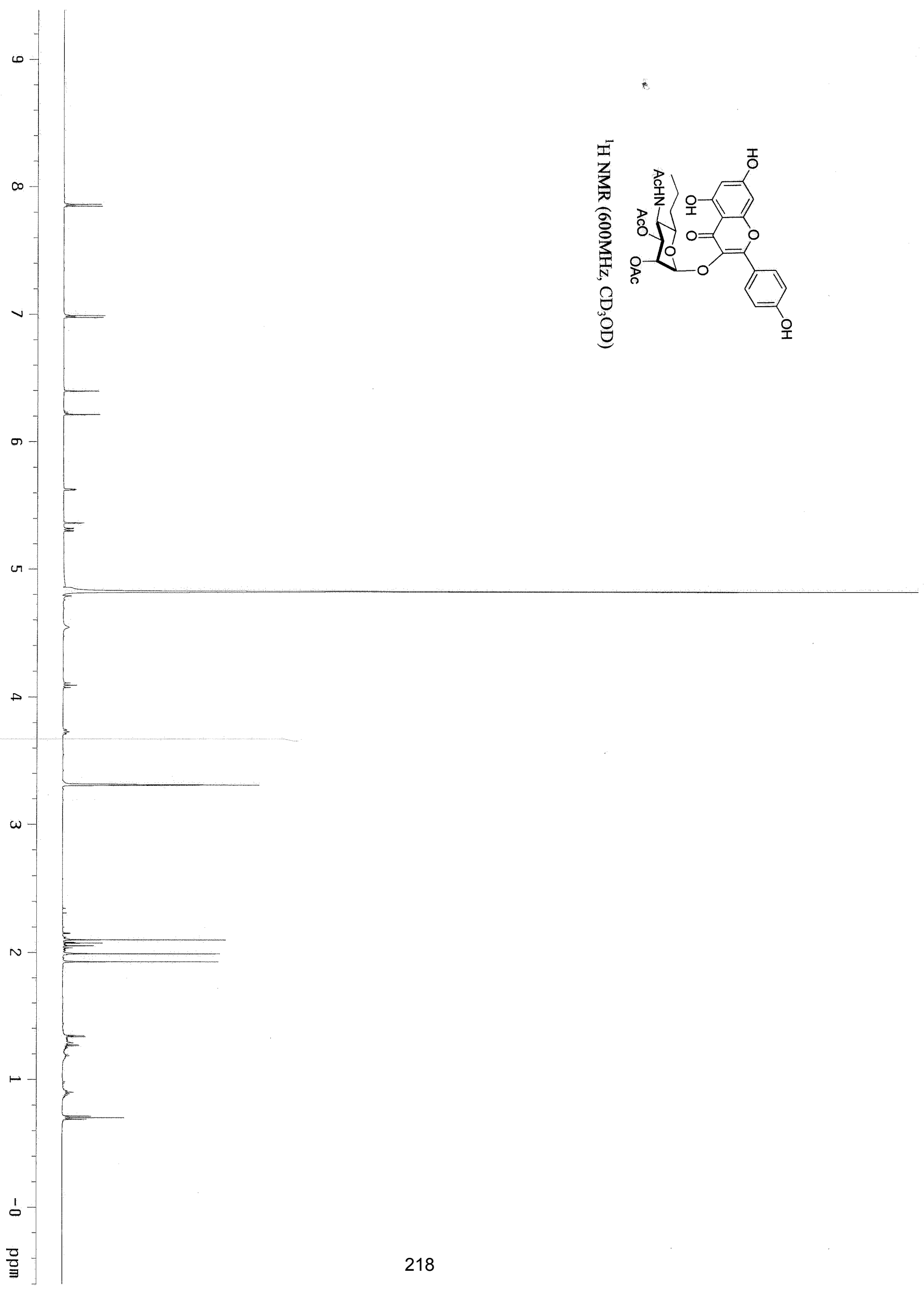




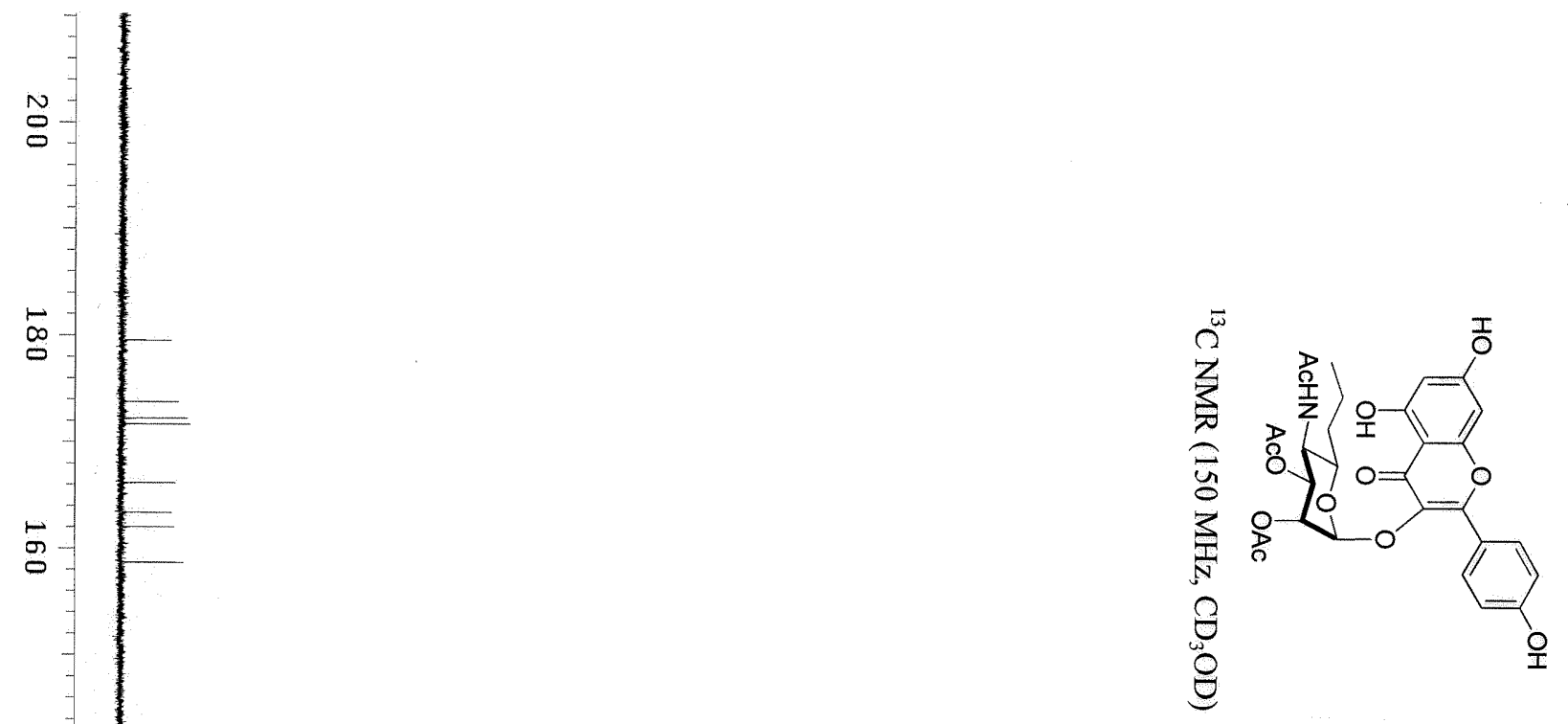

5

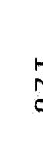

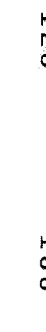

:

$\stackrel{\infty}{\circ}$

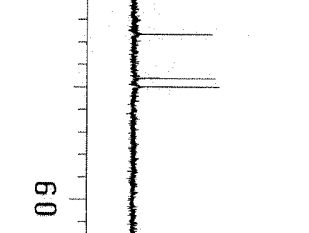

$\circ$

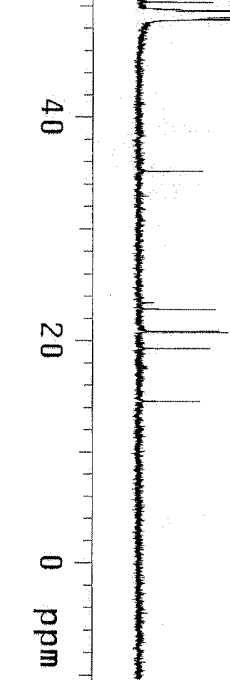




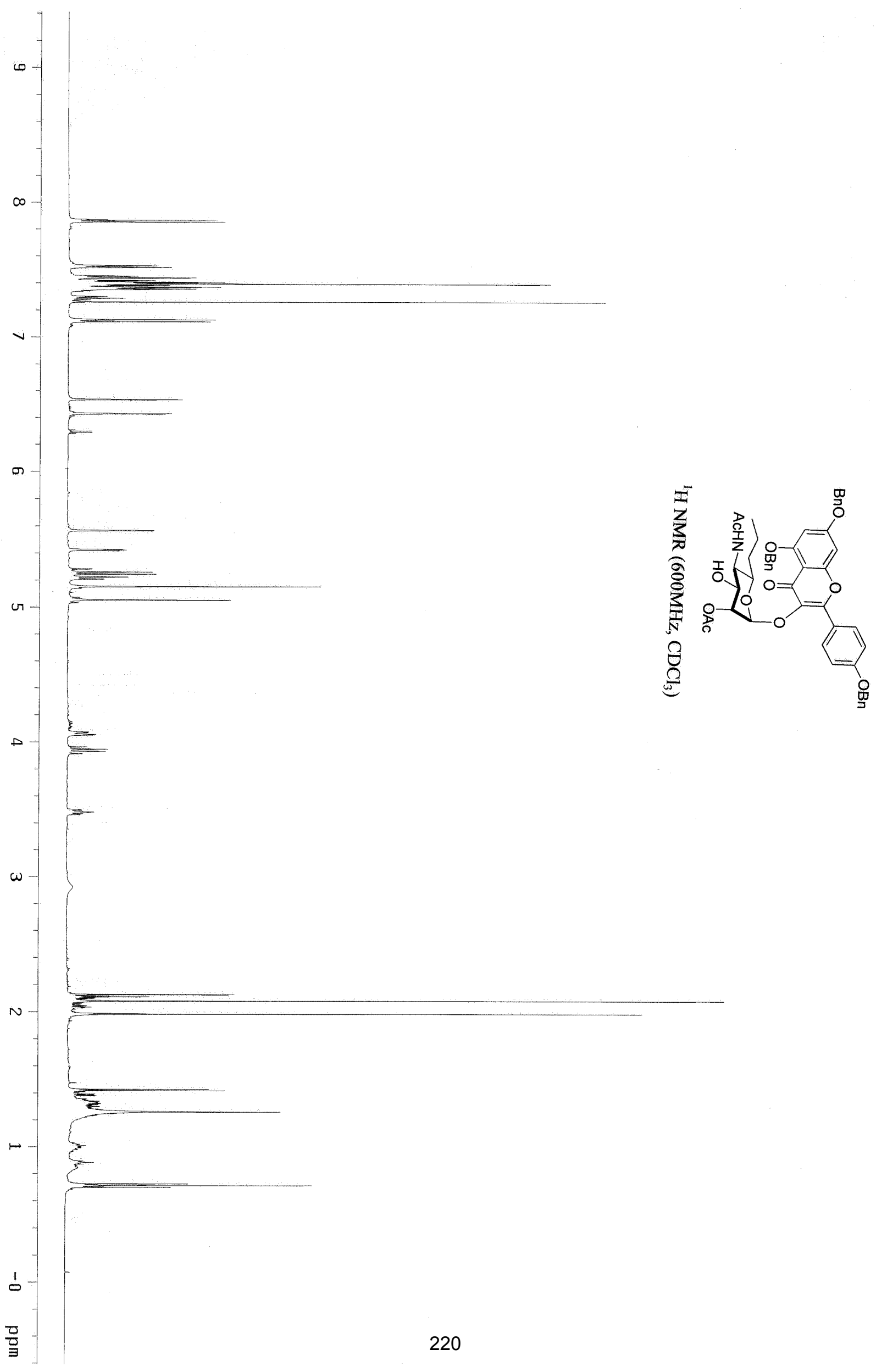




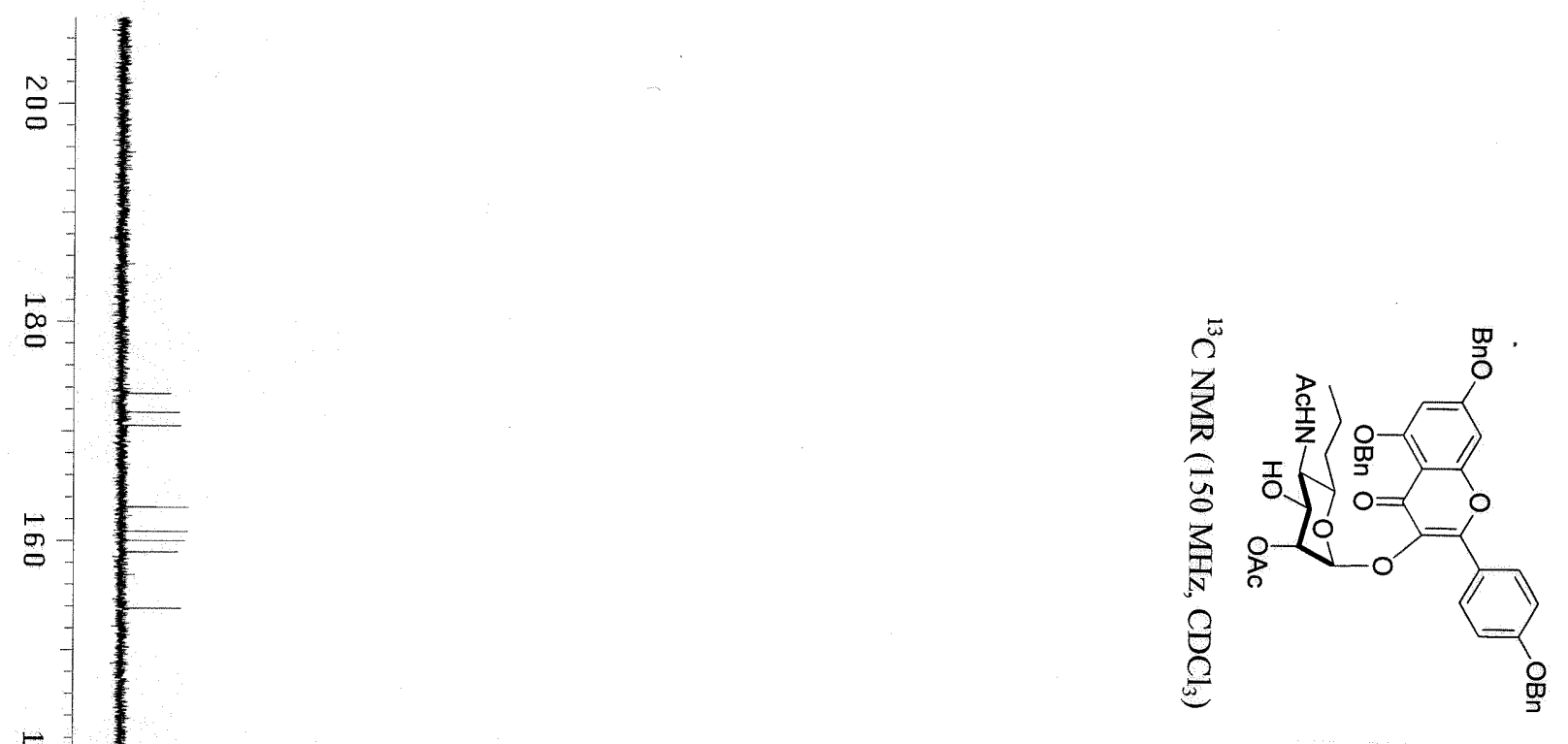




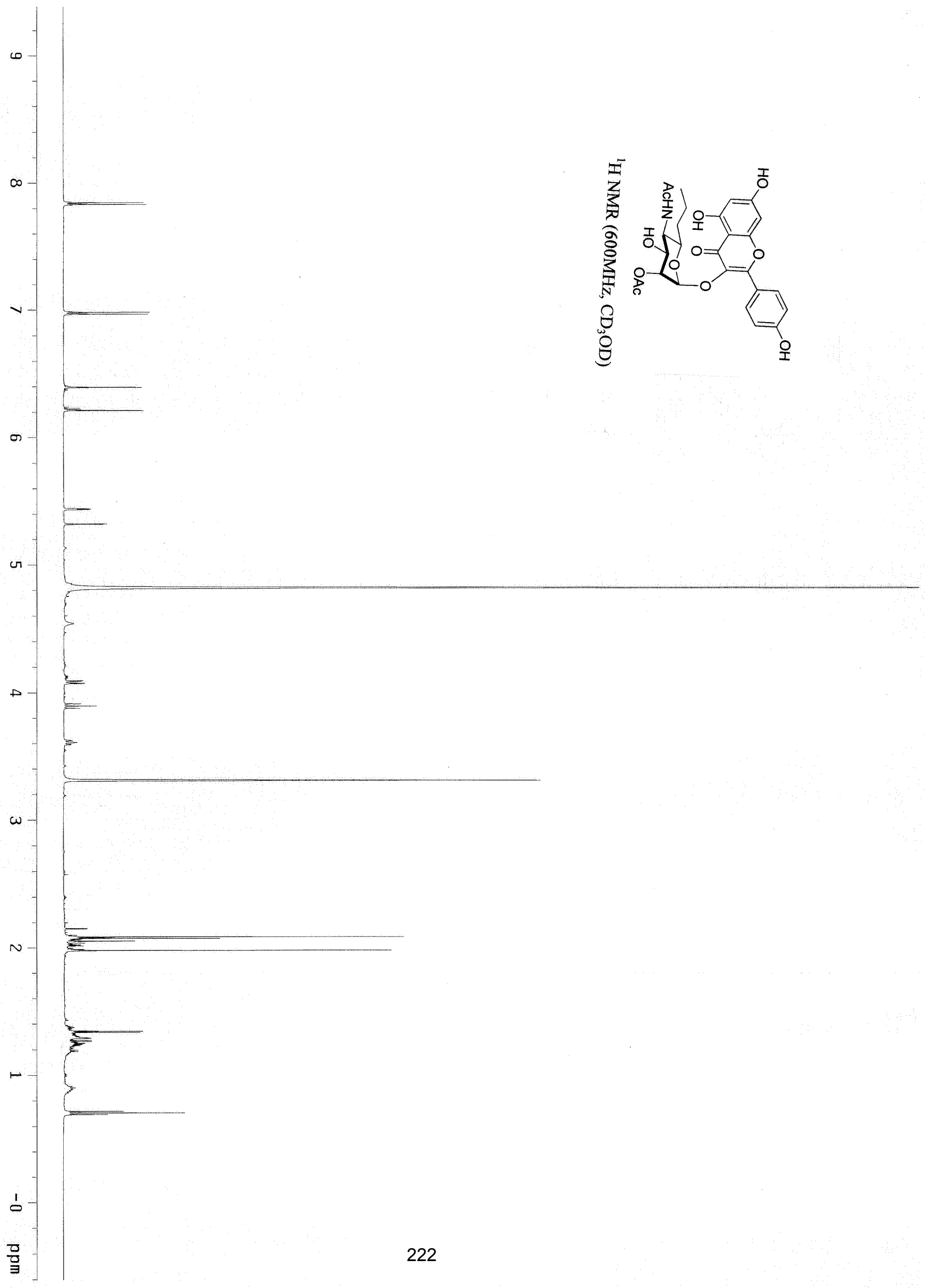




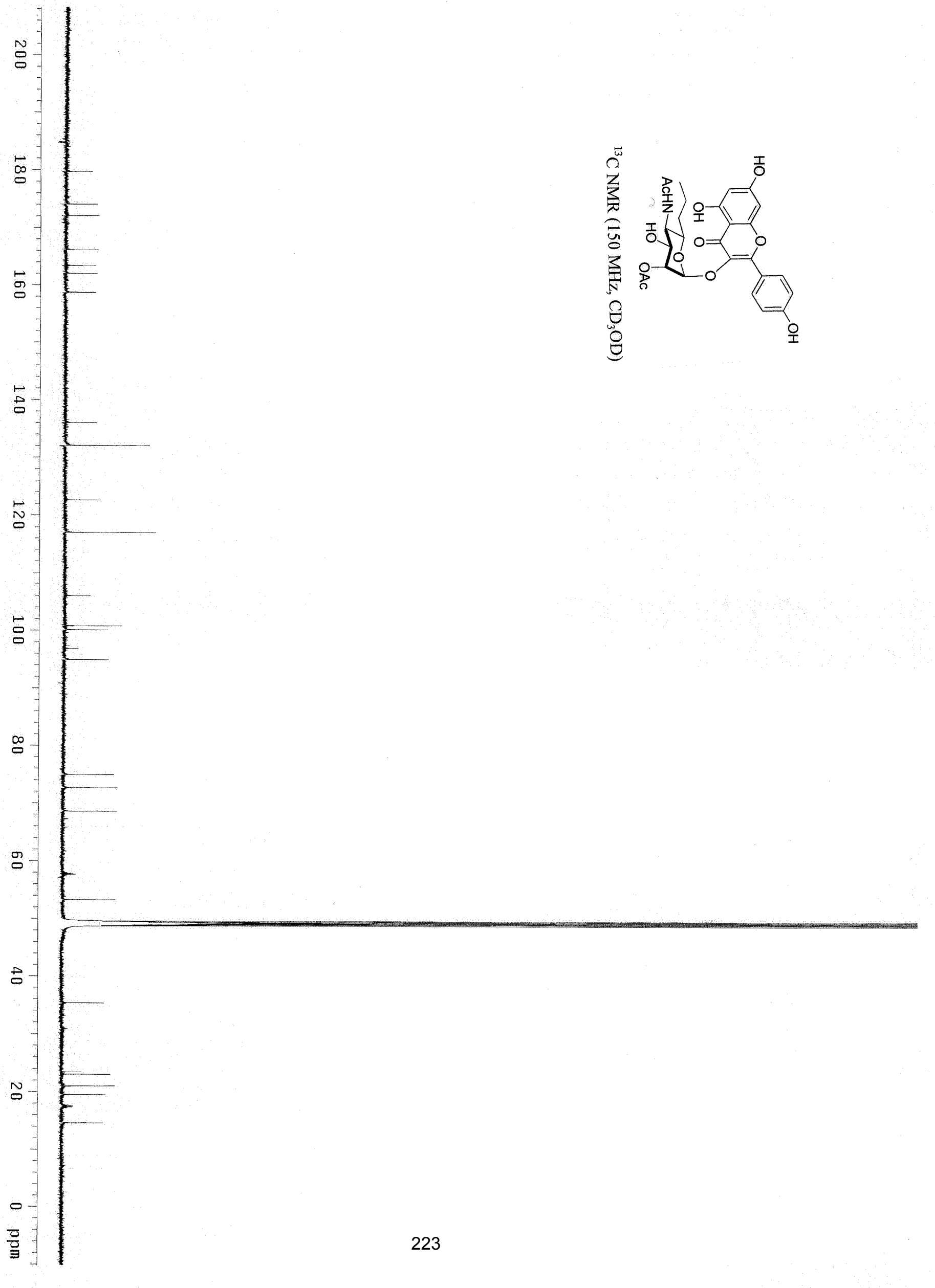

